
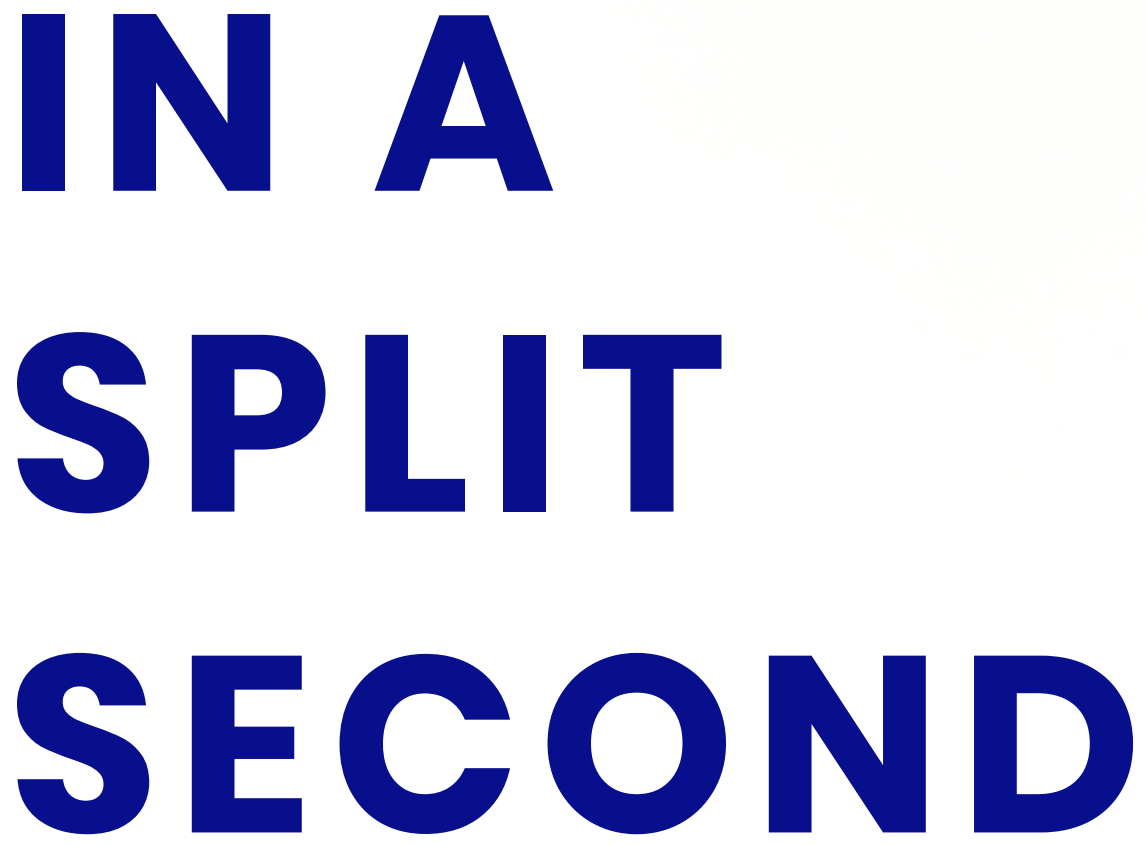

The industrial design and formative evaluation of an instantaneous photogrammetry 3D scanner for children with Cerebral Palsy.

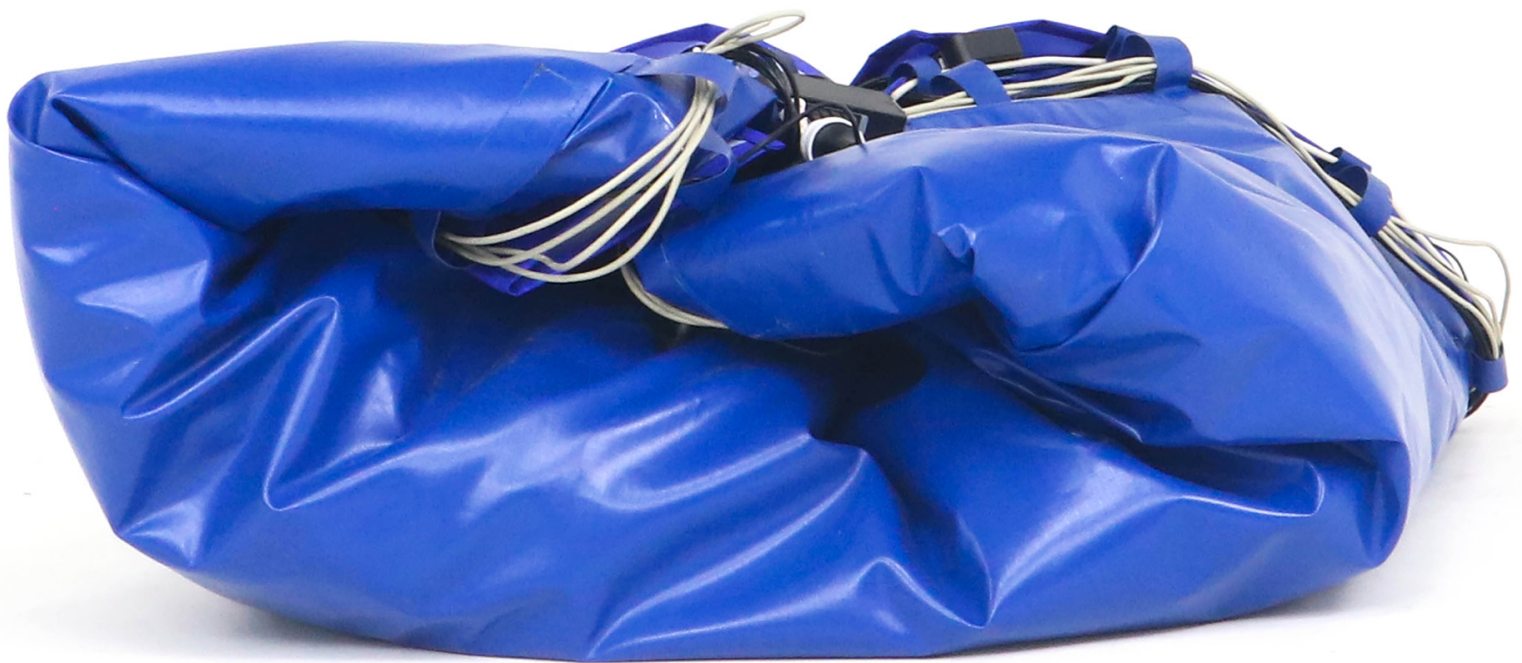

Wen Jun Zheng 


\section{IN A \\ SPLIT \\ SECOND}

A 90-point research portfolio submitted to the

Victoria University of Wellington in fulfilment of

the requirements for the degree of Master of Design

Innovation

By

Wen Jun Zheng

Victoria University of Wellington,

School of Design

2019 


\section{ABSTRACT}

Children and adolescents with the medical condition Spastic Cerebral Palsy (CP) may develop an abnormal gait, resulting in walking difficulties. This may be helped overtime with noninvasive Ankle Foot Orthotics (AFOs) braces, such as Solid Ankle Foot Orthotics (SAFOs), customised to suit patients needs. However, the acquisition of patient measurements for customisation and manufacturing itself is manual, slow, intrusive, subjective, and requires specialist skills to accomplish. This can commonly result in negative experiences for patients and reduce the access to healthcare to many people. This can especially affect vulnerable patients such as children or adolescents with Spastic $\mathrm{CP}$

Research has identified that a 3D digital system that scans patients' limbs and prints orthotics has the potential to improve the AFO creation process through speed, accuracy, and data availability. However, this system requires new technologies to fulfil its required performance, including a reliable way to acquire the three-dimensional shape of the limbs.

As such, a close-range photogrammetry system was identified as a fast and accurate alternative for producing surface measurements through 3D models compiled from images taken simultaneously. This research portfolio explores the design development of such a system by identifying areas of improvement, barriers, and solutions in a multi-method iterative research-through-design approach and pragmatic design framework. The aim was to achieve quick and accurate acquisition of a patient's' lower half measurements, while focusing on the experience of users during system interaction. The final output is a formally evaluated closerange photogrammetry scanner prototype, that created a nonintrusive and accurate alternative to traditional methods via quick and detailed capturing of patient surface measurements for later analysis. While also facilitating the needs of two user groups: vulnerable patients, and operating technician, to better their user experience. 


\section{Acknowledgments}

As my university journey draws to a close with this portfolio, I am grateful to be able to thank those who have helped me get here.

To my family. Mum and Dad, thank you for the boundless love and patience you have given me. For the guidance and support during the times I was unsure if I was ever going to make it, and for all the times you've feed me so I didn't have to eat two minute noodles.

To my sister, for sending your love and support across the world, and for always reminding me that I had the strength to persevere.

To my supervisor Dr Edgar Rodríguez Ramírez, for without you this thesis would not have been possible. Thank you for your support, advice, and coffees. To all those in the Smart Interactions group, thank you for lending me your help and knowledge. To Dr Gillian McCarthy and Dr Catherine Caudwell, thank you for your support, guidance, and words of reassurance throughout this portfolio. To our partners at AUT and ABI, thank you for bringing me on-board to help with the project, I have learnt so much. To our participants, though I cannot name you, thank you for taking the time to help test, develop, and share your thoughts and insights.

To those in the MDI cohort who kept me laughing, kept me sane, and kept my spirits high, thank you. I honestly could not have done it without you. Not without the support, encouragement, banters, coffees, Nerf guns, pegs, and ping pong ball battles. In particular, I would like to mention:

\section{Max Syme \\ Rose Lastovicka}

Maddy Hazelton Watcharawat Ritthisri (Tony)

Christy Wells Nikoo Namini

Jacob Marsh Steve

As well, to Jazmine Tamaiparea, Benjamin Jensen, and Jonathan Casil. Though you weren't stuck with me for eight-twelve hours each day, you all helped me keep my feet on the ground with your love, support, and advice.

To my other friends too many to name, and to everyone else also, thank you all for the love. 


\section{CONTENTS}

\subsection{Introduction}

1.1.0 The larger project scope

1.2.0 Scope of research portfolio

\subsection{Background}

2.1.0 Literature Review

2.1.1 Spastic Cerebral Palsy

2.1.2 Ankle Foot Orthotics

2.1.3 3D Scanners

2.1.4 Close-range stereoscopic photogrammetry

2.2.0 Precedent Review

\subsection{Methodology}

3.1.0 Research Through Design approach

3.2.0 Pragmatic design theoretical framework

3.3.0 Design methods

3.4.0 Ethics

3.5.0 Aims \& Objectives

\section{Prior prototype}

\section{0 assessment}

4.1.0 Methods

4.20 Results

4.3.0 Analysis

4.4.0 Summary

4.5.0 Reflection

\subsection{Design phase one}

5.1.0 Background

5.2.0 Methods

5.3.0 Results

5.4.0 Analysis

5.5.0 Summary

5.6.0 Reflection

\subsection{Design phase two}

$$
\begin{array}{ll}
\text { 6.1.0 } & \text { Background } \\
\text { 6.2.0 } & \text { Methods } \\
\text { 6.3.0 } & \text { Results } \\
\text { 6.4.0 } & \text { Analysis } \\
\text { 6.5.0 } & \text { Summary } \\
\text { 6.6.0 } & \text { Reflection }
\end{array}
$$

7.0 Design phase two

7.1.0 Background

7.2.0 Methods

7.3.0 Results

8.0 Discussion

8.1.0 Final Evaluation

8.2.0 Conclusion

Reference List 


\section{List of Figures}

Figure 1. Larger project output: A novel work-flow for AFO creation.

Figure 2. Human factors approach for developing medical devices visualisation based on the FDA guidelines, and the area addressed by this research portfolio.

Figure 3. Portfolio overview.

Figure 4. A standard AFO manufacturing process.

Figure 5. Research phase aim, objectives, and methods.

Figure 6. Design phase aim, objectives, and methods.

Figure 7. Participant in a load bearing stance within the prototype. Copyright 2019 by Jacob Marsh.

Figure 8. Observation of technician tasks during the scanning procedure. Copyright 2019 by Jacob Marsh.

Figure 9. Participant break area. Copyright 2019 by Jacob Marsh.

Figure 10. Participant filling out rating chart. Copyright 2019 by Jacob Marsh.

Figure 11. A participant filling the final rating chart during the SSI session. Copyright

2019 by Jacob Marsh

Figure 12. Pre-existing lighting solution. Copyright 2019 by Jacob Marsh.

Figure 13. Proposed lighting solution.

Figure 14. Image set from the $50 \%$ brightness LED test.

Figure 15. Image set from the $75 \%$ brightness LED test.

Figure 16. Image set from the $100 \%$ brightness LED test.

Figure 17. Edited image set from the $50 \%$ brightness LED test.

Figure 18. Edited image set from the $75 \%$ brightness LED test.

Figure 19. Edited image set from the $100 \%$ brightness LED test.

Figure 20. Base digital model used to compare against those from the LED lighting

tests. Copyright 2019 by Thor Besier.

Figure 21. Outside view of the scanner prototype. Copyright 2019 by Sophie Price.

Figure 22. Raspberry Pi tablet and cabling. Copyright 2019 by Sophie Price.

Figure 24. Prior lighting solution while on. Copyright 2019 by Sophie Price.

Figure 23. Raspberry Pi camera placement. Copyright 2019 by Sophie Price.

Figure 25. Ideal placement of user. Copyright 2019 by Sophie Price.

Figure 26. Identified constraints in relation to the state of the pre-existing prototype.

Figure 27. User journey identified from observation during user testing sessions.

Figure 28. Front and top view of 3D model generated from participant scan.

Figure 29. Front and top view of 3D model generated from participant scan.

Figure 30. Front and bottom view of 3D model generated from LED lighting test at 50\%

\section{light intensity.}

Figure 31. Front and bottom view of 3D model generated from LED lighting test at $75 \%$ light intensity.

Figure 32. Front and bottom view of 3D model generated from LED lighting test at

$100 \%$ light intensity.
Figure 33. Themes generated from thematic analysis of participant responses. Figure 34. Assessment against criteria from background research.

Figure 35. Generated models from tested LED lighting source and earlier generated model.

Figure 36. Participant models generated with pre-existing lighting solution. Figure 37. Sketch exploration of camera housing. Figure 38. Sketch exploration of scanner form.

Figure 39. Sketch exploration of patient support.

Figure 40.1:5 scale concepts in the three proposed stages of assembly; assembled, midway, and disassembled.

Figure 41. 1:1 sectionals ideas.

Figure 42. Key steps in this prototype's assembly process.

Figure 43. Initial exploration into form and ease of use component designs. Figure 44. Weighted matrix assessing the success of the different 1:5 ideas. Figure 45. Weighted matrix assessing the success of the 1:1 iterations.

Figure 46. One of the damaged parts that hindered testing.

Figure 47 Example of the awkward positioning required to enter and exit the scanner. Figure 48. Two-part inflated tube, creating a circular but 'pointy' form.

Figure 49. Three-part inflated tube, creating a circular form.

Figure 50. Iterative sketch exploration of overall inflatable form

Figure 51. Iterative sketch exploration of a section of an inflatable form. Figure 52. Iterative sketch exploration of arm mounting options.

Figure 53. Iterative sketch exploration of integrated cable management options. Figure 54 Iterative sketch exploration of hardware attachment options.

Figure 55. Rendered CAD model of camera arm prototype.

Figure 56. 3D printed camera arm prototype.

Figure 57. Rendered CAD model of the alternative section for the camera arm prototype.

Figure 58. Camera arm prototype with Raspberry Pi cameras inserted into end mounts. Figure 59. Single cavity form.

Figure 60. Exploration using a removable rigid external force.

Figure 61. Exploration into using removable Velcro/fabric external force. Figure 62. Exploration into using a permanently attached external force.

Figure 63. 1:5 prototype with all explored solutions in one.

Figure 64. Simplified overview of proposed assembly process.

Figure 65. Weighted matrix used to find out best cable management method. Figure 66. Weighted matrix to identify best inflatable form.

Figure 67. Weighted matrix highlighted which idea would be the most successful. Figure 68. Cognitive walk-through comments in relation to design criteria. Figure 69. Most feasible form for manufacture. 
Figure 70. Generated images of participant one from the simulated-scanning test session.

Figure 71. Generated images of participant two from the simulated-scanning test

session.

Figure 72. Generated images of participant three from the simulated-scanning session.

Figure 73. Generated images of participant four from the simulated-scanning session

Figure 74. Edited images of participant one from the simulated-scanning test session

Figure 75. Edited images of participant two from the simulated-scanning test session.

Fisure 76. Edited images of participant three from the simulated-scanning session.

Figure 77. Edited images of participant four from the simulated-scanning session.

Figure 78. Focused sketch iterations of the camera housing.

Figure 79. Serial CAD prototyping of camera mounts

Figure 80. Serial CAD prototyping of cable clips.

Figure 81. Serial CAD prototyping of 'swinging' camera arm section.

Figure 82. Serial CAD prototyping of camera arm to inflatable structure mount.

Figure 83. Final CAD model of camera mounts.

Figure 84. Final CAD model of cable clips.

Figure 85. Final CAD model of 'swinging' camera arm section

Figure 86. Final CAD model of camera arm to inflatable structure mount.

Figure 87. Participant one generated model (background removed).

Figure 88. Participant two generated model (background removed).

Figure 89. Participant three generated model (background removed)

Figure 90. Participant four generated model (background removed).

Figure 91. Fully assembled inflatable scanner.

Figure 92. Comparison of scanner when off and on.

Figure 93. Camera housing and cable management details.

Figure 94. Close up of integrated cable management.

Figure 95. Orientation of cameras and cables when the prototype is fully set up.

Figure 96. User journey visualisation.

Figure 97. Hidden cable and cable management solution.

Figure 98. Changing camera mount height. Copyright 2019 by Senai Leniston-Kahsai.

Figure 99. Inflation of the scanner structure. Copyright 2019 by Senai Leniston-Kahsai.

Figure 100. Proper orientation of the cables, to allow for easier assembly.

Figure 101. Bowing is still present in the camera arms.

Figure 102. Manual connection point to inflatable structure.

Figure 103. Assessment against ease of use related criteria.

Figure 104. State of operator hub.

Figure 105. Interaction between participant and operator. Copyright 2019 by Senai

Leniston-Kahsai.

Figure 106. Assessment against user experience related criteria.
Figure 107. Participant one image set with duplicated images used to compile the images into a 3D model.

Figure 108. Participant one generated models: with background, without, and with

images brightened by $90 \%$.

Figure 109. Participant two generated models: with background, without, and with images brightened by $90 \%$.

Figure 110. Participant three generated models: with background, without, and with images brightened by $90 \%$.

Figure 111. Participant three generated models: without a background, and with images brightened by $90 \%$.

Figure 112. Assessment against digital model generation related criteria.

\section{List of Tables}

Table 1. Overview of commercially available and service provided photogrammetry scanners, and their roles.

Table 2. Overview of studies and research projects related to photogrammetry

scanners.

Table 3. Criteria identified from lite

Table 4. Cognitive walk-through session goals.

Table 5. User testing and observation session goals

Table 6. Lighting test session goals.

Table 7. Identified criteria from cognitive walk-through.

Table 8. User experience based criteria

Table 9. Lighting based criteria.

Table 10. Updated criteria based on chapter four findings.

Table 11. Comments and suggestions from the inspection session.

Table 12. Updated criteria based on chapter five findings.

Table 13. Cognitive walk-through session goals.

Table 14. Updated criteria based on chapter six findings.

Table 15. Simulated-assembly testing session goals

Table 16. Simulated-scanning session goals. 


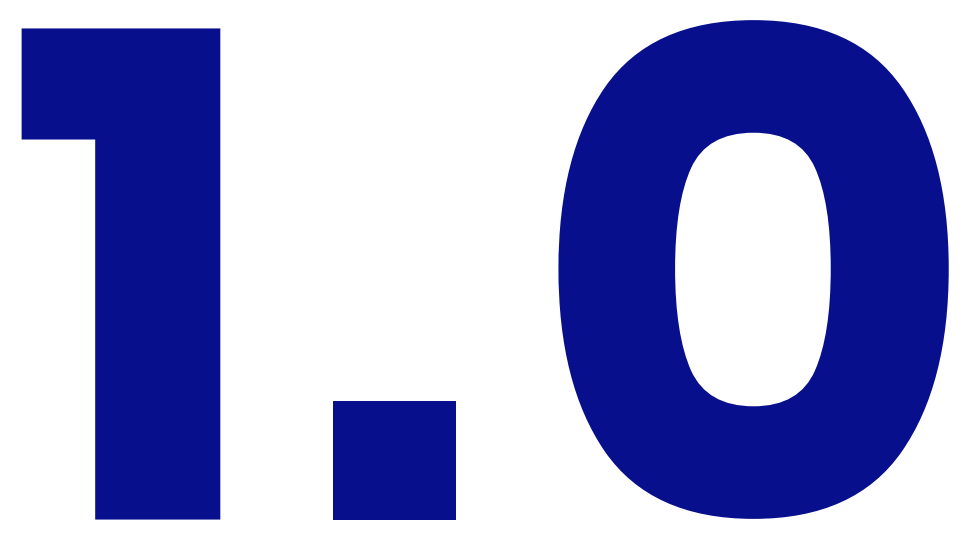

Spastic Cerebral Palsy (CP) can cause an abnormal gait to develop in children and adolescents, where the five prerequisites for an optimal gait are los (Gage, Schwartz, \& Koop, 2009). The functional significance is during the stance phase, where foot misalignment results in a non-stable weight-bearing stance. Ankle Foot Orthotics (AFOs) are a form of treatment to manage gait.

AFOs range in function and designs depending on abnormalities that have developed in the ankle and foot region due to different neurological injuries or disorders (Feng \& Song, 2017). AFOs are prescribed depending on user needs and the opinion of the specialist, meaning they are often customised and patient-specific.

Custom AFOs are currently manufactured through a standard multi-step and artisan-like manual process by orthotic technicians. An essential step is acquiring the surface measurements of the patient's lower limb in a neutral orientation, to allow ideal functionality, a comfortable fit, and avoid incorrect foot positioning. However, the process can be described as highly personalised between patient and specialist, while also time-, energy-, and materialconsuming (Totah, Kovalenko, Saez, \& Barton, 2017; Pallari et al., n.d.).

While this process of generating patient surface measurements is acceptable, it could be improved by digital scanning techniques and devices that measure real-world subjects, such as people and products, and generates detailed 3D copies. Scanning systems vary depending on technology, intended use, and outputs. For example, high-end hand-held 3D scanners, while highly accurate and offering high resolution, require patients to remain stationary for relatively long periods depending on the technician skill level. There is also difficulty in scanning the inside of the legs because of the required focal distance between scanner and subject. This is of great relevance for patients with Spastic $\mathrm{CP}$ who have issues maintaining balance due to abnormal muscle development affecting the lower limb region (Straub \& Kerlin, 2014).

A close-range stereoscopic photogrammetry 3D scanner utilises multiple cameras in a 360-degree orientation, to instantaneously generate images of subjects of interest, including patients with Spastic Cerebral Palsy (CP). The speed reduces model inaccuracies from occurring, by reducing patient interaction time (Mitchell \& Newton, 2002), as the movement of the scanned patient can lead to distorted and unusable models. This is of great relevance for patients with Spastic CP who have issues maintaining balance (Straub \& Kerlin, 2014).

Current available photogrammetry 3D scanners, including existing market and previously studied ones, have unnecessary features, such as high resolution for 3D printed AFO production. Also, few report or focus on the design or user experience of their scanner, such as making children feel comfortable, the space or storage they 
require in clinical settings. Even fewer are explicitly designed for the role of AFO creation, in medical environments that would require such a device for vulnerable users like young patients with Spastic $\mathrm{CP}$, despite needs and wants unique to them.

These users are often under-represented during design development, but they desire common key parameters from medical designs: safety, reliability, effectiveness, and usability. (Martin, Murphy, Crowe, \& Norris, 2006; Shah, Robinson, \& AlShawi, 2009). Other design domains such as aesthetics can also play a role in a medical device's success. Thus, considerations into comfort and ease of learning and use can affect a patient's readiness to follow a treatment regime (Martin et al., 2006), based on their user-device interaction experience. We also suggest that the design can incorporate connotations and semantics that make children feel in more familiar environments and, therefore, more comfortable with the procedure.

Therefore, a 3D digital system that scans patients' limbs and prints orthotics can be semi-automatic, faster, less intrusive, objective, gather and store clinically relevant data, and be more intuitive for a larger number of clinicians and technicians, increasing accessibility to treatments. However, this system requires new technologies to fulfil its required performance, such as a photogrammetry scanner, to reliably acquire the three-dimensional shape of the limbs.

This portfolio explores the design of a close-range stereoscopic photogrammetry scanner for generating usable patient surface measurements, with a focus on the experience of users, such as the vulnerable user group of children and adolescents with Spastic CP and the clinicians and technicians leading the procedure.

\subsubsection{The larger project scope}

This research portfolio is part of a larger cross-disciplinary and cross-institution project. The goal of the larger project is to:

Develop a bioengineering tool to inform decision-making and improve the process of prescription and design of $A F O$ s for children with $C P$.

This goal requires input from different disciplines and institutions. The full team for the project that includes bioengineers from the Auckland Bioengineering Institute (ABI) Dr Thor Besier, Dr Geoffrey Handfield and Dr Julie Choisne, neurophysiotherapists from Auckland University of Technology (AUT) Dr Nada Signal and Dr Denise Taylor and designers from Victoria University of Wellington (VUW) Dr Edgar Rodríguez Ramírez.

The larger project has three aims:

\section{Aim one.}

Characterise the clinical reasoning process for AFO prescription.

Qualitative research and data analysis methods will be used to develop an understanding and thematic description of the existing reasoning process for orthotic prescription and design, and identify the parameters that influence the clinician's decision-making for designing custom-made AFOs.

\section{Aim two.}

Use data-driven models to predict clinical from combining AFO design, clinical measures, and 3D gait data outcomes.

Exploring the combination of existing 3D gait analysis (3DGA) with clinical examination data from 100 children with CP to develop a data-driven modelling approach, through a partial least square regression model (PLSR), allowing for the prediction of known clinical outcomes from available clinical and gait data.

Aims one and two were completed in 2017-2018 by the full team of researchers and led by neurophysiotherapists Dr Denise Taylor and Dr Nada Signal. The findings (Choisne et al, 2016, 2018) have been used to define aim three, the design requirements for the scanner and the AFOs: 


\section{Aim three.}

Develop a rig to position patients in a weight-

bearing position to facilitate functional 3D

\section{scanning.}

Developing the design a suitable rig using stereophotogrammetry methods for the function of 3D scanning a young participant in a weight-bearing stance. The rig will also offer clinicians controlled manipulation of patient joints for positioning in the desired orientation. The scanned limb will be used to create a custom AFO design from extracted data via an automated algorithm developed by the UoA team.

The team to develop the scanner under aim three includes Dr Julie Choisne and VUW's School of Design through Dr Edgar Rodríguez Ramírez and the author Masters student Wen Jun Zheng. Before the start of this portfolio, Dr Choisne's team started with the engineering development of the scanner through putting together 20x Raspberry Pi cameras in a circular $2 \mathrm{~m}$ diameter array and developing the software to take synchronised pictures. This initial engineering 3D scanner was used as the starting point for the development of this project. Dr Choisne continued to give advice as a collaborator for the development of this Masters project.

The outcome for the larger project is the combination of the outputs of each aim into a novel work-flow that improves the prescription and design process of AFOs for children with CP. Completed by integrating clinical measures with standard 3DGA data and a functional 3D scan (Figure 1).

As the larger project goal is to implement this scanner in clinical practice, the larger project has been following a human factors approach based on the guidelines by the Food and Drugs Administration (FDA) from the USA (Center for Devices and Radiological Health [CDRH], 2016). FDA guidelines recommend the following for addressing human factors in the development of medical devices: Preliminary analyses and evaluations; elimination or reduction of use-related hazards; and human factors validation testing (CDRH, 2016). The larger project has started to address preliminary analyses and evaluations through aims one and two. Future research will test findings from this research portfolio for elimination or reduction of use-related hazards and human factors validation testing. The area of human factors addressed in this project, focuses on identification of known-use related problems, analytical approaches to identifying critical tasks and formative usability evaluation through simulated testing (Figure 2) (CDRH, 2016).

\section{Clinician session}

- Orthotic is deemed necessary

\section{Scanning appointment}

- Introduction to procedure

\section{Scan procedure}

Aim three

- Entry, load-bearing stance, scan, exit

Post processing work-flow

Artefact removal and generation of digital surface models

3D model analysis

Aim one

- Analysis by a clinician, and

prescription of orthotic

3D model analysis

Aim two

File model generation and 3D printing

\section{AFO fitting with patient}

Figure 1. Larger project output: A novel work-flow for AFO creation. 
Human factors in

development of Medical

Devices

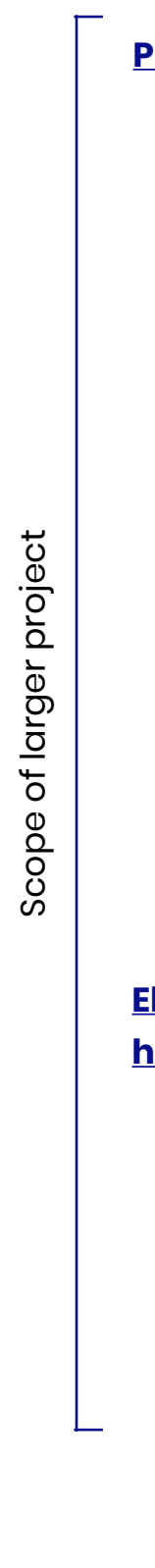

\section{reliminary analysis and evaluations}

Critical task identification and

categorisation

Identification of known use-

related problems

Analytical approaches to

identifying critical tasks

Expert Review

Empirical approaches to

identifying critical tasks

Formative Evaluations

Simulated Use Testing

Elimination or reduction of use-related hazards human factors validation testing

Simulated-use human

factors validation testing

Human factors validation

testing of modified devices

actual use testing

Pre market validation

Figure 2 . Human factors approach for developing medical devices visualisation based on the FDA guidelines, and the area ddressed by this research portfolio.

\subsubsection{Scope of research portfolio}

The research portfolio focuses on the industrial design portion of the third aim by exploring how a photogrammetry scanners' design may: affect the generation of surface measurement models; affect the user's experience of patient and operating technicians; and address identified technical and measurement constraints. This is undertaken through a research through design methodology with a mixture of qualitative and quantitative design research methods.

\subsubsection{Research portfolio overview}

\begin{tabular}{|l|l|l|}
\hline Chapter & Section & Description \\
\hline Two & $\begin{array}{l}\text { Background } \\
\text { research }\end{array}$ & $\begin{array}{l}\text { A review of literature and precedents provided context for and } \\
\text { an initial starting criteria based on findings }\end{array}$ \\
\hline Three & Methodology & $\begin{array}{l}\text { Detailed is the guiding research questions, aims and } \\
\text { objectives. Also the approach, framework, and methods. }\end{array}$ \\
\hline Four & $\begin{array}{l}\text { Pre-existing } \\
\text { prototype } \\
\text { assessment }\end{array}$ & $\begin{array}{l}\text { Presented are findings from assessment of previous work done } \\
\text { by the larger project. We tested the user experience of the } \\
\text { initial engineering rig put together by the UoA. }\end{array}$ \\
\hline Five & $\begin{array}{l}\text { Design phase one } \\
\text { Exploration }\end{array}$ & $\begin{array}{l}\text { Exploratory findings are presented from experiments } \\
\text { generated to address identified criteria }\end{array}$ \\
\hline Six & $\begin{array}{l}\text { Design phase two } \\
\text { Focused exploration }\end{array}$ & $\begin{array}{l}\text { Findings are presented from this second stage of design } \\
\text { development which followed more focused exploration. }\end{array}$ \\
\hline Seven & $\begin{array}{l}\text { Design phase three } \\
\text { Final output }\end{array}$ & $\begin{array}{l}\text { Findings generated from the last stage of design development } \\
\text { of the final prototype are presented. }\end{array}$ \\
\hline Eight & Discussion & $\begin{array}{l}\text { Presented are the main findings of this portfolio, and final } \\
\text { assessment against developed design criteria of the 1:1 } \\
\text { fully functional prototype. With reflection on possible } \\
\text { improvements for future work, and how the design should be } \\
\text { assessed with representative users. }\end{array}$ \\
\hline
\end{tabular}

Figure 3. Portfolio overview. 


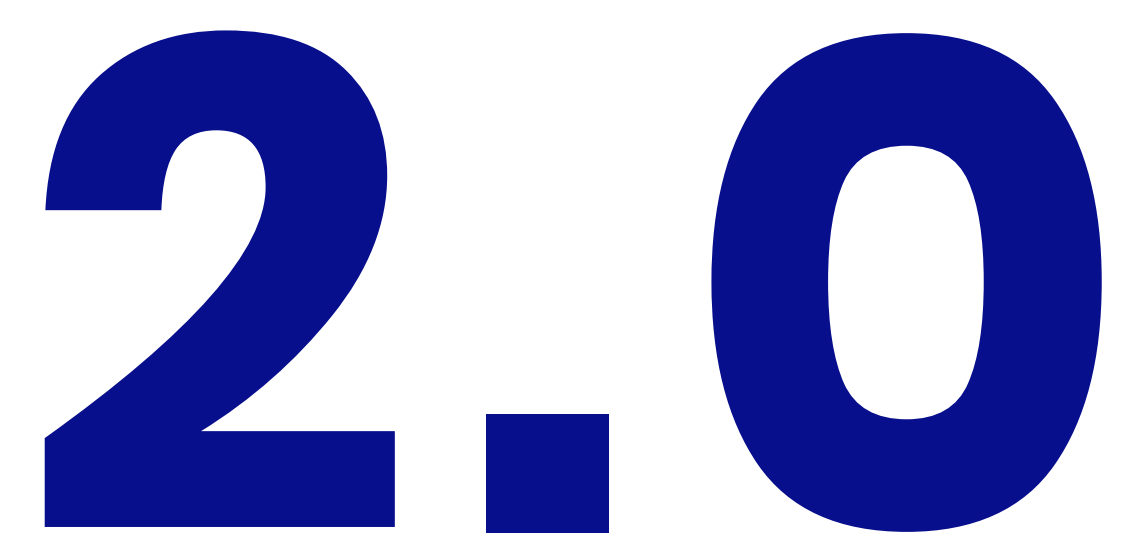

\section{BACKGROUND}

RESEARCH

This chapter situates the project in the current body of knowledge. Presented are findings from the review of the Spastic Cerebral Palsy (CP) medical condition, current methods generating surface

measurements for Ankle Foot Orthotic (AFO), and past studies

involving photogrammetry scanning. Included also are findings

from the assessment of photogrammetry scanners, both in the

current marketplace, and past research studies. 


\subsection{Literature review}

The literature review gathered information about the current state of relevant fields to: develop an understanding of a vulnerable user group's needs and requirements, identify areas of potential improvement in the AFO manufacturing process, and obtain knowledge from 3D scanning sources and studies that could be applied to this research.

\subsubsection{Spastic Cerebral Palsy}

Abnormal development in children

Spastic Cerebral Palsy (Spastic CP) results in symptoms such as fatigue, loss of dexterity and coordination, as well as balance disorders, partial joint dislocation and finally, contractures (Tugui \& Antonescu, 2013). Contractures describes the child's musculotendinous units lengthening at different rates to their neighbouring long bones as they develop (Gage, Schwartz, \& Koop, 2009).

This muscle tone imbalance can affect the function of body parts including the ankle and foot, affecting gait movement, leading to the impairment of an individual's freedom for optimal movement. Left untreated, the symptoms of Spastic CP can lead to a restriction of engagement in physical activities such as play, slowing development of social skills associated through playing (Chiarello, Palisano, Bartlett, \& McCoy, 2011). This can impact the development of children with Spastic CP, reducing their quality of life. Therefore, time and effort are devoted to promoting the independence of Spastic CP children in daily skills. As well as functionality in environments such as home and school early in their life (Brunstrom, 2001; Majnemer \& Mazer, 2004). So poor social skill development due to social isolation is avoided.

Spastic CP can have effect key daily activities, impacting the development of the child. Therefore, there is a need to develop successful treatments and procedures to treat Spastic $\mathrm{CP}$, which may in turn improve their quality of life. Being aware of the consequences and experiences a child with Spastic CP may encounter without successful treatment leads to better-applied and -informed design decisions.

The effects of Spastic Cerebral Palsy on Gait

Normally, the ankle moves in accordance to arcs of dorsiflexion and plantar flexion, but with the presence of abnormal function, excessive ankle dorsiflexion and excessive ankle plantar flexion can occur; motions that are excessive or inadequate in either direction. The foot meanwhile, can experience the loss of neutral alignment any time during the gait phase. The resulting characteristics can lead to three of the most common patterns in children with the condition of Spastic CP: equinus, equinoplanovalgus, equinocavovarus (Davids \& Tabaie, 2016).

Amongst all three patterns are the changes to a child's gait pattern including: disruption of shock absorption, clearance compromise, and ankle foot positioning during the swing stage of the gait cycle (Gage, Schwartz, \& Koop, 2009). Therefore, as an individual accommodates for these symptoms to try and achieve balance and movement (through changes in timing or motion during gait), there is an increase in energy cost (Miller, 2005) while walking, leading to the development of an abnormal gait.

The larger project that this research portfolio is a part of aims to aid in the treatment and therapy process to correct a child's gait by 3D scanning the lower limbs and 3D printing customised orthoses. Current Ankle Foot Orthotics (AFOs), a form of gradual pathological gait treatment, experiences manufacturing issues related to aspects such as time. Greater detail is given later in this chapter. If the manufacturing time can be reduced through digital means like photogrammetry surface measuring and digital manufacturing then there is an opportunity to reduce a child's or adolescent's wait time before receiving the necessary treatment to correct their gait. The design of these digital means, therefore, should be driven by factors that contribute to the overall goal of creating a successful and usable medical devices.

\section{Designing for a vulnerable user group}

Designers have used subjective experiences and assumptions when designing for children and adolescents (Druin, 2002). However, to create a positive user experience, one must consider their needs. It must be understood that these populations have their own unique culture, norms, and complexities (Druin, 2002). For children, it was the common attitude that children "should be seen but not heard" (Scally, 2014, p. 204). While adolescents have in the past been regarded as psychologically and physically, with respect, as tall children, and short adults (Lang, Martin, Sharples, Crowe, \& Murphy, 2014).

If a research and design decision process is based on assumptions such as these, then designers risk creating ineffective treatments that may deter patient use. Thus, designers should try and ensure that inadequate devices and treatments, that are unsafe and ineffective, are not created (Hunfeld \& Passchier, 2012). This notion is made apparent when a child or adolescent with Spastic CP experiences negative interaction due to these assumptions.

Children and adolescents with Spastic CP can experience negative emotions such as pain and anxiety from a negative interaction experience, much like any child or adolescent. However, they may experience increased sensitivity to pain, sometimes 
triggered by invasive medical and rehabilitative procedures. This can lead to anxiety developing, and active avoidance of negative stimuli and activities, in an attempt to reduce these negative emotions (Yamaguchi, Nicholson Perry, \& Hines, 2014). Therefore, this avoidant behaviour can limit the chances of exposure towards opportunities for positive experiences (Yamaguchi et al., 2014).

The unique needs of different user populations are important. Research has found that the user populations of children and adolescents have been ill represented in the past, leading to ineffective treatments when used by these groups. Therefore, it is suggested a system that primarily focuses on vulnerable patient usage, with emphasis on design decisions that meet their needs, be created. In doing so, the system can be used to its full effect, and avoid ineffective design decisions that past treatments and procedures have experienced due to subjective and biased assumptions.

\subsubsection{Ankle Foot Orthotics}

Treating abnormal gait over time

Solid Ankle Foot Orthotics (SAFOs) are one type of AFO types involved in improving gait and aiding in facilitating walking. Others include Dynamic Ankle Foot Orthotics (DAFOs), Hinged Ankle Foot Orthotics (HAFOs), and Knee Ankle Foot Orthotics (KAFOs) (Welsh, 2012). Each function differently, but share the same goal of correcting, or avoiding, the development of an incorrect gait pattern (Welsh, 2012). SAFOs in particular function by reducing and immobilising unnecessary movement during standing and walking (Welsh, 2012). The larger project primarily focuses on SAFOs, as it is one of the primary choices in the management of abnormal gait caused by Spastic CP (Welsh, 2012).

\section{AFO materials}

Past AFOs used local materials such as wood, leather, and metal, and were described as ugly, noisy, and bulky (Rubin \& Dixon, n.d.). Plastic eventually phased these materials out, due to availability and material qualities, both physically, as wel as aesthetically. Modern day mass-produced standard AFOs, including SAFOs, are produced from thermoformed plastics.

The versatility of polyethylene and polypropylene plastics allows the creation of different orthotic designs for easy assignment to different specific areas of clinical application. Another benefit is these plastics are formable at low temperatures, and resistant to fatigue during bending; allowing for easier manipulation during the 'editing' or customisation stages of manufacturing. Thermoformed AFOs are reported to have benefits such as lightness in weight, ease of use, a neater appearance, and most importantly, the availability for customisation for users (Mastro \& Curry, 1980).
The versatility and customisability of orthotics created from thermoformable plastic show the beneficial factors of this material for modern orthotic creation. These properties help maximise their use and effectiveness, and warrants continual improvement and optimisation of the process to ensure patients are offered continued treatments that are effective and cater to their needs. However, there is room for improvement via digital patient measuring and digital orthotic manufacturing.

\section{Current AFO manufacturing \& customisation}

In a traditional orthotic process, the patient can wait one to several days for a completed orthotic (Chen, Jin, Wensman, \& Shih, 2016), with potentially weeks in between follow-up sessions for a finalised and personalised AFO (Totah, Kovalenko, Saez, \& Barton, 2017). This process can be interpreted as an iterative one, where stages of refinement occurs before arriving at the finalised form.

The developed manufacturing guidelines of the International Committee of the Red Cross (ICRC) for AFOs, including SAFOs, highlight the exclusive use of manual techniques. These include: mould casting, thermoforming, and material trimming. Figure 4 outlines these techniques (International Committee of the Red Cross [ICRC] 2006). After these steps, the orthotic has straps and other attachments added so it can be worn by the patient.

Similar manufacturing procedures were assessed and found to also be manual task orientated; where a combination of technician experience, trial and error, and patient verbal feedback is the basis for prescribing correct orthotics (Pallari et al.,n.d.; Totah et al., 2017). Current manufacturing of AFOs is so labour and time intensive, research suggests that other newer technologies may help with this process.

Another aim of the larger project this research portfolio is part of is to use 3D printing technologies within a work-flow to reduce AFO lead time from weeks to potentially hours, and offer a higher level of accuracy than manual manufacturing methods. This work-flow could also include medical data such as gait analysis, so that the AFOs can incorporate data for the best setup for each patient. For instance, by automatically suggesting where more support may be needed according to the standing or gait analysis posture of the patient. This suggests that a reliable and accurate gathering method of the anatomy of the patient that allows for customisation is necessary in order to inform the digital files necessary for 3D printing. As per the paragraphs below, the current customisation methods do not fulfil these requirements. 

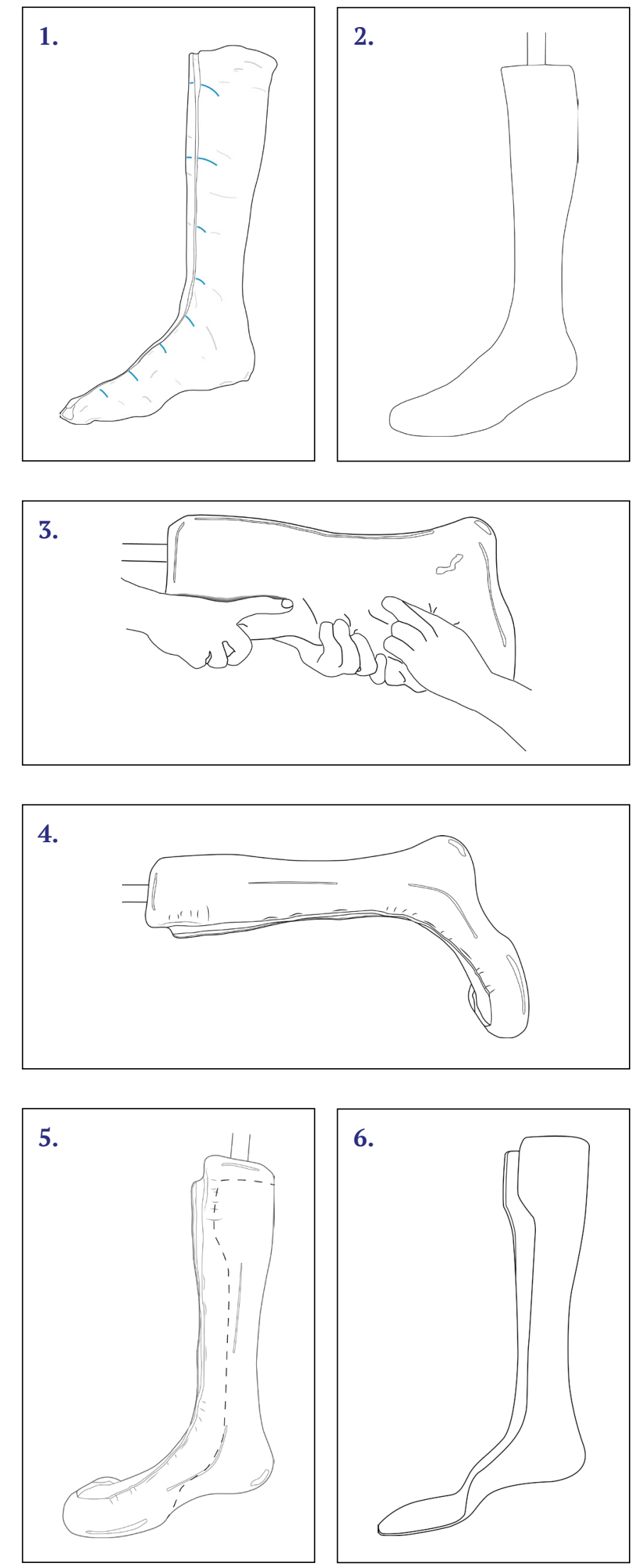

Figure 4. A standard AFO manufacturing process.
1.

A plaster wrap is applied to the patient to act as a negative mould.

2.

Plaster is poured into this mould to create a positive cast

3.

The orthotic is then created out of sheets of thermoformable plastic, moulded around this positive cast

4.

Excess material is then cut from the plastic Manually applied is a trim 'guideline' that the technician uses to manually cut the shape of the orthotic

The trim line is smoothened using a grinding tool.
Digital manufacturing and customisation techniques The standardised method of acquiring patient-specific measurements is during the casting stage, where a surface mould of the patient is taken with Plaster of Paris. However, this can result in inaccurate measurements (Walbran, Turner, \& McDaid, 2016) and cause negative patient experiences (Yamaguchi et al., 2014). An alternative process under investigation is to 3D-scan patients' limbs and use the CAD data to produce 3D-printed AFOs.

Chen et al (2016) outlines the measurements taken in the standard Plaster of Paris procedure for orthotic creation to include "... the length, successive circumferences, and mediolateral and anteroposterior dimensions of the ankle and foot” (p. 82). These dimensions create a mould that acts as a base for the future stages in the AFO manufacturing and customisation process (ICRC, 2006). However, these measurements may be unintentionally altered during stages such as drying. As well, patients may encounter negative experiences during the moulding process, because to ensure the ankle and foot are in the desired position, the clinician may be required to apply light corrective force (Chen et al., 2016). This desired position is the midstance position of the gait cycle, so the patient is required to hold, or be held, in a weight-bearing stance. This is so the base mould for the AFO is created in a neutral position, to avoid potential harm to the patient, or further worsening their gait due to incorrect positioning of the foot during the moulding stage.

Digital scanning and manufacturing studies highlight benefits for orthotic creation and customisation, including reduction of cost, time, and material. Payne (2007) reports on an estimated cost comparison between plaster casting and optical scanning of the foot for orthotic manufacture. In it, a time-in-motion study determined that optical scanning was a cheaper alternative to plaster casting (Payne, 2007). However, factors of the study that influence the results are substantially based on assumptions and estimations. This includes the charge rate of podiatrist, and their time involved in the study.

In contrast, a comprehensive study conducted by Chen et al. (2016) summarises the findings of studies using digital scanning and digital manufacturing. The study reports on benefits seen in small clinical environment from 3D printing (additive manufacturing (AM)), such as increased functionality and aesthetics, without the increased manufacturing time within presented design solutions. However, also identified were barriers related clinical, technological, and financial issues. These barriers included material cost, limited material strength, and a lack of clinical and design interface for AM processes (Chen et al., 2016). The study argues that an interface and software platform created to streamline the AM process of orthotics is the key for the adoption of this technology for larger clinical use (Chen et al., 2016). 
Current manufacturing and data-gathering methods and techniques offer some level of customisation, but rely on manual labour and the tacit knowledge of specialists to offer appropriately customised AFOs. These are not always accurate, as the stages of plaster casting and plastic thermoforming may modify the AFO shape. Further, the patient is required to be in a load-bearing stance for the duration to generate appropriate measurements. If a novel work-flow is to 3D-print AFOs, it will need digital data of the three-dimensional anatomy of the patient. Similar to other researchers working on this topic (with detail in the precedent review section), we suggest that a 3D-scanning system gather the necessary 3D data for generating CAD models of the AFO around the scanned data of the limb, for 3D printing.

\subsubsection{D Scanners}

Fields of use

3D scanners are any device that can measure subjects or objects found in the rea world, ranging from architectural structures to human beings, and generate dense point clouds or polygon meshes of these subjects via lasers, lights or x-rays (Arbutina, Dragan, Mihic, \& Anisic, n.d.).These devices have found roles in many fields, the majority of which are used for measurement (geometry), or visualisation (texture) (Treleaven \& Wells, 2007). In medicine, 3D scanners are used widely by professionals to assess and monitor patient-specific characteristics, such as the development of deformities (Treleaven \& Wells, 2007)

Treleaven and Wells (2007) argue that 3D scanning offers improvement in the diagnosis procedure of body deformities that stem from pathological factors. The basis of improvement is the scanners' ability to convert real objects into a digital format for later assessment (Arbutina et al., n.d.). 3D scanning for the purpose of monitoring or identifying body irregularities in the body allows for quicker and easier reconstruction and visualisation of the point of interest, or indeed, the body in 3D space (Arbutina et al., n.d.). The models generated also become an accessible copy for future analysis and use.

In the field of prosthetics and orthotics creation, creating surface measurements digitally removes the need to perform the timely mould-casting procedure to acquire the same data, while at the same time, creates an accessible and usable reference as a basis for the iterative production procedure of custom orthotic creation.

\section{Scanner systems}

The term "3D scanner" encompasses a range of commercial and developing technologies that use different scanning methods to produce 3D model outputs. These can be categorised on factors such as operating system and method of scanning.
Some current optical 3D scanners used to capture surface measurements experience issues related to time, movement, and duration. For example, laser- and structured light scanning systems require an operator to move around a subject who remains in a fixed, stationary position for this duration (Peyer, Morris, \& Sellers, 2015; Straub, Kading, Mohammad, \& Kerlin, 2015). However, unconsciously or not, people constantly move, from subtle shifting, respiration, or simply keeping their balance (Mitchell \& Newton, 2002; Leipner et al., 2016). For AFO customisation, a child with $\mathrm{CP}$ would need to be scanned in a weight-bearing stance to allow for a proper $\mathrm{AFO}$ fit. But support aids such as crutches can interfere with image capture, making it difficult to hold a weight-bearing stance for any duration of time. Therefore, processes of surface capturing that require extended periods of the patient not moving will be impractical and difficult to use

The process of digitising the surface measurements of patients via 3D scanners highlights increased accuracy and detail with a decrease in capture time. However, also highlighted is the need to reduce distortion opportunities caused by movemen of the patient as they try to maintain a load-bearing stance. Therefore, there is an opportunity to exploit the speed and accuracy of stereoscopic photogrammetry scanning processes to ensure movement is minimised, while accuracy is maximised.

\subsubsection{Close-range stereoscopic photogrammetry}

Medical roles and identified limitations

Photogrammetry scanners boast the benefit of quick image capture. In medicine, close-range stereoscopic photogrammetry has found use in fields that require full, or large parts, of the body scanned, including orthotic creation (Mitchell \& Newton, 2002; Ciobanu, Ciobanu, \& Rotariu, 2013). Other roles include custom garments in fashion (Apeagyei, 2010); documentation of the stature of suspects in policing (Leipner et al., 2016); and for full-body miniature 3D printing. Research has highlighted issues encountered with full-body photogrammetry scanners within these fields.

Leipner et al (2016) identified subject movement and lack of scanner mobility as issues in their system evaluation. They explain that the larger the area of documentation on the subject is, "the greater the influence of movement on the accuracy of the documentation." (p. 123), while the lack of mobility of the scanners structure requires the intended environment to be carefully considered in order to house a static scanner setup. Ciobanu et al. (2013) examined the feasibility of using photogrammetry in the creation of prosthetics and orthotics. They identified poorly taken photos caused by a number of factors, as the culprit for imperfections such 
as holes, being present in the compiled models. This can detract from the accuracy needed for orthotic creation. However, despite these identified issues, Mitchell \& Newton (2002) argue for the continual pursuit and improvement of these systems for use in the field of medicine because of the scanning speed.

The identified issues related to usability, accessibility, and accuracy caused by system setup and hardware may inhibit the use of photogrammetry scanners for generating accurate patient surface measurements. Therefore, it is necessary to include design criteria that can address these issues. In doing so, the operating users can fully benefit from the minimisation of time, effort, and errors because of the speed of photogrammetry systems.

Capture speed and the effect on patient experience A photogrammetry system's speed reduces issues related to movement during image capture. Points of interest, such as a patients face, back, and teeth (Mitchell \& Newton, 2002), or indeed, the whole body (Leipner et al., 2016) are captured in milliseconds and simultaneously with multiple cameras (the numbers range depending on the system). This capture speed reduces the chance for distortion or inaccuracy from movement to develop, and regarding orthotics, this can improve the chances of generating accurate patient specific measurements.

As well as reducing inaccuracies, the scanned patients themselves experience a shortened period of involvement, with physical contact avoided or minimised. Reduction of physical patient contact helps avoid deforming the area of interes (Mitchell \& Newton, 2002), while physical and mental discomfort such as stress that a scanned patient may experience is avoided due to the speed (Mitchell \& Newton, 2002; Luhmann, Robson, \& Kyle, 2006). Therefore, aspects to consider include convenience, comfort, safety, and health (Mitchell \& Newton, 2002), due to the primary scanned subject being a person, and especially when the scanned individual is a child (Luhmann et al., 2006).

Research identifies the speed of a photogrammetry scanner as a solution to reduce model imperfections, and decreases the patient interaction and standing time. This is particularly relevant for children and adolescents with Spastic CP, who may not be able to maintain a stationary stance for too long without aids. As well, the notion of considering patient needs within a photogrammetry system, relates back to the necessity to be aware of vulnerable users' needs, to allow the developed system to be fully effective, and avoid bias design decisions.

\section{2 | Precedent review}

The review of commercial market, and research studies of photogrammetry scanners situated the research, identified areas of past exploration, and highlighted gaps in knowledge that could be addressed though design exploration.

Commercial and research project scanners

Numerous close-range stereoscopic photogrammetry scanners have been identified in the commercial market, and range in function and form, including health and fitness tracking, novel 3D printing for commercial and advertising use, and the VFX and gaming industry, but rarely only for medical use (Table 1). There have been commercial photogrammetry scanners used for medical purposes, and even for orthotic creation, but these are often within systems that are designed for multipurpose and multi-audience use, with no specific focus for the generation of surface data from vulnerable user groups.

Meanwhile, scanners created in research projects related to generating patient surface measurements vary in goals, scanning methods, and outputs (Table 2). For example, projects that focus on custom orthotic creation do not use multi-camera close-range stereoscopic photogrammetry scanning techniques, while others do not use participants with CP. In projects focusing on the design of the scanner itself, it is often with the goal of creating a low-cost alternative, resulting in little to no consideration for the experience of users.

Therefore, to the researcher's knowledge, there are no close-range, multi-camera, stereoscopic photogrammetry scanners developed solely for generating models for custom AFO creation, with focus also placed on the user experience of young patients with Spastic $\mathrm{CP}$, and the operating technician. 


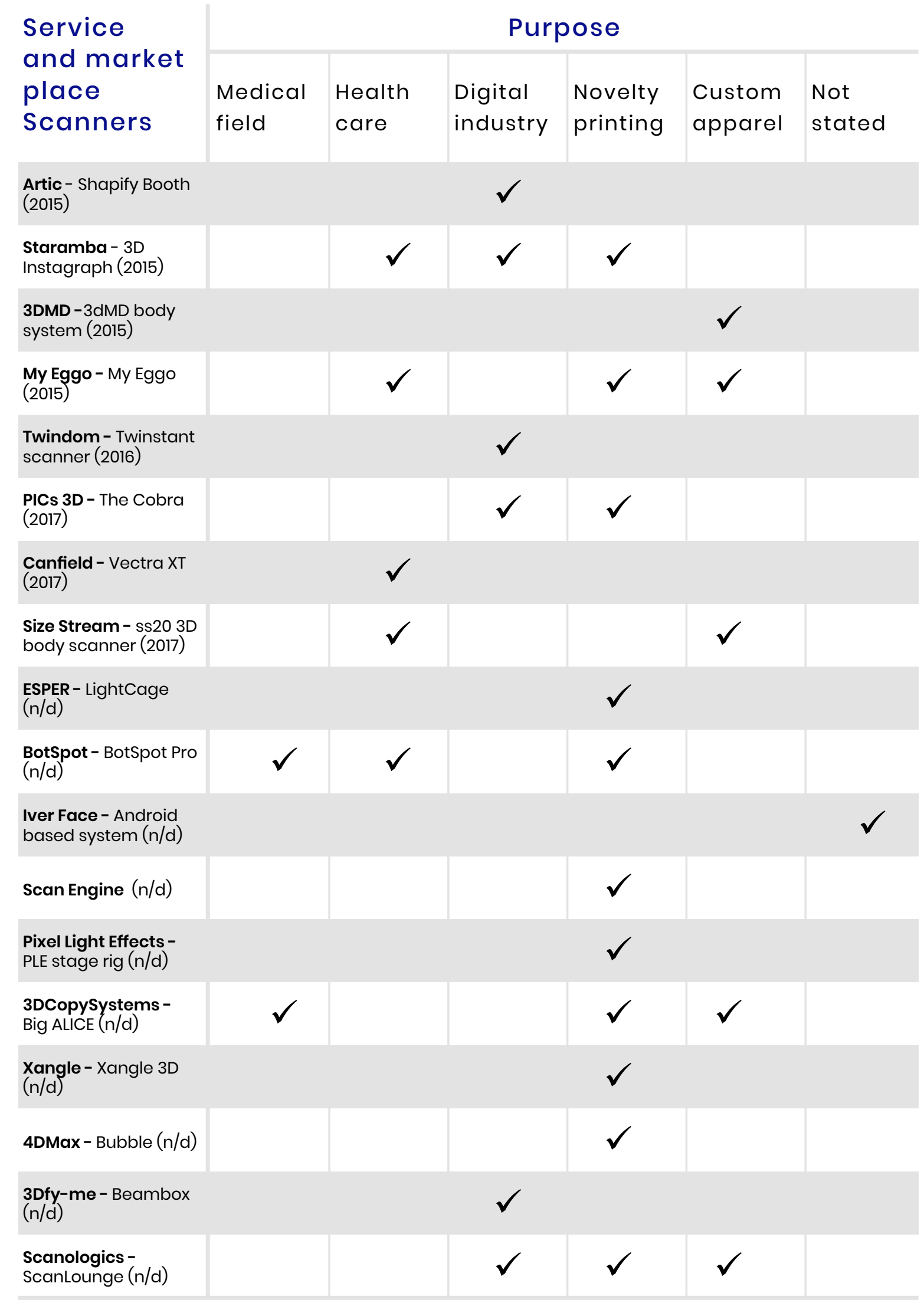

Table 1. Overview of commercially available and service provided photogrammetry scanners, and their roles.

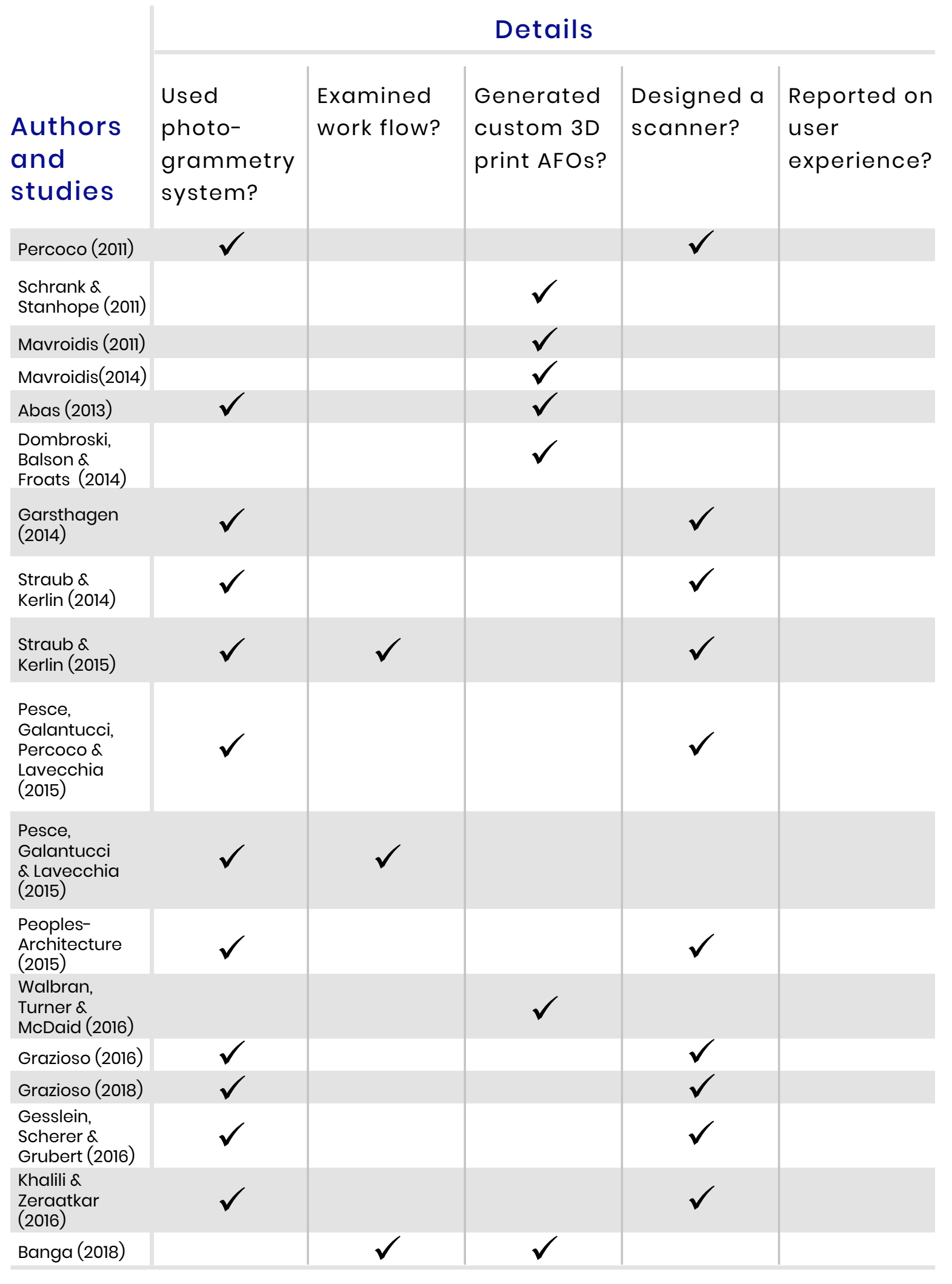

Table 2. Overview of studies and research projects related to photogrammetry scanners. 


\section{Background conclusion}

To conclude, the focus of this research portfolio is the design of a photogrammetry scanner that facilitates digital surface generation, and considers vulnerable patient usage through design decisions based on findings from the literature and precedent review.

Findings highlighted the ill-representation of children and young adults in past design development, resulting in ineffective and unsuccessful solutions based on subjective and bias assumptions. When, especially with Spastic $\mathrm{CP}$ children, informed decisions that understand their unique needs are required to develop successful treatments, procedures, and devices, such as AFOs. Research on current AFO manufacturing and patient surface generation process highlight issues such as manual methods, errors, and subjective opinion as a cause for long lead time and negative patien experiences. Findings from past studies investigating how to improve this process through digital have identified stereoscopic photogrammetry as a solution to address those issues and the experience of patients through its quick capture speed. However it is concluded that there are no photogrammetry scanners, either in commercia markets or research studies that focus on hardware integration and the experience of vulnerable users in a work-flow that generates patient-specific surface measurement data, for use in digital AFO customisation and creation.

\section{Identified criteria}

Relevant findings from the background research were analysed and categorised into a set of initial criteria, to help begin exploration into developing a photogrammetry solution that facilitates 3D scanning, and considers the experience of users. 


\begin{tabular}{|l|l|l|}
\hline SUBJECT/THEME & CRITERIA & SOURCE \\
\hline Photogrammetry scanner & & \\
\hline & $\begin{array}{l}\text { The design should facilitate optimal uniform } \\
\text { lighting }\end{array}$ & Literature (2.1.4) \\
\hline & $\begin{array}{l}\text { The design should facilitate quick patient } \\
\text { scanning }\end{array}$ & \\
\hline Novel scanner development & $\begin{array}{l}\text { The design should facilitate a digital AFO work- } \\
\text { flow }\end{array}$ & Larger project goal \\
\hline Usability & $\begin{array}{l}\text { The design should provide patients with } \\
\text { balancing issues support before, during, and after } \\
\text { use }\end{array}$ & Literature (2.1.1) \\
\hline
\end{tabular}

Table 3. Criteria identified from literature and precedent review findings. 


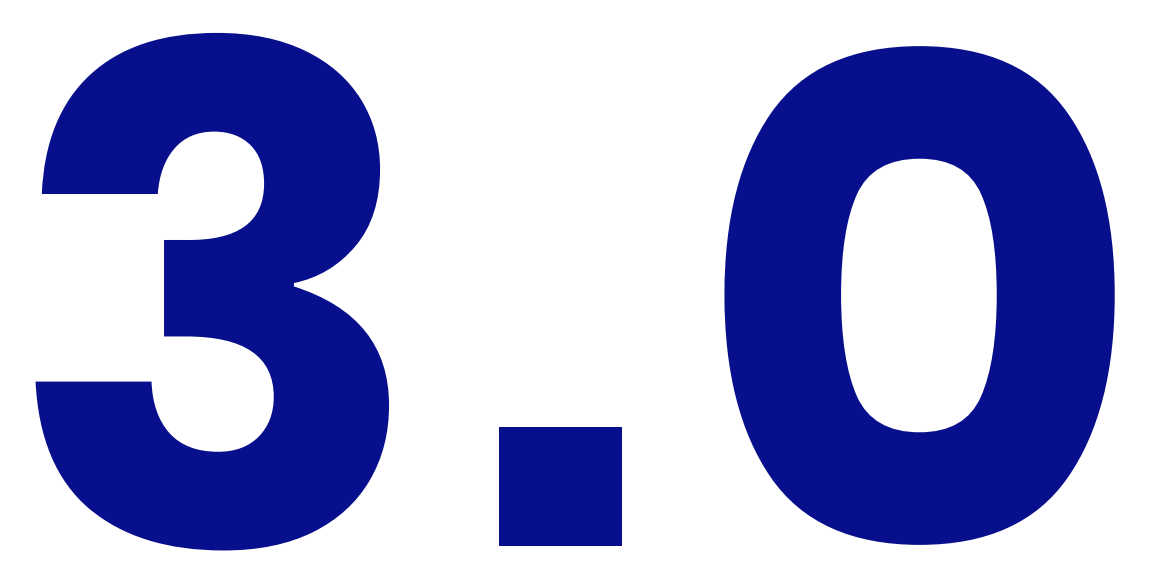

\section{METHODOLOGY}

This chapter introduces and details the research question that drove the design development of this research portfolio, as well as the research approach, research scope, aims, and objectives chosen to explore it. 


\subsubsection{Research Through Design approach}

How might we design a photogrammetry scanner that addresses the user experience of technicians, and Spastic Cerebral patients in a load bearing stance during the generation of 3D lower limb

data?

\section{Situating the research}

The identified research question guided the research portfolio and the methodology. It is based on the findings generated in the background chapter. First, it is important to base design decisions that meet the needs of users to better their experience. Second, current steps for generating patient surface measurements, are manual and can be inaccurate, whereas close range photogrammetry systems can accurately, objectively, and quickly generate the same measurements. Finally, a review of photogrammetry scanners and studies highlighted obstacles and flaws that can prevent adoption for use in clinical settings, such as immobility and image quality. As well, a lack of scanners that focus on both data generation, and user experience were identified.
A research through design (RtD) based approach was the underlying methodology for this portfolio. Results and knowledge were generated through its iterative multi-method design process, which involved ideation and experimentation for the generation of initial concepts, and the arrival at a "right" solution (Martin \& Hangington, 2012, p. 146). The use of a criteria based model structured this process into a necessary systematic form of enquiry that included stages of ideation, experimentation, and critique (Martin \& Hangington, 2012).

\section{Criteria}

Design experiments comprises a core section of inquiry within RtD based research. This portfolio was no exception. A model of RtD based around criteria (Rodríguez Ramírez, 2017) allowed systematic analysis, assessment, and discussion to be applied to experiments, and formed the basis for the portfolio's methodology. Development and refinement of criteria throughout the design process based on generated findings allowed them to act as starting points for focused experimentation as development progressed. Assessment against criteria identified new knowledge at each research stage (Rodríguez Ramírez, 2017). This systematic format prevents poorly communicated outputs that cannot be called knowledge from being created (Rodríguez Ramírez, 2017). Instead, it allowed for the knowledge produced to be communicable, and most importantly, systematically analysed and assessed.

\section{RtD stages based on categorisation of experiment} As explained earlier, the experimentation process was structured in stages via systematic assessment and analysis against criteria to ensure knowledge produced could be identified and addressed, as well as be communicable, so experiments were effectively built upon in future stages.

Krogh, Markussen, and Bang (2015) introduced five classifications of experiments to use to further structure RtD. This was in response to the identification of the poor articulation regarding how experiments: are carried out, used to identify new design avenues, or build knowledge. Along with a concern of how trusting the results of a RtD study could be without any form of systematic structure (Krogh et al., 2015). Here, they propose categorising experiments into any one of the stages of "accumulative, comparative, serial, expansive, and probing” experimentation (Krogh et al., 2015, p. 40) The forms of experimentation most relevant to this portfolio was expansive and serial. 
Expansive experimentations do not follow a strict or linear order of exploration. Rather, they are experiments that generate new knowledge by identifying and exploring previously unknown areas. This is relevant to design phase one and two, where potential solutions for further experimentation and exploration were identified. Serial experimentation however, follows a sequential order of iteration, based on the influence of previous experiments; each experiment generates insigh that then moves the work onwards. This is most evident in design phase three, where concepts were refined chronologically, based on past iterations.

Basing the structure of the design phases on these experiment categories helped this portfolio to address the proposed research question, while structuring the conducted experiments into a design work-flow that was easily communicable when sharing the knowledge generated.

\subsubsection{Pragmatic design theoretical framework}

A pragmatic design paradigm frames design inquiry as a process that is experimental that calls for the designer to draw on all available resources, and develop their own understanding of the situation (Dalsgaard, 2014). Pragmatic design is a research paradigm that also uses a multi-method approach to find the best answer to the identified design research situation (a question or a problem). The pragmatic design framework orients research towards the solving of real-world situations. The focus is not on the methods, but primarily on the results that emerged from them. These results, including principles and concepts, are appraised in accordance with how they improve and inform practices, and whether or not they were the best solution to address the research situation (Datta, 1997; Wang \& Hannafin, 2005; Wahyuni, 2012).

Both the framework and methodology employ a mixture of methods. These are comprised of qualitative and quantitative methods, depending on what the situation calls for, and are used to help address the research situation. There is value in the freedom to choose between the two. By employing a mixed range of methods that generate acceptable knowledge in the form of "observable phenomena and subjective meaning," (Wahyuni, 2012, p. 70-71) a larger data range is generated, better informing and consequently leading to, a better understanding of social reality for the researcher (Wahyuni, 2012). As design problems are seldom fully defined, so designers must adopt an experimental design approach (Dalsgaard, 2014) to arrive at a satisfying solution or product; the best solution to the design research situation.

\subsubsection{Design methods}

\subsubsection{Data generation}

Literature and precedent review

A literature review gathered core knowledge from relevant research fields that informed design decisions and situated the portfolio in the current body of knowledge (Martin \& Hanington, 2012). A review of precedents developed an understanding of the state of past and current experiments, methods, and applications of photogrammetry scanners. Conclusions drawn from the literature and precedent review revealed areas of opportunity, and contributed to the development of the initial design criteria (Martin \& Hanington, 2012)

Semi-structured interviews

Semi-structured interviews (SSIs) gathered valuable comments and feedback at different stages of the design process from both user bases; operating technician and patients. Ethics approval was sought and granted (Appendix 2) for method such as SSIs and user testing. SSIs facilitated the use of both closed and open ended questions using follow up 'why' or 'how' questions. In a relaxed environment, this encouraged independent thoughts to be discussed (Adams, 2015), and allowed the serendipity of new avenues of thought and discussion to be discovered.

\section{Observation}

Participant observation gathered baseline information in areas that were new to the researcher, and was structured in a systematic format that used methods to code observed behaviour and events (Martin \& Hanington, 2012). Observations led to the generation of qualitative data and eventually criteria, when used in conjunction with other methods such as deductive thematic analysis.

Thematic analysis

Thematic analysis allowed qualitative analysis of data from methods such as SSI's and questionnaires. This led to data interpretation that provided appropriate explanations for factors such as participant behaviour, and generated themes via dat coding and categorisation (Ibrahim, 2012). Themes were developed by connecting relevant variables and factors together, providing a way to create a chain of evidence that was reasonable and logical, while also reflecting the reality of the data collection to relevant audiences (Ibrahim, 2012).

Deductive thematic analysis also generated qualitative data from the perception of participants (Ibrahim, 2012), but also constructed meaning from observationa data during the user testing or walk-through sessions present throughout the design development. The generated data and constructed meanings were also formed into themes and conclusions (Guest et al., 2012). 


\subsubsection{Design generation}

Design criteria development

Design-relevant criteria was developed throughout the design process as new knowledge was generated. Assessment of experimentation against criteria that is built upon past knowledge allowed for systematic, focused iteration of solutions that had the most potential to occur (Rodríguez Ramírez, 2017).

\section{Prototyping}

Prototyping involved multiple methods employed to explore different avenues. These included sketch ideation, and rapid, parallel prototyping. In detail, rapid prototyping included low and high-fidelity mock-ups, through mediums such as paper, cardboard, fabrics, and textiles. As well as digital 3D CAD modelling, 3D FDM printing, and different build scales (Rodríguez Ramírez, 2017; Martin \& Hanington, 2012).

\section{Experience prototyping}

Experience prototyping was used throughout because it allowed: the prototype to be understood in the context of the user and their experiences, the exploration and evaluation of design ideas, and the communication of those ideas to others (Buchenau \& Suri, 2000). Low-fidelity prototypes were substituted for final designs to allow for evaluation through realistic user scenarios early on, and throughout the design process (Martin \& Hanington, 2012).

\subsubsection{Design evaluation and assessment}

Formative Evaluation

The scope of a Masters' thesis defined this research portfolio to be a Formative Evaluation (Center for Devices and Radiological Health [CDRH], 2016), to ensure issues regarding usability and safety were identified prior to testing a final design with a vulnerable population; young patients with Spastic CP. Therefore, it was necessary to test with participants without Spastic $\mathrm{CP}$, and evaluate and assess prototypes through expert opinion via technician assessment. This was given by a bioengineer with experience in designing and working with 3D scanners. As well, a formative evaluation helped assess the effectiveness of solutions that aimed to reduce or eliminate hazards or errors for the users (CDRH, 2016). Further details regarding how the next stage of the larger project could test with $\mathrm{CP}$ participants and a greater range of operating technicians, based on these findings, is outlined in the future research section of the final research portfolio discussion (chapter eight).

The formative evaluation was completed through simulated-use testing. Detailed in chapter seven, simulated-use testing is described as a powerful, systematic method to study the interaction between user and device user interface, as well as the performance of actual tasks (CDRH, 2016).

\section{Cognitive walk-through}

Cognitive walk-throughs were used during early design phases with focus on the users' ease of learning. They were primarily used early on as it did not require actual users, but evaluators that acted as hypothetical ones (Wilson, 2014), and it did not require a working design. This quickly generated solutions to those problems found during the evaluation (Wilson, 2014). But only for those specifically identified, potentially resulting in other problems being missed. The walk-throughs were often done with project collaborators, giving expert opinions.

\section{Weighted matrix}

Concepts were collated into comparable tables for analysis against a set of success criteria. This prompted discussion amongst the design team, and filtered many designs into only a few that could be focused on (Cagan \& Vogel, 2002). While a weighted matrix is a subjective and qualitative approach to analysing designs, it structures discussions about a concept's success on criteria, rather than personal opinions (Martin \& Hanington, 2012).

\subsubsection{Testing and feedback}

\section{Questionnaire}

The questionnaire was formatted as an emotional rating scale (Appendix 1), and used during the user testing sessions in chapter four to gather and record subjective participant opinion (Martin \& Hanington, 2012), and when used in conjunction with SSIs, drove discussion. The scale allowed participants emotional responses to be assessed, and generated qualitative data that helped the researcher understand when and, with SSIs, why they felt a certain way. The emotions were based on the Geneva Emotion Wheel (GEW) (Scherer, 2005). However, it was unnecessary to use the GEW or similar, despite being previously reported on, because of the participants' ages. As stated before, the questionnaire's role was to clearly record participant emotions. So it was necessary to determine the intended audience readability level to ensure that it was appropriate for, in this case, school aged participants (Radhakrishna, 2007) Therefore, the GEW was determined to be too broad and in depth for the participant age group, requiring the researcher to develop a simplified variant.

\section{Usability testing}

Usability testing sessions tested effectiveness, efficiency, and satisfaction of prototypes with participants through tasks that represented real-world users and situations the designs were created for (Barnum, 2010). These were measured agains the prototypes ability to allow participants to complete specific tasks through participant observations, determining if the tested designs added value to the users experience; whether or not it is 'better' than the current way of working (Barnum, 2010). Usability testing enabled further critique of the final prototype. 


\section{Collaborative usability inspection}

A team of 'inspectors' were assembled and provided feedback during the stages of the inspection session. The first phase, interactive inspection, called for a stepby-step scenario walk-through using a prototype or actual product (Wilson, 2014). During this, defects or successes were identified, and general feedback given after each stage. Following the interactive inspection stage was the static inspection phase (Wilson, 2014) where unexamined user paths were discussed. Finally, the results were assembled, prioritised, and solutions suggested to improve the prototype (Wilson, 2014).

\subsubsection{Ethics}

Assessment with participants through user testing and similar methods was approved by the University of Auckland Human Participants Ethics Committee (UAHPEC) (Ref 017026) (Appendix 2). Due to UoA ethics approval prior to this portfolio, four preselected participants, who represented Wyoung patient users, were available for testing purposes. The participants, aged between 1-16, were divided into a contro and CP group. Three typically developing school aged children made up the control, while the CP group had one 16-year-old adolescent with Spastic CP. Only the three children were used for testing. Four more typically developing school-aged children were later recruited for formal prototype evaluation through relation with research project members. No CP users were recruited for testing, as detailed earlier on in this chapter. Also, as per recommendation by ethics, assessment was given through Expert Reviews in an Analytical Approach to Identifying Critical Tasks throughout the project, and during the formative evaluation of the final design.

\subsubsection{Aims \& Objectives}

\begin{tabular}{|l|l|l|}
\hline Aim & Objective & Method \\
\hline & $\begin{array}{l}\text { Gather insight from } \\
\text { technicians with } \\
\text { photogrammetry experience, to } \\
\text { understand the technological } \\
\text { requirements needed for the } \\
\text { system to succeed. }\end{array}$ & $\begin{array}{l}\text { Semi-structured interviews } \\
\text { (SSIs) with technicians }\end{array}$ \\
(Adams, 2015)
\end{tabular}

Figure 5. Research phase aim, objectives, and methods. 


\begin{tabular}{|c|c|c|}
\hline Aim & Objective & Method \\
\hline \multirow{4}{*}{$\begin{array}{l}\text { Design phase } \\
\text { Design a prototype that } \\
\text { facilitates the generation of } \\
\text { quality data from scanned } \\
\text { patients in load-bearing } \\
\text { stance, whilst creating } \\
\text { a positive patient and } \\
\text { technician experience. }\end{array}$} & $\begin{array}{l}\text { Create prototypes in stages } \\
\text { of iteration based on criteria } \\
\text { to identify potential issues, } \\
\text { followed by potential solutions. }\end{array}$ & $\begin{array}{l}\text { Experimentation through } \\
\text { prototyping through, rapid } \\
\text { prototyping, sketching, } \\
\text { (Rodriguez Ramirez, 2017), } \\
\text { parallel prototyping (Martin } \\
\text { \& Hanington, 2012). }\end{array}$ \\
\hline & $\begin{array}{l}\text { Analyse and assess iterated } \\
\text { prototypes through review and } \\
\text { discussion. }\end{array}$ & $\begin{array}{l}\text { Experience prototyping } \\
\text { (Martin \& Hanington, 2012; } \\
\text { Buchenau \& Suri, 2000), } \\
\text { collaborative usability } \\
\text { inspection (Wilson, 2014), } \\
\text { observation (Martin \& } \\
\text { Hanington, 2012), weighted } \\
\text { matrix (Cagan \& Vogel, 2002; } \\
\text { Martin \& Hanington, 2012), } \\
\text { design criteria evaluation } \\
\text { (Rodriguez Ramirez, 2017), } \\
\text { thematic \& deductive } \\
\text { thematic analysis (Ibrahim, } \\
\text { 2012) }\end{array}$ \\
\hline & $\begin{array}{l}\text { Create a final prototype based } \\
\text { on criteria and solutions from } \\
\text { previous iterated prototypes. }\end{array}$ & $\begin{array}{l}\text { Prototype iteration through } \\
\text { systematic assessment against } \\
\text { developed criteria (Rodriguez } \\
\text { Ramirez, 2017) }\end{array}$ \\
\hline & $\begin{array}{l}\text { Assess and test the final } \\
\text { developed prototype through } \\
\text { formative evaluation via } \\
\text { simulated-use testing session }\end{array}$ & $\begin{array}{l}\text { Simulated-use testing (CDRH, } \\
\text { 2011), observation (Martin } \\
\text { \& Hanington, 2012), SSIs } \\
\text { (Adams, 2015), assessment } \\
\text { against developed criteria } \\
\text { (Rodriguez Ramirez, 2017, } \\
\text { deductive thematic analysis } \\
\text { (Ibrahim, 2012) }\end{array}$ \\
\hline
\end{tabular}

Figure 6. Design phase aim, objectives, and methods. 

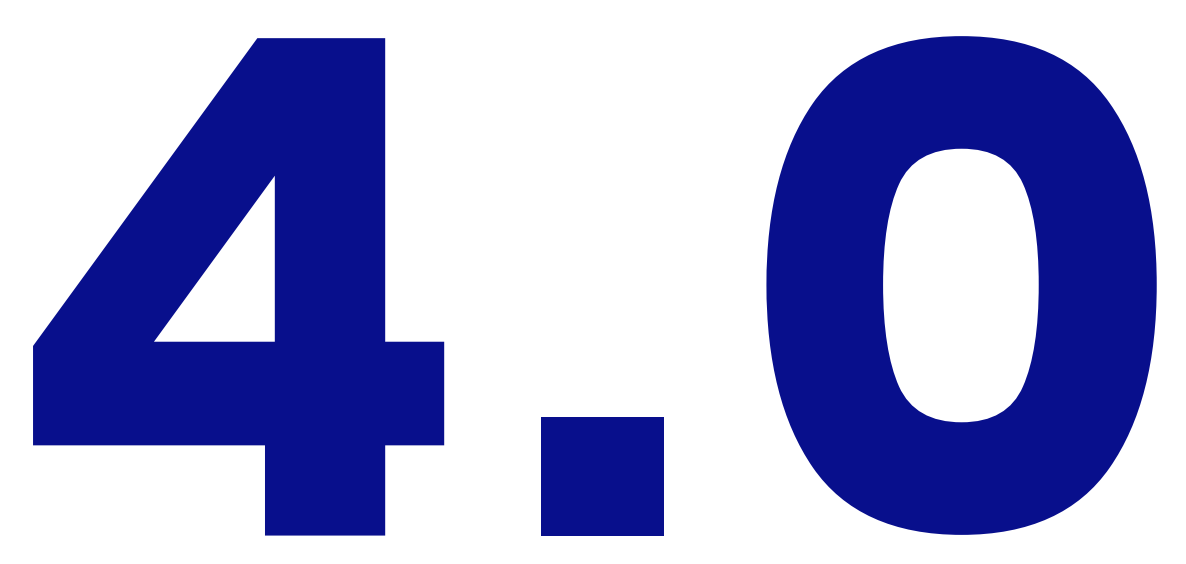

PRIOR

\section{PROTOTYPE ASSESSMENT}

This section presents findings and results from the assessment of the pre-existing prototype from the larger research project.

These were generated through multi-method assessment and

data analysis approaches to create criteria related to usability,

assembly, and similar. These were added to the one outlined in the

background chapter, creating an initial design criteria. This was

then used as a starting platform to begin the design process. 


\subsubsection{Methods}

Concept assessment

The pre-existing prototype was assessed using testing and assessment methods from the methodology chapter. Outlined within this chapter are the methods that were used in context to the chapter's goals.

\section{Data analysis}

Qualitative data in the form of themes was generated through thematic analysis of participant responses, while deductive thematic analysis generated themes from the observational findings and documentation. These themes were categorised and contextualised into criteria related to user experience.

\subsubsection{Cognitive walk-through session}

The researcher was shown the pre-existing scanner, and given a walk-through of the intended scanning procedure with the UoA technician team, during which documentation of the pre-existing scanner via notes and images were taken. These were then assessed via discussion with the team, developed, and added to the initial design criteria.

\section{Session goals}

\begin{tabular}{|l|l|}
\hline Goal & Method \\
\hline Identify project constraints & Cognitive walk-through \\
\hline Document pre-existing prototype & Cognitive walk-through \\
\hline $\begin{array}{l}\text { Assess pre-existing prototype against current } \\
\text { knowledge }\end{array}$ & Assessment against criteria \\
\hline
\end{tabular}

Table 4. Cognitive walk-through session goals.

\subsubsection{User testing and observation session}

The session aimed to investigate the user experience of the operating technician and patient during the proposed scanning procedure, set as though it were in a real-world setting. In the process, areas of improvement and consideration for both users were identified, through documentation.

\section{Session goals}

\begin{tabular}{|l|l|}
\hline Goal & Method \\
\hline $\begin{array}{l}\text { Document the user journey as participants } \\
\text { interacted with the scanner. }\end{array}$ & Observation \\
\hline $\begin{array}{l}\text { Develop a list of tasks needed to be completed } \\
\text { by technicians to achieve a successful scan. }\end{array}$ & Observation and SSIs \\
\hline $\begin{array}{l}\text { Investigate participant emotional response } \\
\text { during different interaction stages, and } \\
\text { understand the elements that caused them }\end{array}$ & SSIs, and questionnaire \\
\hline $\begin{array}{l}\text { Identify areas of improvements needed in the } \\
\text { scanner's design according to user experience } \\
\text { (patients and clinicians). }\end{array}$ & $\begin{array}{l}\text { Observation, SSIs, and } \\
\text { questionnaire }\end{array}$ \\
\hline
\end{tabular}

Table 5. User testing and observation session goals.

The methods to assess the sessions' success and the results at completing these goals are detailed further in this chapter.

\section{Participants}

As per ethics requirements, the session was completed with the control group of participants, due to participant with Spastic CP's vulnerability. The session adhered to the UAHPEC ethics approval requirements. Alongside the three participants, we observed the operating technician interactions with the systems and functions.

\section{Procedure}

Consent and ethics

The participants ages deemed them as vulnerable users as per the project ethics. Consent was therefore required, and only received with the approval of present parents or guardians. Also, all generated information and documentation, were ether kept confidential, or identifying features such as faces are blurred, or not shown.

Testing and observation

The user observation and testing procedure began with a consultation, where participants and guardians were introduced to the session and implemented safety protocols. Once consent was given, the session began, taking 10-20 minutes, followed by a debriefing stage. Images, video, and audio documentation was taken throughout. 
First, participants were shown the prototype and given time to familiarise themselves with it. Second, participants were asked to step inside, stand in a load-bearing stance in the centre (Figure 7), and then scanned by the technicians. This was completed by taking 20 images of the participants. Third, participants were asked to step back outside. At the same time, the operating technician and tasks needed to be completed were observed (Figure 8). Afterwards the participants were offered a short break, and then completed the debriefing session. At the three key stages of the testing session, the participant was asked to fill out, using stickers, the emotional-rating-styled questionnaire (Figure 10) (Appendix 1).

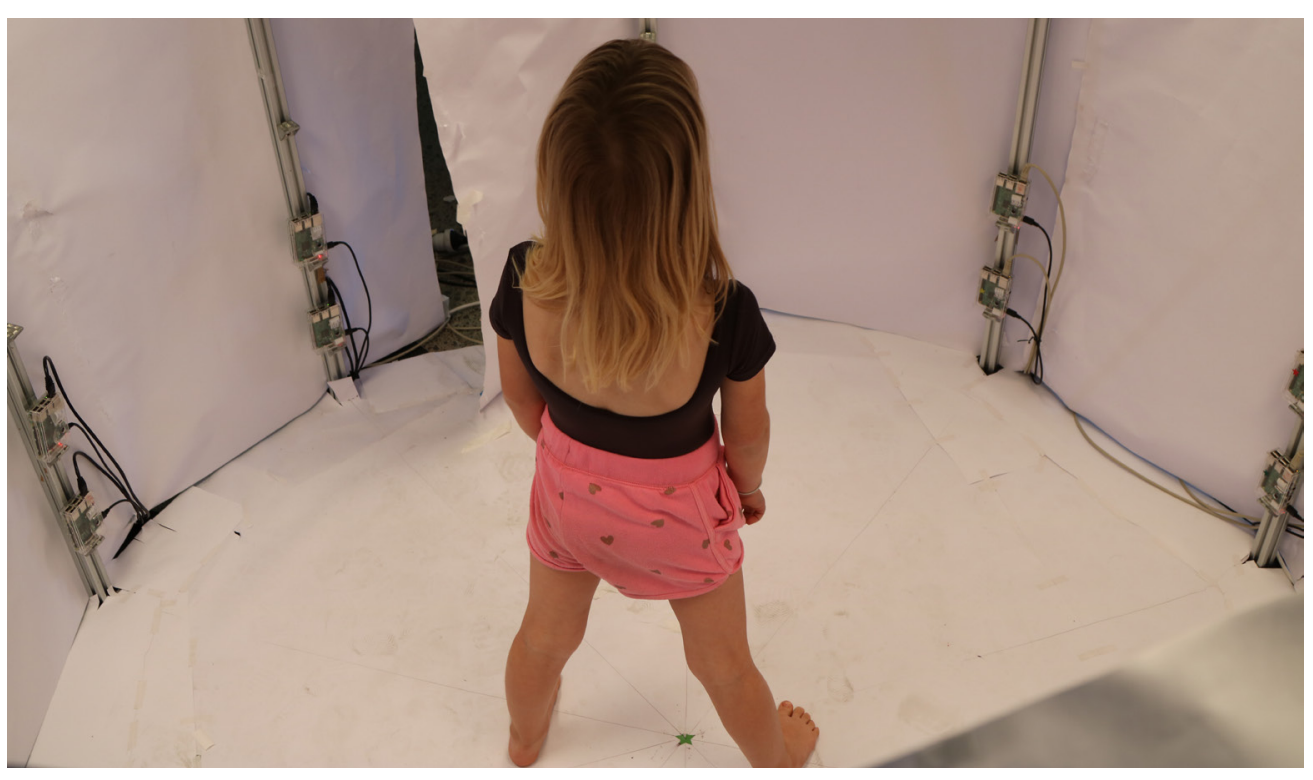

Figure 7. Participant in a load bearing stance within the prototype. Copyright 2019 by Jacob Marsh.

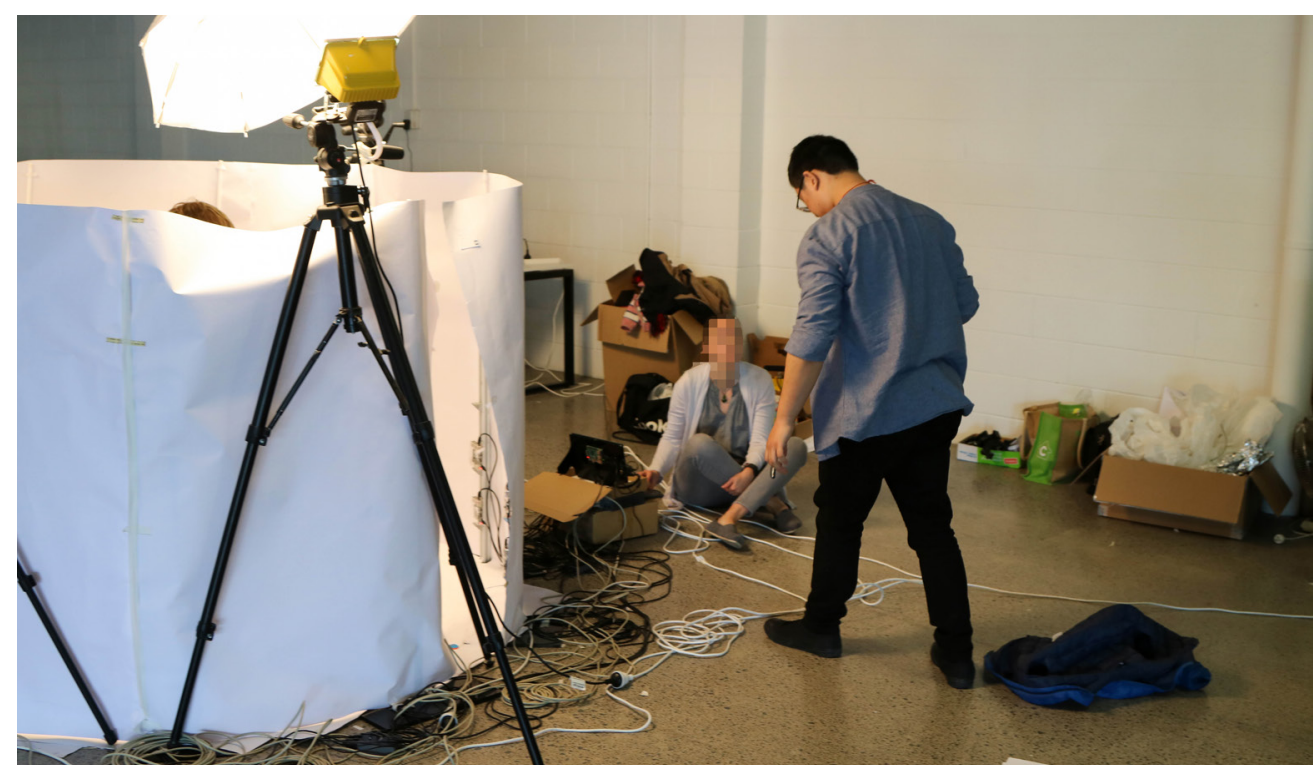

Figure 8. Observation of technician tasks during the scanning procedure. Copyright 2019 by Jacob Marsh.

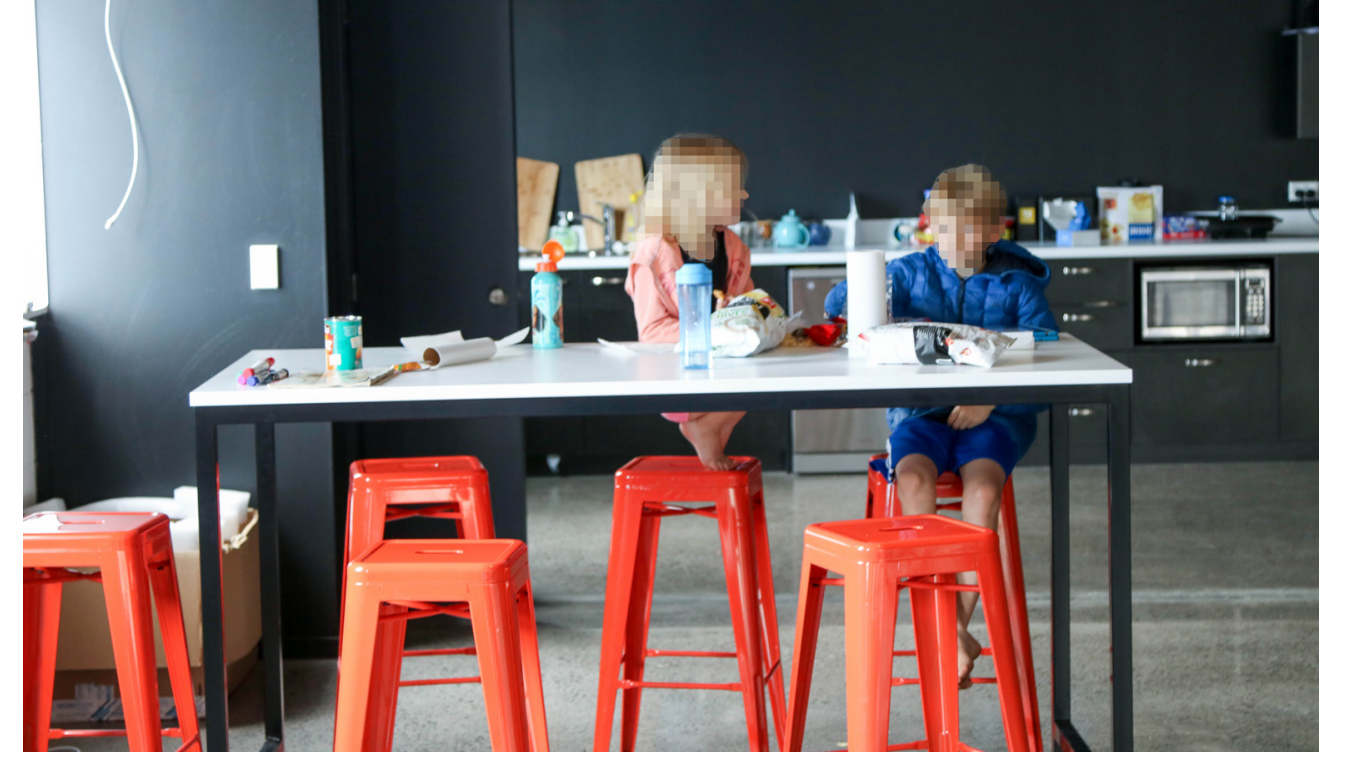

Figure 9. Participant break area. Copyright 2019 by Jacob Marsh.

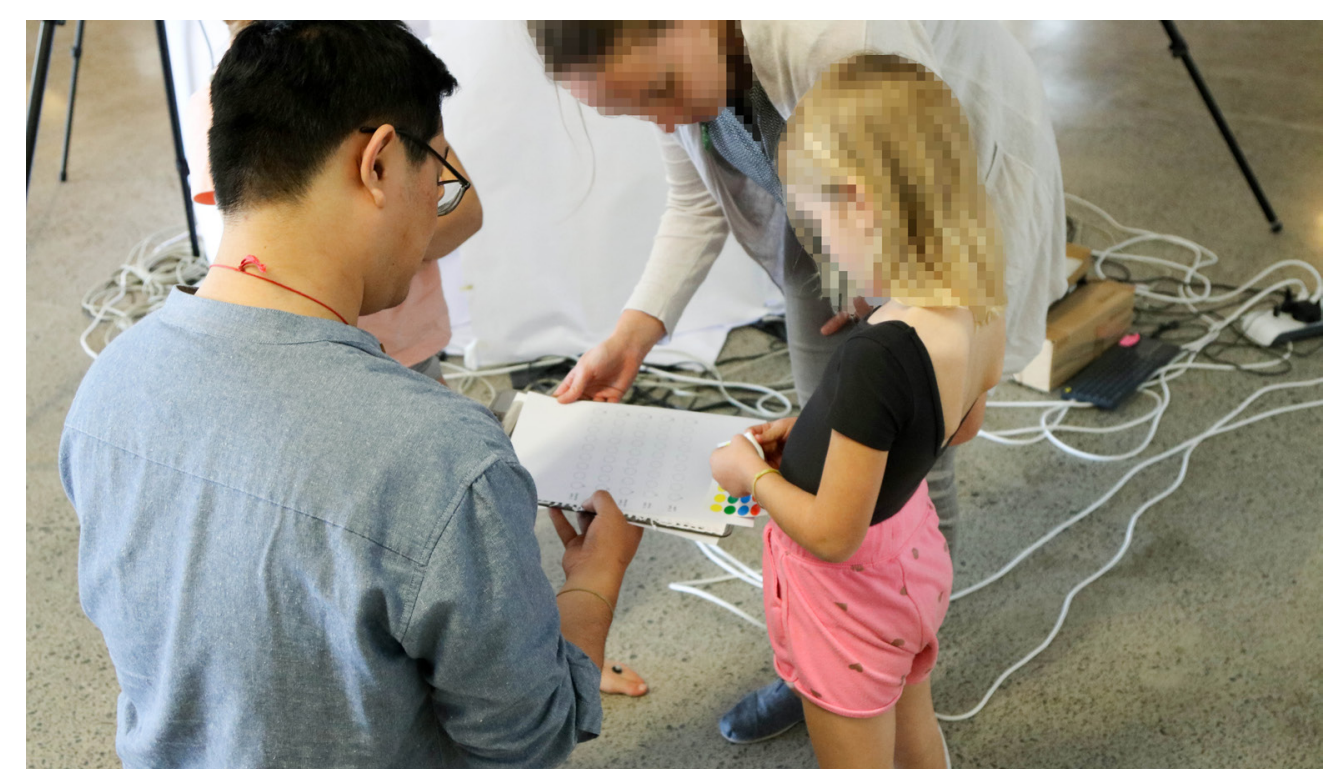

Figure 10. Participant filling out rating chart. Copyright 2019 by Jacob Marsh.

\section{Debrief}

After the participants had completed a short rest, a SSI was conducted using a script to gather insight into their experience (Appendix 3). The goal was to gather qualitative data through the SSI and emotional rating questionnaire. Once completed, participants were offered a koha, or a small gift, as a show of gratitude for their time. 


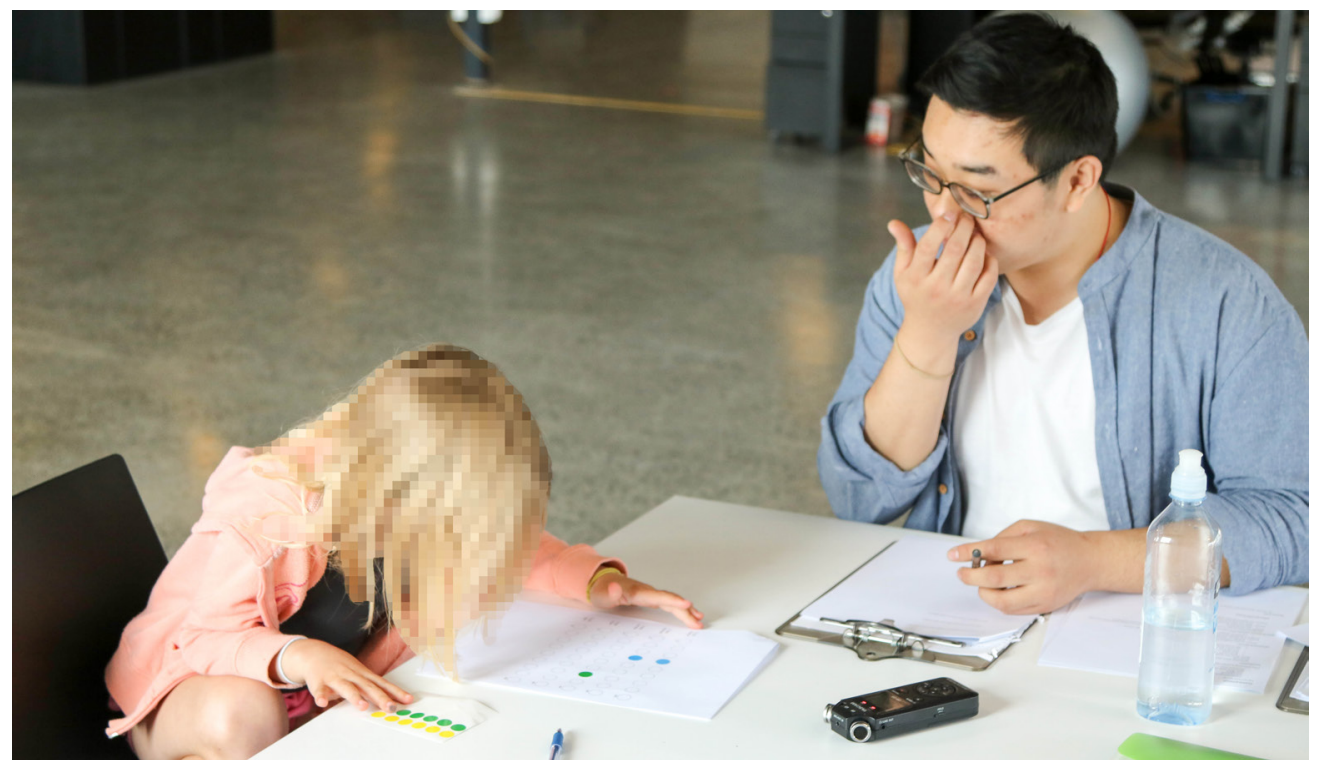

Figure 11. A participant filling the final rating chart during the SSI session. Copyright 2019 by Jacob Marsh.

\subsubsection{Lighting test \& assessment session}

During the testing session, a pre-existing lighting solution was used (Figure 12). Afterwards, a potential lighting solution using LED strips was tested. The solution tested were two 10-metre length LED strips positioned horizontally that ran the diameter of the scanner at the top and bottom (Figure 13). The strips used were 660 lumens per metre and came with a dimming feature. The dimming feature was used to systematically test the intensity of the lighting, and its effect on the images and the subsequent digital model.

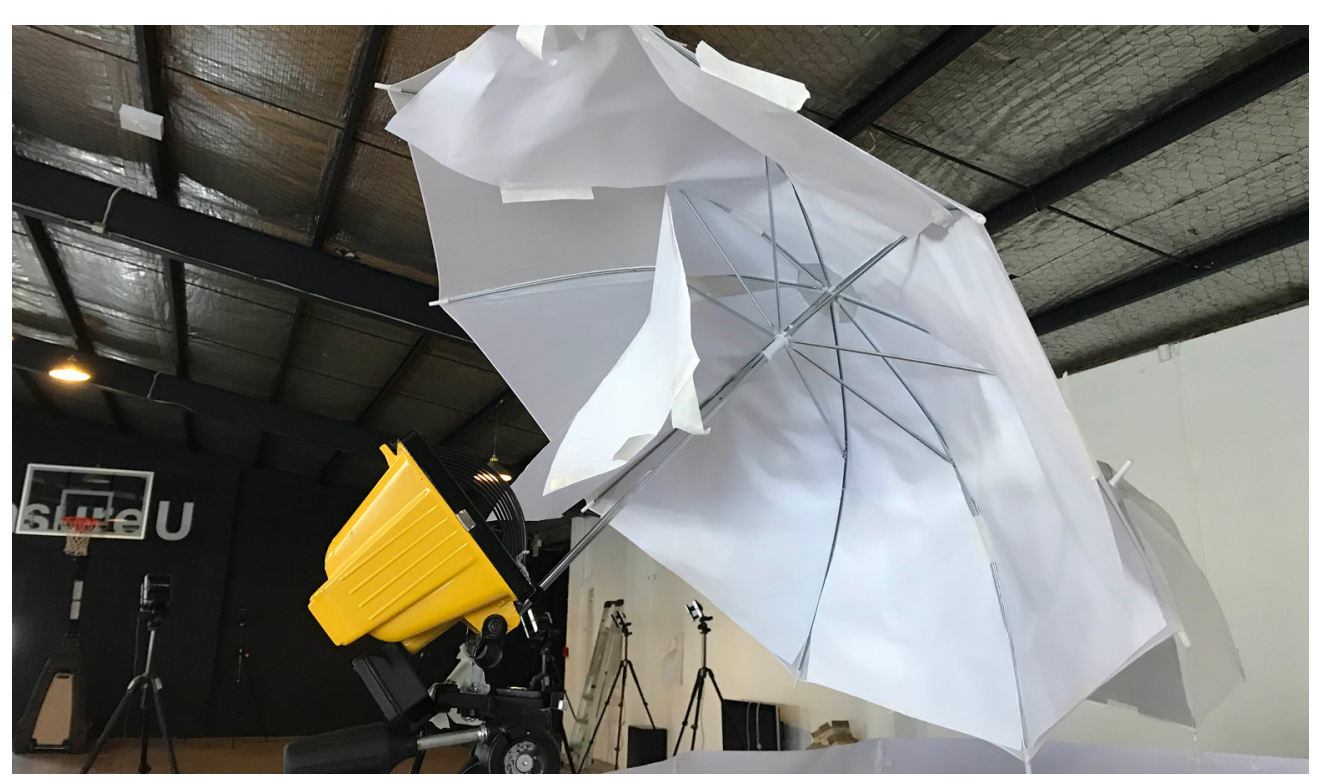

Figure 12. Pre-existing lighting solution. Copyright 2019 by Jacob Marsh.

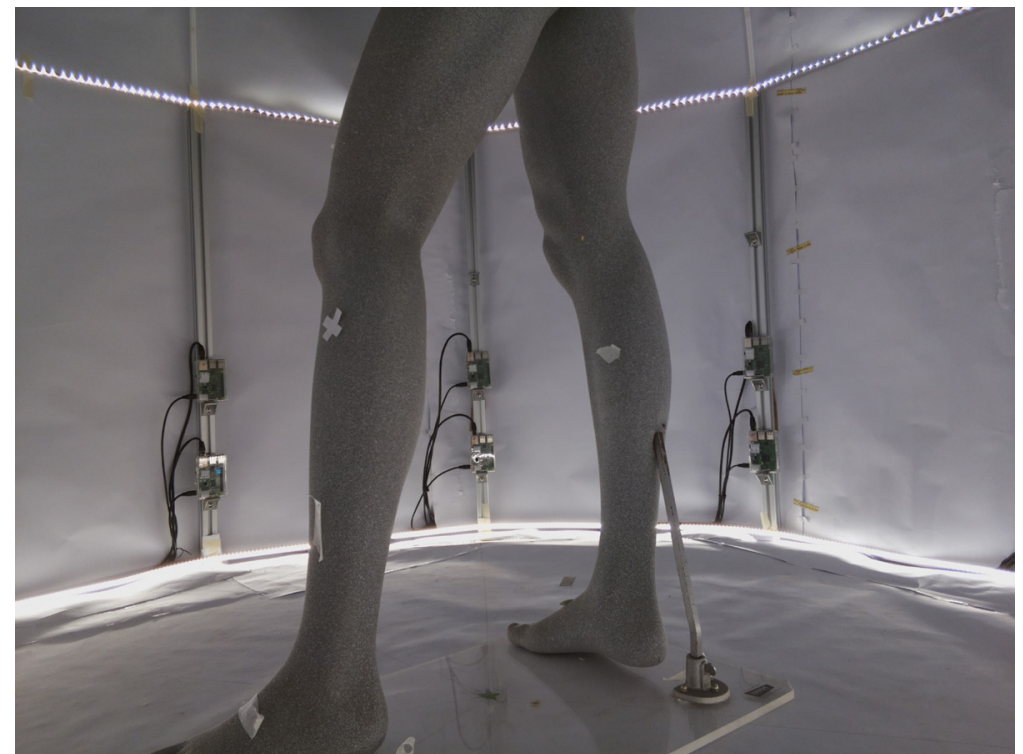

Figure 13. Proposed lighting solution

Session goals

\begin{tabular}{|l|l|}
\hline Goal & Method \\
\hline $\begin{array}{l}\text { Evaluate and compare the models } \\
\text { generated from the different lighting } \\
\text { solutions. }\end{array}$ & $\begin{array}{l}\text { Evaluation with project members and } \\
\text { Analytical Approach to Identifying } \\
\text { Critical Tasks through Expert Review } \\
\text { (CDRH, 2016) }\end{array}$ \\
\hline $\begin{array}{l}\text { Evaluate digital model quality from } \\
\text { both lighting solutions by comparing } \\
\text { them to the one from previous research } \\
\text { project. }\end{array}$ & $\begin{array}{l}\text { Evaluation with project members and } \\
\text { Analytical Approach to Identifying } \\
\text { Critical Tasks through Expert Review } \\
\text { (CDRH, 2016) }\end{array}$ \\
\hline Generate criteria for future exploration. & Assessment against criteria \\
\hline
\end{tabular}

Table 6. Lighting test session goals. 


\section{Procedure}

Image generation

Three tests were conducted at varying light intensity controlled by the LED strips built in dimmer function: 50\% brightness level (Figure 14), followed by 75\% (Figure

15), then $100 \%$ (Figure 16). Instead of participants from the user testing sessions, the

lower half of a mannequin was used as a stand-in. It was positioned at the centre of

the prototype, and then photographed a total of three times, producing 60 images (20

images per test). They then went through the post-processing work-flow described

below, identified after the lighting test session.

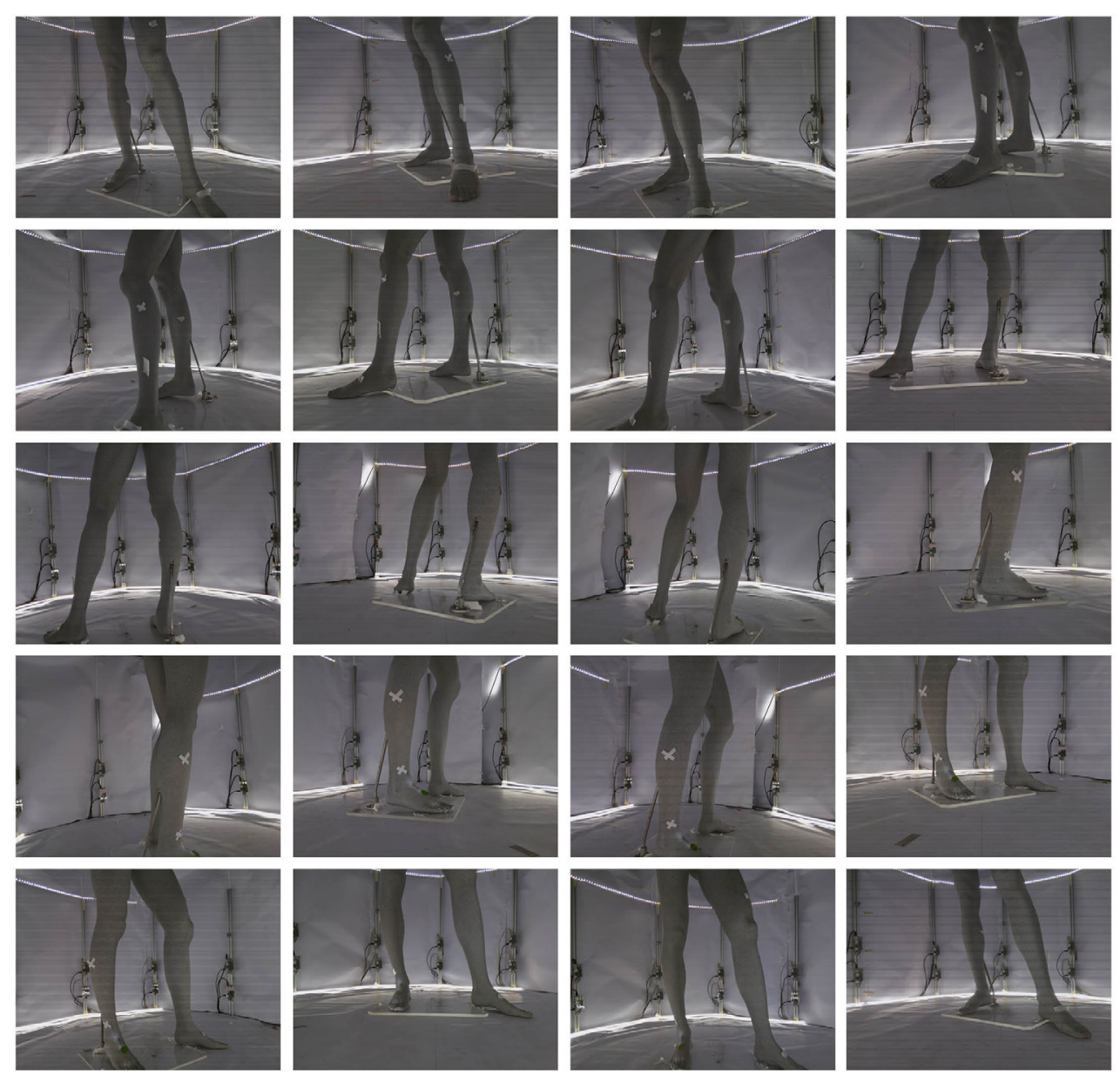

Figure 14. Image set from the $50 \%$ brightness LED test. 


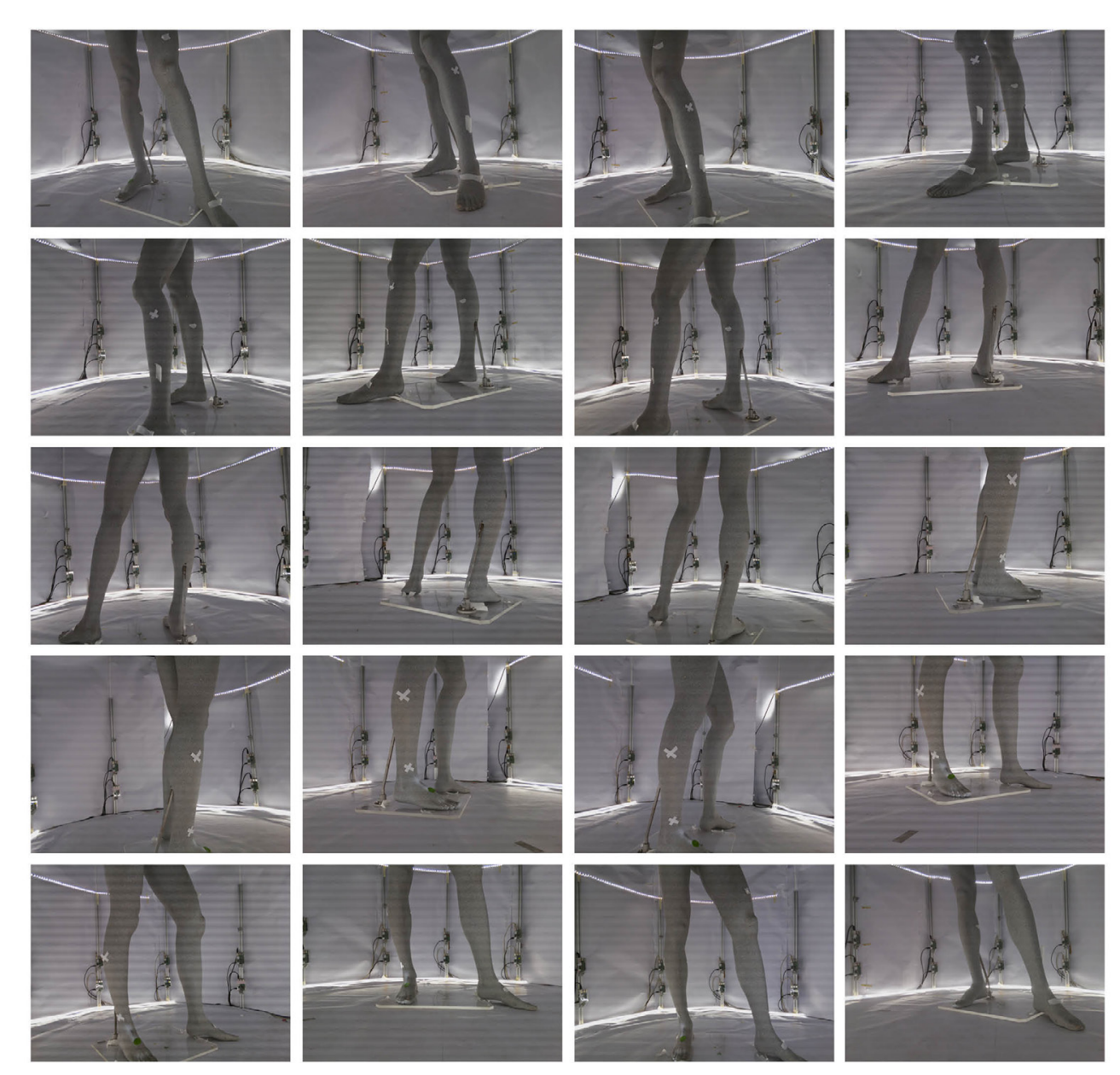

Figure 15. Image set from the 75\% brightness LED test.

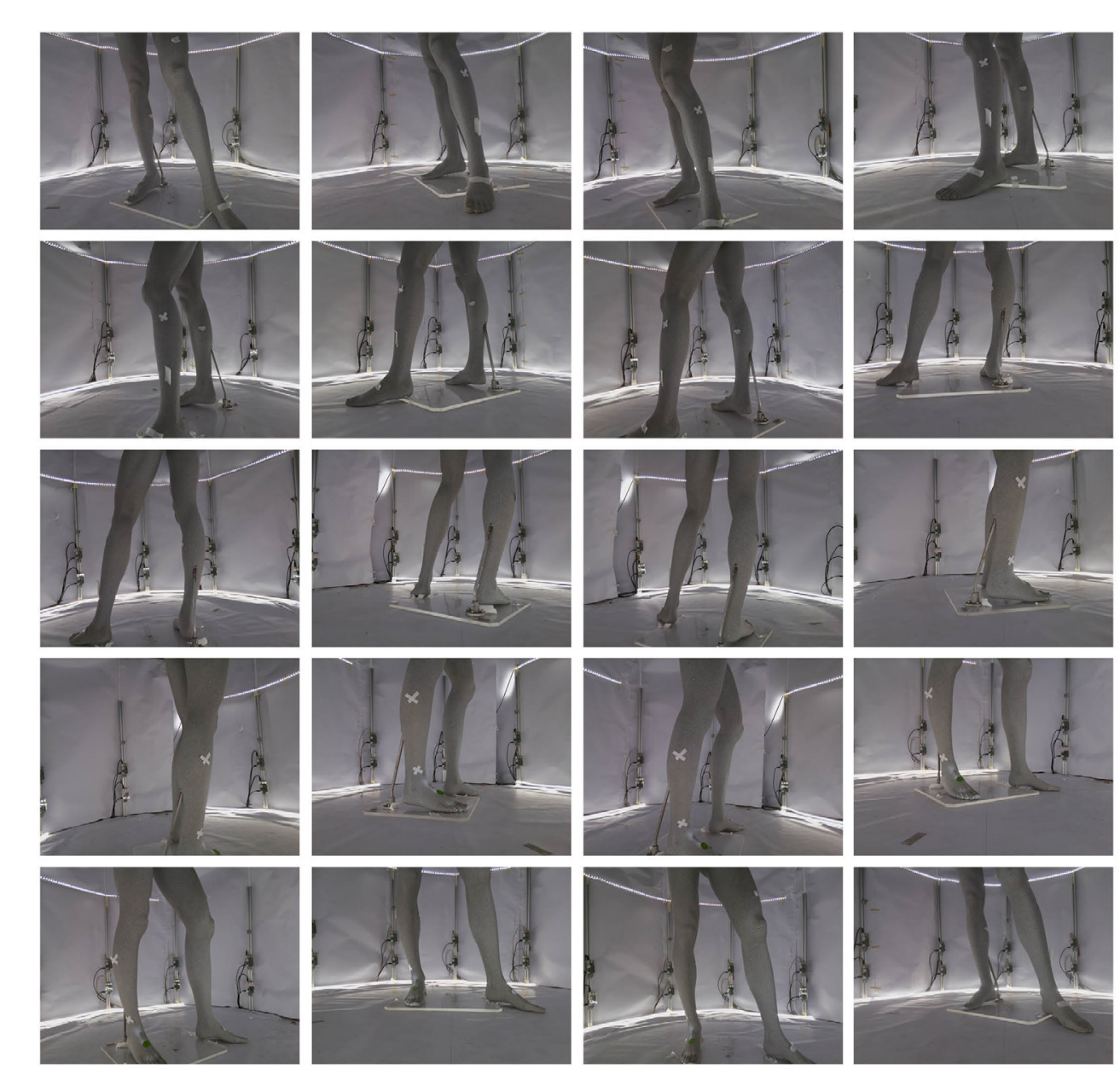

Figure 16. Image set from the 100\% brightness LED test. 
Post-processing

To begin, unwanted artefacts such as the enclosure in the background were removed,

done manually through Adobe Photoshop, with the Polygon Lasso Tool. Each three

sets of 20 images (Figures 17-19) went through the process of outlining, selecting, and

then deleting the unwanted artefacts. Afterwards, the edited images were exported

as JPEG files, and imported into the AutoDesk ReCap program.

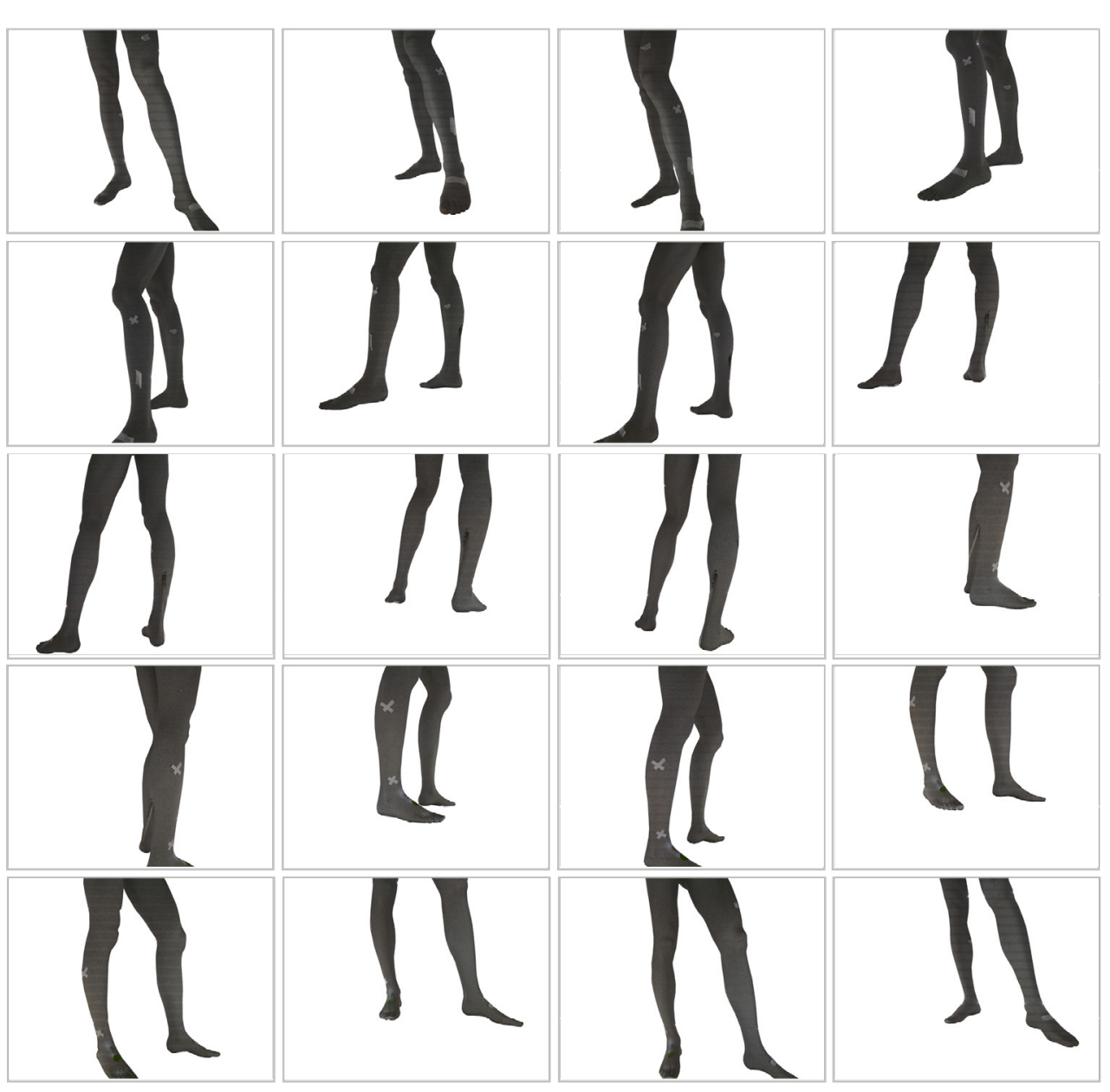

Figure 17. Edited image set from the 50\% brightness LED test. 


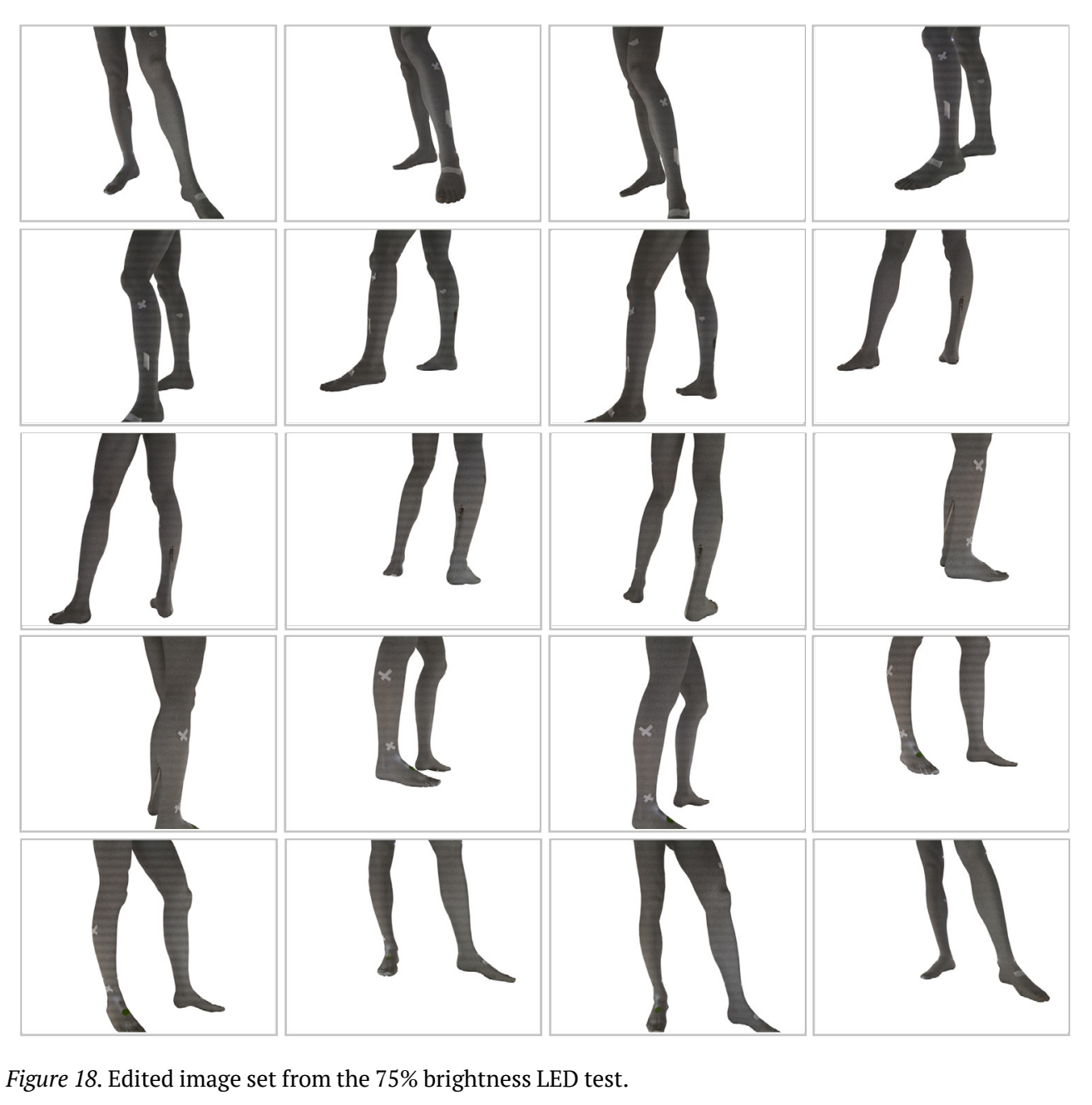

Figure 18. Edited image set from the $75 \%$ brightness LED test.

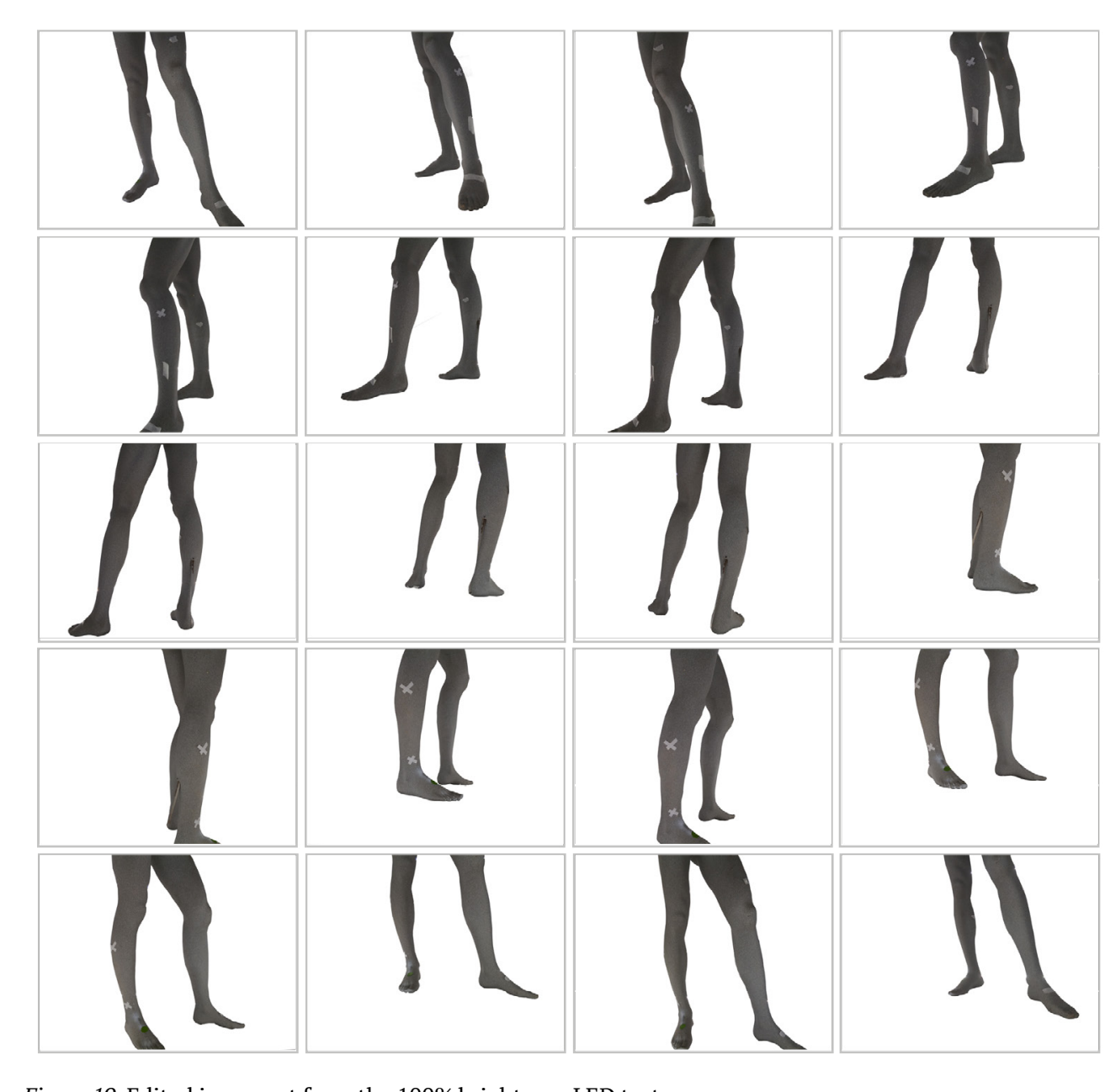

Figure 19. Edited image set from the 100\% brightness LED test. 


\section{D-model generation}

The images were imported into the AutoDesk ReCap software through the ReCap photo extension, launched when the 'photo to 3D' feature is selected. The model is automatically generated from the images once the 3D model type is selected using the default settings, in this case, the 3D model is an 'object.'

\section{Evaluation}

The models were then viewed and assessed in the program's digital space, and downloaded for offline assessment. The quality of the generated models using LED lighting was evaluated against the pre-existing base digital model (Figure 20), with discussion from the design and UoA teams. The generated models from the patient sessions followed the same procedure, with the exception of using the pre-existing lighting solution.

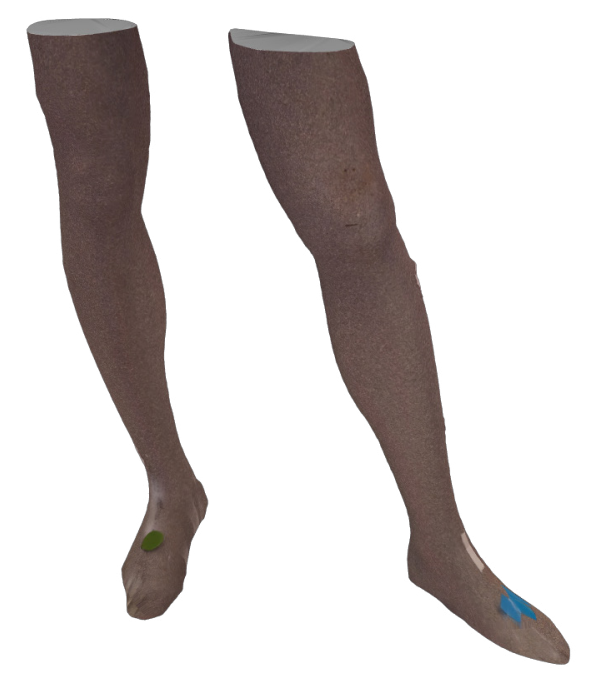

Figure 20. Base digital model used to compare against those from the LED lighting tests. Copyright 2019 by Thor Besier.

\subsubsection{Results}

\section{Pre-existing prototype}

The following images show an overview of the pre-existing scanner prototype (Figure 21 ), as well as other details such as: the Raspberry Pi tablet and connection cables (Figure 22), orientation of Raspberry Pi cameras (Figure 23), intended positioning within the scanner (Figure 24), and finally, the pre-existing lighting solution when on (Figure 25).

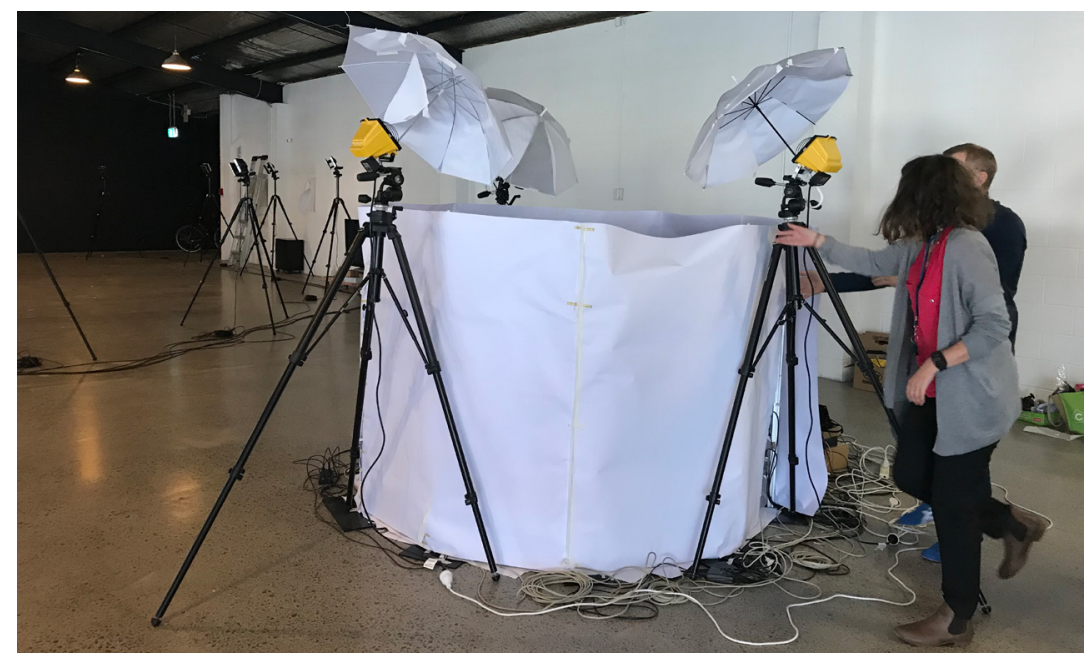

Figure 21. Outside view of the scanner prototype. Copyright 2019 by Sophie Price.
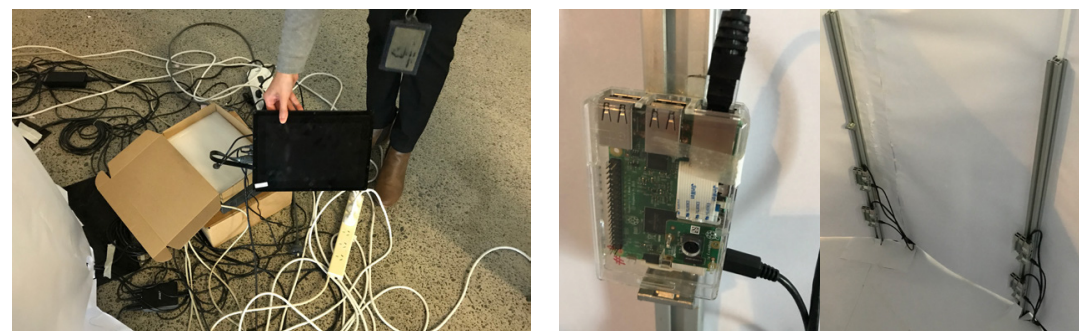

Figure 22. Raspberry Pi tablet and cablin Copyright 2019 by Sophie Price.

Figure 23. Raspberry Pi camera placement.

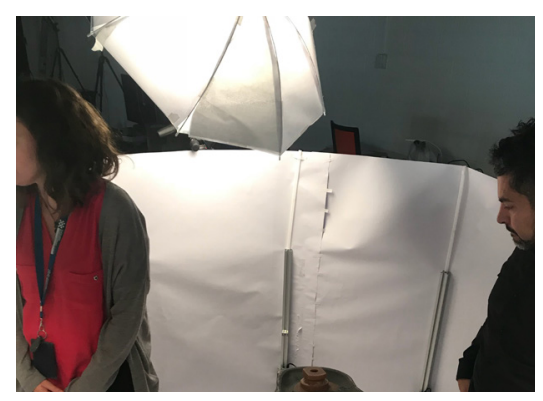

Copyright 2019 by Sophie Price.

Figure 24. Prior lighting solution while on. Copyright 2019 by Sophie Price.

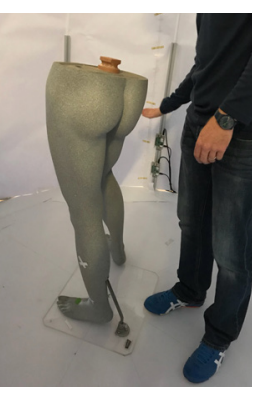

Figure 25. Ideal placement of user Copyright 2019 by Sophie Price. 


\section{Project constraints}

Constraints the research project must work within were identified from the cognitive walk-through (Figure 26).

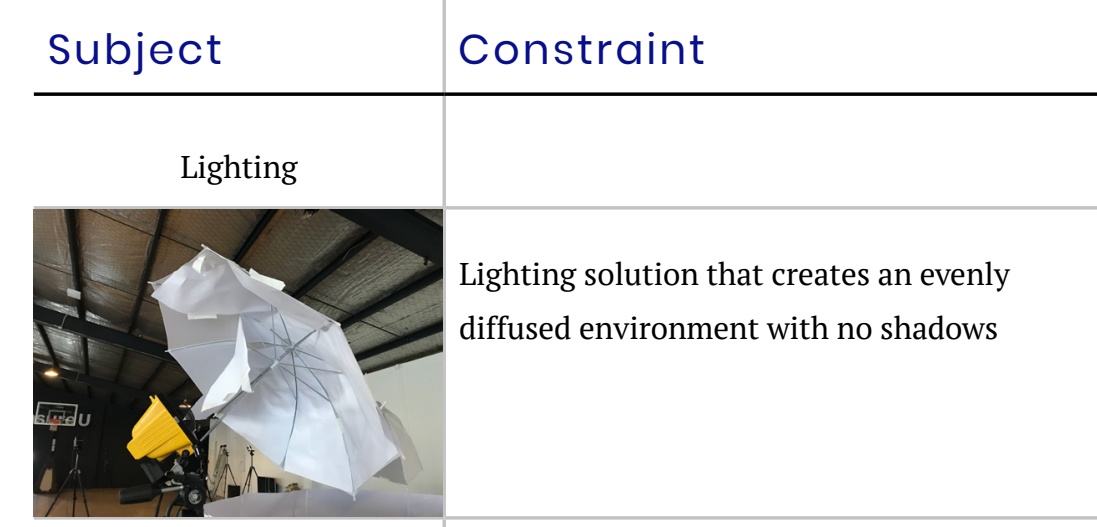

Hardware

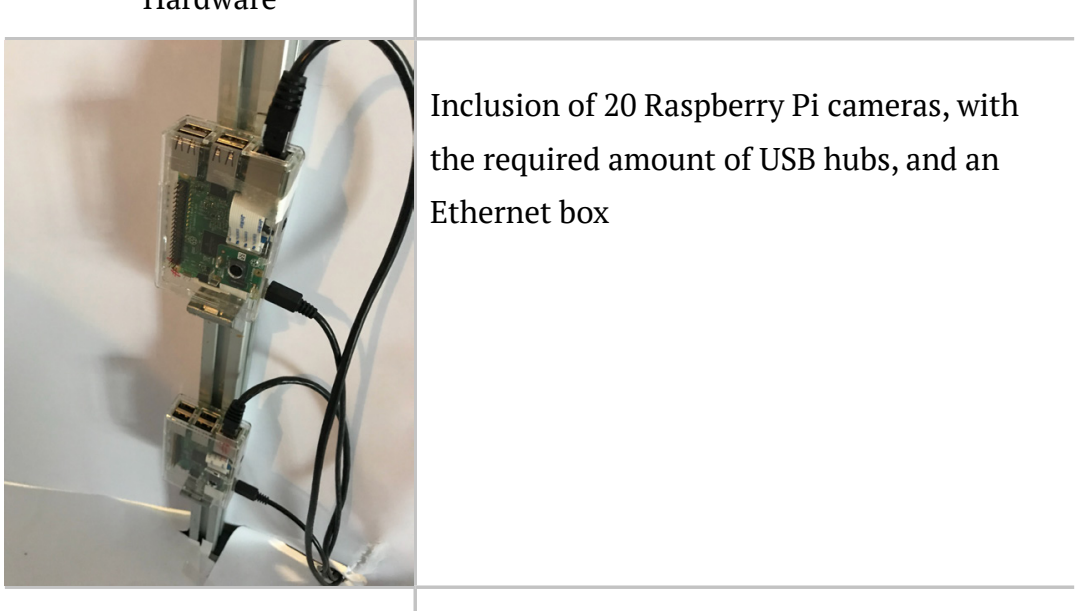

Connectivity

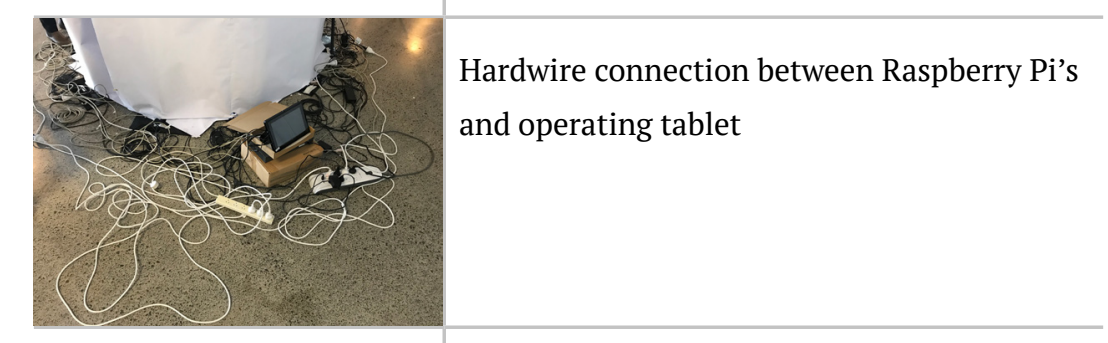

Dimensions

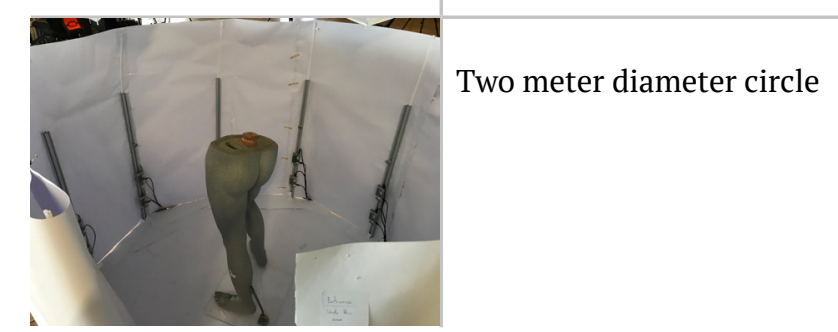

Figure 26. Identified constraints in relation to the state of the pre-existing prototype.

\section{User journey}

Identified journeys of patient and operating technician during a proposed scanning procedure, there were identified from the cognitive walk-through, and observation during user testing session (Figure 27).

Patient

Technician

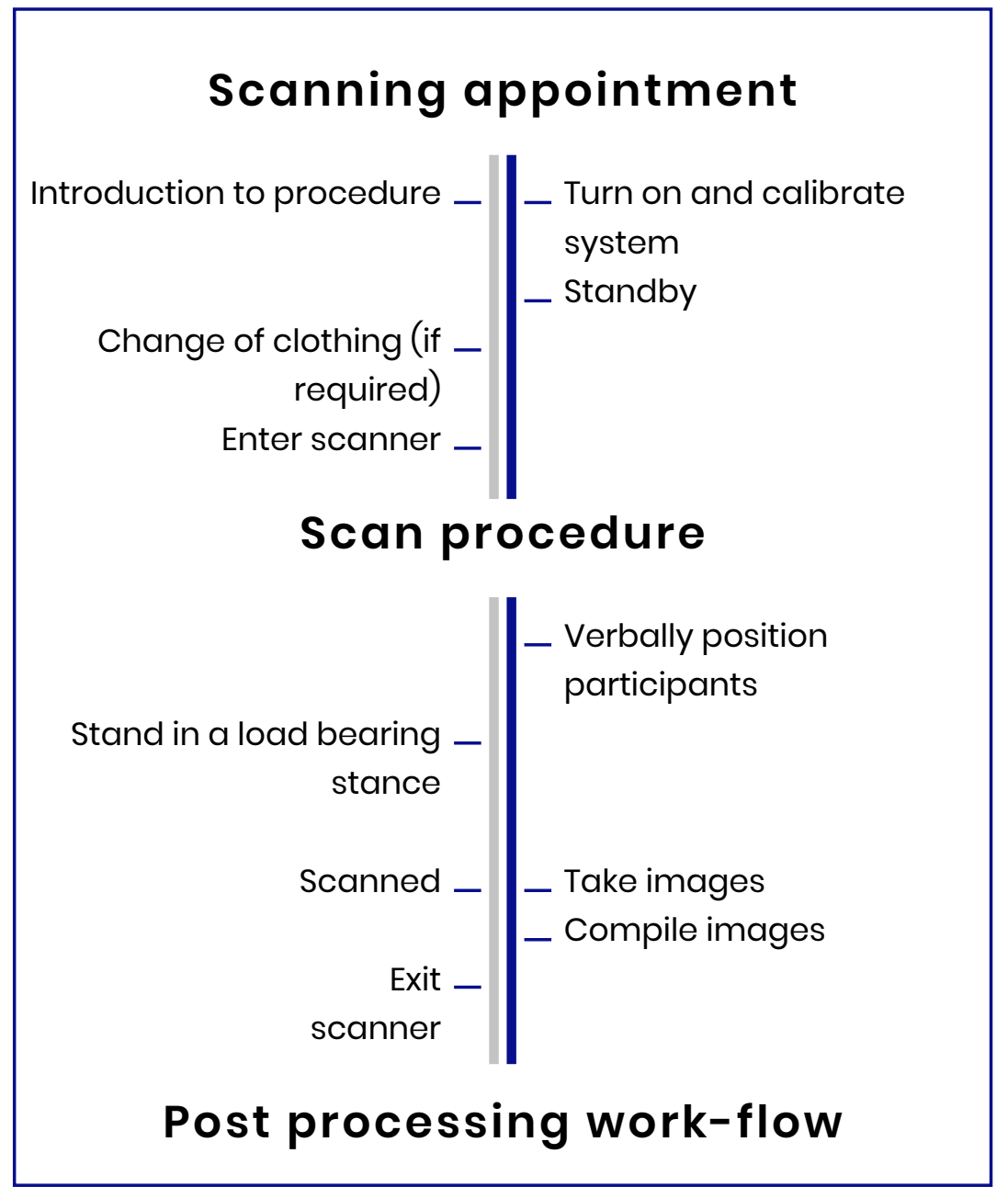

Figure 27. User journey identified from observation during user testing sessions. 


\section{Digital 3D models}

Pre-existing lighting test

Generated models of participants from the user testing sessions.

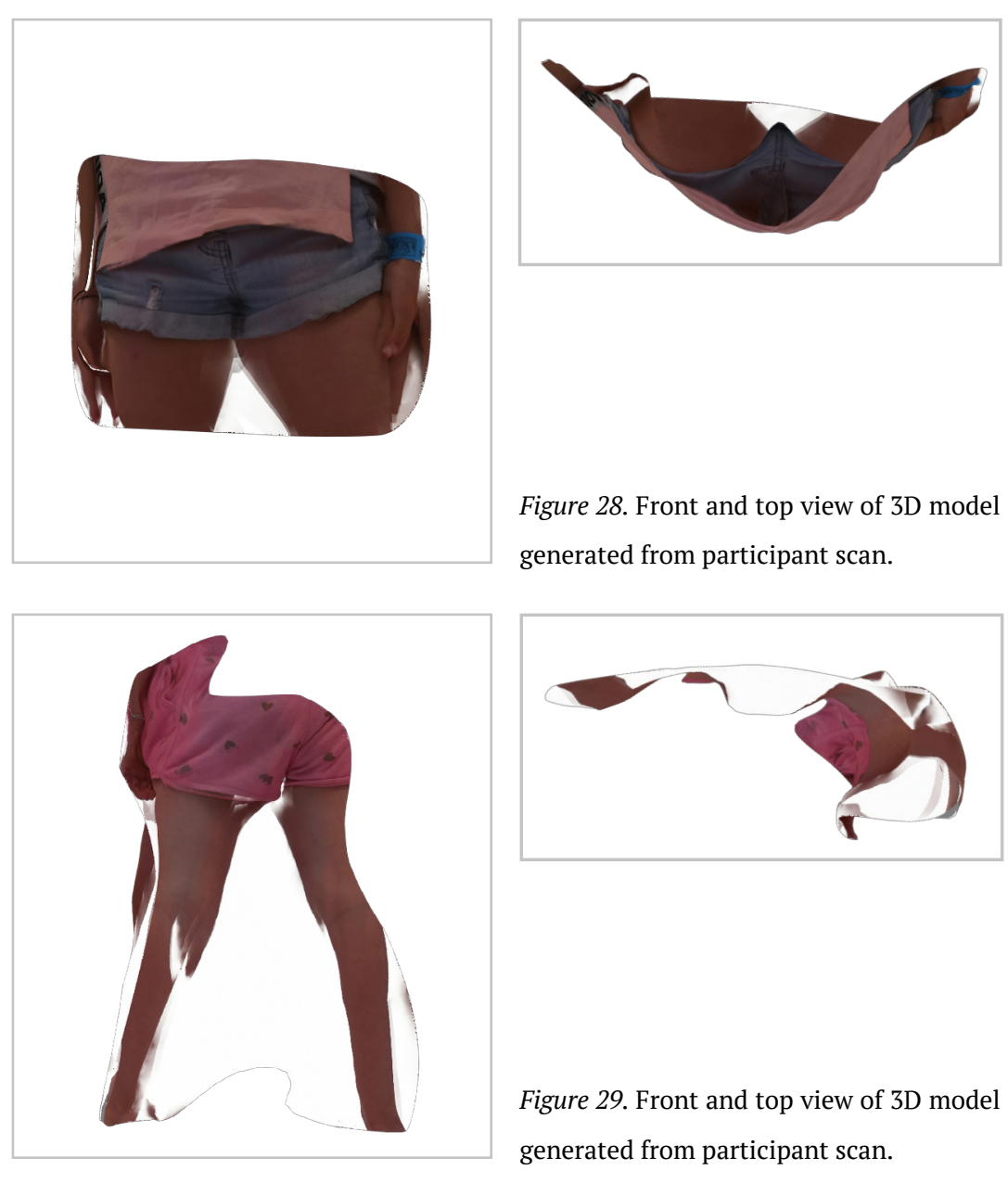

LED Lighting test

Generated models of the mannequin from the LED light tests.
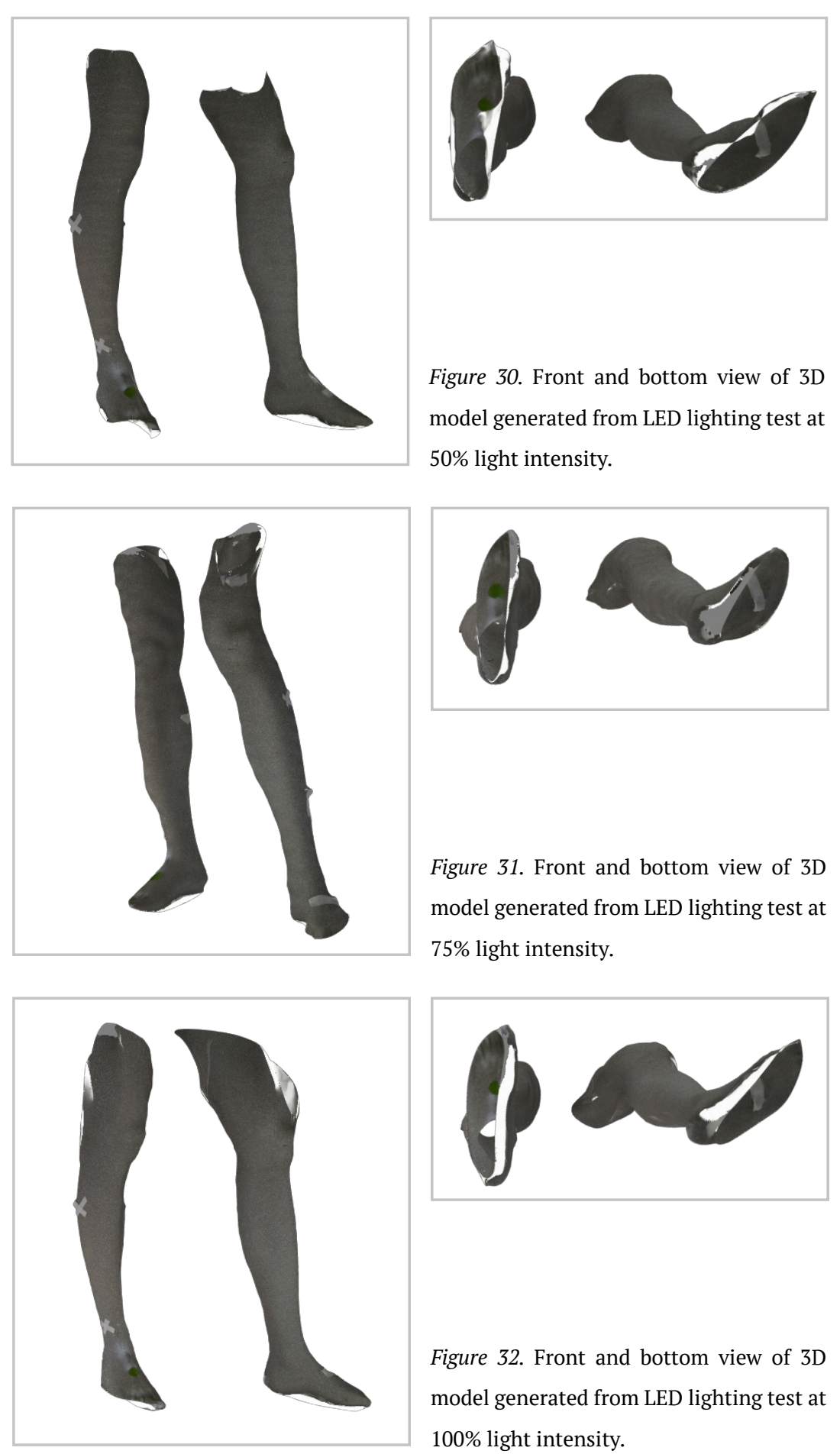


\section{User experience themes}

From the thematic analysis of responses given by participants during the SSIs of the user testing sessions, themes related to a patient's user experience were generated (Figure 33)

\begin{tabular}{|c|c|c|c|}
\hline Theme & Description & Code & mple \\
\hline Engagement & $\begin{array}{l}\text { Current overall design and } \\
\text { aesthetics show low level of } \\
\text { patient engagement. }\end{array}$ & $\begin{array}{l}\text { I don't know, } \\
\text { No feedback, } \\
\text { Nothing, Not } \\
\text { interesting }\end{array}$ & \\
\hline Communication & $\begin{array}{l}\text { Current overall design } \\
\text { choices impact interaction } \\
\text { between patient and } \\
\text { operating technician, and } \\
\text { thus, the patient experience }\end{array}$ & $\begin{array}{l}\text { Scared, Lonely, } \\
\text { By myself, } \\
\text { Calm }\end{array}$ & \\
\hline Familiarity & $\begin{array}{l}\text { Current design and procedure } \\
\text { influence learnability, and } \\
\text { the development of patient } \\
\text { understanding }\end{array}$ & $\begin{array}{l}\text { Done already, } \\
\text { Ready, Know, } \\
\text { Calm }\end{array}$ & $\begin{array}{l}\text { "probably just the same thing, } \\
\text { just a bit more calm, cause you've } \\
\text { already done it once, and you } \\
\text { know what's going to } \\
\text { happen." }\end{array}$ \\
\hline
\end{tabular}

Figure 33. Themes generated from thematic analysis of participant responses.

\subsubsection{Analysis}

Assessment of pre-existing prototype

The pre-existing prototype was assessed against previously identified criteria. This established the state of the design against current knowledge, and determined wher initial exploration would start. Some criteria could not be assessed due to factors such as unavailability of hardware, or participants with Spastic CP (Figure 34).

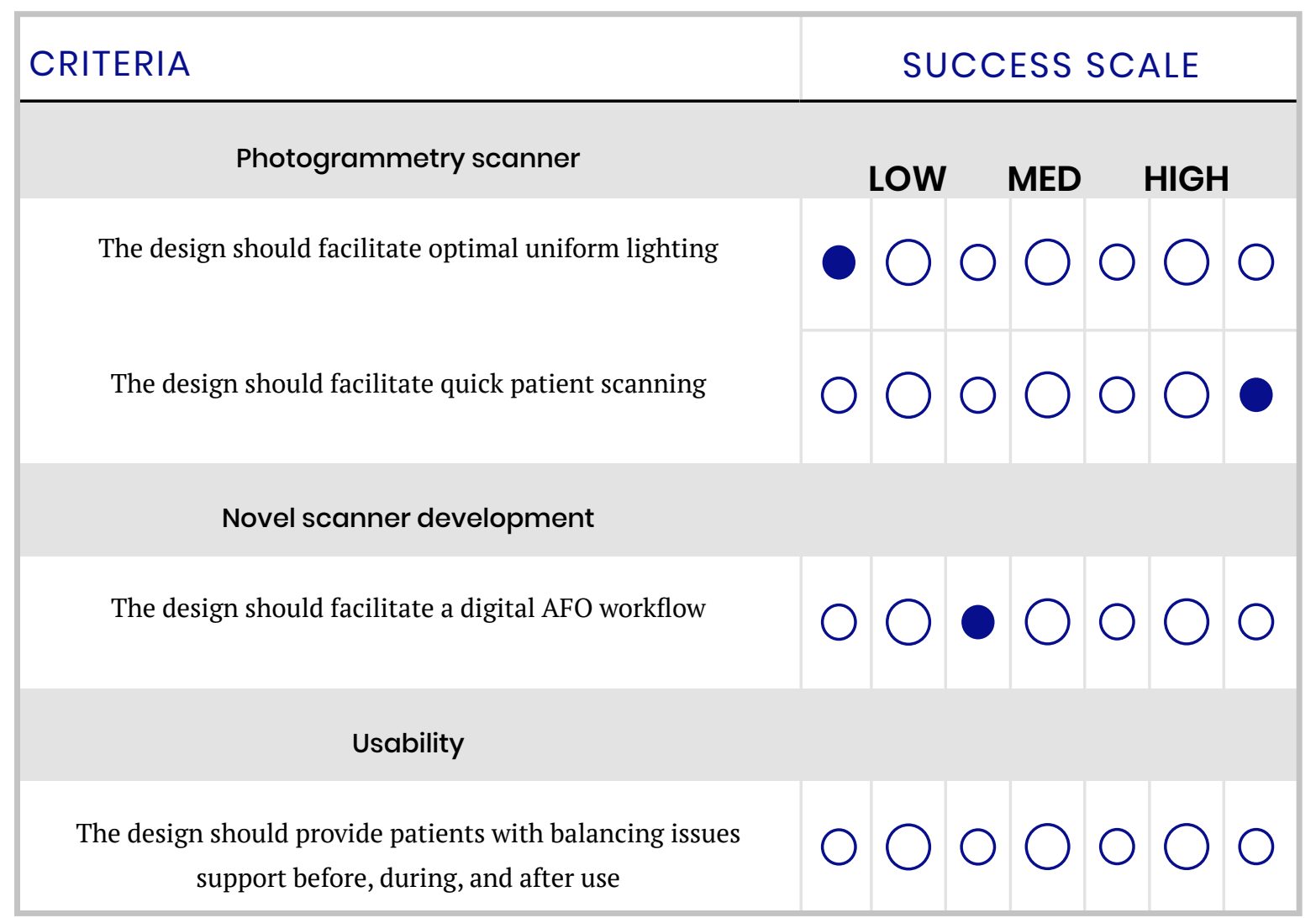

Figure 34. Assessment against criteria from background research.

\section{Analysis of user responses}

Generated from the SSIs and questionnaires were themes primarily related to use experience. Further evidence to support these themes were sourced from observation of the users' actions during the testing session, recorded though video and images.

\section{Engagement}

The debrief session identified a lack of engagement from the scanner's current design amongst each participant session. Participants one and two commented on the overall design as uninteresting and boring, with participant two likening it to being in bed because "it wasn't really interesting." Drawing from these comments, the user experience is uninteresting. However, all participants highlighted features 
like the diffusion umbrellas, the cameras, and the cables as points of interest. Because these features are not integrated into the 'overall' scanner structure, but were highlighted, it can be deduced that the 'plain' nature of the white, paper enclosure, allowed the 'uniqueness' of these features to stand out.

\section{Communication}

Engagement relates to communication between the user and operating technicians, from explaining the procedure at each stage and to general conversation. As a result, participants reported experiencing a calmer interaction. For example, participant one identified communication as a factor for their calmer state "Um, well (pause), well, I just felt like calm because, um, I just knew what was going to happen." Therefore, when informed, users were able to develop an understanding of what was happening, lessening feelings such as anxiety, due to clear communication.

\section{Familiarity}

From participant responses, clear communication between the operating technician and the patient helped the patient become more familiar with the scanning procedure. Therefore, they became more relaxed with the scanner, the scanning procedure, and the idea of future scans. For example, participants believed that they would feel more calm if they had to go through another scanning procedure. When prompted further, they revealed that it was because they had, or were, becoming familiar with the scanner procedure:

"Um, probably just the same thing, just a bit more calm, cause you've already done it once, and you know what's going to happen." (participant one)

“Not even scared, I won’t be scared." (participant two)

"Um, like ready, because I know what's going to happen." (participant three)

This is a significant finding of the research. If a sense of familiarity can make children feel more comfortable during the procedure, perhaps the design of the scanner can offer an appearance that is more suitable for children, while solving functional aspects.

\section{Analysis of cognitive walk-through}

The identified constraints from the cognitive walk-through were analysed and categorised into criteria related to themes such as usability and assembly (Table 7).

\begin{tabular}{|l|l|}
\hline SUBJECT/THEME & CRITERIA \\
\hline Photogrammetry scanner & $\begin{array}{l}\text { The design should integrate suitable lighting for } \\
\text { generating images of acceptable quality }\end{array}$ \\
\hline Novel scanner development & $\begin{array}{l}\text { The design should allow use of research-project- } \\
\text { provided hardware }\end{array}$ \\
\hline Usability & $\begin{array}{l}\text { The design should be easily assembled in under one } \\
\text { hour in different clinical environments }\end{array}$ \\
\cline { 2 - 2 } & $\begin{array}{l}\text { The design should allow custom vertical orientation of } \\
\text { cameras }\end{array}$ \\
\hline Assembly & $\begin{array}{l}\text { The design should integrate easy-to-use and } \\
\text { understandable cable management }\end{array}$ \\
\hline Aesthetics & $\begin{array}{l}\text { The design should be circular to allow for camera } \\
\text { overlap. }\end{array}$ \\
\hline
\end{tabular}

Table 7. Identified criteria from cognitive walk-through.

\section{Analysis of proposed lighting solution}

Relevant to 4.1.3, an LED strip lighting solution was tested to address issues identified in that section. The main factors identified were errors (the number of missing parts); post-processing (the time to remove artefacts); and accuracy (how accurate is the model to its real-life counterpart).

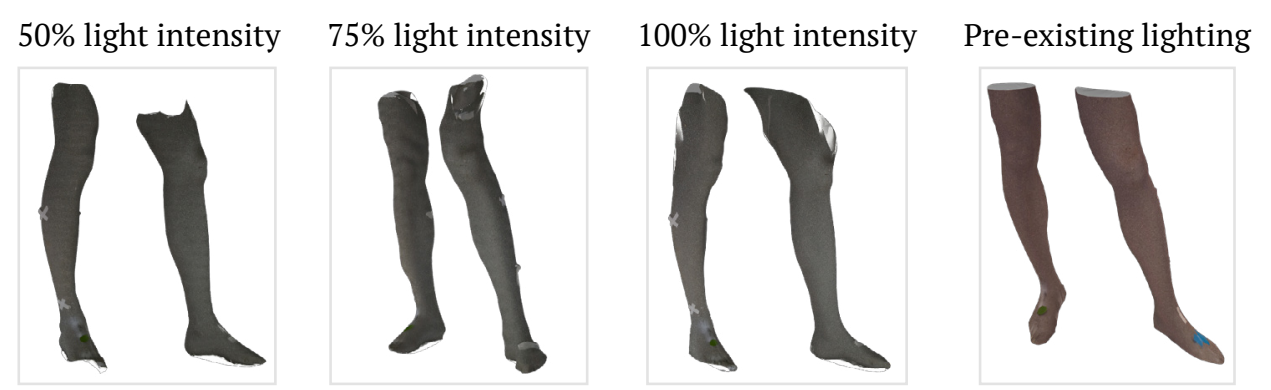

Figure 35. Generated models from tested LED lighting source and earlier generated model. 
Evaluation of models generated from the LED tests showed no noticeable difference between the different light intensities. Nonetheless, each model generated had missing surfaces (Figure 35), meaning none of the lighting levels provided adequate coverage of the subject. When those models were compared to the model generated from the project done earlier in the larger project, there was a noticeable difference. Whereas the models generated from this test had deformities such as missing surfaces, the earlier model seemed to have a more consistent surface. The researcher was later informed that the model was generated by physically moving light sources each time an image was taken.

The generated models of participants from the user testing sessions, which used preexisting lighting, were of considerably worse quality then the LED lighting test (Figure 36). The models exhibited incomplete and distorted surfaces, despite going through the same post-processing and digital software as the mannequin. The inadequate lighting, combined with the white colour tone of the pre-existing scanning enclosure, further hindered the post-processing of the images. As well, when the images are imported into the digital model software with artefacts such as the background still present, the models were also of poor quality.

A discussion with the UoA engineering team suggested that the quality of the digita models, and experience of the operating technician, could be improved by using and integrating a LED lighting solution. Feedback given drove future design decisions within the initial design criteria.

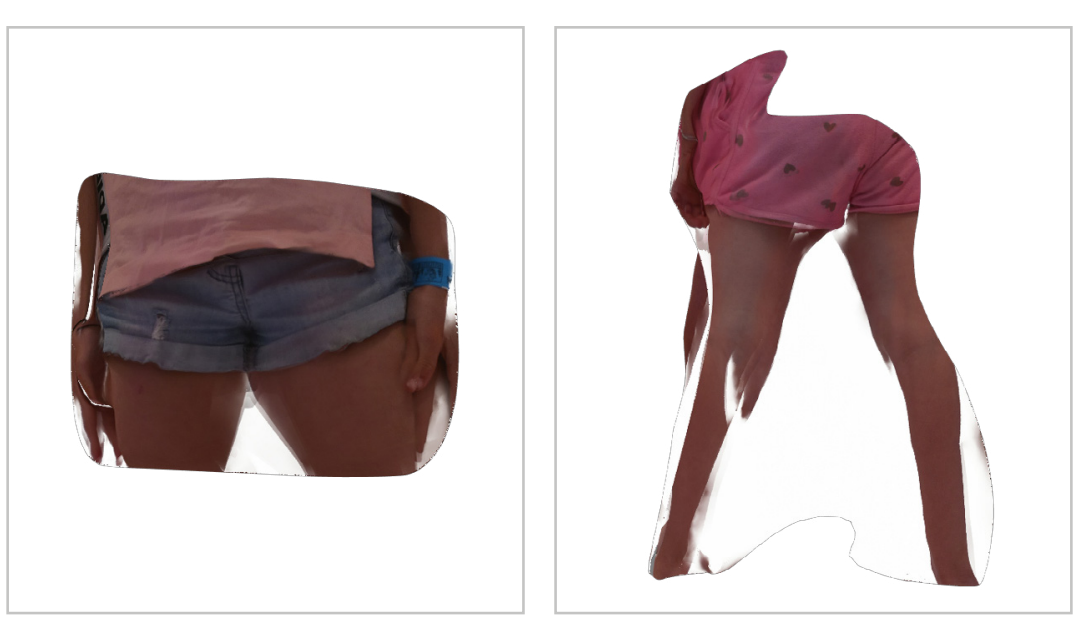

Figure 36. Participant models generated with pre-existing lighting solution.

\subsubsection{Summary}

\section{User session goals}

1. Develop a user journey as the scanning procedure is carried out

A visualisation of the patient and operating technician user journey was generated.

Though only a small part of the overall project work-flow from chapter one, a user journeyvisualisation provided a more detailed overview of the potential steps involved in the proposed solution. It also identified potential areas for design exploration. A major issue mentioned by the technician was the prototype's assembly time and the space it takes in a clinical setting. This is particularly important when the scanner is not used constantly, so a way to store it while it is not being used could be beneficial.

2. Investigate the emotional response participants have during different stages of the interaction, and understand the elements that cause them Themes related to user experience were created from the analysis of qualitative data generated from participant responses, and observational findings. These themes were developed into criteria for the creation of positive user experience. It is interesting that children stated the experience was boring. It is suggested that the scanner can allow for a more "fun" experience for children, while still focusing on offering a clinically appropriate session.

3. Identify areas of improvements needed in the scanner's design according to user experience (patients and clinicians)

Qualitative data generated from SSIs and observations produced criteria related to patient user experience, and were included into the initial design criteria (Table 8).

\section{Light test session goals}

1. Evaluate and compare the models generated from the pre-existing and proposed lighting solutions and

2. Appraise the quality of the digital models from the LED lighting solution by comparing them to the one from previous research.

Comparison of the models generated from images taken with both pre-existing lighting and proposed LED lighting solution, highlight inadequate lighting as the cause of model imperfection and lengthy post-processing time. Therefore, it can be concluded that without the proper lighting environment, missing or distorted surfaces will always be present in the digital models. However, models generated from LED illuminated images were of better quality, indicating this is a potential solution to solve highlighted lighting issues.

\section{Generate criteria for future exploration}

Criteria were created to address identified areas that required improvement through design exploration, experimentation, and development (Table 9). 


\begin{tabular}{|l|l|}
\hline SUBJECT/THEME & CRITERIA \\
\hline Novel scanner development & $\begin{array}{l}\text { The scanner interaction should consider use by patients } \\
\text { aged between 1-16 years }\end{array}$ \\
\cline { 2 - 2 } & $\begin{array}{l}\text { The design should allow the patient to be positioned into a } \\
\text { load-bearing stance for scanning }\end{array}$ \\
\hline Usability & $\begin{array}{l}\text { The design should provide easy entry and exit for patients } \\
\text { who may have difficulty moving }\end{array}$ \\
\cline { 2 - 3 } & $\begin{array}{l}\text { The design should allow custom vertical orientation of } \\
\text { cameras }\end{array}$ \\
\hline Patient experience & $\begin{array}{l}\text { The design should create positive user experience, such } \\
\text { as through visual engagement, and not evoke negative } \\
\text { responses. Possibly through familiar and fun connotations. }\end{array}$ \\
\hline Technician experience & $\begin{array}{l}\text { The design should allow for easy set up and potential } \\
\text { storage }\end{array}$ \\
\hline
\end{tabular}

\subsubsection{Reflection}

These testing sessions with users were an opportunity to gain insight and vital information for the early development of the close-range photogrammetry scanner. Some of the prepared questions and prompts for children seemed ineffective to engage them during the SSIs. This resulted in a confusing experience for participants, and answers not being pursued further. The length of the debrief session, upon evaluation, was also too long for the participant age group, and resulted in behaviour such as boredom, distraction, and fidgeting. Therefore, for future sessions, it will be essential to develop a script of questions, or something similar, with comprehensive questions and effective prompts that can be used to pursue participant answers.

The findings from the sessions of this chapter were contextualised into criteria related primarily to user experience and functions the scanner's design must facilitate. So, the next chapter focuses on generating solutions that address these criteria.

Table 8. User experience based criteria.

\begin{tabular}{|l|l|}
\hline SUBJECT/THEME & CRITERIA \\
\hline Photogrammetry scanner & $\begin{array}{l}\text { The design should integrate suitable lighting for generating } \\
\text { images of acceptable quality }\end{array}$ \\
\cline { 2 - 2 } & $\begin{array}{l}\text { The design should allow the patient to be positioned into a } \\
\text { load-bearing stance for scanning }\end{array}$ \\
\hline Aesthetics & $\begin{array}{l}\text { The enclosure aesthetic should allow for easy post- } \\
\text { processing. }\end{array}$ \\
\hline
\end{tabular}

Table 9. Lighting based criteria. 


\section{Updated criteria}

As stipulated within the methodology chapter, as more findings are uncovered, the criteria is updated to generate more focused concepts. Therefore, some identified criteria, such as "the design should be easily assembled in under one hour in different clinical environments" have replaced initial criteria like "the design should be usable in a range of environments." While criteria similar to those identified previously, did not need to be included again.

Note: Updated criteria in italics

\begin{tabular}{|c|c|c|}
\hline SUBJECT/THEME & CRITERIA & SOURCE \\
\hline \multicolumn{3}{|c|}{ Photogrammetry scanner } \\
\hline & $\begin{array}{l}\text { The design should facilitate optimal uniform } \\
\text { lighting }\end{array}$ & \multirow[t]{2}{*}{ Literature (2.1.4) } \\
\hline & $\begin{array}{l}\text { The design should facilitate quick patient } \\
\text { scanning }\end{array}$ & \\
\hline \multicolumn{3}{|c|}{ Novel scanner development } \\
\hline & $\begin{array}{l}\text { The design should allow use of research-project- } \\
\text { provided hardware }\end{array}$ & \multirow[t]{3}{*}{$\begin{array}{l}\text { Research project } \\
\text { constraints }\end{array}$} \\
\hline & $\begin{array}{l}\text { The design should allow the patient to be positioned } \\
\text { into a load-bearing stance }\end{array}$ & \\
\hline & $\begin{array}{l}\text { The design should be circular to allow for camera } \\
\text { overlap }\end{array}$ & \\
\hline & $\begin{array}{l}\text { The scanner interaction should consider use by } \\
\text { patients aged between 1-16 years old }\end{array}$ & $\begin{array}{l}\text { Ethic testing } \\
\text { population constraint }\end{array}$ \\
\hline & $\begin{array}{l}\text { The design should facilitate a digital AFO work- } \\
\text { flow }\end{array}$ & Larger project goal \\
\hline \multicolumn{3}{|l|}{ Usability } \\
\hline & $\begin{array}{l}\text { The design should allow custom vertical orientation } \\
\text { of cameras }\end{array}$ & \multirow[t]{3}{*}{$\begin{array}{l}\text { Pre-existing prototype } \\
\text { assessment }\end{array}$} \\
\hline & $\begin{array}{l}\text { The design should create a clear and easy entry and } \\
\text { exit point for patients to move through }\end{array}$ & \\
\hline & $\begin{array}{l}\text { The design should provide patients with balancing } \\
\text { issues support before, during, and after use }\end{array}$ & \\
\hline
\end{tabular}




\begin{tabular}{|c|c|c|}
\hline SUBJECT/THEME & CRITERIA & SOURCE \\
\hline \multicolumn{3}{|l|}{ Assembly } \\
\hline & $\begin{array}{l}\text { The design should integrate easy-to-use and } \\
\text { understandable cable management }\end{array}$ & \multirow[t]{8}{*}{$\begin{array}{l}\text { Pre-existing prototype } \\
\text { assessment }\end{array}$} \\
\hline & $\begin{array}{l}\text { The design should be easily assembled in under one } \\
\text { hour in different clinical environments }\end{array}$ & \\
\hline \multirow[t]{2}{*}{ Aesthetics } & & \\
\hline & $\begin{array}{l}\text { The enclosure aesthetic should allow for easy post- } \\
\text { processing }\end{array}$ & \\
\hline \multicolumn{2}{|l|}{ Patient experience } & \\
\hline & $\begin{array}{l}\text { The design should create a positive user experience } \\
\text { potentially through familiarity and fun connotations, } \\
\text { and not evoke negative responses }\end{array}$ & \\
\hline \multirow[t]{2}{*}{ Technician experience } & & \\
\hline & $\begin{array}{l}\text { The design should allow for easy set up and } \\
\text { potential storage }\end{array}$ & \\
\hline
\end{tabular}

Table 10. Updated criteria based on chapter four findings. 


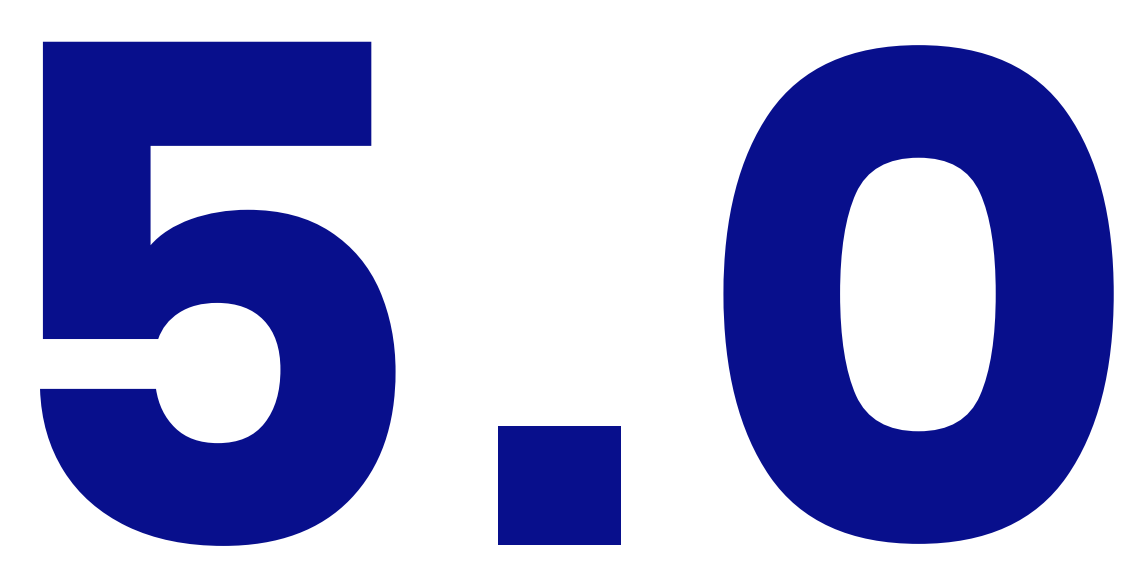

\section{DESIGN PHASE ONE}

This chapter presents findings from expansively generated

concepts, which aimed to address criteria identified in chapter

four. These focused on assembly and disassembly, as well as how

different aspects of a photogrammetry scanner could be arranged

into a full-scale prototype. 


\subsubsection{Background}

Transformative rigid structures

Expanding and contracting structures are intended to transform to meet changing requirements, and time is considered as an influencing design parameter. Transformation can be accomplished through deployable and foldable mechanisms, or demountable and reconfigurable components (De Temmerman, Mira, Vergauwen, Hendrickx, \& De Wilde, 2012). Structures can have mechanisms that allow transformation from a compact configuration, into a larger, expanded state, or components that can be reconfigured, replaced, or re-used (De Temmerman et al, 2012; Fenci \& Currie, 2017). Either method allows for a temporary structure to be designed that can quickly and easily be deployed or assembled, and then stored.

\section{Materials for image post-processing}

Highlighted within chapter two and three is the need for post-processing work-flow optimised for image to software compilation. Therefore, research was conducted into methods in which visual production industries optimise images. Highlighted was the influence of colour and background surfaces on the post-production process (Foster, 2010). Two colours are primarily used in the removal of unwanted artefacts: green and blue. Though use varies depending on circumstances (Foster, 2010), green is currently the most widely used options, because of its performance in removing unwanted artefacts, and its seldom chose as clothing. The surface of the material also influences the post-processing process, as the smoother the surface, the less work is required to remove it (Foster, 2010).

Taking these findings into consideration, the development of the scanners design began by exploring solutions that would create an easier user experience for the operating technician.

\subsubsection{Methods}

Concept generation

Design development was through concepts quickly generated through multiple methods, with a focus on concept generation, rather than quality. This approach generated a range of prototypes, and variants of them in parallel that could be evaluated. This period of design development eventually led to a large-scale experience prototype that could be assessed against criteria.

\section{Concept analysis}

The concepts generated during design development were primarily assessed against weighted matrix. This method collated design criteria into key criteria that helped the identification and prioritisation of early concepts. In circumstances where it was not appropriate to assess concepts against the full set of design criteria, such as the scale prototypes, it allowed aspects that could not be tested in scale to be assessed. However, the large-scale experience prototype was assessed through a collaborative usability inspection session and against design criteria. Design defects and design successes were identified in a real-world context during the inspection session through immediate feedback and discussion from multiple perspectives. The feedback was contextualised via a final assessment against design criteria, which refined criteria, setting it up as a platform for exploration in the next chapter. 


\subsubsection{Results}

\subsubsection{Design development}

\section{Sketch ideation}

Generated sketch ideas explored a range of different solutions that could address the initial design criteria (Figures 37-39). Some generated ideas were not pursued further in this chapter, as the primary focus was on assembly and disassembly procedures. However, they still served as a starting platform for ideation in later phases.

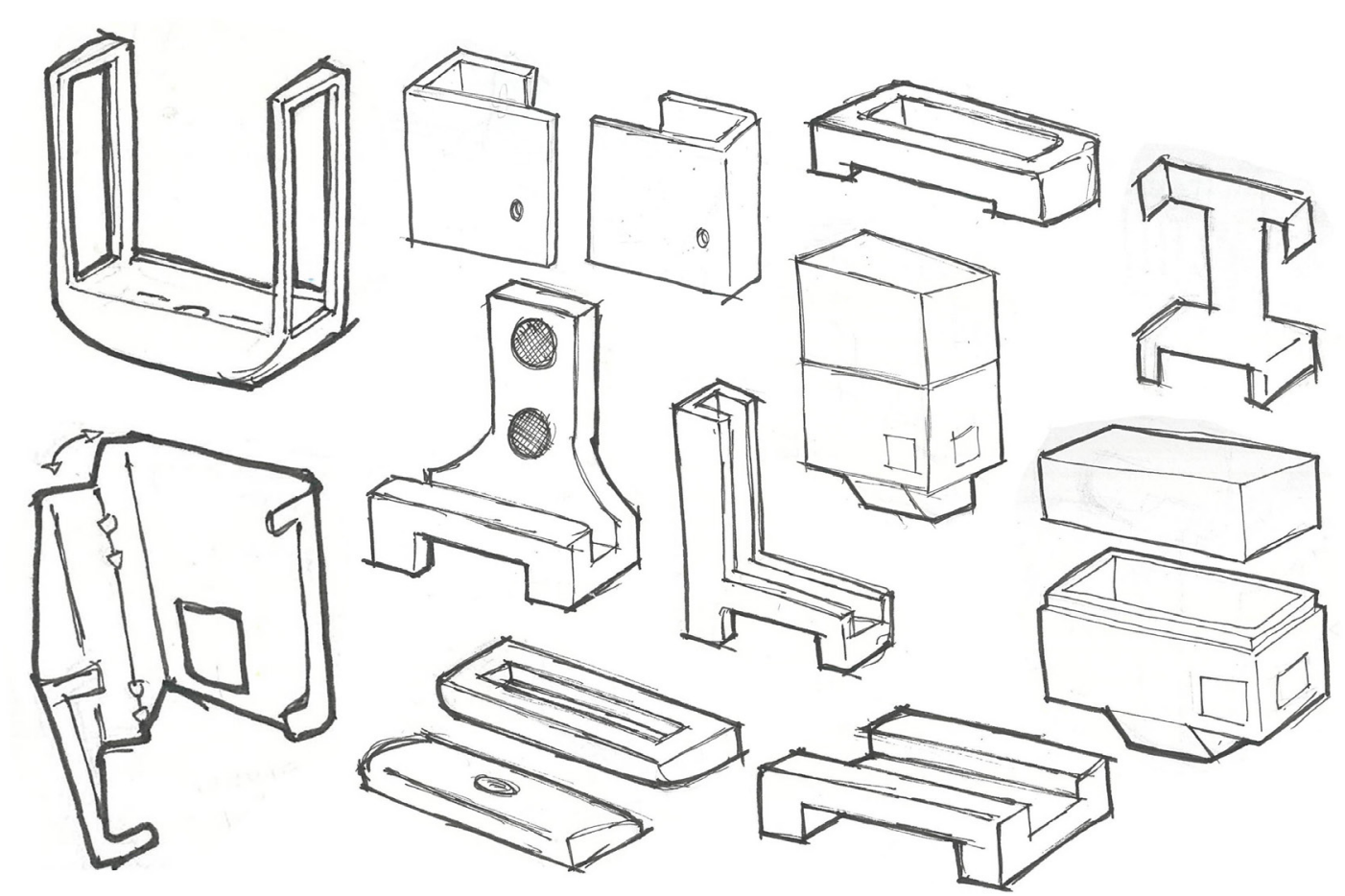

Figure 37. Sketch exploration of camera housing.
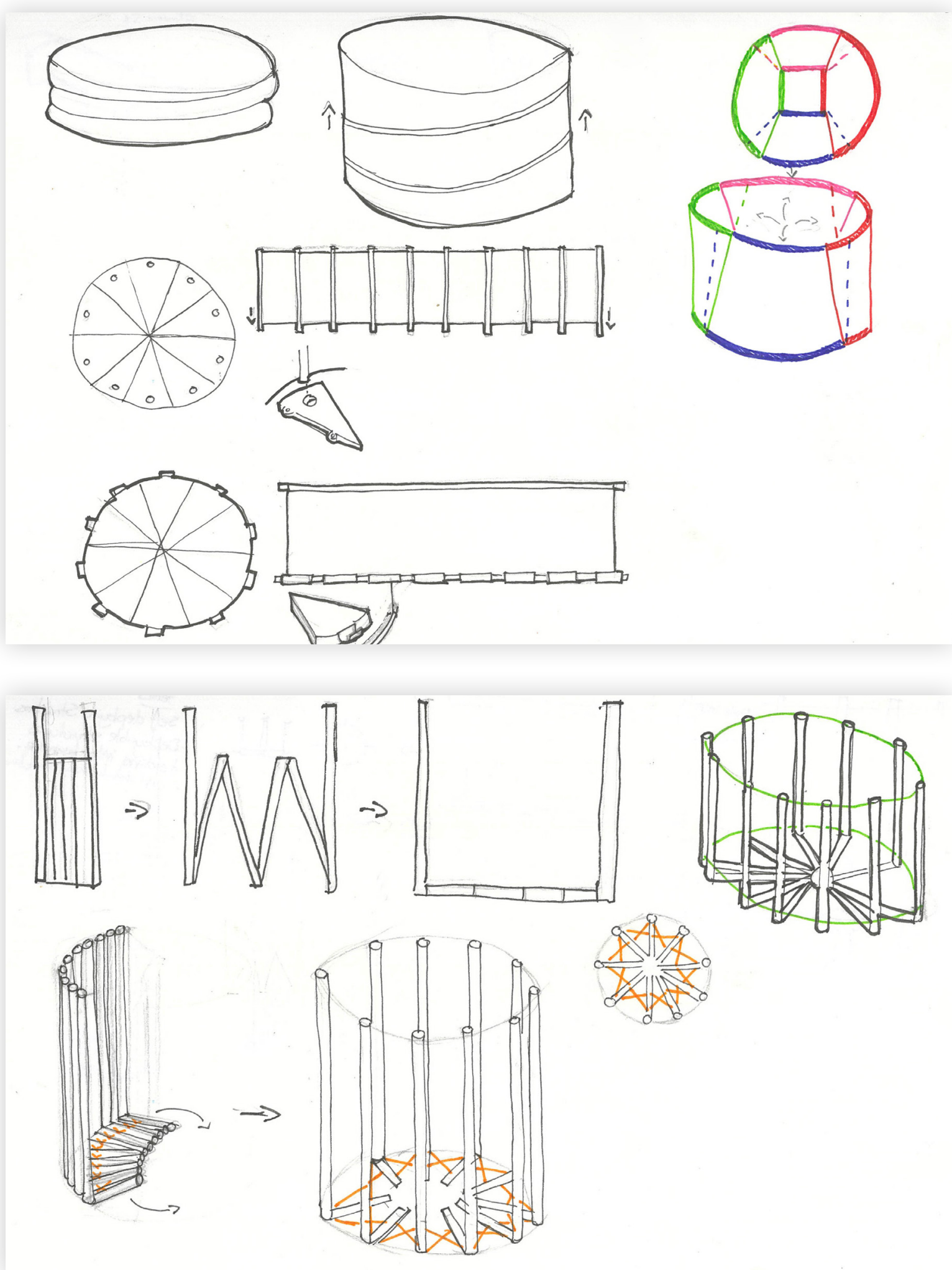

Figure 38. Sketch exploration of scanner form. 

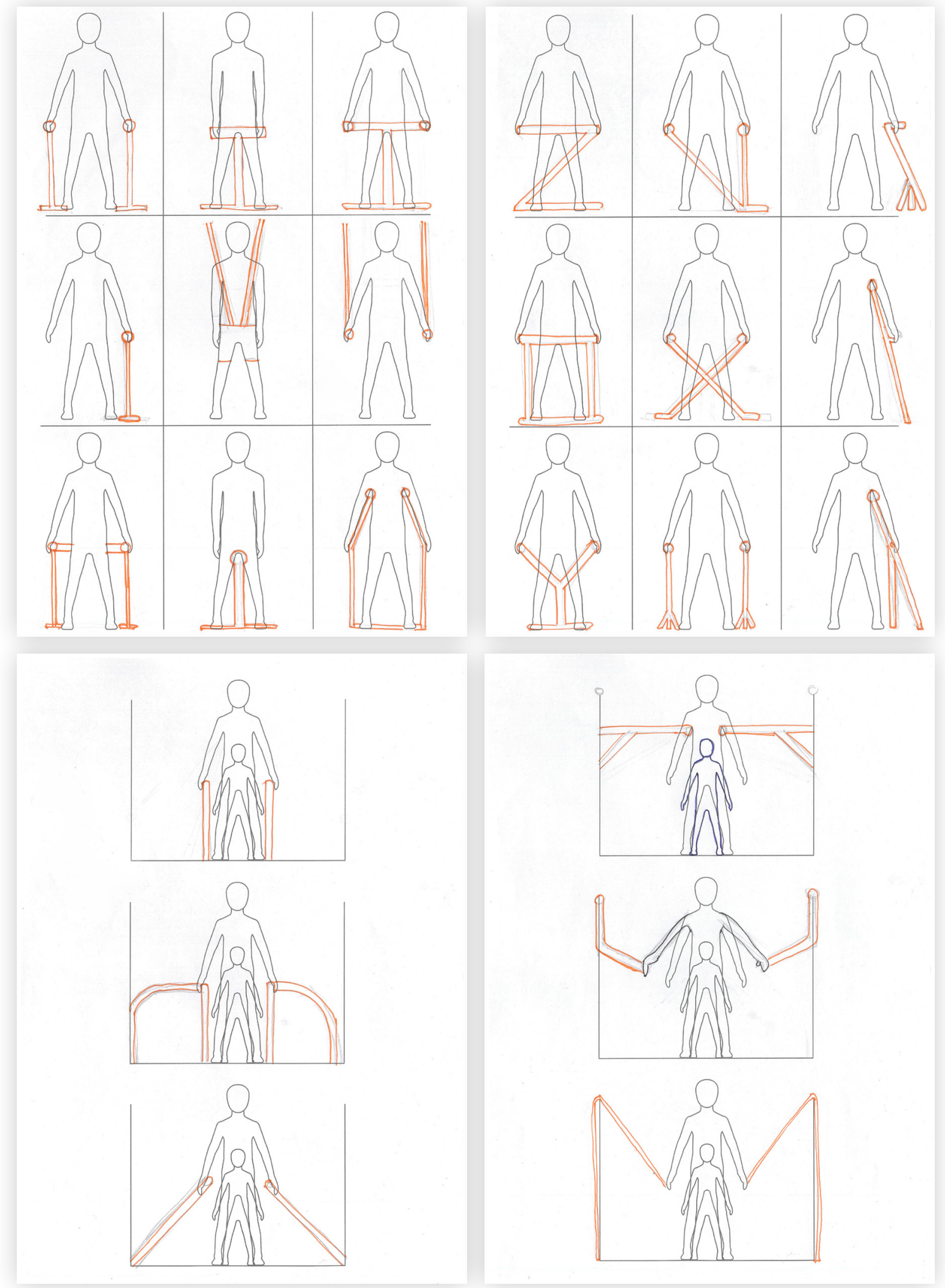

Figure 39. Sketch exploration of patient support.

\section{1:5 Scale prototypes}

Assembly and disassembly procedures were explored in parallel through 1:5 scaled

prototypes (Figure 40). 1:5 was manageable scale for prototyping as it was small

enough to efficiently utilise available time and material, but large enough to still

express design details. Parallel prototyping allowed different of rigid assembly solutions to be explored and assessed via a weighted matrix.

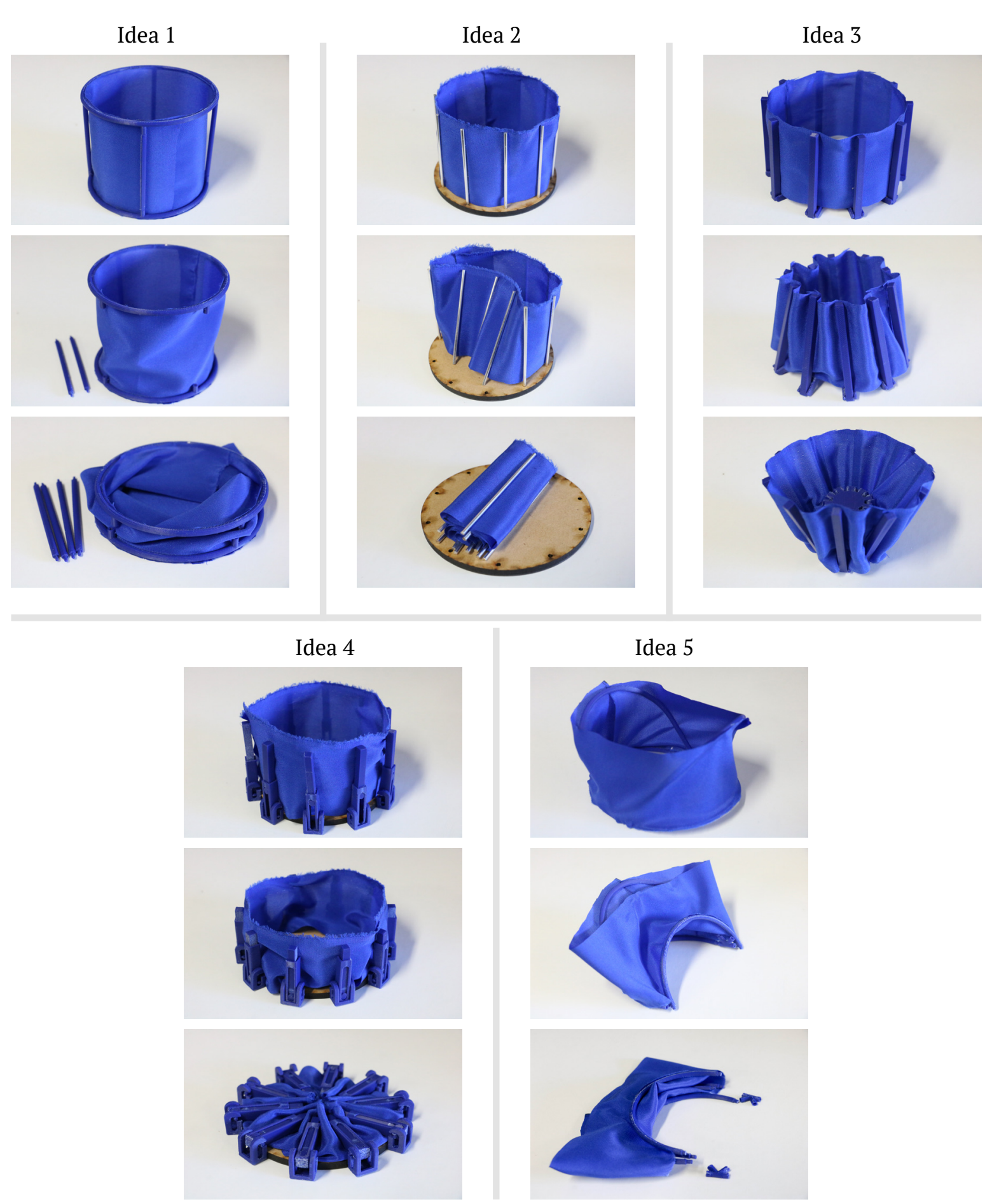

Figure 40. 1:5 scale concepts in the three proposed stages of assembly; assembled, midway, and disassembled. 


\section{1:1 Sectional prototypes}

1:1 sectional prototypes (Figure 41) were created based on assessment and feedback on the 1:5 scale prototypes. The sectionals were large-scale iterations of Idea 1 , the most successful assembly concept from the 1:5 scale prototypes, and further explored different assembly methods. The sectionals were also assessed via weighted matrix. A sectional detail was appropriate for these prototypes, as it was a manageable solution given the rapid prototyping and exploration role in design phase one.

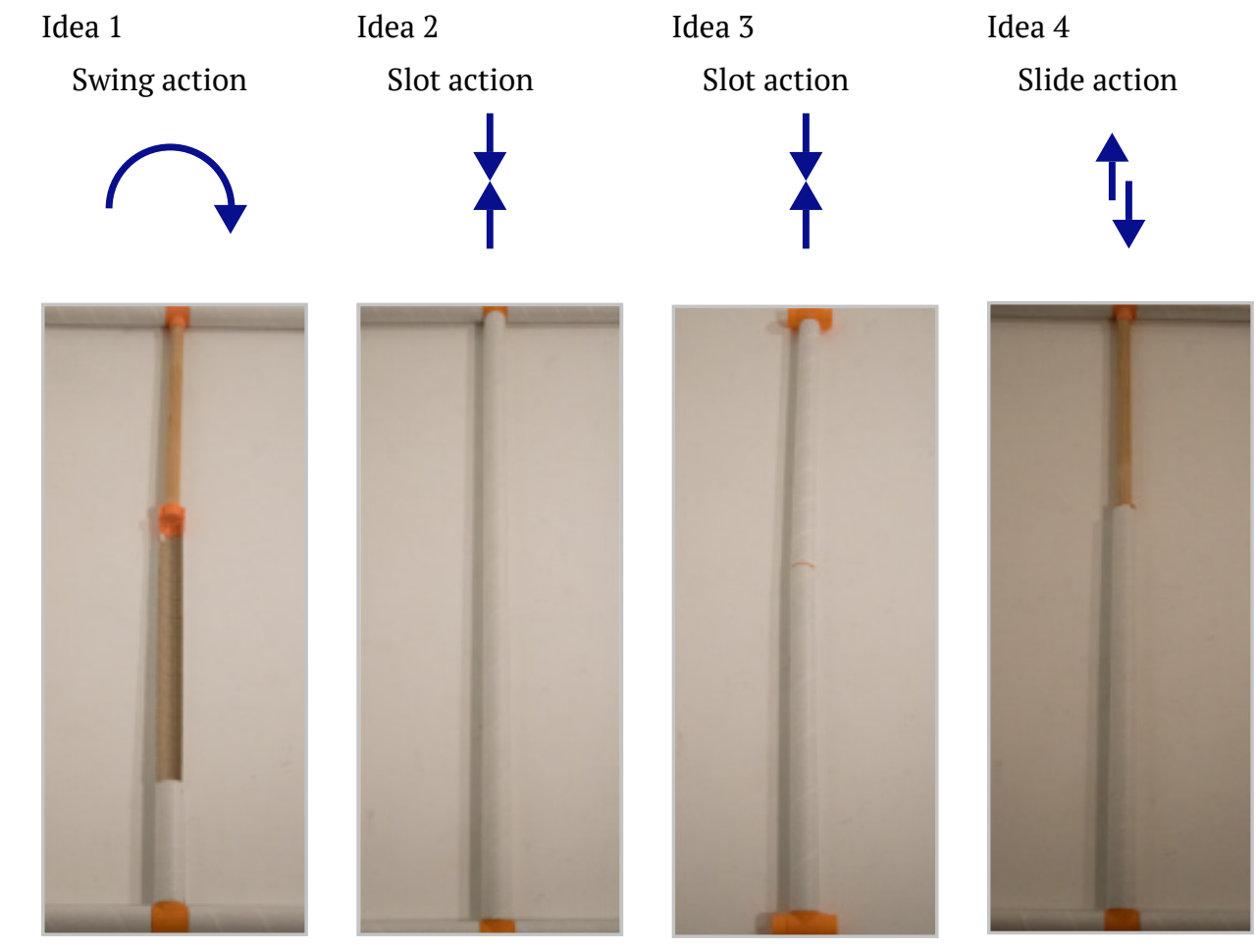

Figure 41.1:1 sectionals ideas.

\subsubsection{Experience prototype}

The design of the 1:1 full-scale prototype was based on assessment of the 1:5 scale and 1:1-sectional prototypes. The prototype demonstrates solutions found to have the most potential from the design development period. The presented solutions relate to assembly procedure and integration of components into the design of the overall structure.

\section{Intended assembly}
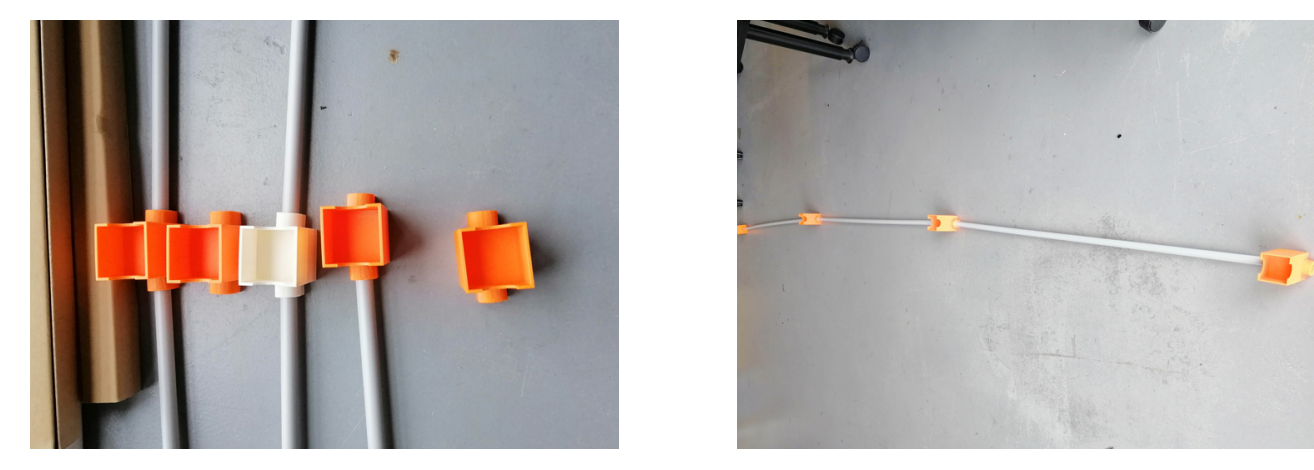

1. Slot rods into joints, and thread mounts

2. Shape the bottom and top rings

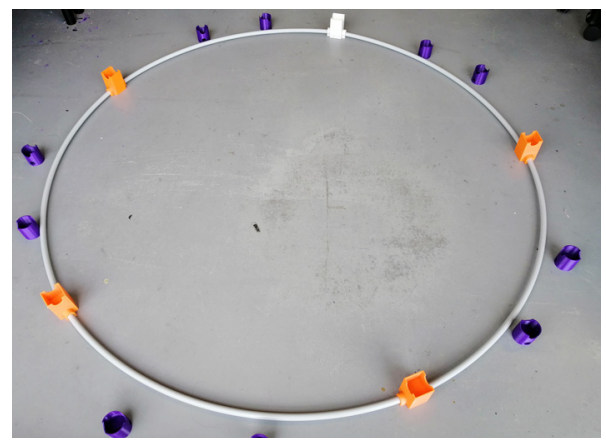

3. Connect the ends to complete the two rings

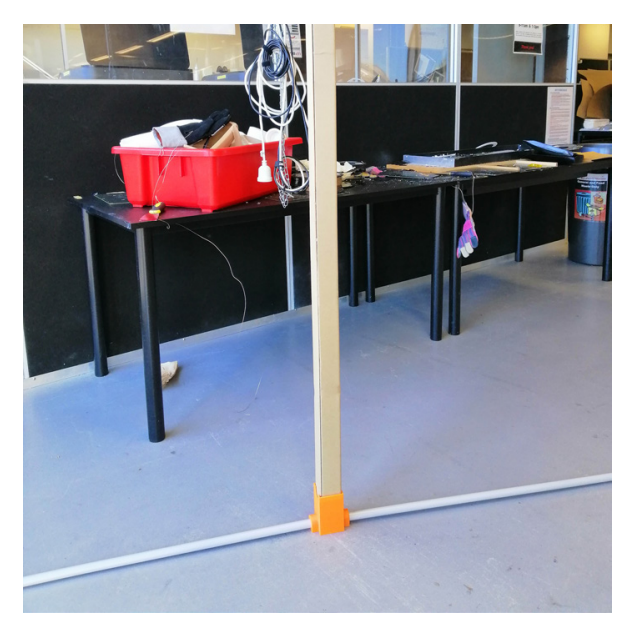

3. Slot vertical poles

gure 42. Key steps in this prototype's assembly por

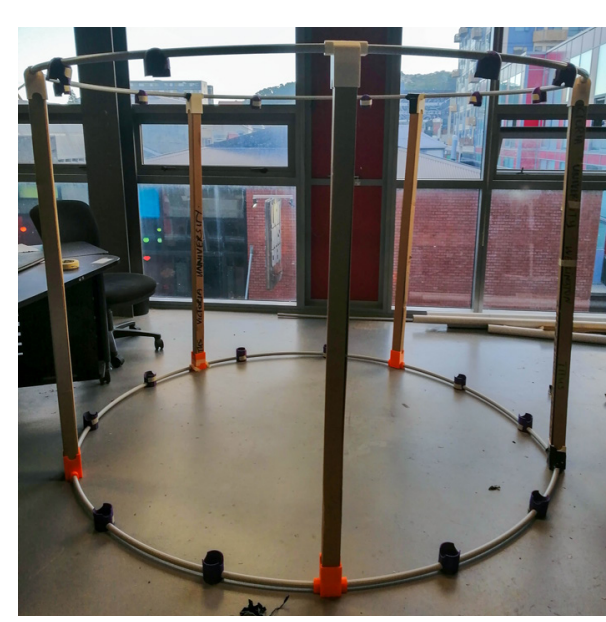

4. Attach fabric enclosure 
Overview of experience prototype
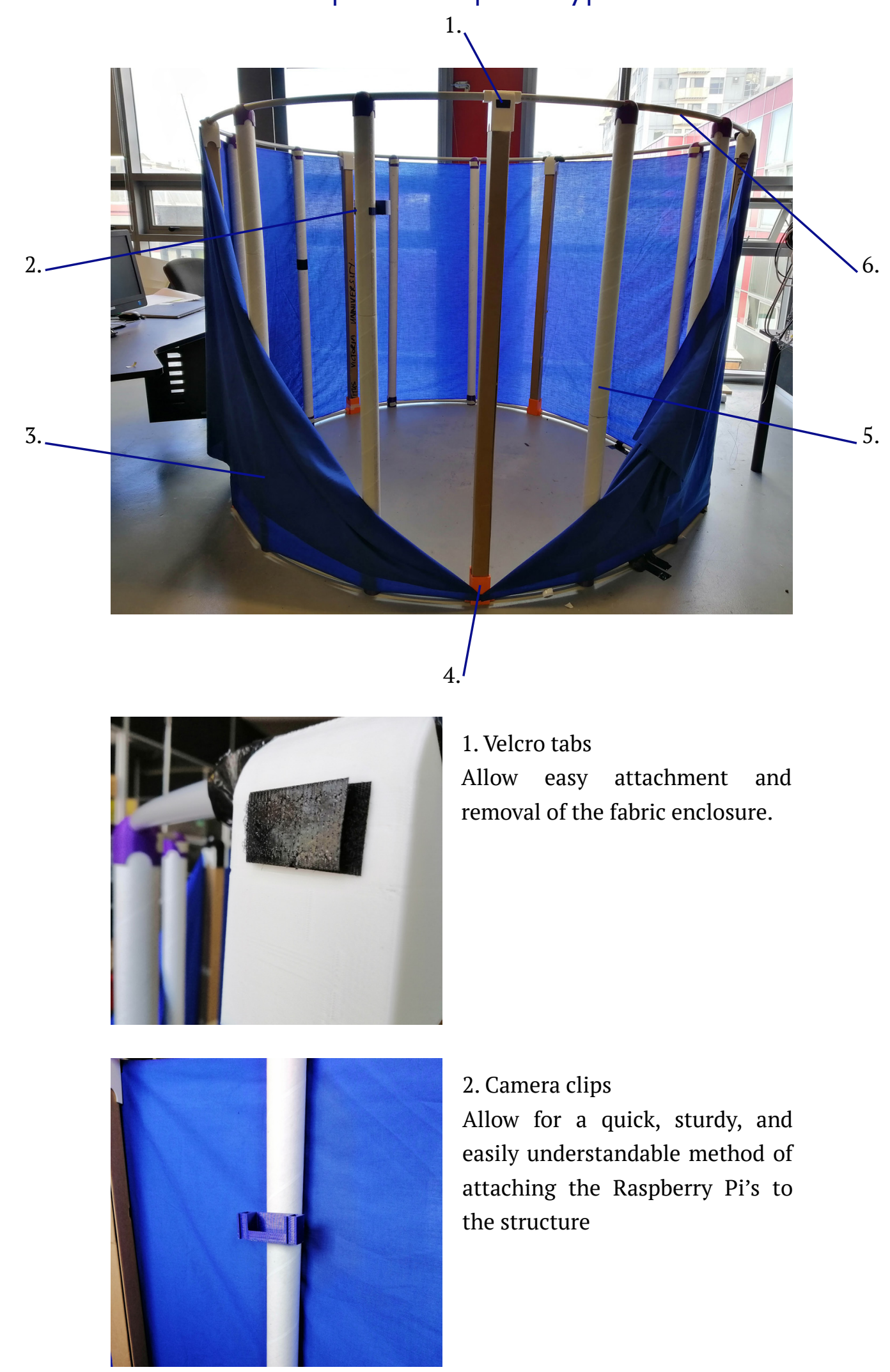

Allow for a quick, sturdy, and

easily understandable method of

attaching the Raspberry Pi's to

the structure

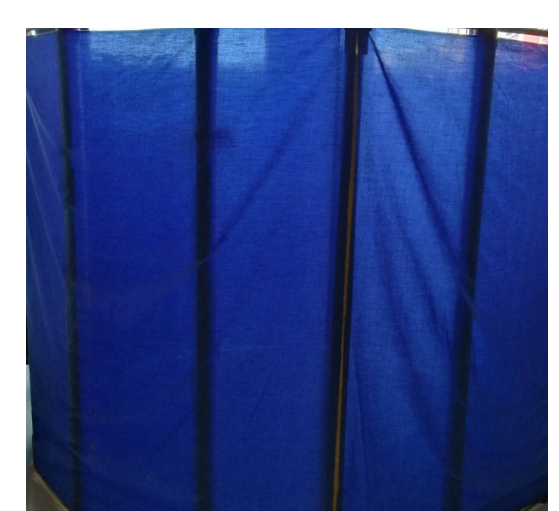

Fabric enclosure

The blue colour allow for easier post-processing and removal of artefacts from images. Depending on the fabric, it can be lightweight and easily transportable

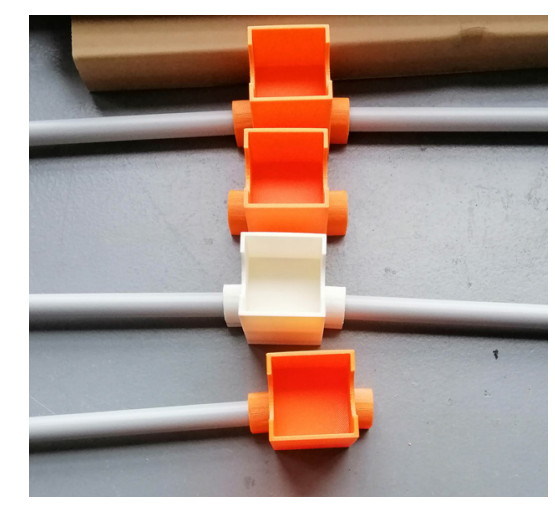

4. 3D printed inserts

The inserts can be designed to visually tell the user how to assembly the structure

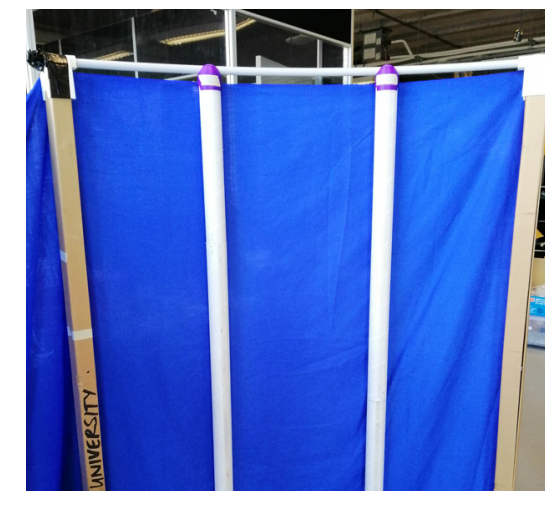

5. Vertical poles

The poles add stability to the structure, as well as functioning housing for hardware

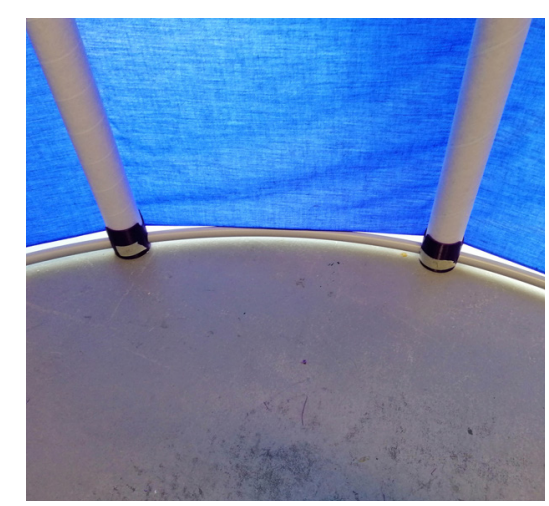

5. Removable rigid Frame

The rigid frame can be taken apart, allowing for easier transportation

Figure 43. Initial exploration into form and ease of use component designs. 


\subsubsection{Analysis}

\section{1:5 Prototypes}

The prototypes were compiled into a weighted matrix, and given a performance rating against five core criteria, condensed from initial criteria related to user experience and assembly (Figure 44) (Cagan \& Vogel, 2002). A value of importance, or weight, was then given to those criteria: one (low); two (medium); or three (high), and multiplied against the performance rating. The rating value was assigned depending on how successfully criteria was addressed.

\begin{tabular}{|r|c|c|c|c|c|c|}
\hline Weight & Idea I & Idea 2 & Idea 3 & Idea 4 & Idea 5 \\
\hline Clarity & 3 & 3 & 3 & 2 & 1 & 2 \\
\hline Simplicity & 3 & 3 & 3 & 2 & 1 & 3 \\
\hline Stability & 3 & 3 & 2 & 2 & 2 & 1 \\
\hline Aesthetics & 2 & 3 & 2 & 3 & 2 & 1 \\
\hline Convenience & $\mathbf{1}$ & 2 & 2 & 1 & 1 & 1 \\
\hline TOTAL & & 35 & 30 & 25 & 13 & 21 \\
\hline
\end{tabular}

Figure 44. Weighted matrix assessing the success of the different 1:5 ideas.

The first concept was the most successful, rating highly on priority criteria such as simplicity and stability. These criteria, along with ease of use, were given a higher weight value, as it was important to start developing concepts that addressed user experience in this early phase. While other criteria, like aesthetics, though also important for a successful design, could be addressed in later phases. Therefore, though model one rated lower on convenience, because it was not a priority criterion, it did not lessen the model's success. Whereas other concepts, such as the fourth one, which rated lower on the same criteria, was eliminated as an avenue of exploration. Feedback from the UoA technician team based on the weighted matrix results was then used to inform the next stage, 1:1 scale sectionals.

\section{1:1 Sectional prototypes}

The prototype sectionals were assessed in the same format as the scale prototypes: each criterion was given a priority weight value, the concepts were ranked out of three, and the most successful one was discussed, and then built upon (Figure 45).

\begin{tabular}{|r|c|c|c|c|c|}
\hline Weight & Idea 1 & Idea 2 & Idea 3 & Idea 4 \\
\hline Simplicity & 3 & 2 & 3 & 3 & 3 \\
\hline Stability & 3 & 1 & 3 & 3 & 2 \\
\hline Clarity & 3 & 2 & 3 & 3 & 3 \\
\hline Convenience & 3 & 2 & 2 & 3 & 3 \\
\hline Assembly & $\mathbf{2}$ & 2 & 3 & 1 & 3 \\
\hline Component parts & $\mathbf{1}$ & 2 & 3 & 2 & 2 \\
\hline TOTAL & & 27 & 42 & 40 & 41 \\
\hline
\end{tabular}

Figure 45. Weighted matrix assessing the success of the 1:1 iterations.

The core criteria for the sectional prototype's weighted matrix were altered from the previous matrix to reflect the focus on function, rather than form. On top of the four priority criteria shown, 'aesthetics' was removed, and replaced with 'assembly' and 'components', to address identified criterion related to assembly. The fifth criterion in the matrix, assembly, focused on the complexity of solutions, and its effect on the user assembly journey, while the sixth one, components, assessed the number of parts required, and its effect on later lead and assembly time.

The weighted matrix results show that concept two was the most successful, but only by one value. Concepts three and four can also been seen as successful. However, discussion with the design and UoA technician team deemed concept two the most successful across the criteria range. This is due to its rating against criteria of simplicity, stability, and understandability, while also requiring the smallest number of parts. Therefore, concept two called for further exploration and inclusion in the experience prototype.

\section{Experience prototype}

A common theme identified in the collaborative usability inspection feedback session was the design's rudimentary solutions to assembly procedure, and aspects related to that (Table 11). For example, some solutions were highlighted as good beginning points, but would require a great deal of iteration or exploration to arrive at solutions that meet identified criteria. Next, the number of parts present and their materiality were identified as flaws that hindered assembly time (Figure 46). Continuing, 
comments highlighted the awkwardness, difficulty, and unclear nature of the entry and exit point as something that needed focus in the next phase (Figure 47). Finally, a lack of consistent visual communication in the design of the prototype's parts was highlighted, with concern that the user may get confused assembling the scanner if instructions are not present. A recommendation was to design consistent forms that could convey the assembly procedure, rather than have the user rely completely on a set of instructions. These comments, along with reflection by the researcher, were taken into consideration when the prototype was assessed against criteria.
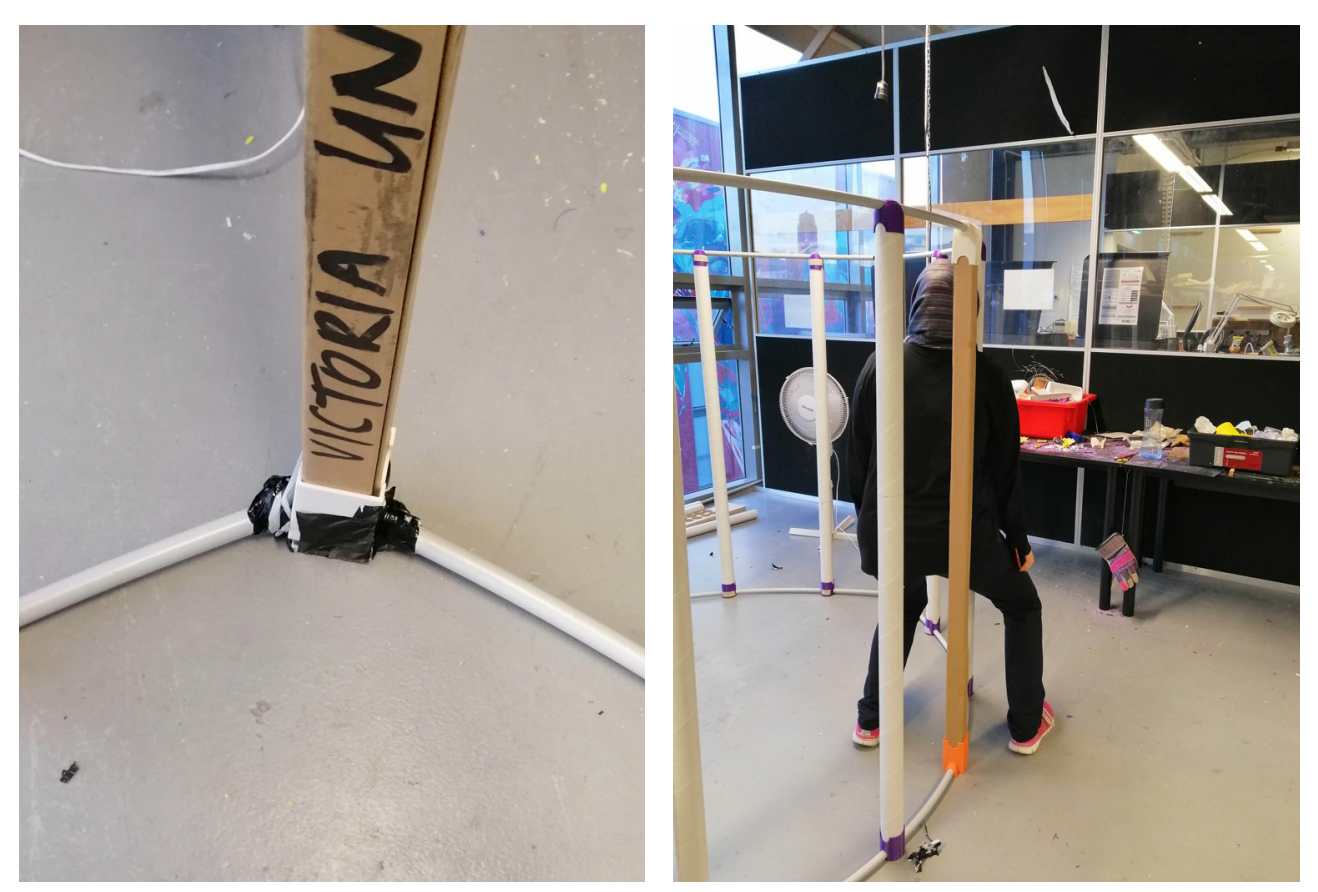

Figure 46. One of the damaged parts that hindered Figure 47 Example of the awkward positioning testing. required to enter and exit the scanner.

\begin{tabular}{|c|c|c|c|}
\hline Subject & Success & Defects & Comments \\
\hline \multirow[t]{2}{*}{ Assembly } & $\begin{array}{l}\text { Enclosure assembly } \\
\text { method with Velcro } \\
\text { is simple and easy to } \\
\text { understand }\end{array}$ & $\begin{array}{l}\text { Rigid frame has too many } \\
\text { parts, slowing down } \\
\text { assembly }\end{array}$ & 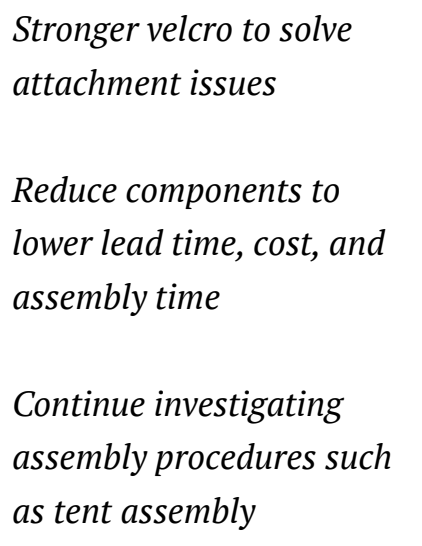 \\
\hline & $\begin{array}{l}\text { Familiar assembly } \\
\text { actions }\end{array}$ & $\begin{array}{l}\text { Parts of the assembly } \\
\text { procedure was confusing } \\
\text { Vertical poles fall without } \\
\text { upper ring support }\end{array}$ & $\begin{array}{l}\text { Have support pins or } \\
\text { something similar to } \\
\text { support poles during } \\
\text { assembly }\end{array}$ \\
\hline Rigid Frame & $\begin{array}{l}\text { Strong structure when } \\
\text { downward force is } \\
\text { applied } \\
\text { Rigid ring at the top } \\
\text { and bottom to stop } \\
\text { unwanted swaying }\end{array}$ & $\begin{array}{l}\text { Sways side to side when } \\
\text { horizontal force is } \\
\text { applied }\end{array}$ & $\begin{array}{l}\text { Address joint connection to } \\
\text { potentially solve this. }\end{array}$ \\
\hline Materials & $\begin{array}{l}\text { Use of low fidelity } \\
\text { materials }\end{array}$ & $\begin{array}{l}\text { Tension present in tubes } \\
\text { will lead to assembly } \\
\text { difficulties }\end{array}$ & $\begin{array}{l}\text { Rigid form could work, but } \\
\text { removal of tension would be } \\
\text { important }\end{array}$ \\
\hline Customise & $\begin{array}{l}\text { Option for custom } \\
\text { camera positioning }\end{array}$ & $\begin{array}{l}\text { No systematic method } \\
\text { to achieve consistent } \\
\text { positioning }\end{array}$ & \\
\hline Design & $\begin{array}{l}\text { Easy snap on and off } \\
\text { camera mounts }\end{array}$ & $\begin{array}{l}\text { No clear entry or exit } \\
\text { point, resulting awkward } \\
\text { movement }\end{array}$ & \\
\hline
\end{tabular}




\begin{tabular}{|c|c|c|c|}
\hline Subject & Success & Defects & Comments \\
\hline & & Looks flimsy & $\begin{array}{l}\text { Choose materials that } \\
\text { would not convey negative } \\
\text { emotions (unease) }\end{array}$ \\
\hline Clarity & $\begin{array}{l}\text { Different forms to } \\
\text { visually indicate part } \\
\text { placement }\end{array}$ & & $\begin{array}{l}\text { Be careful to balance visual } \\
\text { understanding and amount } \\
\text { of parts }\end{array}$ \\
\hline User Support & & There is none & $\begin{array}{l}\text { Investigate patient support } \\
\text { location in scanner (inside } \\
\text { or outside) }\end{array}$ \\
\hline
\end{tabular}

The next design phase will be one of exploration and serial ideation, to explore ideas and refine concepts related to criteria such as simplifying the assembly process, reducing component parts, and designing appropriate housing for hardware.

\subsubsection{Summary}

This phase primarily focused on using the multi-method RtD approach to quickly generate concepts to address assembly criteria. The assessment of concepts via weighted matrix led to a prototype that had solutions identified as having the most potential. The solutions, when assessed against design criteria, identified clear, familiar, and easy-to-understand assembly solutions. With feedback from the design and UoA team, the prototype was deemed a good, but rudimentary, starting platform for concept development for design phase two.

\subsubsection{Reflection}

Despite research stating otherwise, the choice of colour and material for the background was decided to remain blue and as a fabric material because of availability, and perceived notion that a blue aesthetic would look better than a green one. While assessment of the prototype against some criteria determined the prototype's success in a real-world context, not all criteria could be fully explored.

Therefore, some criteria were left unchanged, requiring exploration in design phase two, a phase which otherwise should be reserved for refining concepts through serial ideation. Based upon discussion with team members, other criteria were removed due to the project scope, such as criteria related to supporting patient users as they interact with scanner, and shifting focus from including patient support, to designing a scanner that did not create obstacles or hindrances for the user. 


\section{Updated criteria}

The design criteria has been updated to reflect knowledge generated in this chapter.

Note: Updated criteria in italics

\begin{tabular}{|c|c|c|}
\hline SUBJECT/THEME & CRITERIA & SOURCE \\
\hline \multicolumn{3}{|c|}{ Photogrammetry scanner } \\
\hline & $\begin{array}{l}\text { The design should facilitate optimal uniform } \\
\text { lighting }\end{array}$ & \multirow[t]{2}{*}{ Literature (2.1.4) } \\
\hline & $\begin{array}{l}\text { The design should facilitate quick patient } \\
\text { scanning }\end{array}$ & \\
\hline \multicolumn{3}{|c|}{ Novel scanner development } \\
\hline & $\begin{array}{l}\text { The design should allow use of research-project- } \\
\text { provided hardware }\end{array}$ & \multirow[t]{3}{*}{$\begin{array}{l}\text { Research project } \\
\text { constraints }\end{array}$} \\
\hline & $\begin{array}{l}\text { The design should allow the patient to be } \\
\text { positioned into a load-bearing stance }\end{array}$ & \\
\hline & $\begin{array}{l}\text { The design should be circular to allow for camera } \\
\text { overlap }\end{array}$ & \\
\hline & $\begin{array}{l}\text { The scanner interaction should consider use by } \\
\text { patients aged between } 1-16 \text { years old }\end{array}$ & $\begin{array}{l}\text { Ethic testing } \\
\text { population constraint }\end{array}$ \\
\hline & $\begin{array}{l}\text { The design should facilitate a digital AFO work- } \\
\text { flow }\end{array}$ & Larger project goal \\
\hline \multicolumn{3}{|l|}{ Usability } \\
\hline & $\begin{array}{l}\text { The design should allow systematic custom vertical } \\
\text { orientation of cameras }\end{array}$ & \multirow[t]{2}{*}{ Design phase one } \\
\hline & $\begin{array}{l}\text { The design should create a clear and easy entry and } \\
\text { exit point for patients to move through }\end{array}$ & \\
\hline & $\begin{array}{l}\text { The design should allow custom vertical } \\
\text { orientation of cameras }\end{array}$ & $\begin{array}{l}\text { Pre-existing prototype } \\
\text { assessment }\end{array}$ \\
\hline
\end{tabular}




\begin{tabular}{|c|c|c|}
\hline SUBJECT/THEME & CRITERIA & SOURCE \\
\hline \multicolumn{3}{|l|}{ Assembly } \\
\hline & $\begin{array}{l}\text { The scanner structure should use as few components } \\
\text { as possible }\end{array}$ & Design phase one \\
\hline & $\begin{array}{l}\text { The design should integrate easy-to-use and } \\
\text { understandable cable management }\end{array}$ & $\begin{array}{l}\text { Pre-existing prototype } \\
\text { assessment }\end{array}$ \\
\hline & $\begin{array}{l}\text { The design should be easily assembled in under } \\
\text { one hour in different clinical environments }\end{array}$ & \\
\hline \multicolumn{3}{|l|}{ Aesthetics } \\
\hline & $\begin{array}{l}\text { The design should create an easy-to-understand } \\
\text { experience through familiar actions, and visual } \\
\text { guides }\end{array}$ & Design phase one \\
\hline & $\begin{array}{l}\text { The enclosure aesthetic should allow for easy } \\
\text { post-processing }\end{array}$ & $\begin{array}{l}\text { Pre-existing prototype } \\
\text { assessment }\end{array}$ \\
\hline \multicolumn{3}{|l|}{ Patient experience } \\
\hline & $\begin{array}{l}\text { The design should create a positive user } \\
\text { experience potentially through familiarity and fun } \\
\text { connotations, and not evoke negative responses }\end{array}$ & \\
\hline Technician experience & $\begin{array}{l}\text { The design should allow for easy set up and } \\
\text { potential storage }\end{array}$ & \\
\hline
\end{tabular}

Table 12. Updated criteria based on chapter five findings. 


\section{0}

\section{DESIGN PHASE}

TWO

Focused exploration
This chapter presents outputs generated to explore previously unaddressed criteria, and iterations of solutions identified to be the most promising from the previous chapter. Presented also are findings on how the designs and procedures of inflatable structures could be used to address identified criteria. 


\subsubsection{Background}

Inflation

Based on previous chapter findings and discussion with project team members, it was decided to investigate inflatable processes as a possible solution to criteria such as reduction of components for easier assembly and transportation.

Known as pneumatic structures, the design and use of an inflatable structure is decided based on whether the system is one structure that inflates in one step, or a continually inflated (Tschuppik \& Martins, 2006). This is dependent on the situation, as a single inflated structure can of high air pressure and rigidity, while a continually inflated structure can have its shape quickly changed (Friedman, 2012; Tschuppik \& Martins, 2006). The benefit of using inflatable principles in the design of a structure, or indeed a scanner, is the ability to be small in weight and packing size, allowing for easier transportation and installation (Friedman, 2012).

As well, communication between researcher and an inflatable manufacturer was established. This allowed feedback from experts familiar with the field of inflatables to be generated, which influenced the design development. Further detail is given in the analysis section of this chapter.

\subsubsection{Methods}

\section{Concept generation}

This phase followed a similar approach for early exploration as the previous chapter. Because focus shifted from exploring rigid solutions to inflatable ones, a period of focused, but still exploratory experimentation had to occur. To determine the feasibility of using an inflatable solution to address design criteria. However, later in the design development, the concepts were generated through a serial approach. Hence, methods previously used in quick-solution exploration were altered to achieve more focused exploration, while refining concepts through focused serial experimentation. These methods include sketching, low- and high-fidelity prototyping, and experience prototyping.

\section{Concept analysis}

Like chapter five, the generated concepts were assessed against criteria using multiple methods that followed the systematic framework to develop, refine, analyse, and present findings to inform future design decisions. Generated concepts were assessed via weighted matrices, while 1:1 prototypes were assessed against a cognitive walkthrough. Further explanation is given in this chapter's summary.

\subsubsection{Cognitive walk-through session}

As per recommendation by ethics, the session was structured as an "assessment of the designs" development (CDRH, 2016, p. 18) via expert opinion given by a project collaborator.

\section{Session goals}

\begin{tabular}{|l|l|}
\hline Goal & Method \\
\hline Assess proposed assembly method & $\begin{array}{l}\text { Cognitive walk-through with project } \\
\text { collaborator }\end{array}$ \\
\hline $\begin{array}{l}\text { Identify areas of improvement for focused } \\
\text { development }\end{array}$ & $\begin{array}{l}\text { Cognitive walk-through with project } \\
\text { collaborator }\end{array}$ \\
\hline $\begin{array}{l}\text { Refine assembly criteria in relation to } \\
\text { inflation process }\end{array}$ & Assessment against criteria \\
\hline
\end{tabular}

Table 13. Cognitive walk-through session goals.

\section{Participants}

The collaborator was apart of the UoA technician team who, as mentioned before, assessed the assembly process and overall quality of the design through their expert opinion.

\section{Procedure}

Cognitive walk-through

A collaborator was given a walk-through of a proposed assembly procedure that used inflation and a 'plug and play' style. The observational findings and opinion given during the walk-through highlighted success and areas for improvement. These results were assessed, and used to refine and develop criteria. 


\subsubsection{Results}

\subsubsection{Design development}

\section{1:1 inflatable sectional}

Large-scale inflatable sectionals were created to gain an understanding of inflatable principles, and be used as a testing platform, to demonstrate and assess the feasibility of using inflatables to address criteria related to assembly and user experience. Second, the tubes were used to test concepts that addressed aspects such as hardware integration into the scanner structure. Third and finally, the tubes acted as a visual reminder that influenced the aesthetic design decisions of concepts and prototypes.
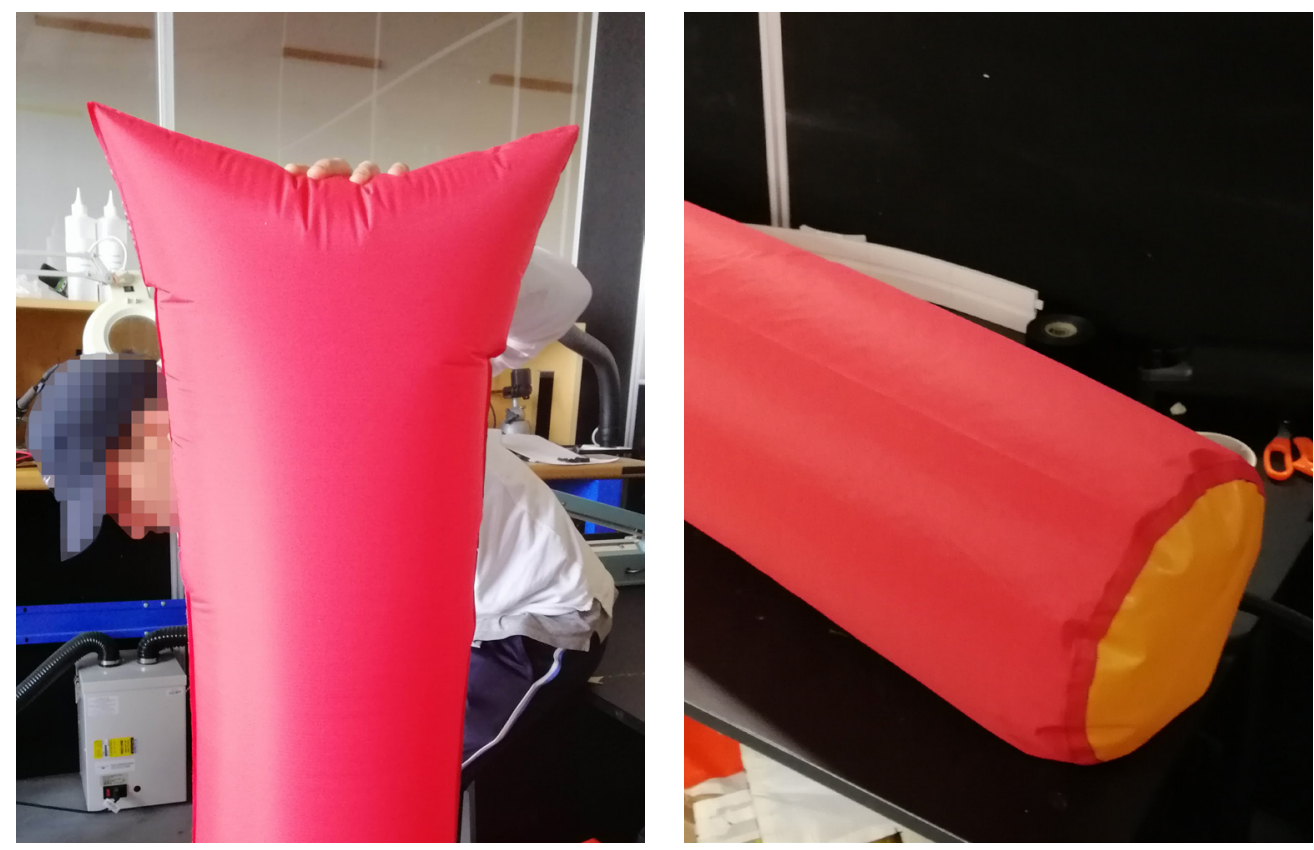

Figure 48. Two-part inflated tube, creating a circular Figure 49. Three-part inflated tube, creating but 'pointy' form. circular form

\section{Serial sketch ideation}

Sketching in this phase allowed for iteration and assessment of large-scale forms such as the inflatable structure, and others that otherwise could not be assessed without a large-scale prototype. These were influenced based on knowledge gained from the creation process, and visual aesthetic of the 1:1 inflatable sectionals.
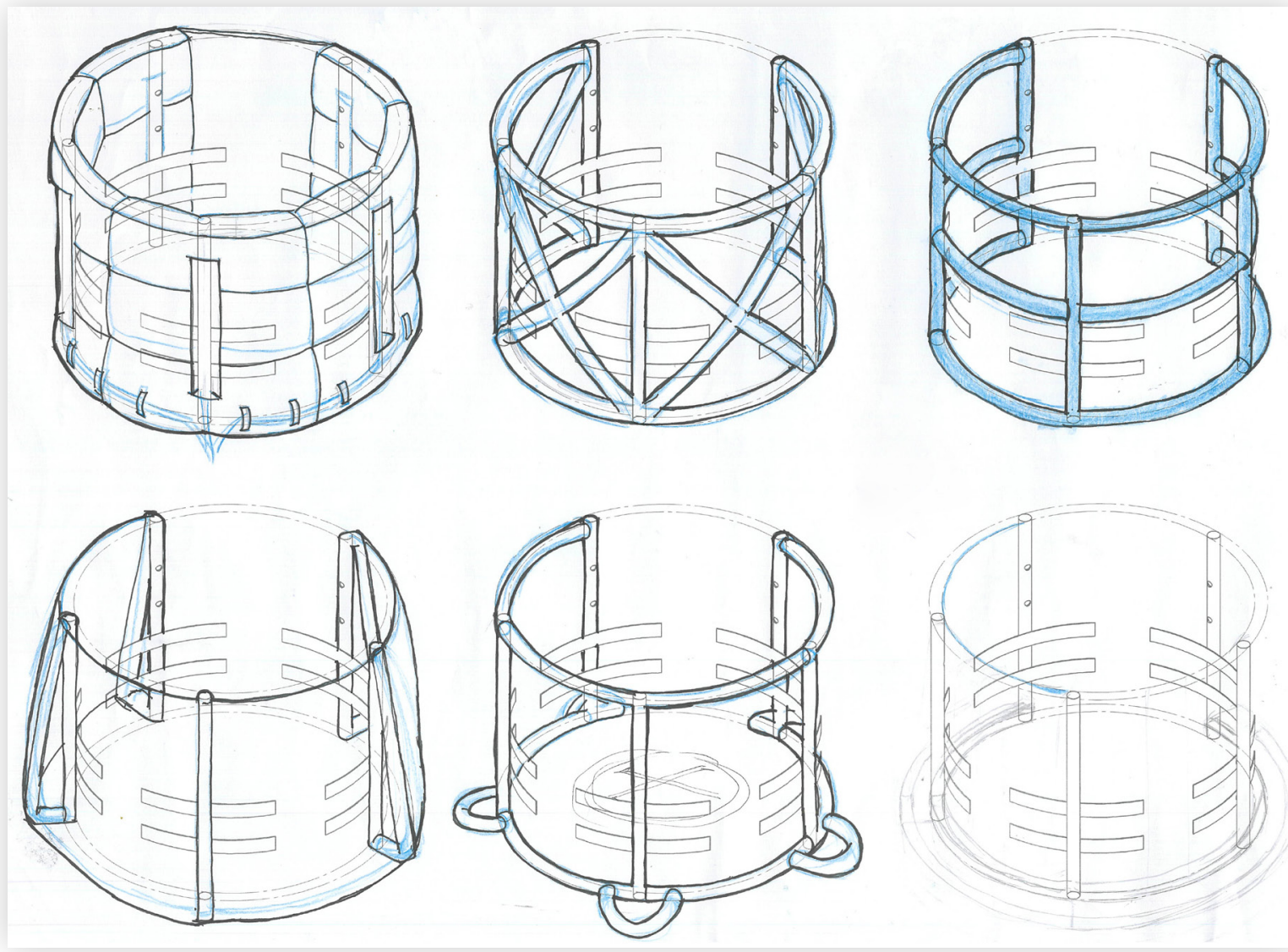

Figure 50. Iterative sketch exploration of overall inflatable forms

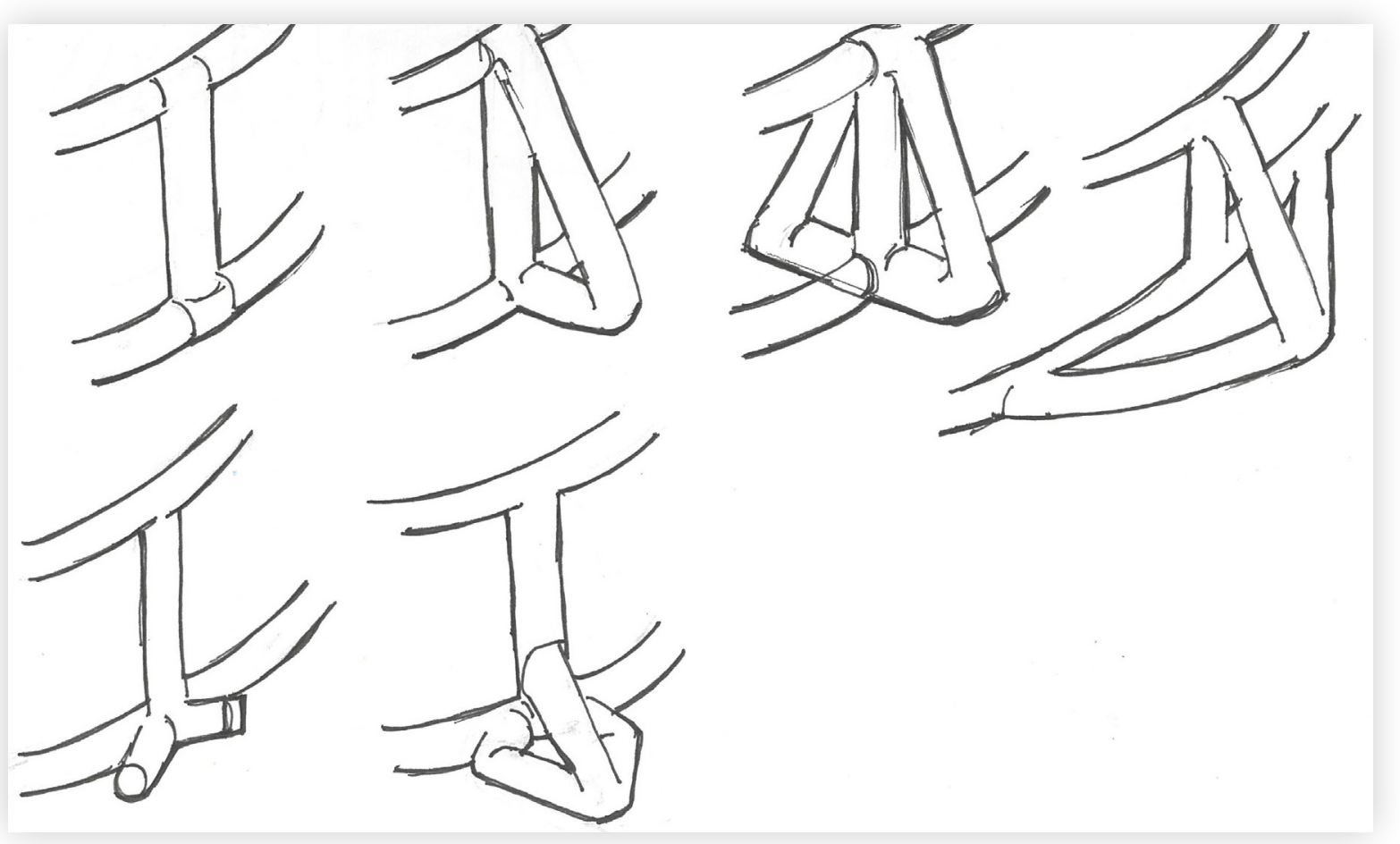

Figure 51. Iterative sketch explo 


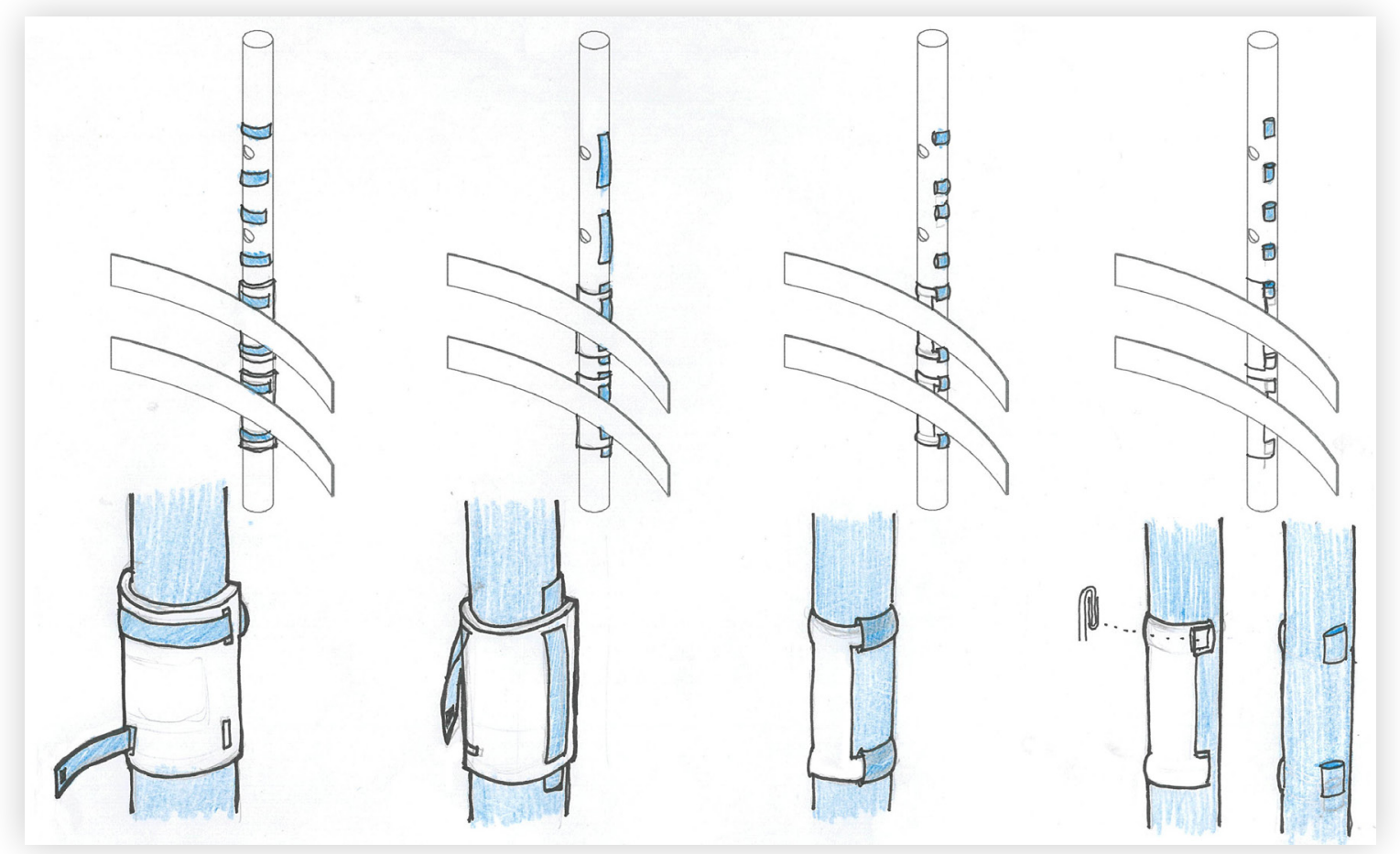

Figure 52. Iterative sketch exploration of arm mounting options.
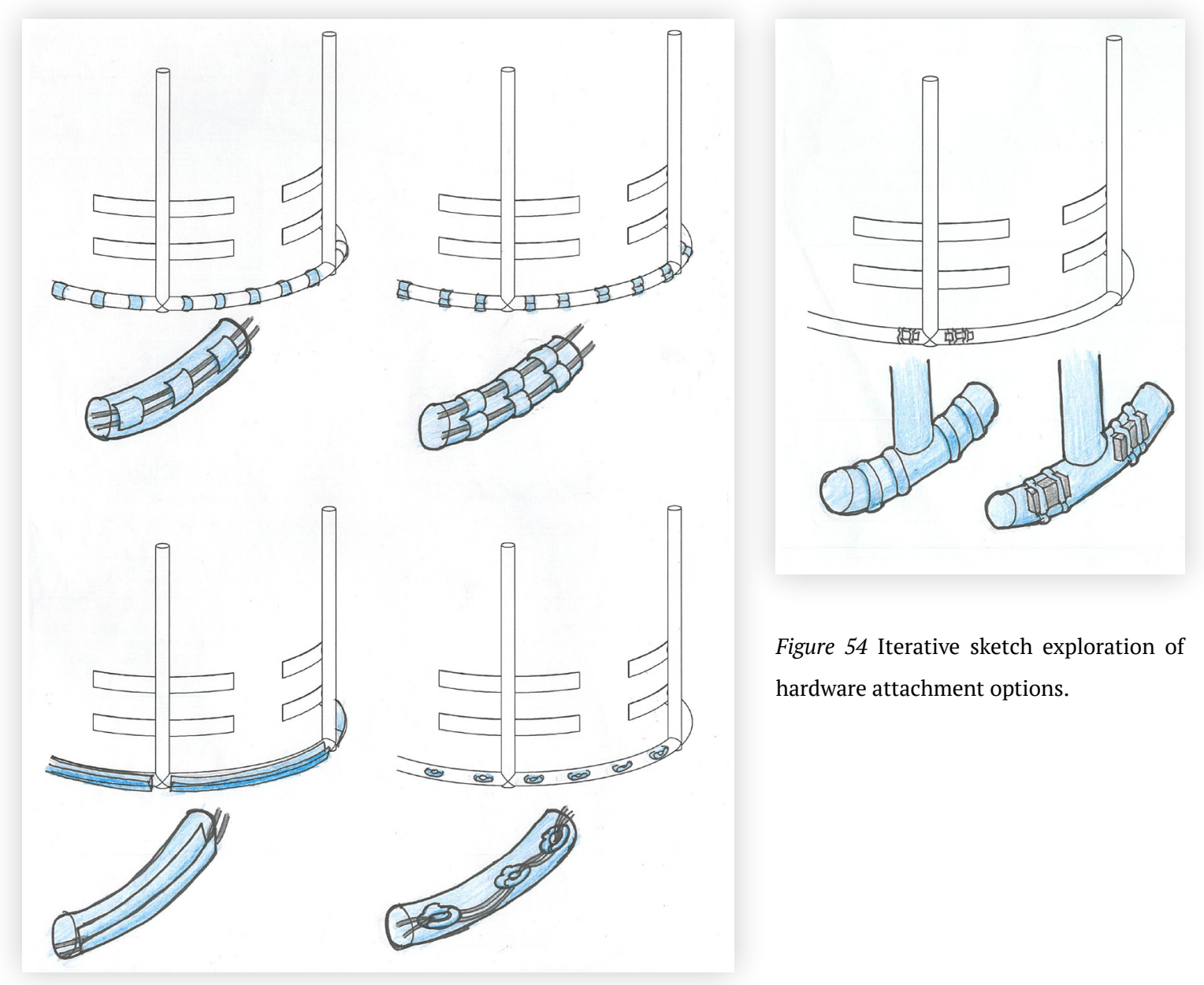

Figure 54 Iterative sketch exploration of hardware attachment options.

\section{Component prototype}

A high-fidelity prototype was created through CAD modelling and rapidly prototyped

through 3D printing. It was designed to be a 'plug and play' solution to criteria related to the integration of cameras, lighting and cable management. To 'plug and play' is to be able to allow the operating technician to quickly attach components and connect hardware into the scanning system. As well, an alternative part of the arm (Figure 57) was created to demonstrate how the arm can open and close, to show a possible solution for criteria related to entry and exit.

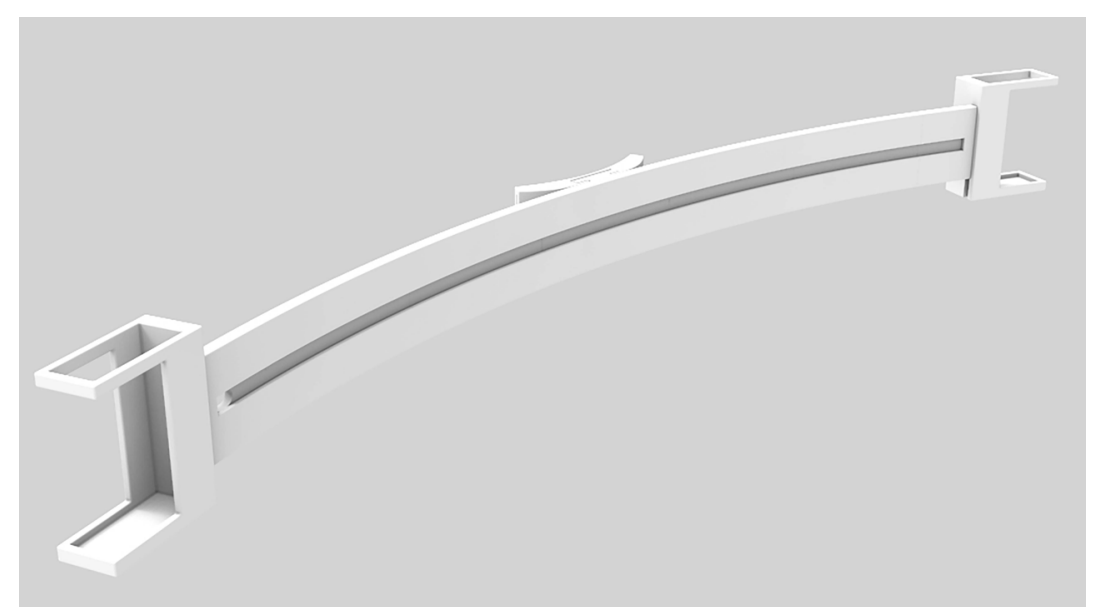

Figure 55. Rendered CAD model of camera arm prototype.

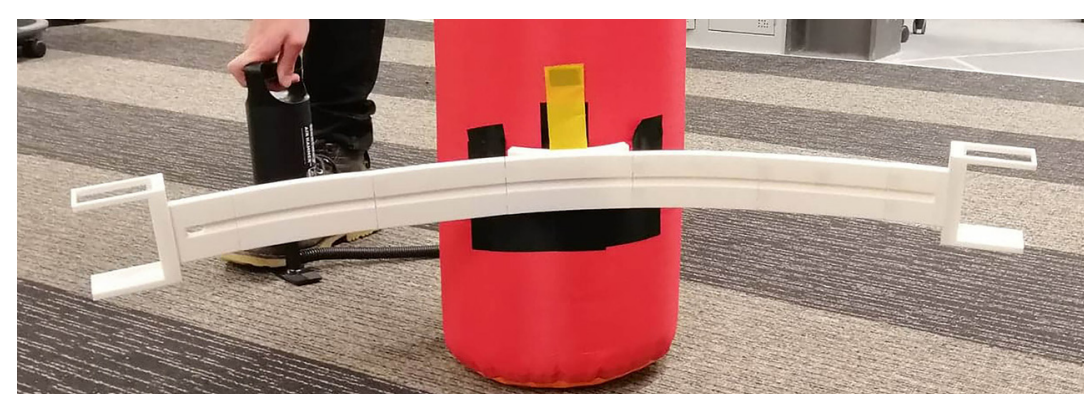

Figure 56. 3D printed camera arm prototype.

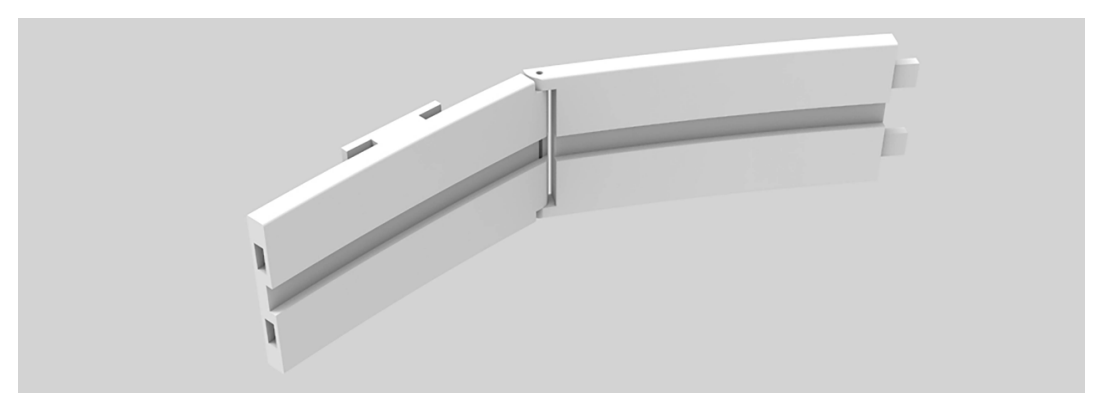

Figure 57. Rendered CAD model of the alternative section for the camera arm prototype.

Figure 53. Iterative sketch exploration of integrated cable management options. 


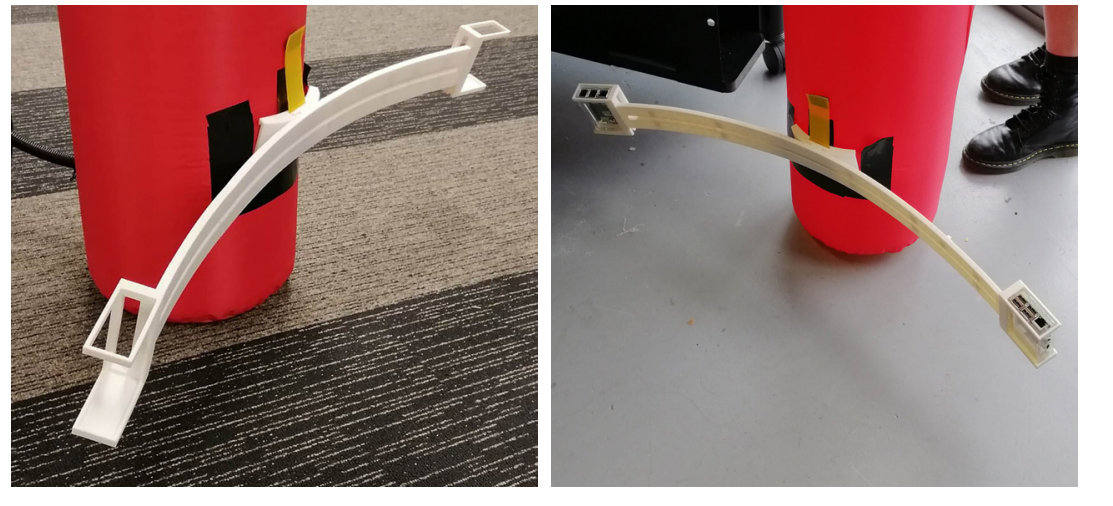

Figure 58. Camera arm prototype with Raspberry Pi cameras inserted into end mounts.

\section{1:5 scale prototypes}

The 1:5 scale prototypes were developed in response to findings generated by the cognitive walk-through of the proposed assembly method. A single inflatable cavity was used as the primary structure for the scanner (Figure 59) and, in parallel, different external means were explored to see what would best influence and shape the cavity into the desired form. The 1:5 size also allowed potential forms of the scanners to be viewed in its entirety, and generated a better understanding of what the final form could look like.

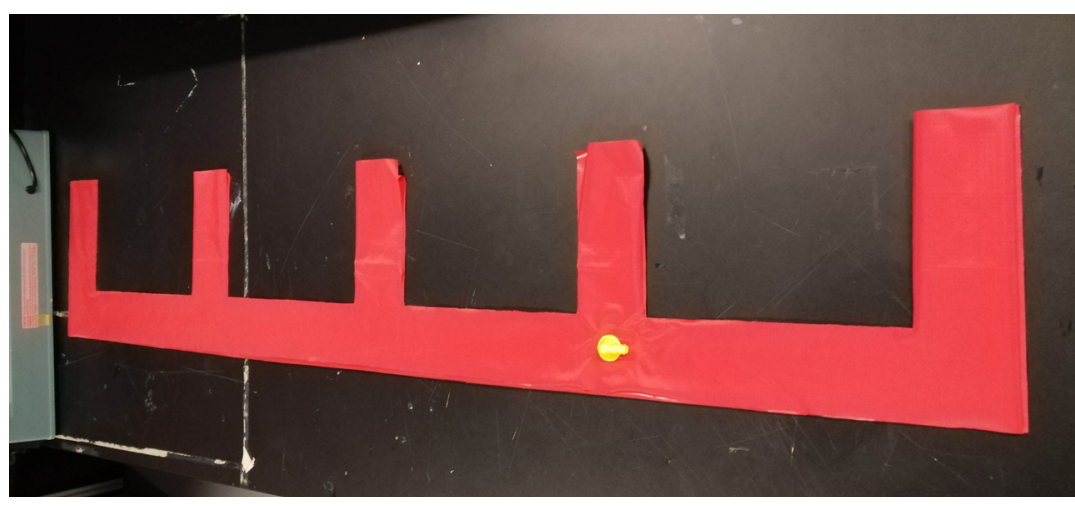

Figure 59. Single cavity form.

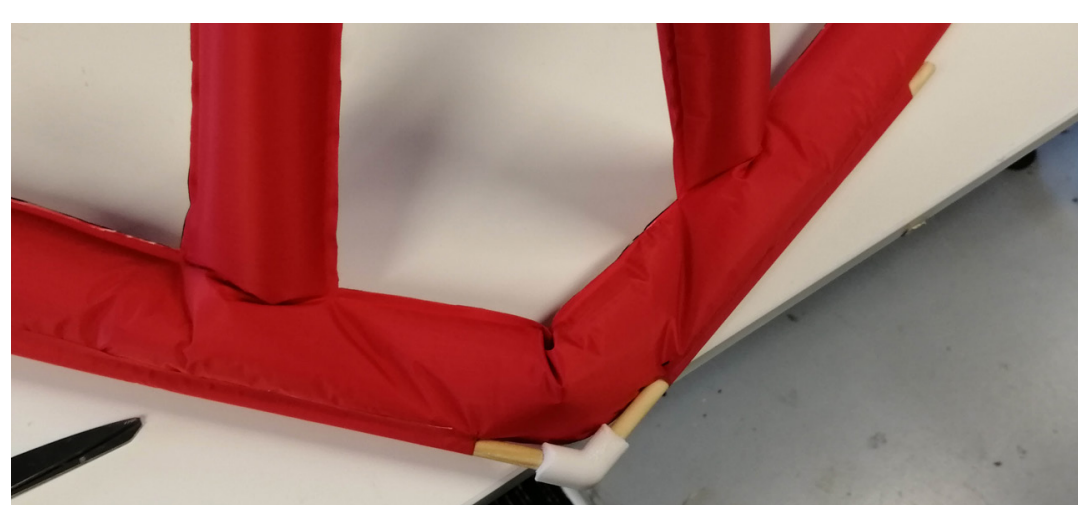

Figure 60. Exploration using a removable rigid external force.

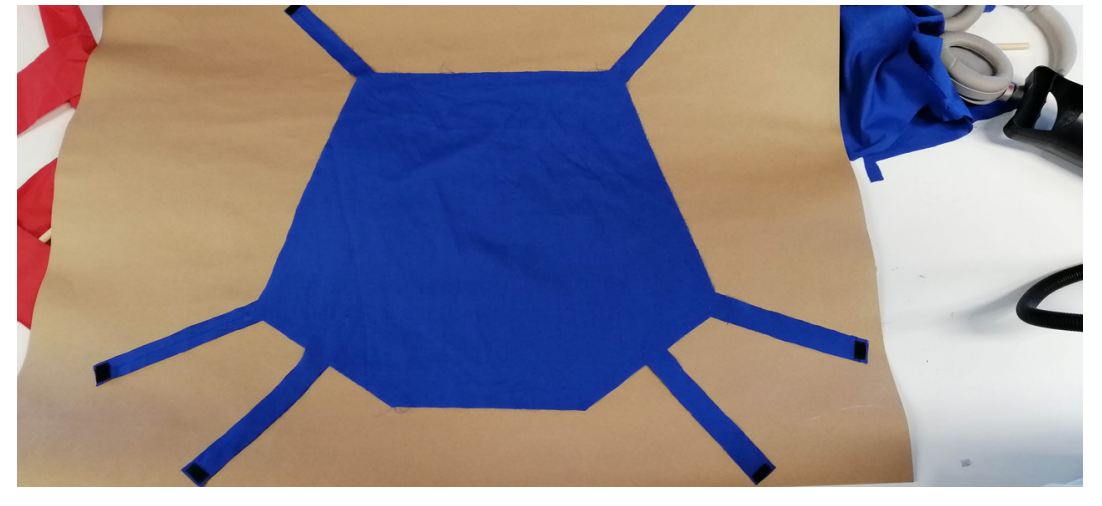

Figure 61. Exploration into using removable Velcro/fabric external force.

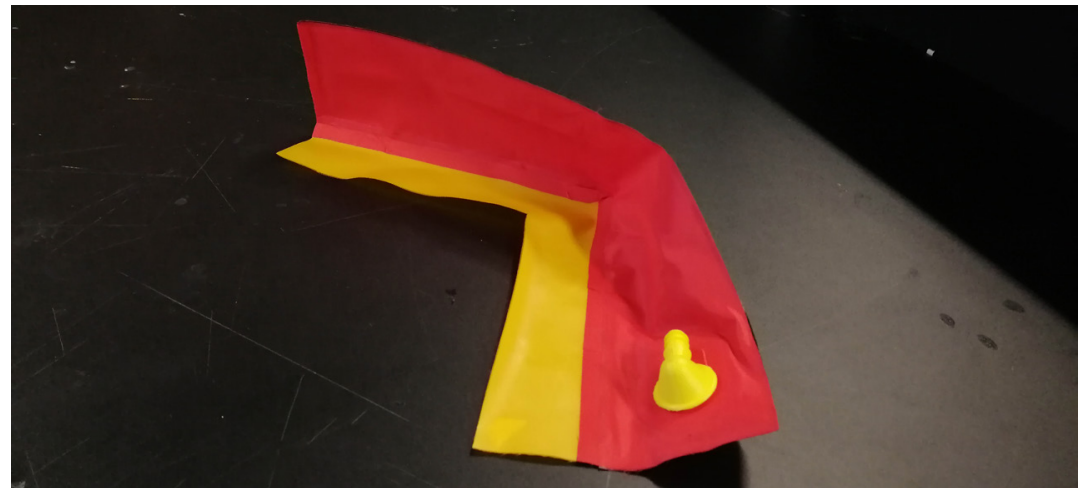

Figure 62. Exploration into using a permanently attached external force.

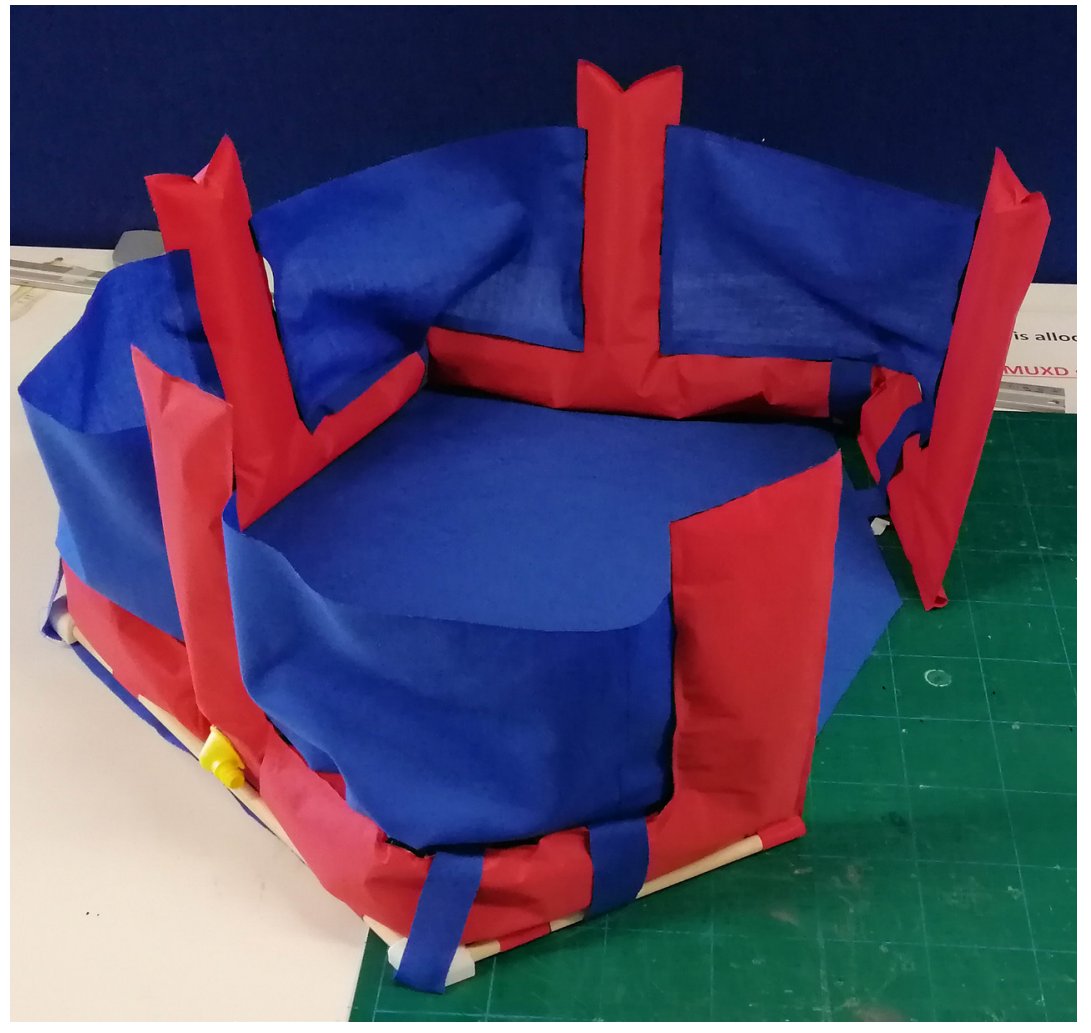

Figure 63. 1:5 prototype with all explored solutions in one. 


\section{Proposed assembly method}

The final scanner was designed to be partially pre-packaged, where hardware like cameras are pre-assembled onto components like the camera arms, or others like cables are pre-placed into the sleeves of the inflatable structure. This is so an operating technician can simply attach that component to the structure (plug and play). Therefore, the steps of the proposed assembly reflect this intention (Figure 64).

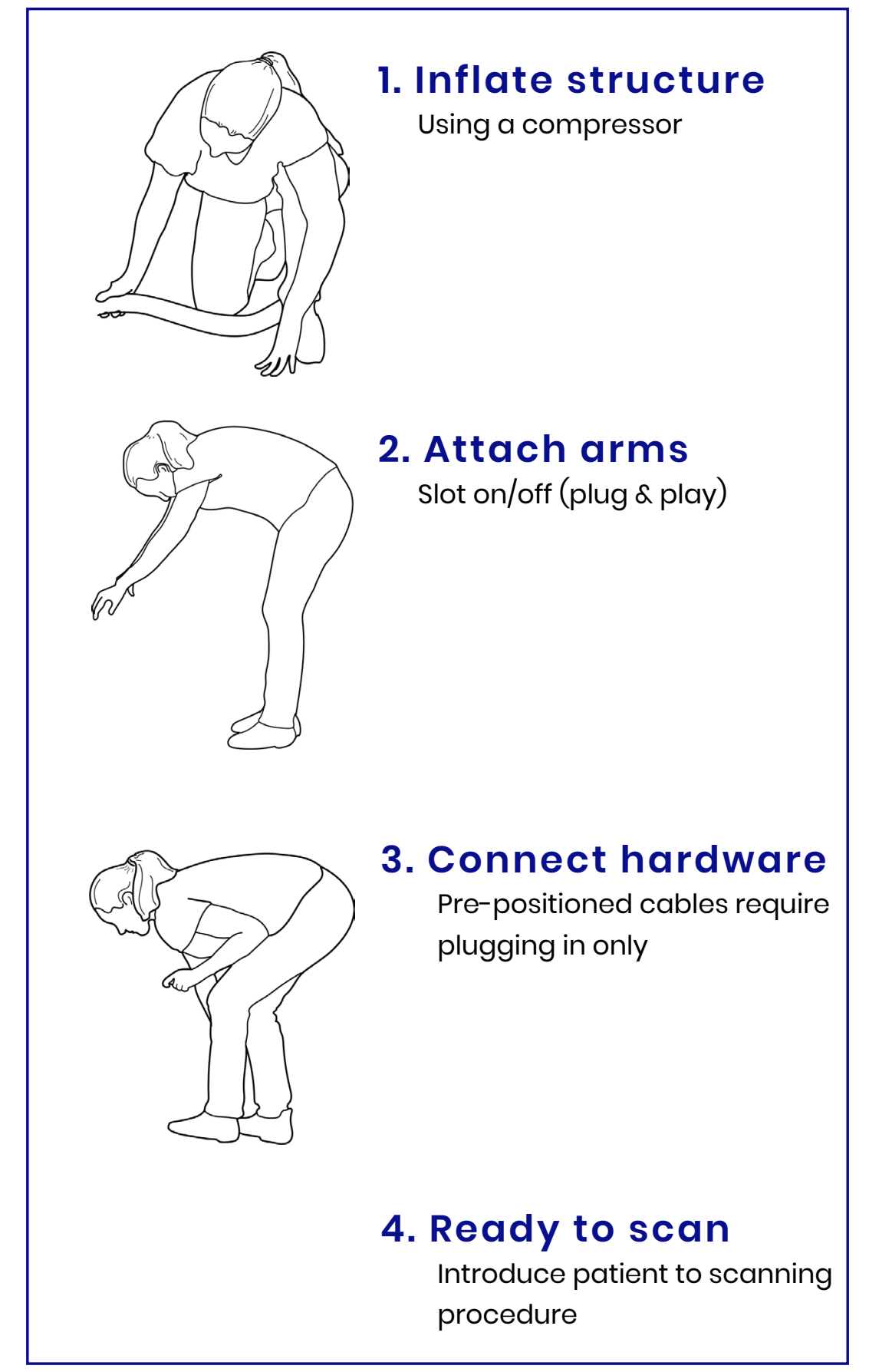

Figure 64. Simplified overview of proposed assembly process.

\subsubsection{Analysis}

\section{Sectional prototypes}

The purpose of creating 1:1 scale inflatable sectionals was to gain an understanding of inflatables, primarily different types of inflation methods, to decide which would be best for the intended use and for manufacturing. The most notable finding was the lengthy creation time and process. It was necessary to go slow and carefully, especially when creating and cutting the pattern (Appendix 3), otherwise the created form could not successfully inflate, or inflate in an unintended and often unwanted way.

\section{Sketches}

Weighted matrix (Figures 65-67) and discussions from the design team and inflatable manufacturer assessed the generated ideas against related core criteria. To determine the best solutions for later manufacturing and inclusion into the final prototype.

Overall, concepts deemed successful were those that were simple; simple in form, simple in cable management, and simple in attaching components. This was determined from feedback given by expert opinion from the UoA collaborator, and from an inflatable manufacturer. This is detailed later in this chapter.

Integrated cable management

\begin{tabular}{|l|c|c|c|c|c|}
\hline & & & \\
\hline
\end{tabular}

Figure 65. Weighted matrix used to find out best cable management method. 
Overall inflatable form
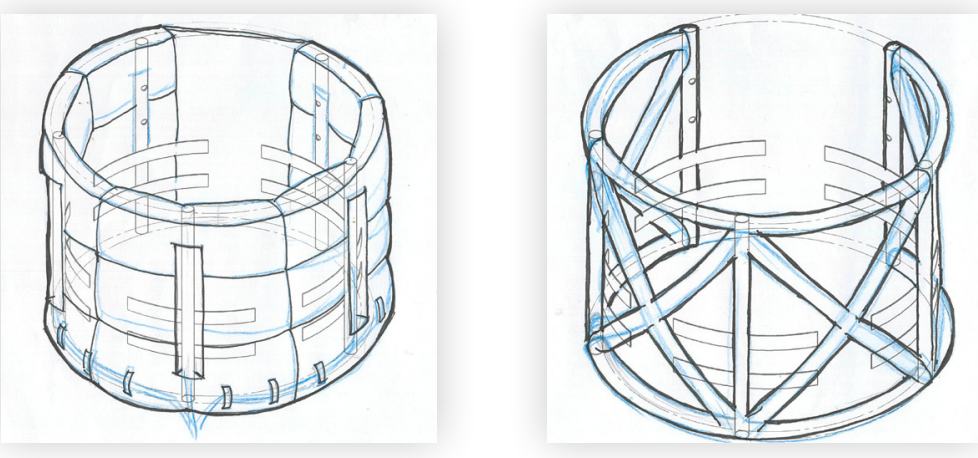

Idea 2

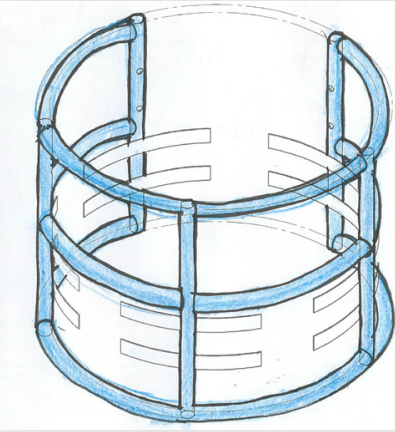

Idea 1

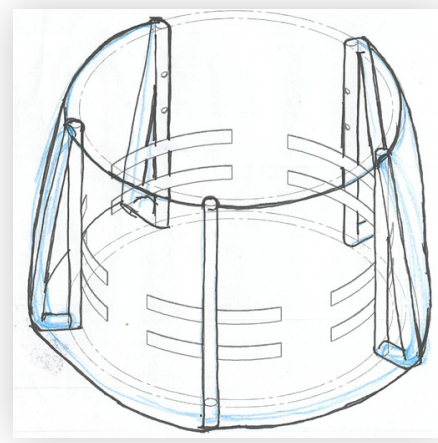

Idea 4

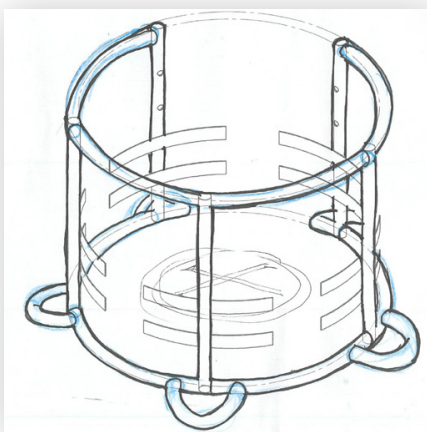

dea 5

\begin{tabular}{|r|c|c|c|c|c|c|}
\hline Weight & Idea 1 & Idea 2 & Idea 3 & Idea 4 & Idea 5 \\
\hline $\begin{array}{r}\text { Stability } \\
\text { Easy entry and exit }\end{array}$ & $\mathbf{3}$ & 3 & 3 & 3 & 1 & 3 \\
\hline $\begin{array}{r}\text { point } \\
\text { component }\end{array}$ & $\mathbf{3}$ & 3 & 2 & 2 & 2 & 2 \\
\hline $\begin{array}{r}\text { integration } \\
\text { Form simplicity }\end{array}$ & $\mathbf{2}$ & 1 & 2 & 3 & 3 & 2 \\
\hline Aesthetics & $\mathbf{2}$ & 3 & 2 & 3 & 2 & 2 \\
\hline TOTAL & & 35 & 32 & 36 & 28 & 32 \\
\hline
\end{tabular}

Figure 66. Weighted matrix to identify best inflatable form.

Attachment method of cable arm to inflatable structure
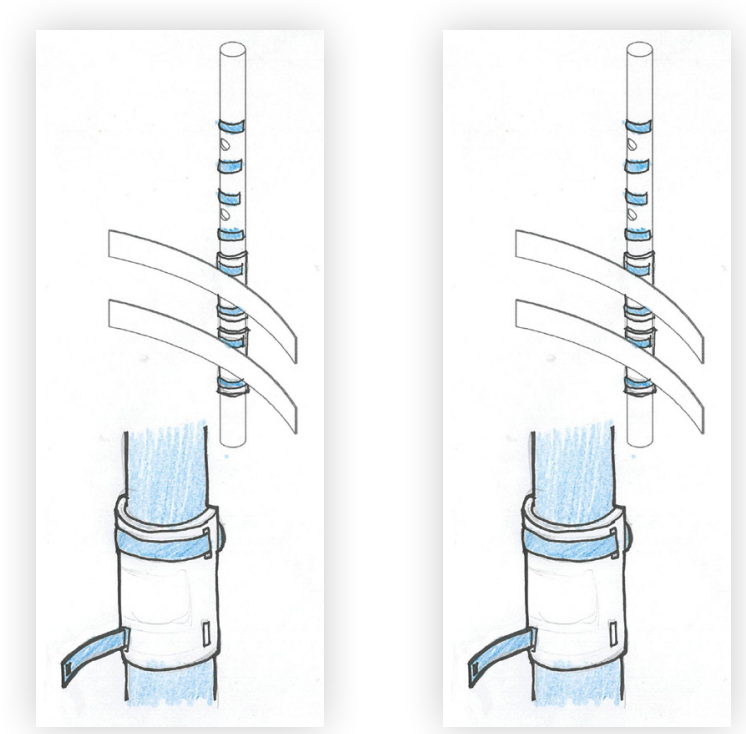

Idea 2

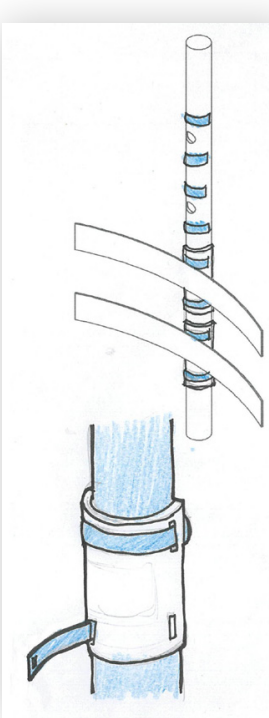

Idea 3

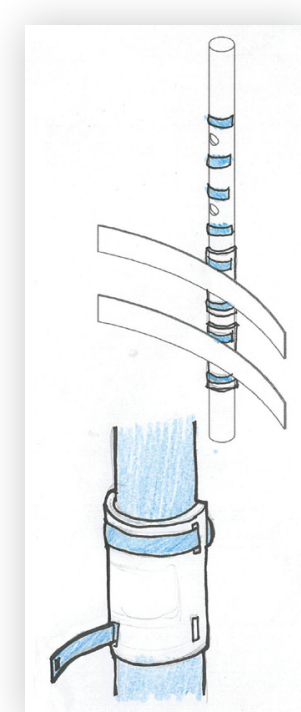

Idea 4

\begin{tabular}{|c|c|c|c|c|c|}
\hline \multicolumn{2}{|c|}{ Weight } & Idea 1 & Idea 2 & Idea 3 & Idea 4 \\
\hline Ease of attachment & 3 & 2 & 2 & 3 & 2 \\
\hline Hardware support & 3 & 3 & 2 & 1 & 3 \\
\hline Aesthetics & 3 & 3 & 3 & 3 & 1 \\
\hline TOTAL & & 21 & 18 & 18 & 19 \\
\hline
\end{tabular}

Figure 67. Weighted matrix highlighted which idea would be the most successful. 


\section{Proposed assembly method}

The assessment focus of the cognitive walk-through was the feasibility of using inflation as the primary assembly method, and how it may reduce assembly time and component amounts. Assessed also were prototypes that explored these features. Despite the unavailability of hardware (cameras and cables) for testing, the generated prototypes were sufficient to carry out the walk-through with a member of the UoA technician team. Findings from the cognitive walk-through found the proposed assembly procedure to be worth further exploration and refinement (Figure 68).

First, assembly via inflation was commented on as a unique solution that could effectively address assembly-related criteria, such as assembly time. An interesting comment was the "bouncy castle" aesthetic of the proposed assembly method, highlighting how the positive characteristics associated with bouncy castles may create a positive patient experience. Second, the intention to integrate hardware into components beforehand, creating a partially 'pre-packaged' scanner was met with positivity by the collaborator. Third, feedback on the decision to change camera attachment from vertical to horizontal orientation was positive, described as a novel way to attach cameras, and reduce component parts. Continuing, when informed of the intention to use the swinging version of the camera arms to create the entry/ exit point, the collaborator responded with similar positivity, as it would remove the need to create a doorway, or similar, further reducing the complexity of the scanner structure, and number of components.

A concluding comment by the UoA project collaborator highlighted the importance of creating a full-size working prototype. This is because the concepts and ideas presented could be better understood within a full, coherent, prototype. This would also allow the presented concepts to be better evaluated through more systematic methods such as formative evaluation, rather than assessment based solely on subjective opinion of sketches and sectional prototypes from hypothetical users.

\section{Component prototypes}

Prototypes, primarily the camera arm, were evaluated during the cognitive walkthrough, with feedback and suggestions given to optimise design usability, and for manufacturing. First, the weight should be reduced, and attachment point to the inflatable structure made wider, to eliminate the bowing seen in the walk-through. As well, a systematic method that allows the operating technician to determine the angle of cameras, through visual, audio, or tactical cues, could improve user experience. Second, 3D printing was determined as an ineffective manufacturing method because of weight and lead time. Therefore, exploration should be made into solutions that will reduce component parts.

\begin{tabular}{|c|c|c|}
\hline Steps & Feedback & Related criteria \\
\hline $\begin{array}{l}\text { Inflation with cabling } \\
\text { pre-placed }\end{array}$ & $\begin{array}{l}\begin{array}{l}\text { Unique and a good solution for quick } \\
\text { assembly }\end{array} \\
\text { 'Almost like a bouncy castle.' } \\
\text { Slow and manual inflation however } \\
\text { Interested in the concept of integrating } \\
\text { cables and other aspects for semi- } \\
\text { permanent attachment: "cooool" }\end{array}$ & 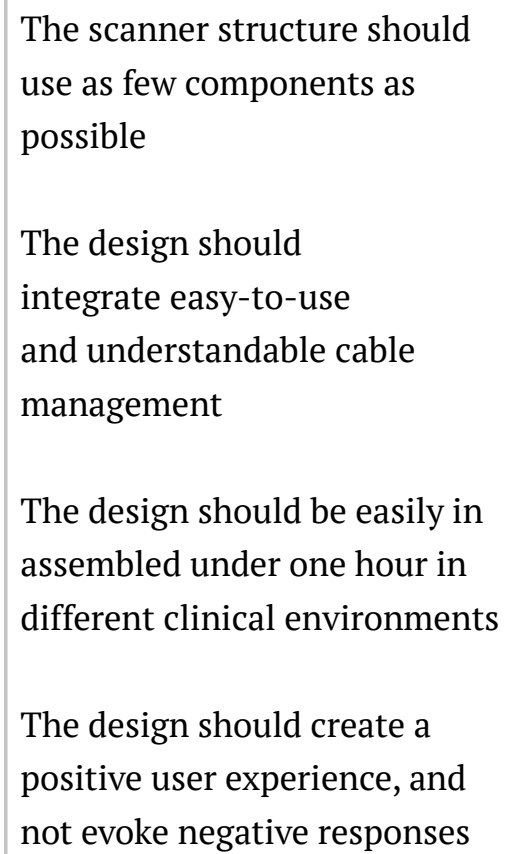 \\
\hline $\begin{array}{l}\text { Attachment } \\
\text { of camera arm } \\
\text { component with } \\
\text { hardware pre- } \\
\text { assembled }\end{array}$ & $\begin{array}{l}\text { Quick and easy-to-use and understand. } \\
\text { Good idea to have the cameras the } \\
\text { same width apart. } \\
\text { Should allow for modular placement at } \\
\text { different points of the scanner. } \\
\text { The camera arm bows downwards. } \\
\text { The connection point and air pressure } \\
\text { are not strong enough to support } \\
\text { hardware weight. } \\
\text { Good current placement of the arm low } \\
\text { to the base. }\end{array}$ & $\begin{array}{l}\text { The design should create a } \\
\text { clear and easy entry and exit } \\
\text { point for patients to move } \\
\text { through } \\
\text { The design should create an } \\
\text { easy-to-understand experience } \\
\text { through familiar actions, and } \\
\text { visual guides }\end{array}$ \\
\hline
\end{tabular}

Figure 68. Cognitive walk-through comments in relation to design criteria. 


\section{1:5 prototypes}

Based on the findings generated from the cognitive walk-through, 1:5 scale prototypes explored external ways to shape a single inflatable cavity to form the scanner structure. This was done via parallel prototyping and followed a hexagon form, under the assumption that this would make for easier manufacturing. However, manufacturer feedback deemed these forms as inefficient, because of production process constraints and the characteristics of inflatable structures. In detail, the structure's form must be pre-determined during production, otherwise it would be very difficult to form a single cavity into the desired shape through external means. Therefore, this avenue of form exploration was unsuccessful. However, when shown the sketches of designs for the overall inflatable structure, the one with the simplest form was decided as the most feasible (Figure 69).

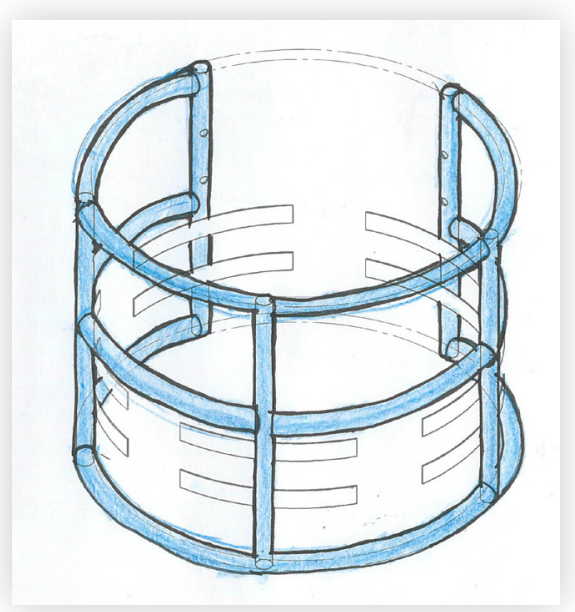

Figure 69. Most feasible form for manufacture.

\subsubsection{Summary}

This design phase did not produce a 'final' prototype. Only a proposed assembly method, and potentially successful prototypes that would require the manufacture of a full prototype in order to be fully assessed. As such, no assessment against criteria was done in this phase. Evaluation and design development were based upon the feedback of the UoA collaborator and manufacturer, which led to the prototype's form to follow its function; the form is dictated by constraints present in inflatable production, and the project requirements that need to be met. This is reflected by criteria added, creating the final set of design criteria.

\subsubsection{Reflection}

The switch to inflatable form exploration resulted in a period of exploration, in place of serial refinement of previously identified concepts, and require testing in full scale in order to be fully assessed. However, it was deemed impractical and inefficient to create large, 1:1 scale prototypes to test every idea. This is due to inexperience and amateur skill level of the researcher in regard to inflatable form creation. Therefore, early exploration and assessment methods, such as sketches and weighted matrix, were used to prioritise successful concepts for inclusion into the later large-scale prototype. However, some concepts could not be developed further than sketch ideation, this meant design decisions were based on the opinion of the design team UoA collaborator, and the expertise of the inflatable manufacturer.

Therefore, the next design phase focuses on refining and manufacturing solutions deemed the most successful and feasible by the UoA collaborator, design team, an manufacturer. This will allow assessment of solutions in the last design phase. 


\section{Updated criteria}

The design criteria has been updated to reflect knowledge generated in this chapter.

Note: Updated criteria in italics

\begin{tabular}{|c|c|c|}
\hline SUBJECT/THEME & CRITERIA & SOURCE \\
\hline \multicolumn{3}{|c|}{ Photogrammetry scanner } \\
\hline & $\begin{array}{l}\text { The design should facilitate optimal uniform } \\
\text { lighting }\end{array}$ & \multirow[t]{2}{*}{ Literature (2.1.4) } \\
\hline & $\begin{array}{l}\text { The design should facilitate quick patient } \\
\text { scanning }\end{array}$ & \\
\hline \multicolumn{3}{|c|}{ Novel scanner development } \\
\hline & $\begin{array}{l}\text { The inflatable form should balance manufacturing } \\
\text { constraints and project needs }\end{array}$ & Design phase two \\
\hline & $\begin{array}{l}\text { The design should allow use of research-project- } \\
\text { provided hardware }\end{array}$ & \multirow[t]{3}{*}{$\begin{array}{l}\text { Research project } \\
\text { constraints }\end{array}$} \\
\hline & $\begin{array}{l}\text { The design should allow the patient to be } \\
\text { positioned into a load-bearing stance }\end{array}$ & \\
\hline & $\begin{array}{l}\text { The design should be circular to allow for camera } \\
\text { overlap }\end{array}$ & \\
\hline & $\begin{array}{l}\text { The scanner interaction should consider use by } \\
\text { patients aged between } 1-16 \text { years old }\end{array}$ & $\begin{array}{l}\text { Ethic testing } \\
\text { population constraint }\end{array}$ \\
\hline & $\begin{array}{l}\text { The design should facilitate a digital AFO work- } \\
\text { flow }\end{array}$ & Larger project goal \\
\hline \multicolumn{3}{|l|}{ Usability } \\
\hline & $\begin{array}{l}\text { The design should allow systematic custom vertical } \\
\text { orientation of cameras }\end{array}$ & \multirow[t]{2}{*}{ Design phase one } \\
\hline & $\begin{array}{l}\text { The design should create a clear and easy entry and } \\
\text { exit point for patients to move through }\end{array}$ & \\
\hline
\end{tabular}




\begin{tabular}{|c|c|c|}
\hline SUBJECT/THEME & CRITERIA & SOURCE \\
\hline & $\begin{array}{l}\text { The design should allow custom vertical } \\
\text { orientation of cameras }\end{array}$ & $\begin{array}{l}\text { Pre-existing prototype } \\
\text { assessment }\end{array}$ \\
\hline \multicolumn{3}{|l|}{ Assembly } \\
\hline & $\begin{array}{l}\text { The assembly process should follow a 'plug and play' } \\
\text { style }\end{array}$ & Design phase two \\
\hline & $\begin{array}{l}\text { The scanner structure should use as few } \\
\text { components as possible }\end{array}$ & Design phase one \\
\hline & $\begin{array}{l}\text { The design should integrate easy-to-use and } \\
\text { understandable cable management }\end{array}$ & $\begin{array}{l}\text { Pre-existing prototype } \\
\text { assessment }\end{array}$ \\
\hline & $\begin{array}{l}\text { The design should be easily assembled in under } \\
\text { one hour in different clinical environments }\end{array}$ & \\
\hline \multicolumn{3}{|l|}{ Aesthetics } \\
\hline & $\begin{array}{l}\text { The design should create an easy-to-understand } \\
\text { experience through familiar actions, and visual } \\
\text { guides }\end{array}$ & Design phase one \\
\hline & $\begin{array}{l}\text { The enclosure aesthetic should allow for easy } \\
\text { post-processing }\end{array}$ & $\begin{array}{l}\text { Pre-existing prototype } \\
\text { assessment }\end{array}$ \\
\hline \multicolumn{3}{|l|}{ Patient experience } \\
\hline & $\begin{array}{l}\text { The design should create a positive user } \\
\text { experience potentially through familiarity and fun } \\
\text { connotations, and not evoke negative responses }\end{array}$ & \\
\hline Technician experience & $\begin{array}{l}\text { The design should allow for easy set up and } \\
\text { potential storage }\end{array}$ & \\
\hline
\end{tabular}

Table 14. Updated criteria based on chapter six findings. 


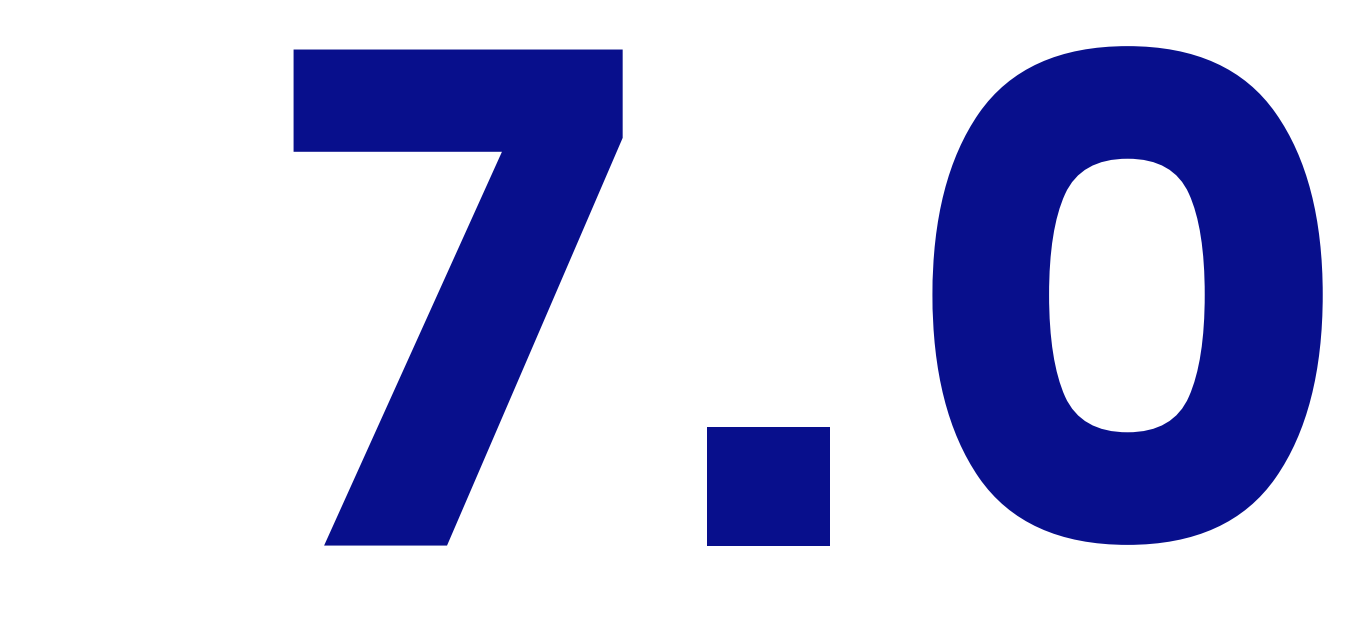

\section{DESIGN PHASE}

This final phase of design presents the final development and evaluation of the inflatable photogrammetry scanner.

\section{THREE}

Final output 


\subsubsection{Background}

The aim was to develop a final output that was the best solution for the design research situation. Based on the findings generated from the background research, the assessment of the pre-existing prototype, and the design development of the two previous design phases. The final assessment of the prototype is in chapter eight, as it informed the final discussion of the research.

\subsubsection{Methods}

Concept generation

A research through design (RtD) multi-method approach was again used in this final design phase to develop the final prototype, but with a focus on finalising and refining. Concept generation followed a serial, iterative-like design process, and developed already identified solutions, rather than the generation of new ones. This included serial sketching, and high-fidelity serial prototyping.

\section{Prototype analysis}

The final prototype was assessed against the finalised set of criteria developed in chapter six, and a formative evaluation (as described in the methodology chapter)

through two simulated-use testing sessions, with observations.

Each session tested the participants as they interacted with the prototype and system in a realistic use scenario, but under simulated conditions of use (CDRH, 2011). The first session was with the UoA project collaborator, where they assessed the proposed assembly process and design. The second session was with operating technician and child participants, where they tested the scanning procedure with the prototype. The sessions allowed investigation into the interaction between user and overal device, along with specific elements identified from early analysis, this included tasks identified to be difficult, such as scanner assembly. Qualitative data was generated during this evaluation through observations, (CDRH, 2011), and SSI responses. Thi data, through deductive thematic and thematic analysis, generated qualitative data.

\subsubsection{Simulated-assembly testing session}

The session aimed to assess the assembly process previously proposed in chapter six through observation and expert opinion. This generated qualitative data used in the assessment of the final prototype against design criteria.

\section{Session goals}

\begin{tabular}{|l|l|}
\hline Goal & Method \\
\hline $\begin{array}{l}\text { Observe user interaction during assembly } \\
\text { process }\end{array}$ & Observations \\
\hline $\begin{array}{l}\text { Assess user experience during the } \\
\text { assembly process }\end{array}$ & Observation, conversation, and SSIs \\
\hline $\begin{array}{l}\text { Assess the final prototype's success to } \\
\text { address identified criteria }\end{array}$ & SSIs, and assessment against criteria. \\
\hline
\end{tabular}

Table 15. Simulated-assembly testing session goals.

\section{Participants}

As per ethics recommendation, this simulated-use testing session was structured as an 'assessment of the designs' development via expert opinion given by a UoA project collaborator.

\section{Procedure}

Testing and observation

The collaborator was made aware the intention of this session was to observe them and their actions as they assembled the scanner to the best of their ability. The researcher then stayed silent, taking notes and observing, and only when asked for help, did they interact with the session.

\section{Debriefing}

After the assembly process was completed to the best of the collaborator's understanding, a debriefing session occurred, where discussion about the process was had. The questions asked related to criteria such as user experience, usability, function, and aesthetics (Appendix 5). 


\subsubsection{Simulated-scanning testing session}

The second session aimed to assess the user experience of patient and operator during a scanning procedure using the prototype through observation and SSIs. This generated qualitative data used to assess the final prototype against design criteria.

\section{Session goals}

\begin{tabular}{|l|l|}
\hline Goal & Method \\
\hline $\begin{array}{l}\text { Observe interaction between participants } \\
\text { and operator }\end{array}$ & Observations \\
\hline $\begin{array}{l}\text { Assess user experience during scanning } \\
\text { process }\end{array}$ & Observation, conversation, and SSIs \\
\hline $\begin{array}{l}\text { Assess the final prototype's success to } \\
\text { address identified criteria }\end{array}$ & $\begin{array}{l}\text { SSIs, and assessment against } \\
\text { criteria. }\end{array}$ \\
\hline
\end{tabular}

Table 16. Simulated-scanning session goals.

\section{Participants}

Four participants were recruited through contacts from research project team members. They were aged eight or eleven years old, and represented the age group that are intended to use the scanner.

\section{Procedure}

Consent and ethics

The age of participants deemed them as vulnerable users, as per the project's ethics. Consent was given with approval from present parents or guardians. All generated information, including recordings, both video and audio, and images, as per ethics were kept confidential. There were shown only to participants and those involved in the research project upon request, with identifying features removed, or blurred.

\section{Testing}

The researcher assumed the role of observer during the simulated-use testing session, with the primary goal to observe and take notes of the patient experience (child participants), and interaction between the operating technician (UoA technician) and patient during the scanning procedure. Also noted were the actions of the operator as they completed the scanning process. Once again, the researcher only interacted with the session when asked to, and when it came time to conduct the SSI during the debriefing session.

\section{Debrief}

Once the scanning process was completed, the participants were asked to answer some questions through SSIs related to their experience (Appendix 6), after which, they were thanked for their participation.

\subsubsection{Digital model generation protocol}

Generated from the simulated scanning test sessions were sets of images of each participant. These images went through a similar process as described in chapter four in order to be assessed and determine if the scanner addresses criteria related to digital model generation

\section{Procedure}

Image generation

Images of the participants in a load bearing stance positioned in the centre of the scanner were taken with the Raspberry Pi system, and final integrated lighting solution (Figures 70-73).

\section{Post-processing}

Unwanted artefacts are removed using Adobe Photoshop, and a combination of the Polygon- and magnetic lasso tool, completed by outlining, selecting, and deleting the unwanted artefacts. The edited images were then exported as PNG files (Figures 74-77)

\section{D-model generation}

Models from the images are automatically generated when imported into the AutoDesk ReCap software through its default settings.

\section{Evaluation}

The models were viewed and assessed in the program's digital space, and downloaded for offline assessment. These models were evaluated against those from chapter four, and from previous project work. 


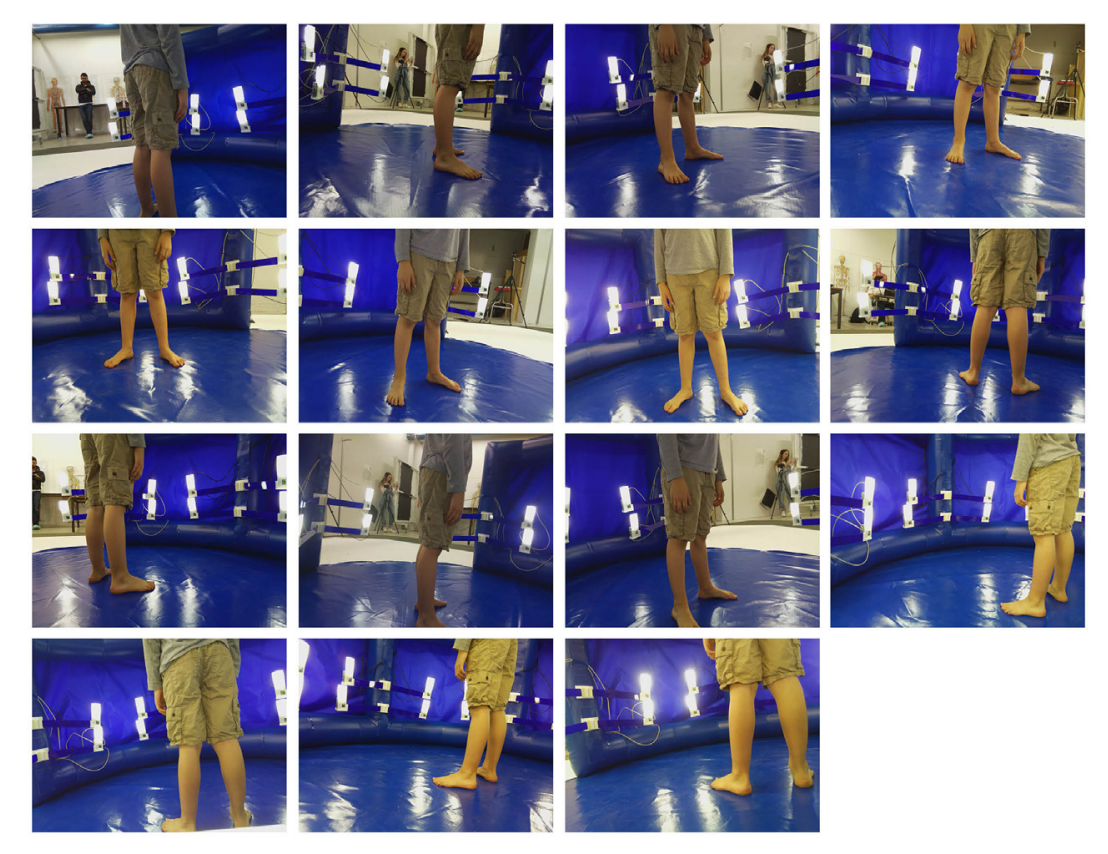

Figure 70. Generated images of participant one from the simulated-scanning test session.

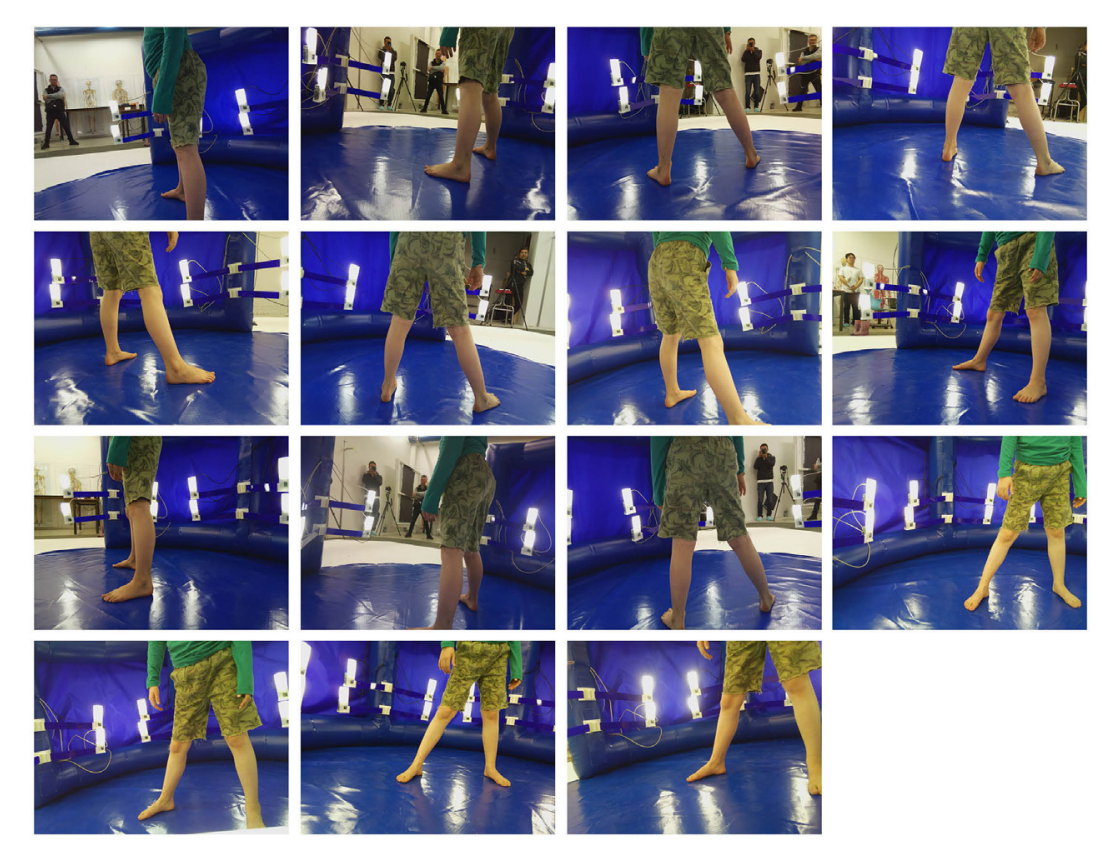

Figure 71. Generated images of participant two from the simulated-scanning test session.

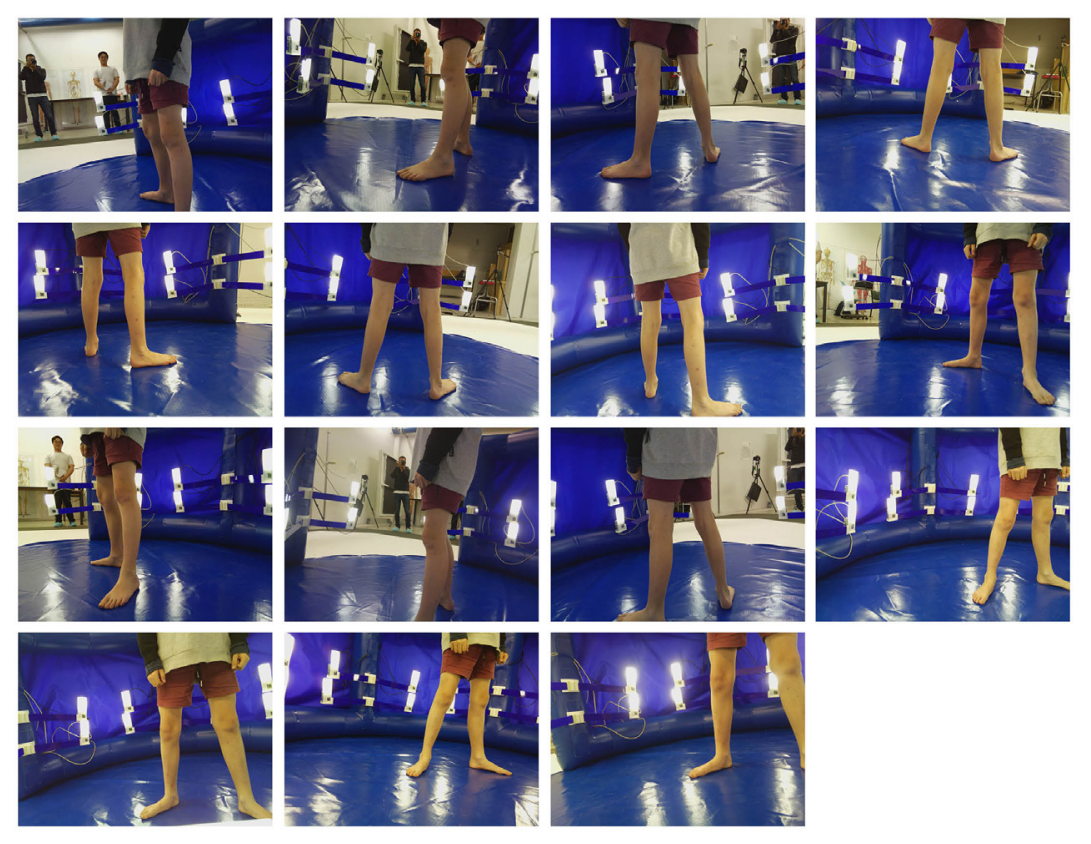

Figure 72. Generated images of participant three from the simulated-scanning session.

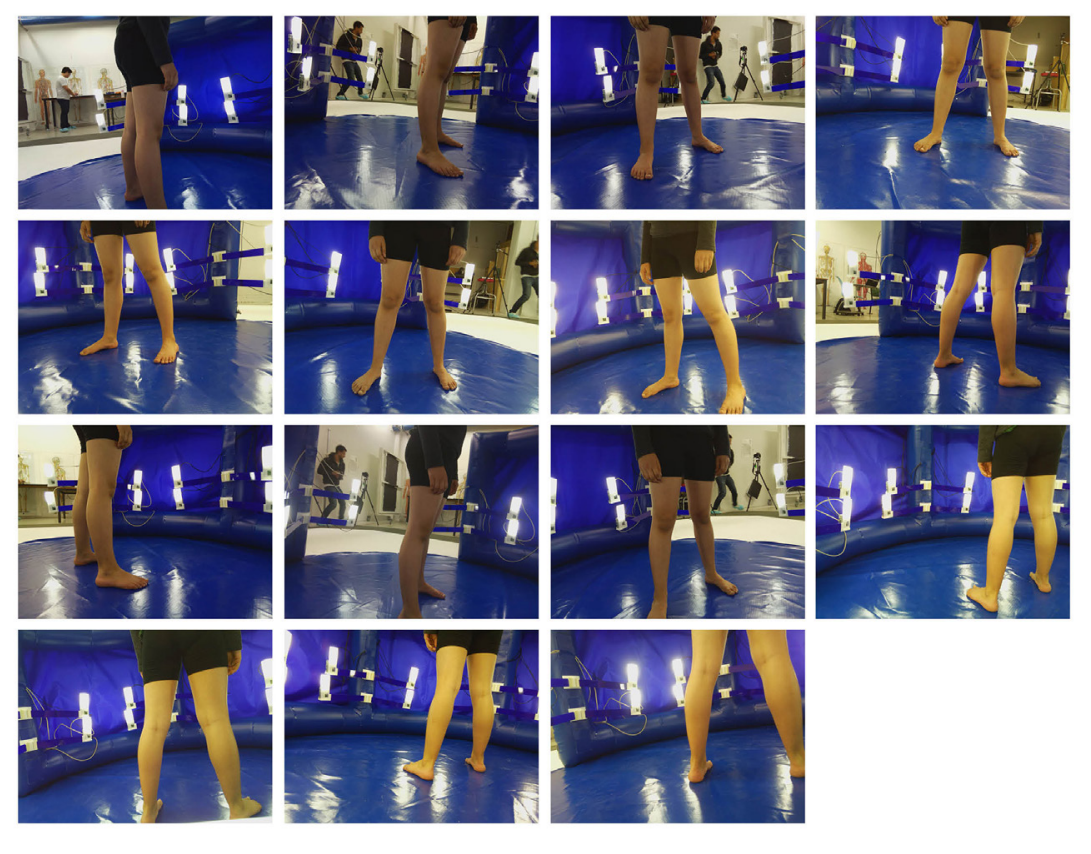

Figure 73. Generated images of participant four from the simulated-scanning session. 


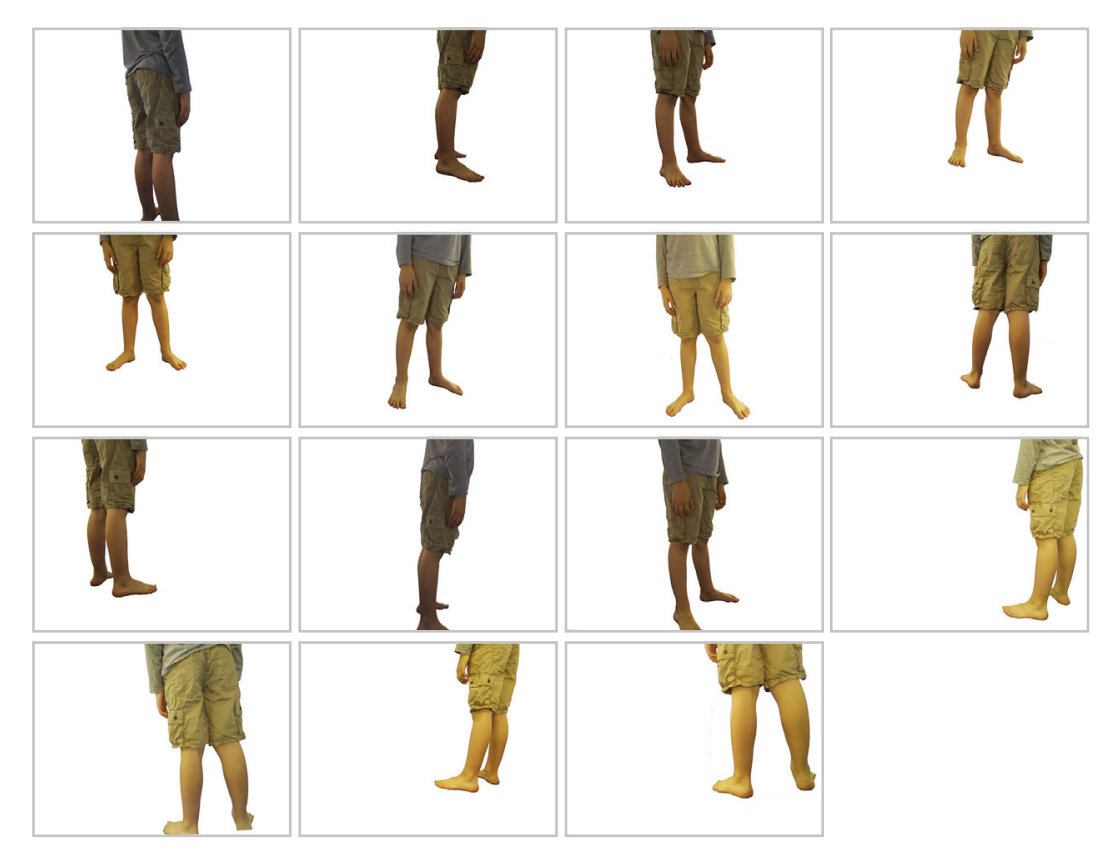

Figure 74. Edited images of participant one from the simulated-scanning test session.

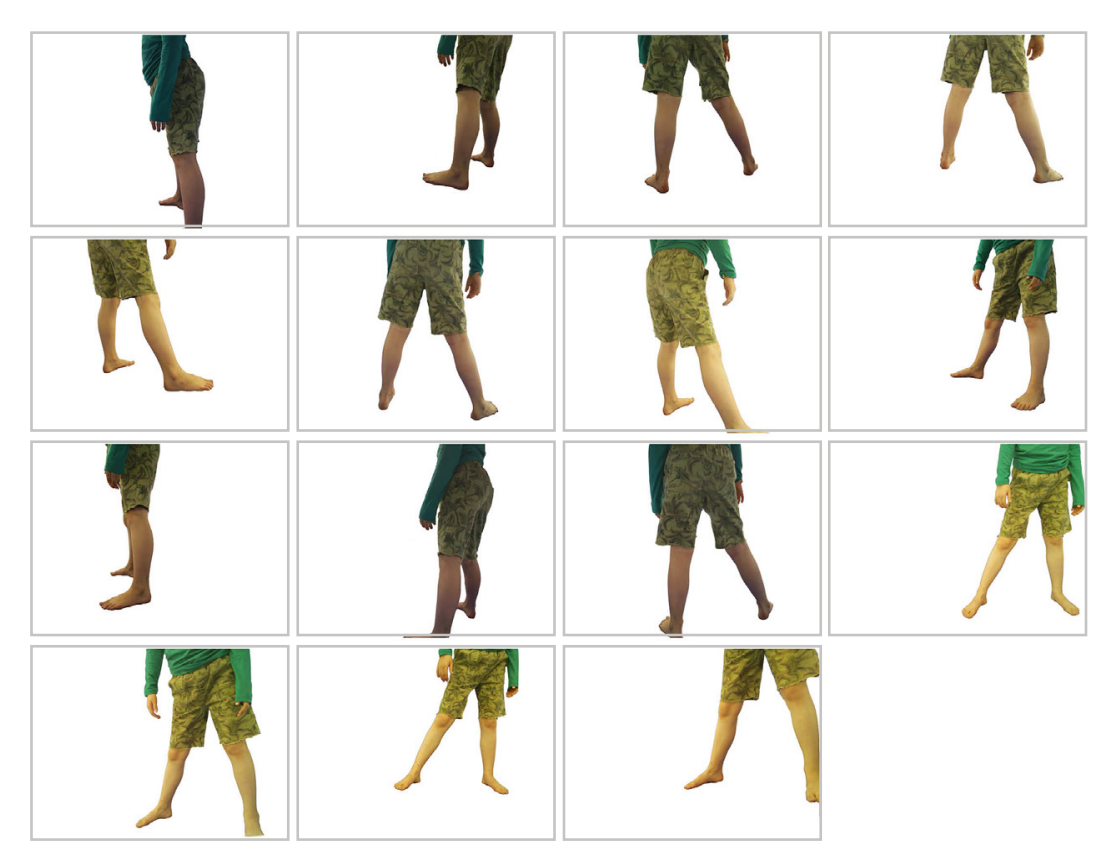

Figure 75. Edited images of participant two from the simulated-scanning test session.

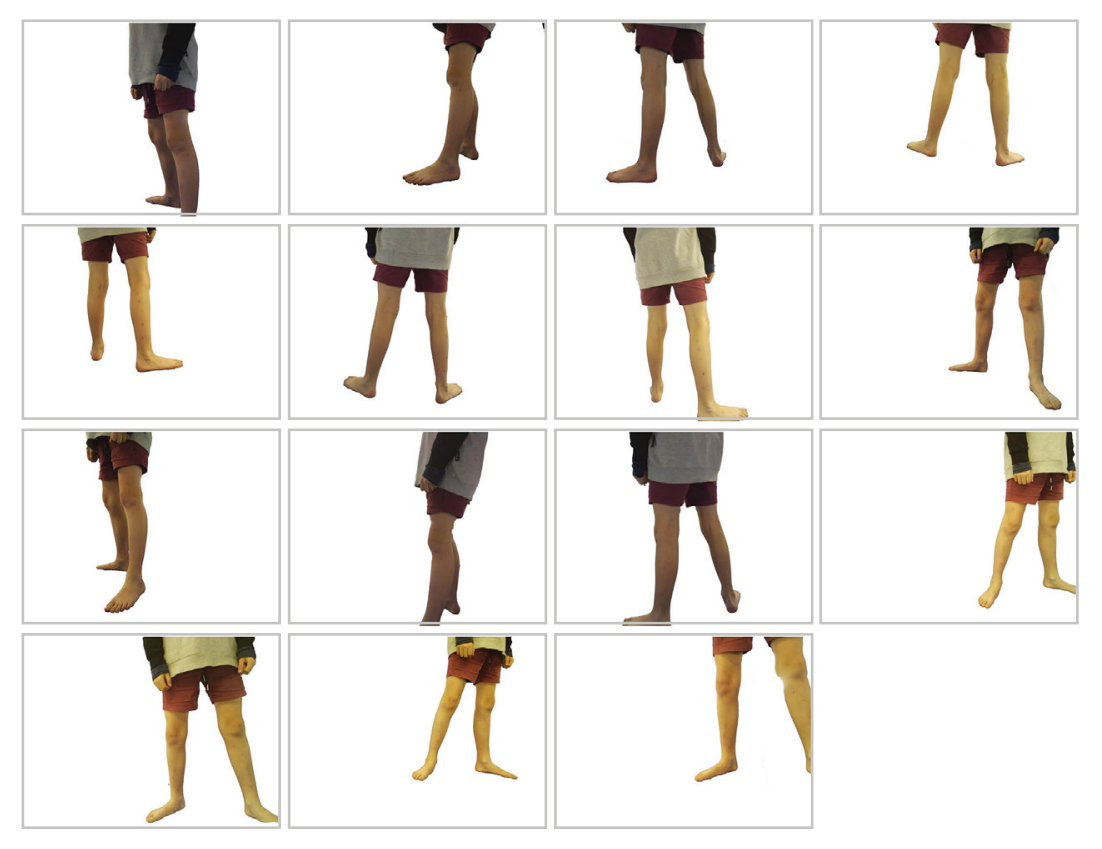

Figure 76. Edited images of participant three from the simulated-scanning session.

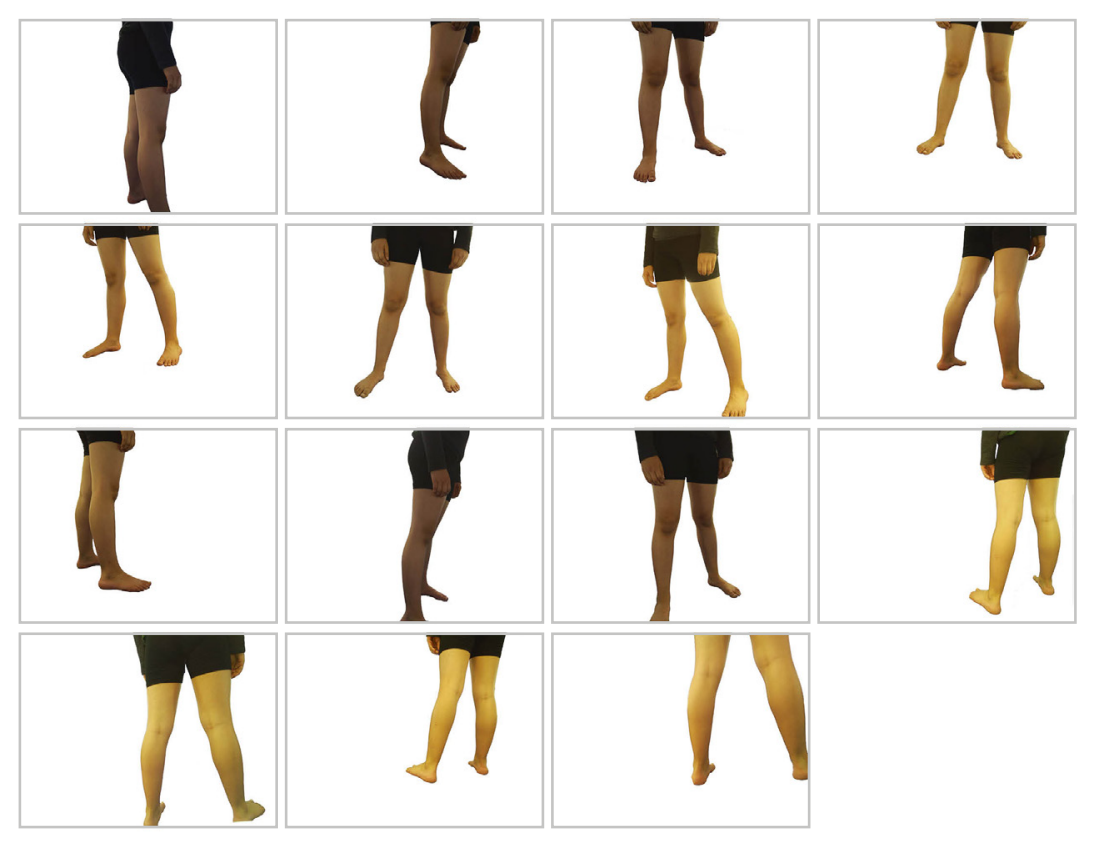

Figure 77. Edited images of participant four from the simulated-scanning session. 


\subsubsection{Results}

\subsubsection{Design development}

\section{Serial sketching}

Sketches generated different iterations of solutions identified in the previous design

phase. These were used as visual references during the CAD modelling process, to generate high-fidelity prototypes.
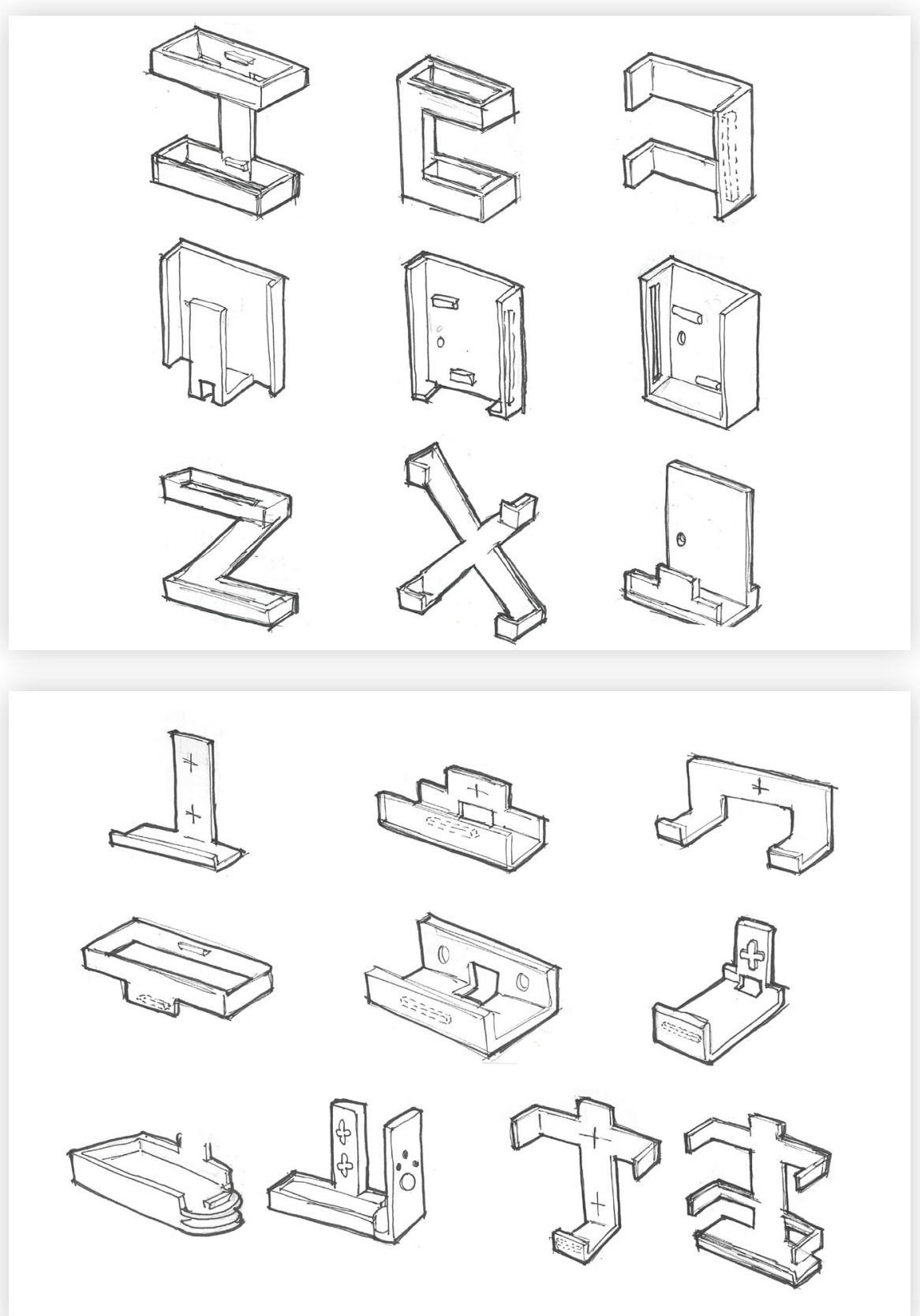

Figure 78. Focused sketch iterations of the camera housing.

\section{High-fidelity serial prototyping}

Sketches generated different iterations of solutions identified in the previous design phase. These were used as visual references during the CAD modelling process, to generate high-fidelity prototypes.

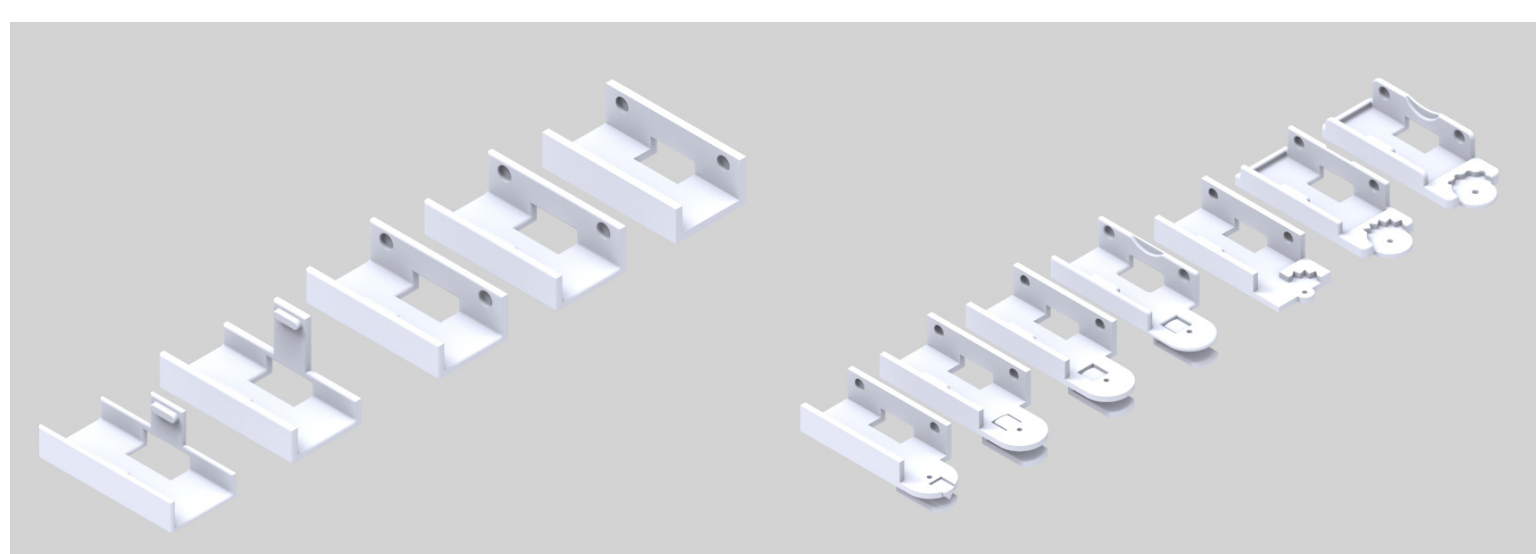

Figure 79. Serial CAD prototyping of camera mounts

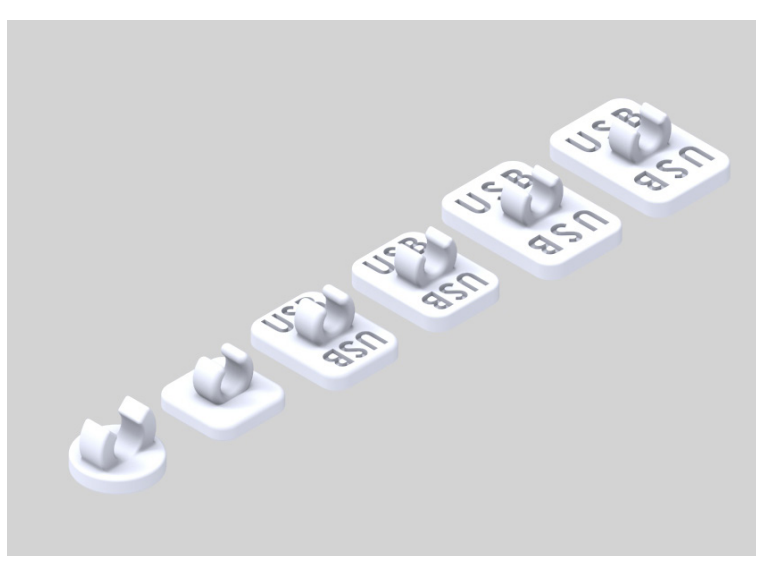

Figure 80. Serial CAD prototyping of cable clips.

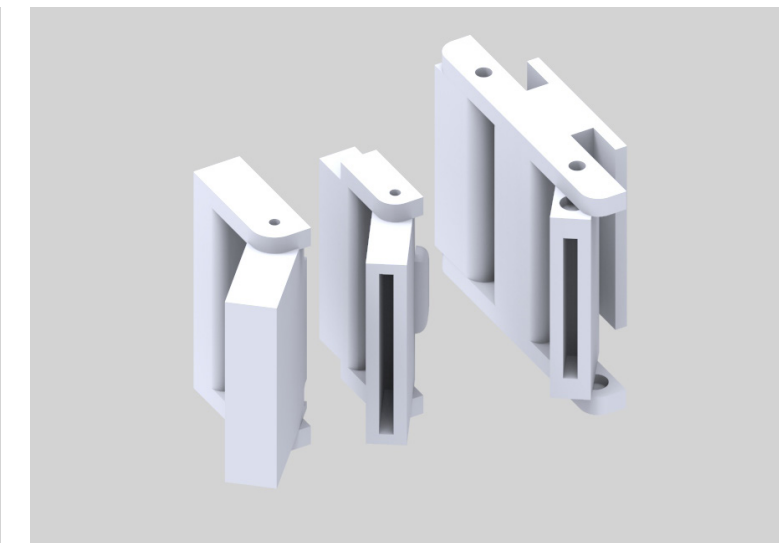

Figure 81. Serial CAD prototyping of 'swinging' camera arm section.

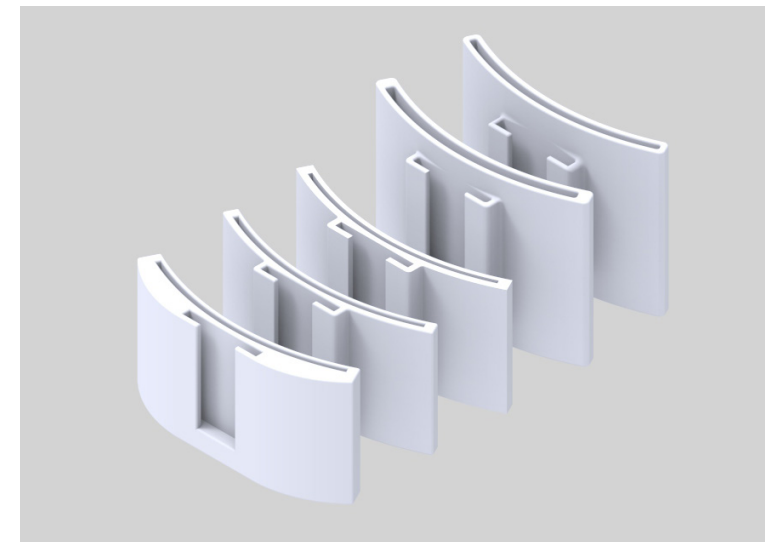

Figure 82. Serial CAD prototyping of camera arm to inflatable structure mount. 


\subsubsection{Final 3D parts}

Following a period of rapid, serial prototyping to refine aspects such as tolerances and aesthetics, final CAD files for parts such as the camera mounts and camera arm hinges were sent to manufactures to be produced in bulk (Appendix 7).

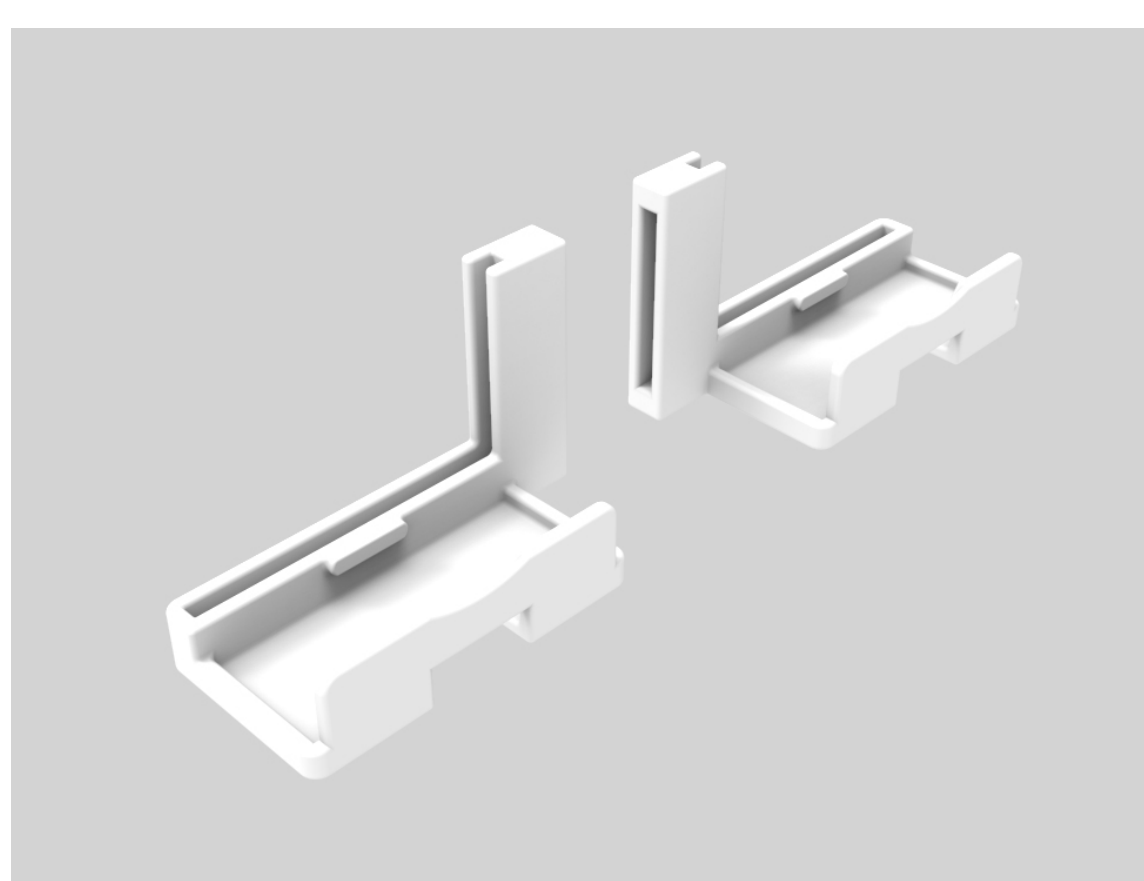

Figure 83. Final CAD model of camera mounts.

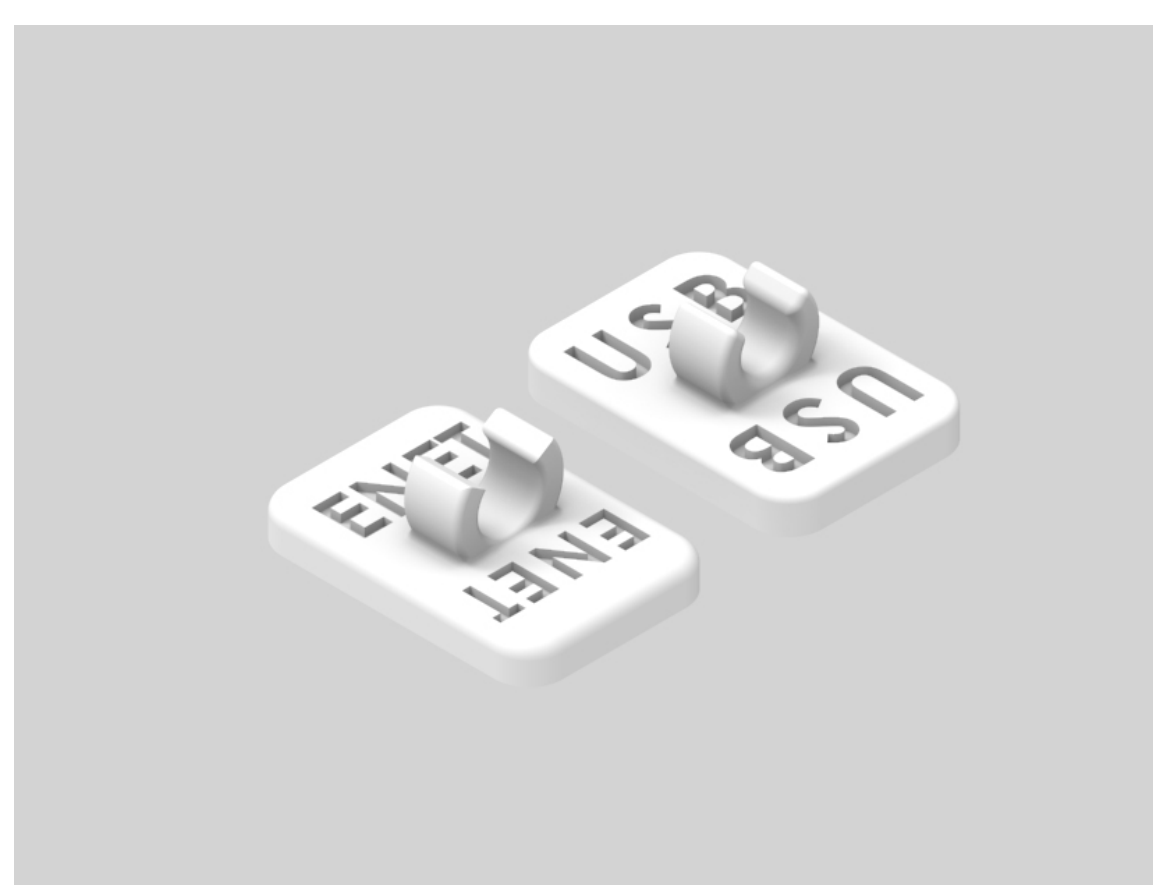

Figure 84. Final CAD model of cable clips.

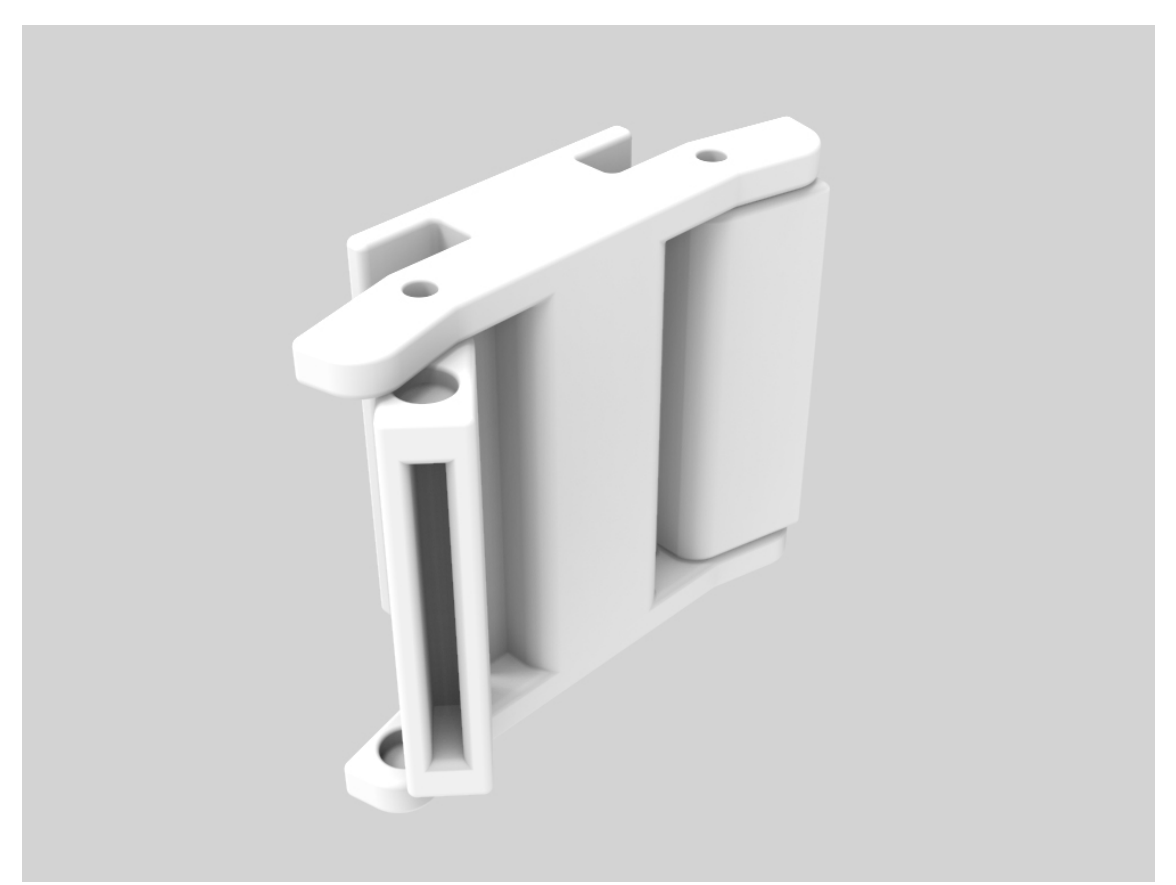

Figure 85. Final CAD model of 'swinging' camera arm section.

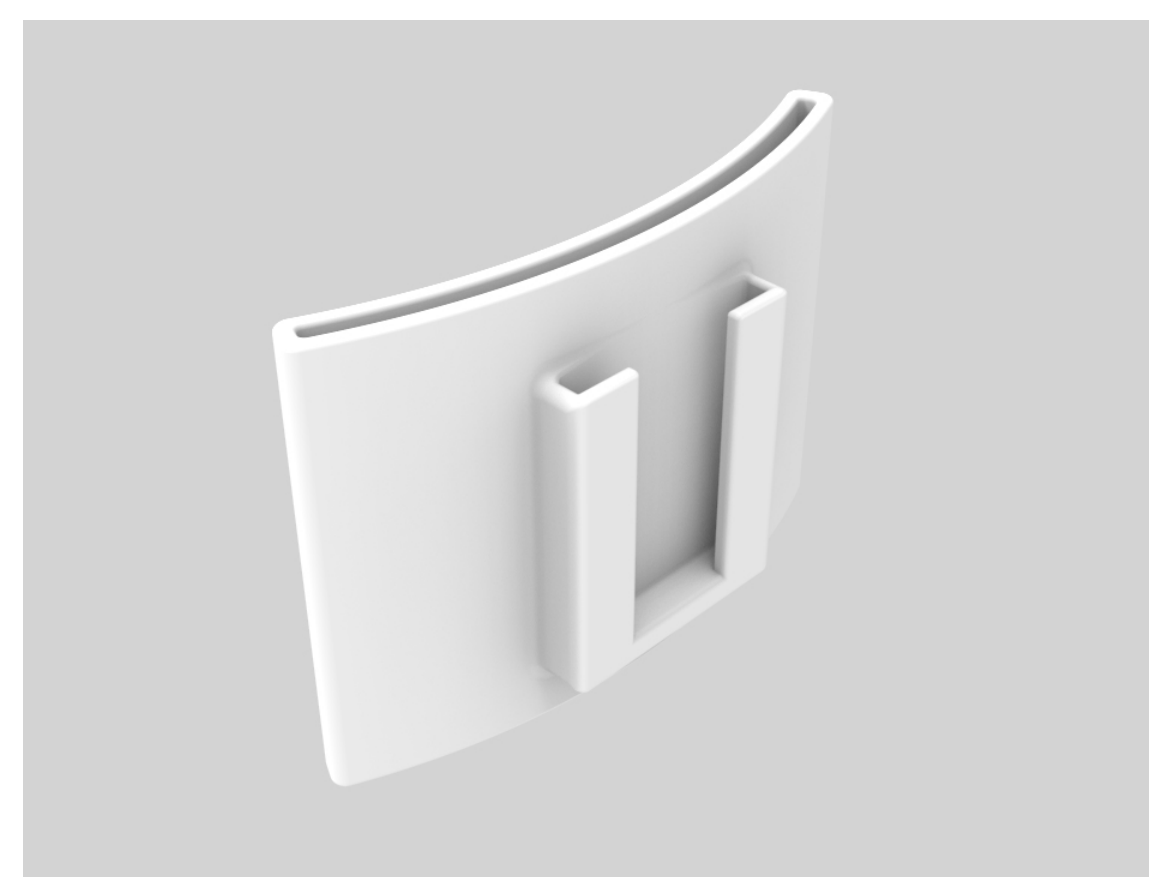

Figure 86. Final CAD model of camera arm to inflatable structure mount. 


\subsubsection{Generated surface models}

Sets of models were generated from each participant scanning session. The lighting chosen was picked to address criteria related to reducing component numbers, and for ease of use. However, it is clear that the light qualities were not enough, despite different attempts to edit the images to address criteria related to generating usable models. This is discussed further in chapter eight.

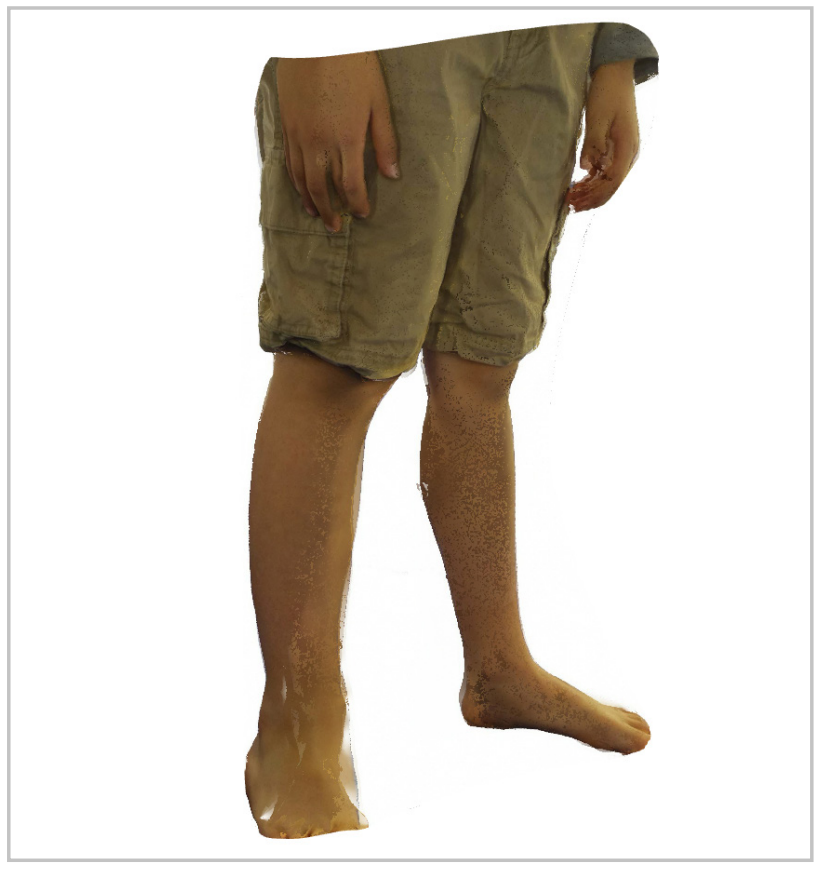

Figure 87. Participant one generated model (background removed).

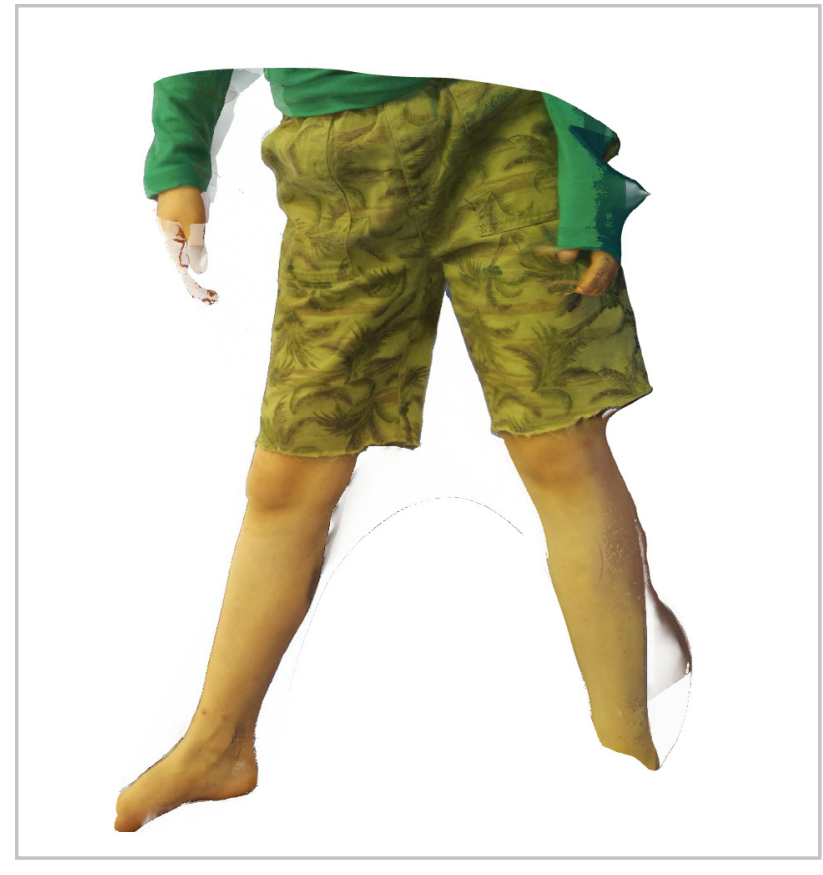

Figure 88. Participant two generated model (background removed).

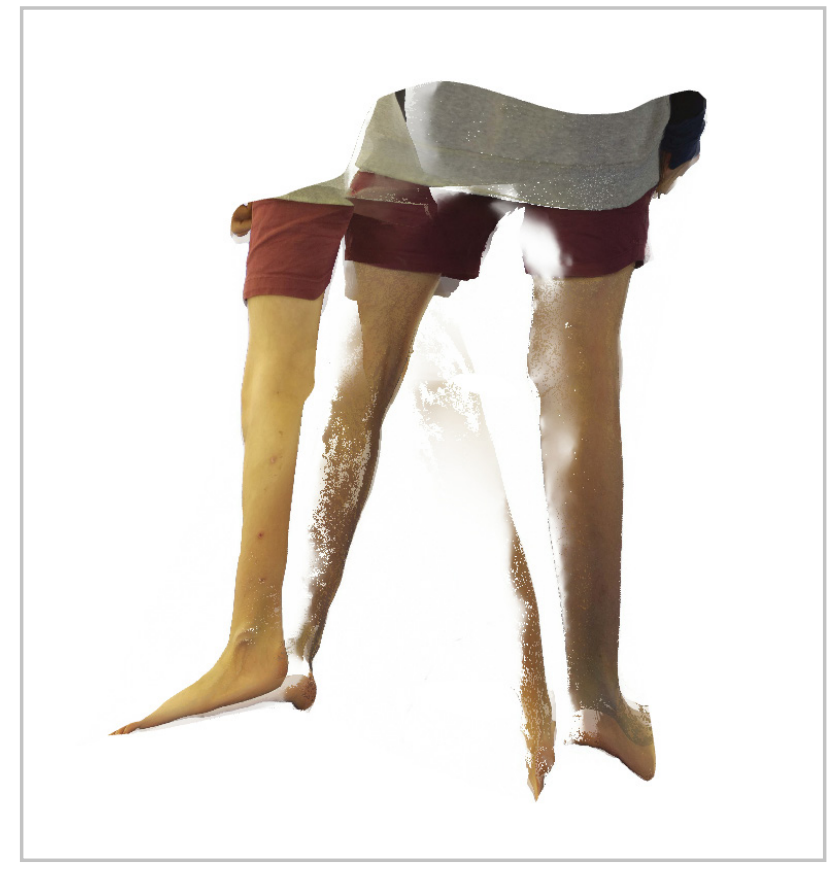

Figure 89. Participant three generated model (background removed).

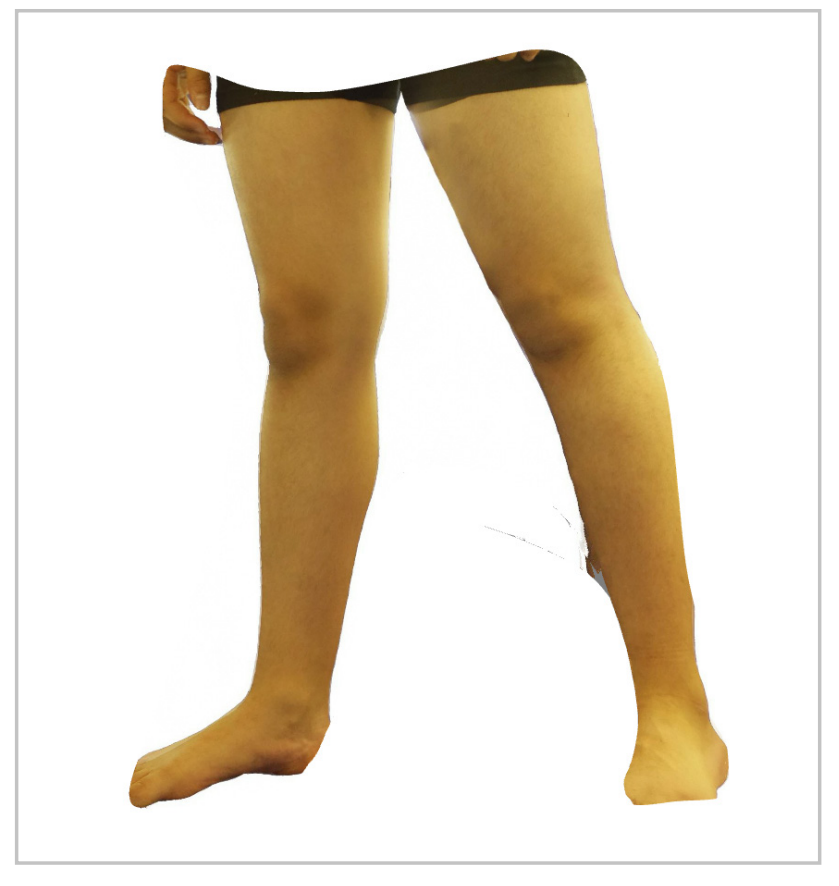

Figure 90. Participant four generated model (background removed). 


\subsubsection{Final prototype}

A full-scale, photogrammetry scanner prototype with the intention to facilitate digital data generation, and address the experience of users was created through a professional manufacturer (Appendix 8).

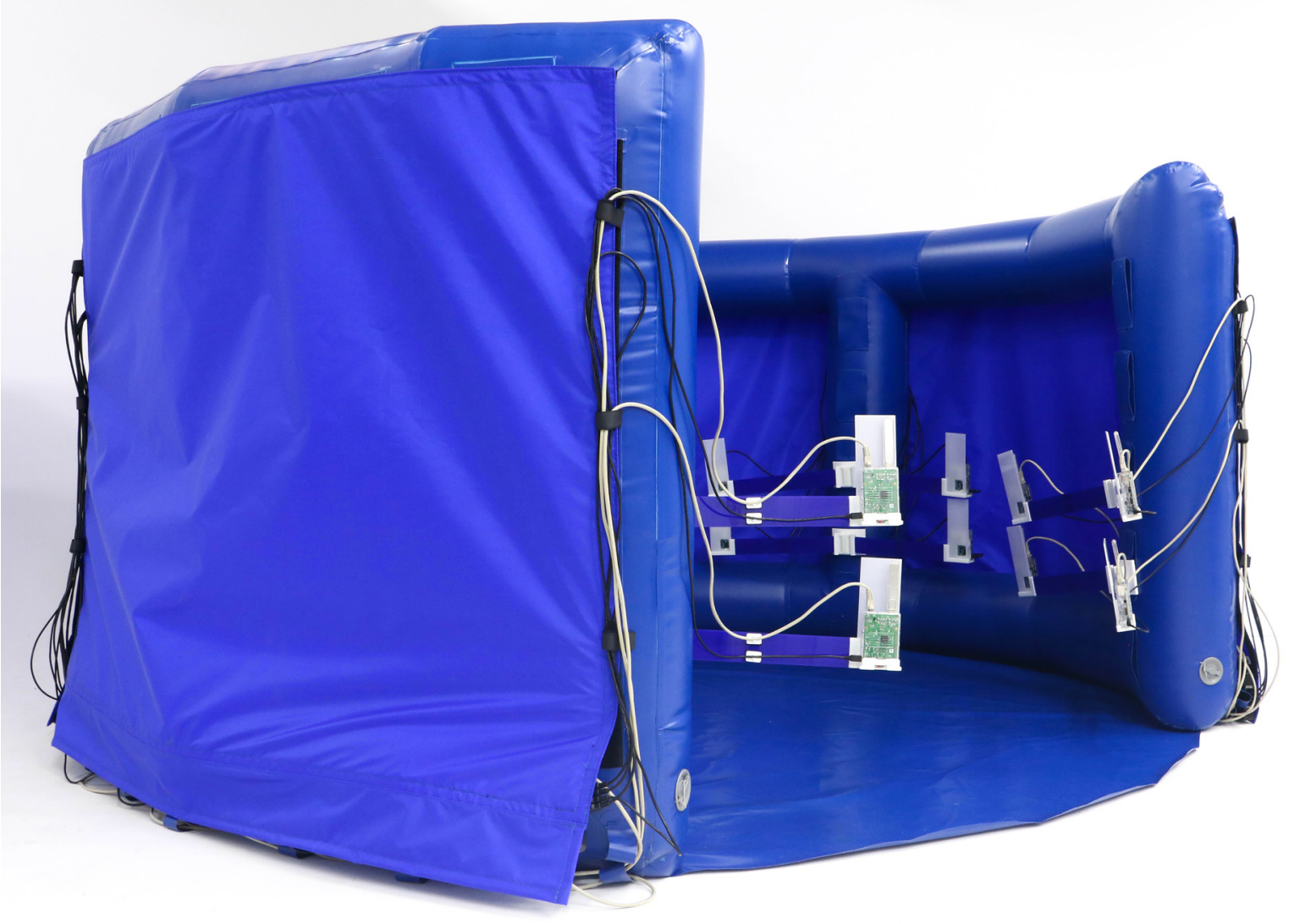

Figure 91. Fully assembled inflatable scanner.
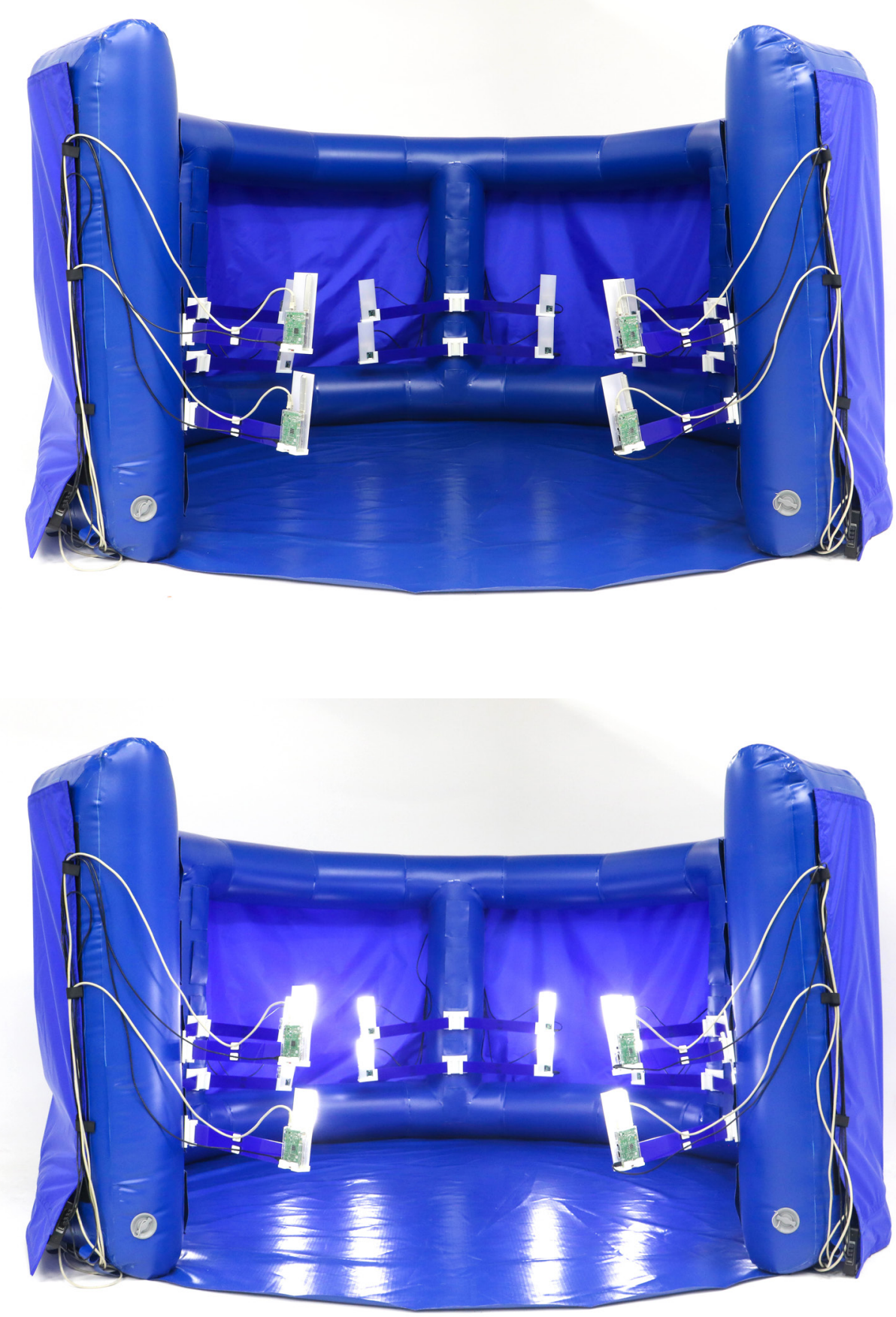

Figure 92. Comparison of scanner when off and on. 


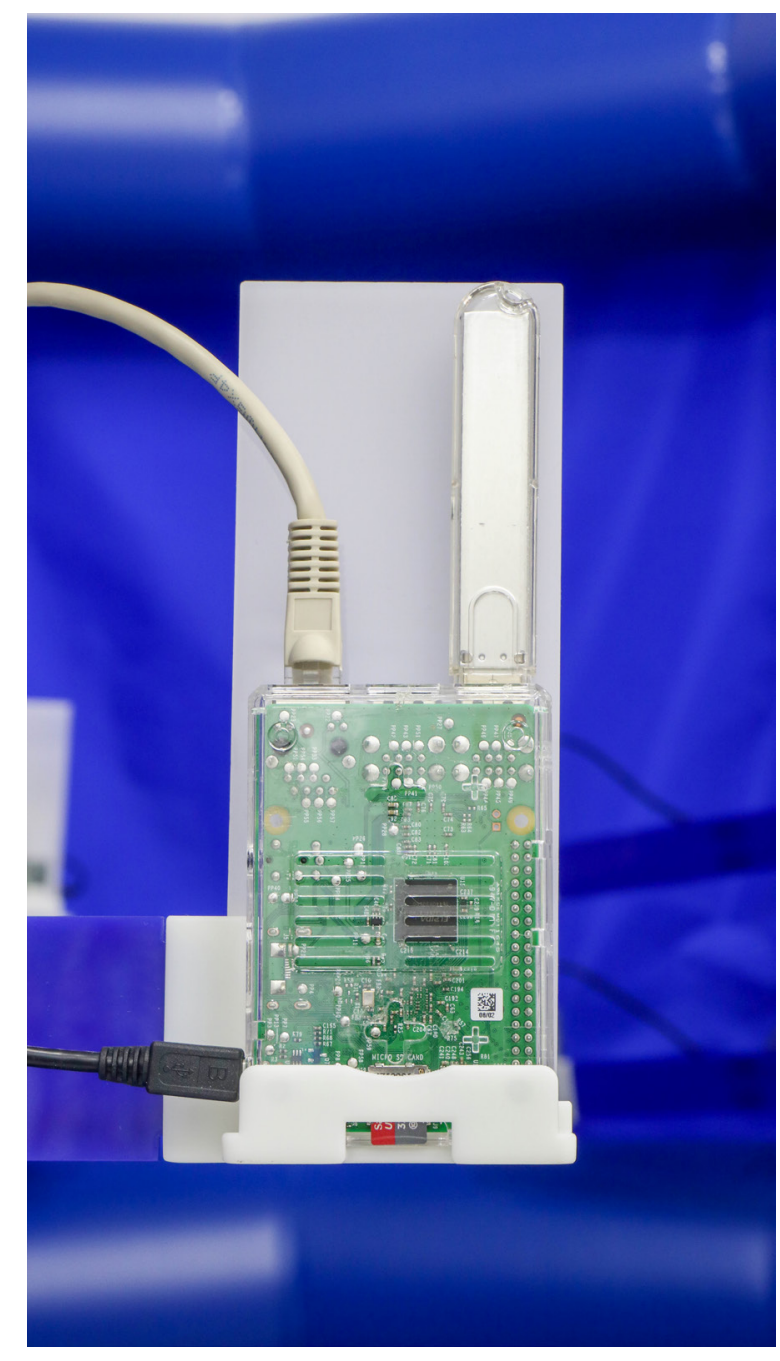

Figure 93. Camera housing and cable management details.

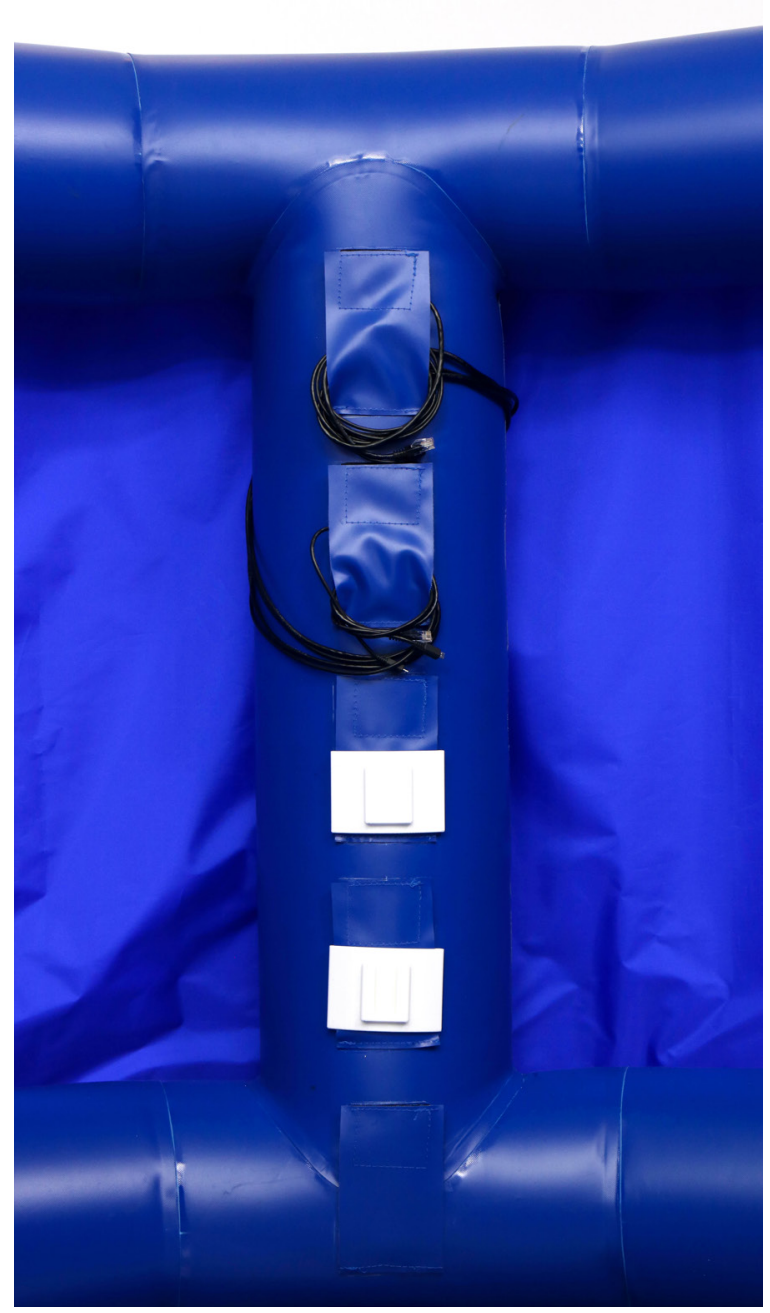

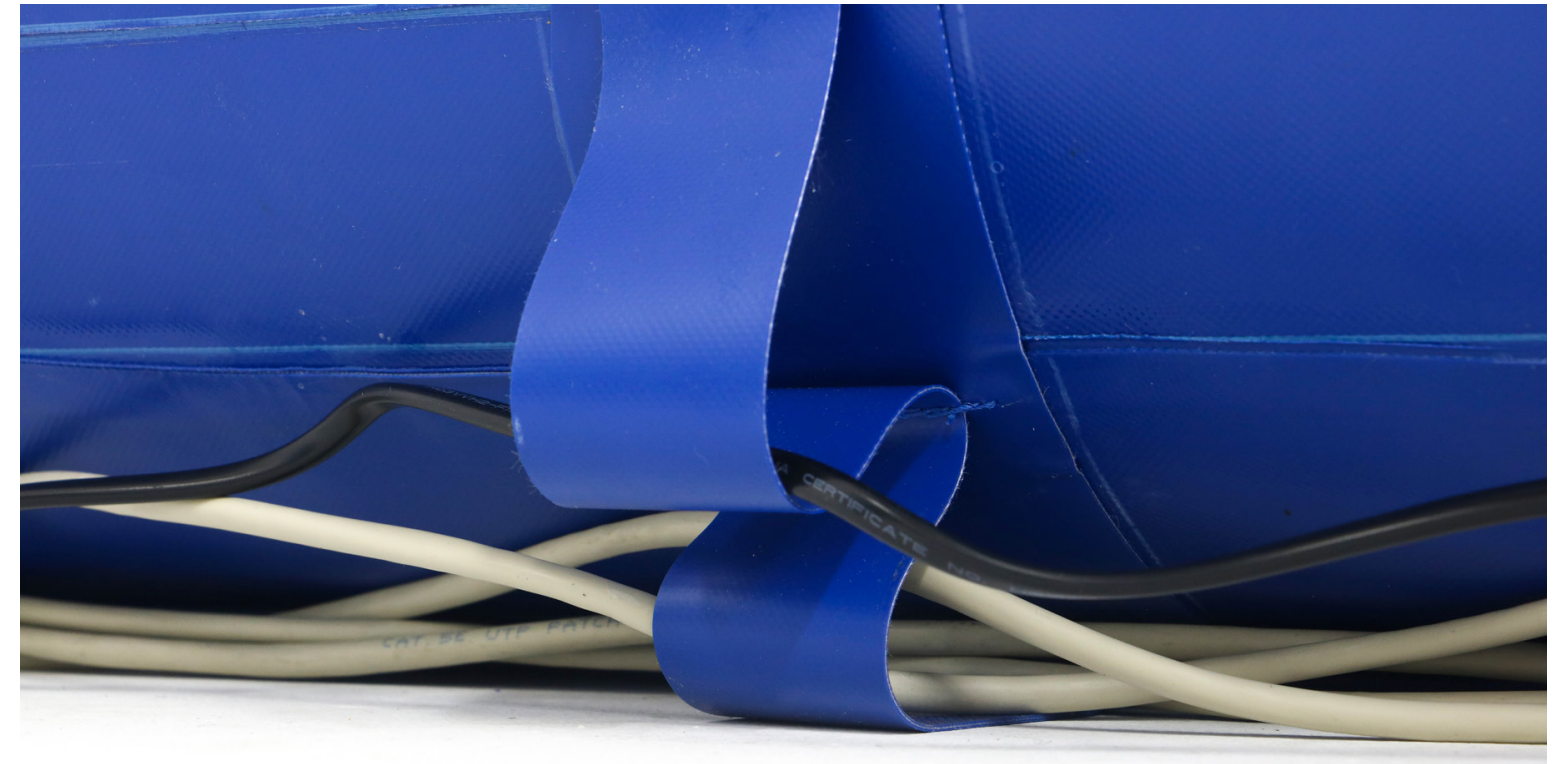

Figure 94. Close up of integrated cable management.

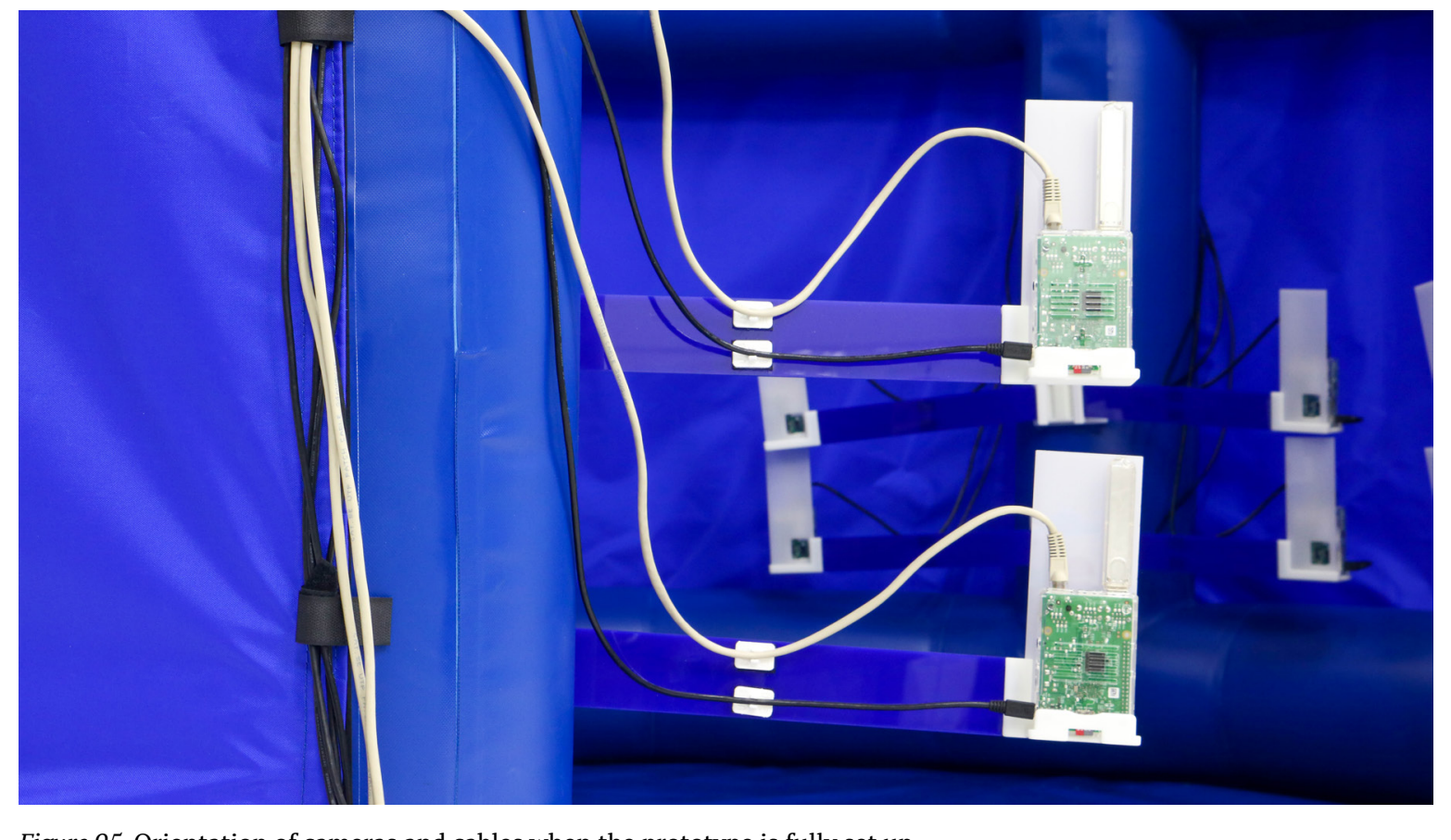

Figure 95. Orientation of cameras and cables when the prototype is fully set up. 


\subsubsection{User journey}

Generated from the simulated assembly and scanning test sessions is a final user journey visualisation showing the intended process of use for both operator and patient.

\section{A. transport}

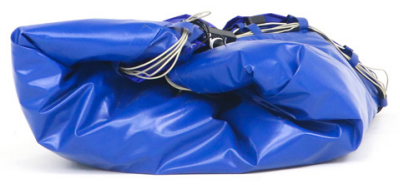

Scanner bundled up for transport/storage

Figure 96. User journey visualisation.

\section{B. assemble}

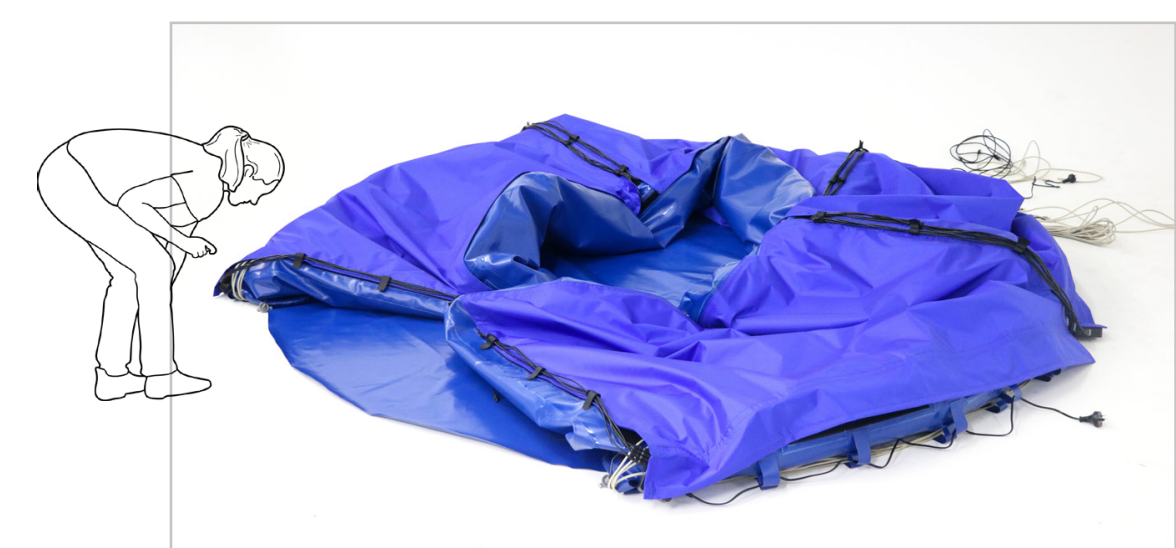

Unfurl inflatable structure

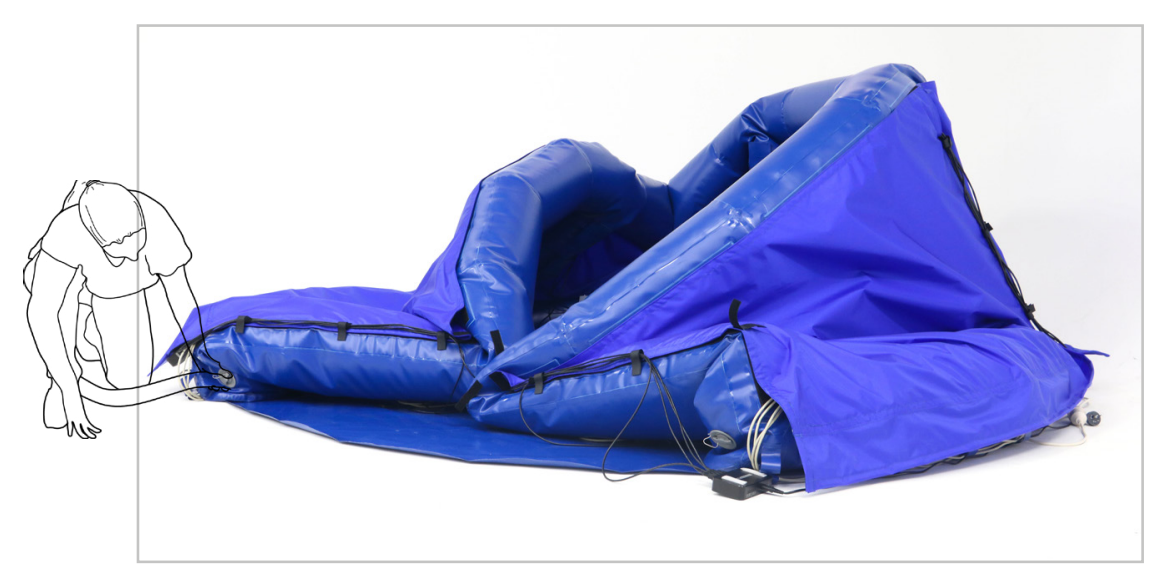

Inflate scanner

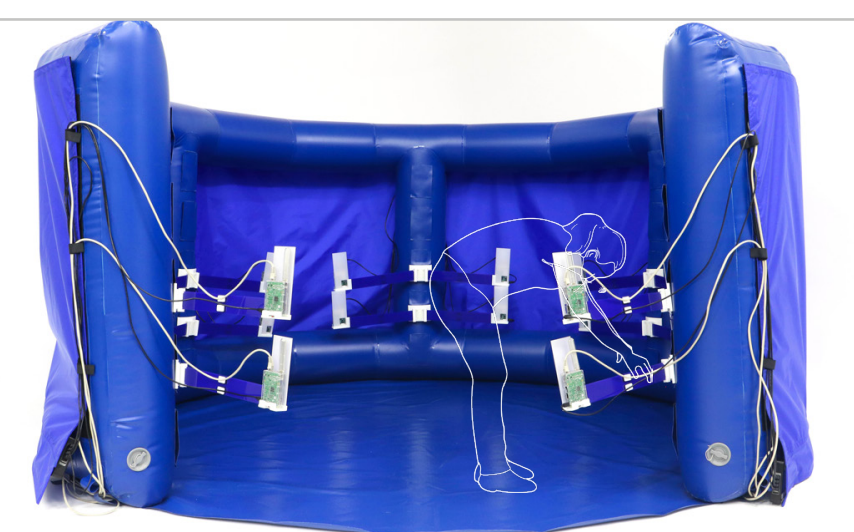

Attach hardware, then 'plug and play'
C. scan

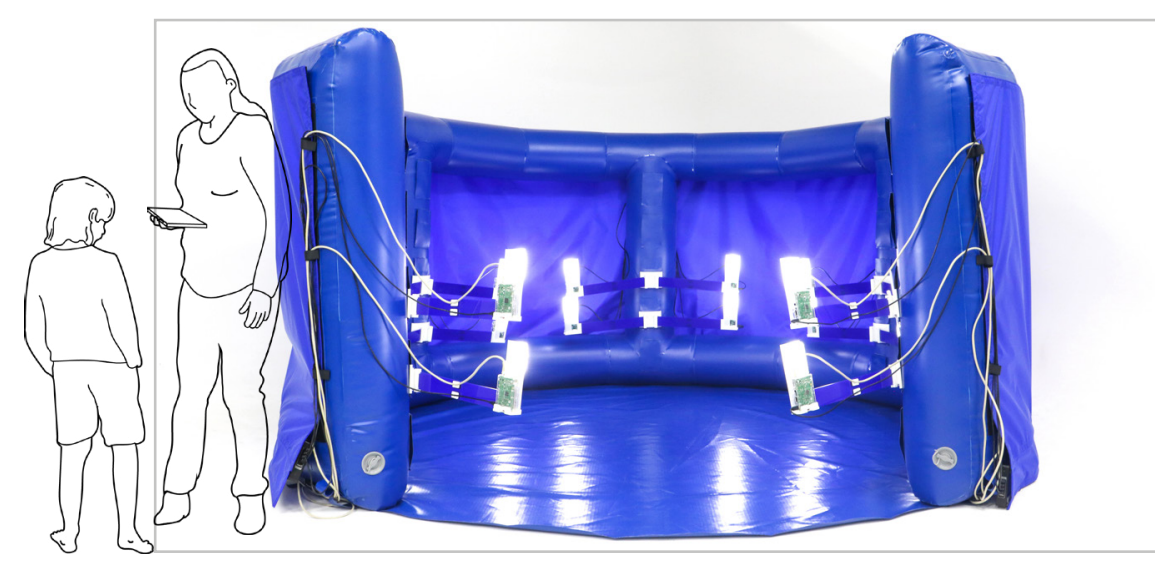

Introduce patient to scanner and scanning procedure

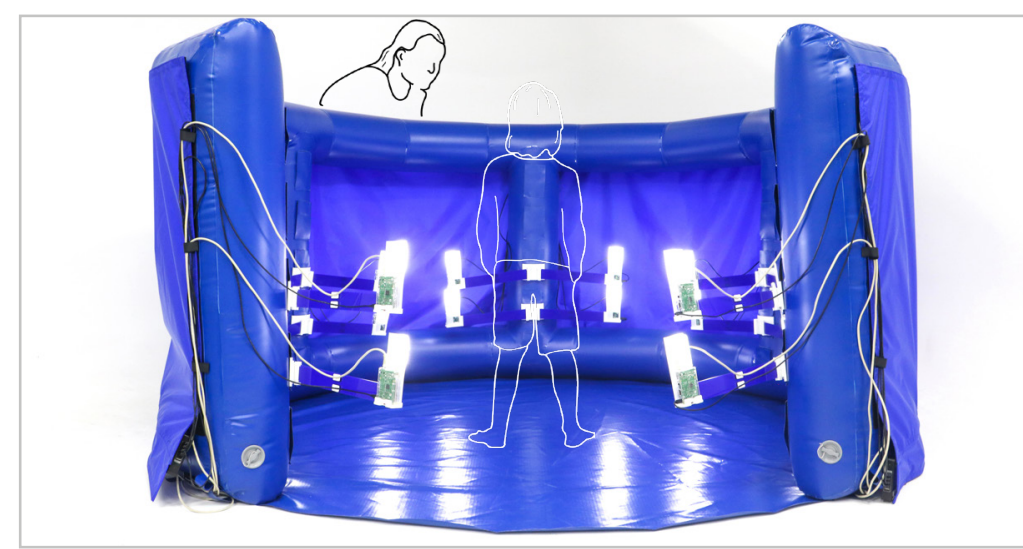

Position patient into load bearing stance, then scan 

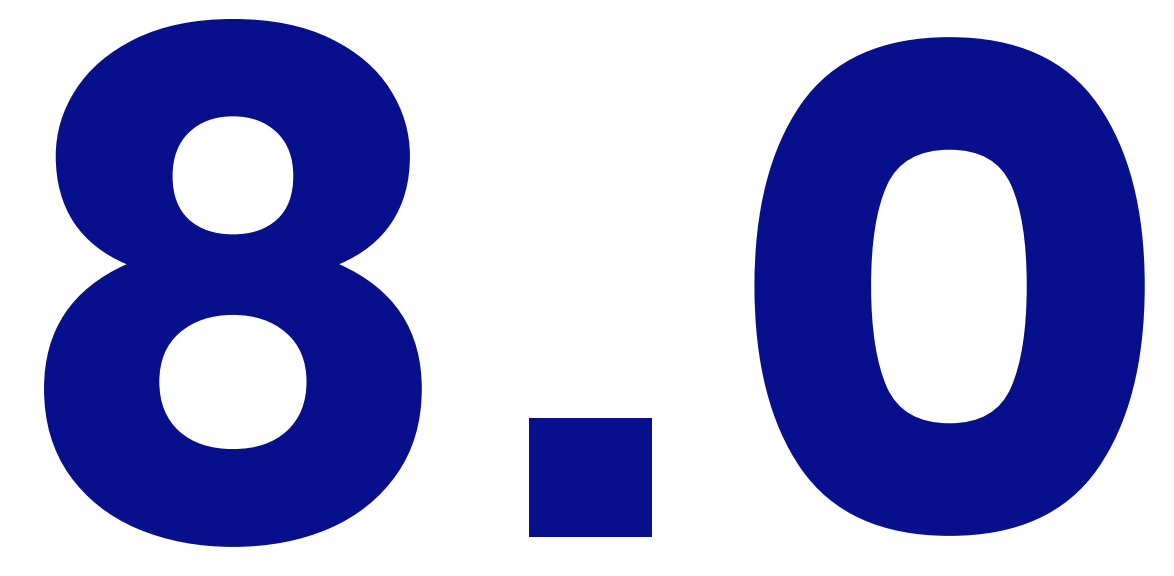

\section{DISCUSSION}

This chapter discusses findings from the final evaluation of the prototype, and makes references to previous research. Also

discussed are the limitations, implications, possible improvements

and future research opportunities. The applications of the

photogrammetry scanner and its design development is also

analysed, in the continual exploration of photogrammetry systems

for digital orthotic creation. 


\subsubsection{Final evaluation}

\section{Assembly}

During the formative evaluation of the prototype, the observed assembly process was different to the one proposed, however, the feedback given was overall positive. While the observational findings and analysis of opinions indicate future exploration and development. The following three key features were identified; cable concealment, plug and play assemble, and inflation.

The concealment and integration of a large portion of the cables into the structure of the scanner (Figure 97) was reported to be surprising, noting “I didn't think you would be able to hide the cables so well...yeah, it's very nice.” This greatly reduced assembly time and any difficulty the operator may have experienced. The 'plug and play' style of attaching components, and the ability to customise vertical camera position (Figure 98) were noted as: "They were pretty easy to fix. And it was pretty straightforward to move up and down the connectors onto the tubes.” This allowed for quick component assembly. The use of inflation as the primary method for structure assembly (Figure 99), and the speed it was completed in, impressed the collaborator. "Very good. I liked that inflatable, uh thing. Makes things much quicker." These features allowed the collaborator to quickly and with little hassle, assemble the scanner by themselves in less than one hour.

As noted, beyond what has been produced, there is still space for future improvements Consideration into the connecting contact points within the structure could improve the positioning of cables (Figure 100) "I think it would be wise to put the cables that connect to the left camera on the left side and the cable that connects to the right camera on the right side of the tube." Second, the camera arms still bowed, so a sturdier surface was suggested to better support the camera arms (Figure 101). "Maybe having a metal bar, that you strap. And then you clip this one on the metal bar so that maybe it stays more put." Third, the point of contact between structure and inflation device should be better considered (Figure 102). "Because you have to hold it. But at one point the thing moved when it was going up and I lost the entry and I couldn't find out where it was. Well, till I found it. But yeah if you just connect and then leave it."

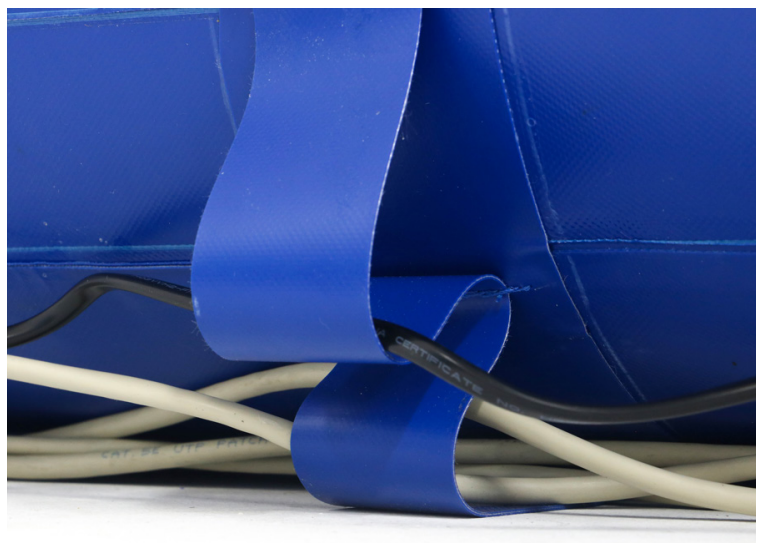

Figure 97. Hidden cable and cable management solution. Figure 98 . Changing camera mount height. Copyright 2019 by Senai Leniston-Kahsai.

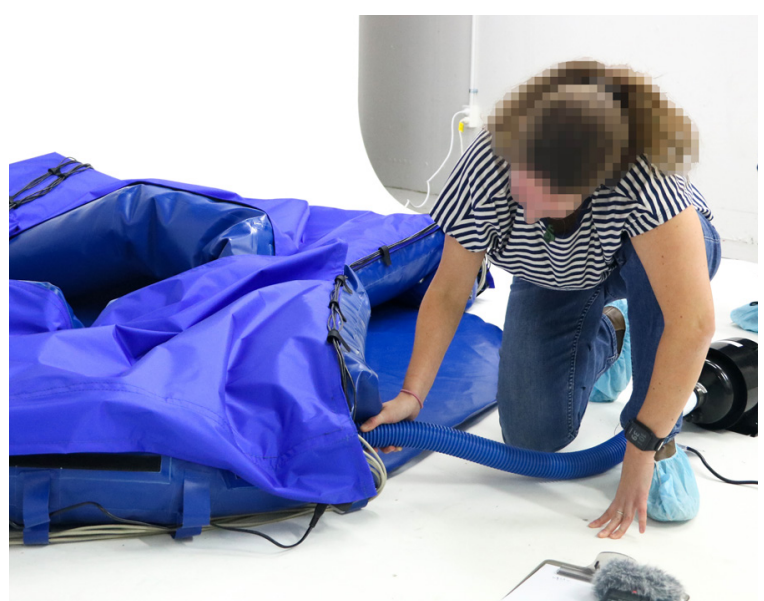

Figure 99. Inflation of the scanner structure. Copyright 2019 by Senai Leniston-Kahsai. easier assembly.

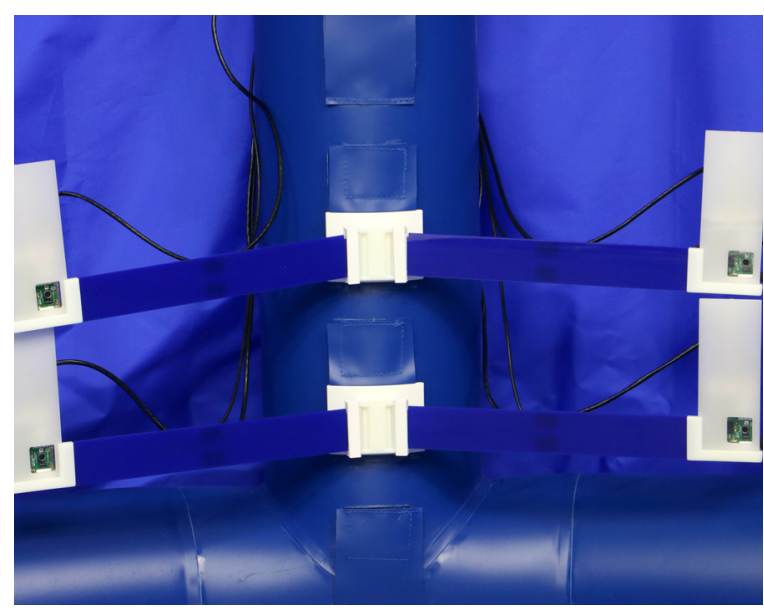

Figure 101. Bowing is still present in the camera arms.
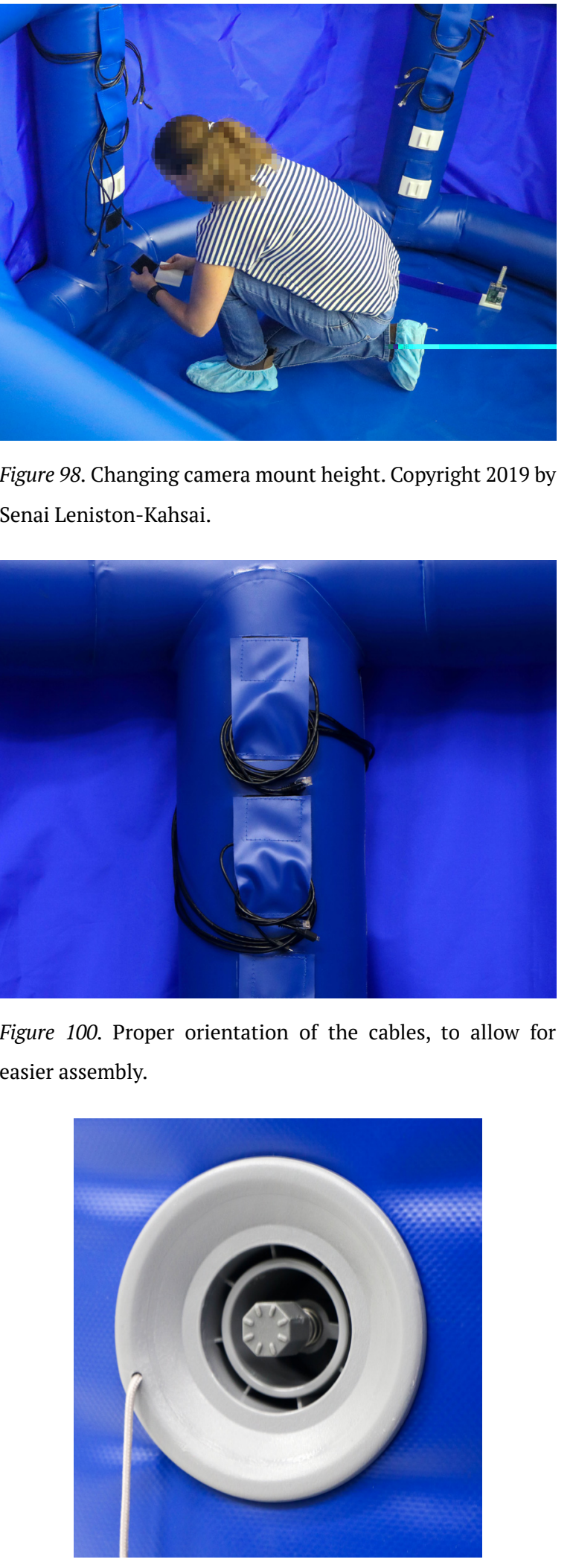

Figure 102. Manual connection point to inflatable structure. 


\section{Assessment and evaluation against criteria}

Novel scanner development

LOW MED HIGH

The inflatable form should balance manufacturing constraints and project needs

$\bigcirc \bigcirc \bigcirc \bigcirc \bigcirc \bigcirc \bigcirc$

The design should allow research-project-provided hardware us

$0 \bigcirc \bigcirc \bigcirc \bigcirc \bigcirc \bigcirc$

The design should facilitate a digital AFO work-flow

$\bigcirc \bigcirc \bigcirc \bigcirc \bigcirc \bigcirc \bigcirc$

Assembly

The assembly process should follow a 'plug and play' style

$0 \bigcirc \bigcirc \bigcirc \bigcirc \bigcirc 0$

The scanner structure should use as few components as possible $\bigcirc \bigcirc \bigcirc \bigcirc \bigcirc \bigcirc$

The design should integrate easy-to-use and understandable $\bigcirc \bigcirc \bigcirc \bigcirc \bigcirc \bigcirc$ cable management

The design should be easily assembled in under one hour in $\mathrm{O} O \mathrm{O} O \mathrm{O}$ different clinical environments

\section{USABILITY}

The design should allow systematic custom vertical orientation $\bigcirc \bigcirc \bigcirc \bigcirc \bigcirc \bigcirc$ of cameras

\section{Aesthetics}

The design should create an easy-to-understand experience $\mathrm{O} O \mathrm{O} O \mathrm{O}$ through familiar actions, and visual guide

\section{Technician experience}

The design should allow for easy set up and potential storage

$\bigcirc \bigcirc \bigcirc \bigcirc \bigcirc$

\section{Scanning}

Operating technician experience

Based on the observation and notes taken during the four sessions, it was concluded that the scanner successfully facilitated clear operation, and communication between operator and patient. Despite the cluttered nature of the operating hub (Figure 104) the overall design of the scanner itself was observed to not have interrupted the operator, or the tasks performed. For example, the patient was required to stand in a loadbearing stance. The scanner's height not only provided optimal scanning coverage, but allowed the operator to visually assess the participant's stance, and verbally advise accordingly (Figure 105). Following this, easy interaction occurred between operator and participant via communication this way. This allowed participants to be engaged, while ensuring the operator successfully completed scanning.

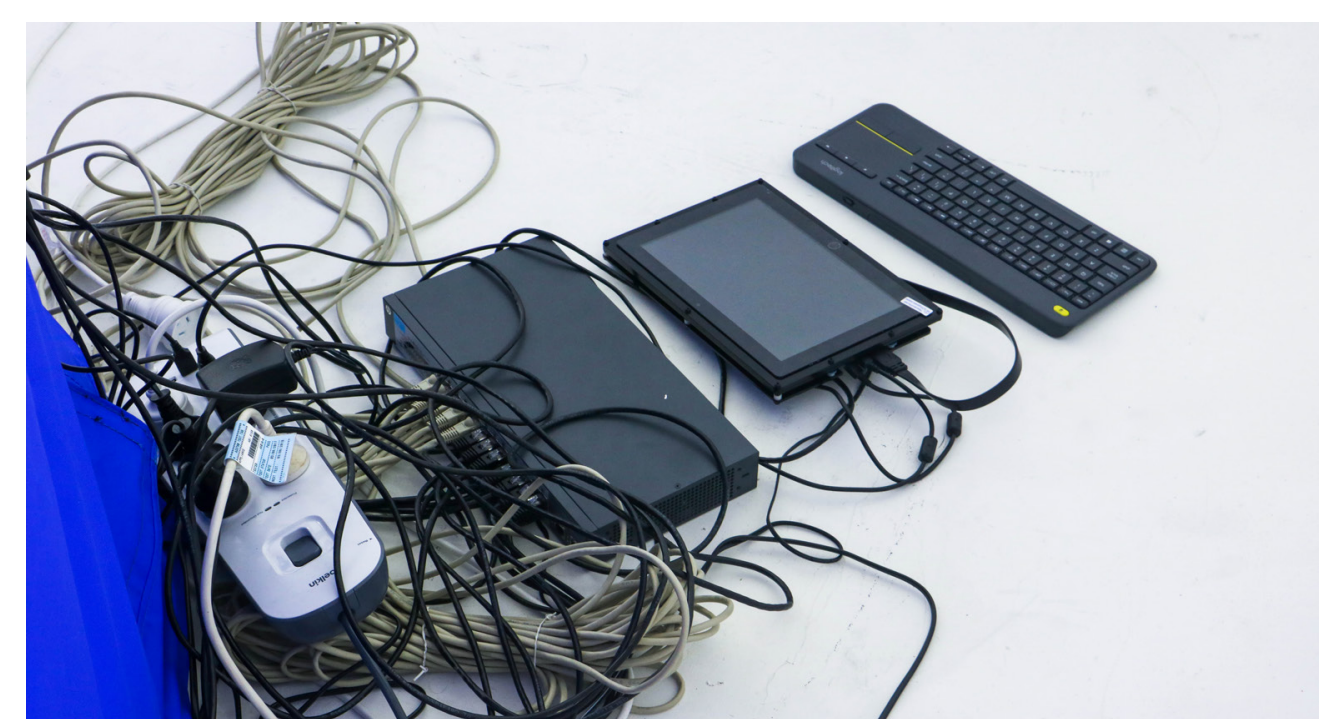

Figure 104. State of operator hub.

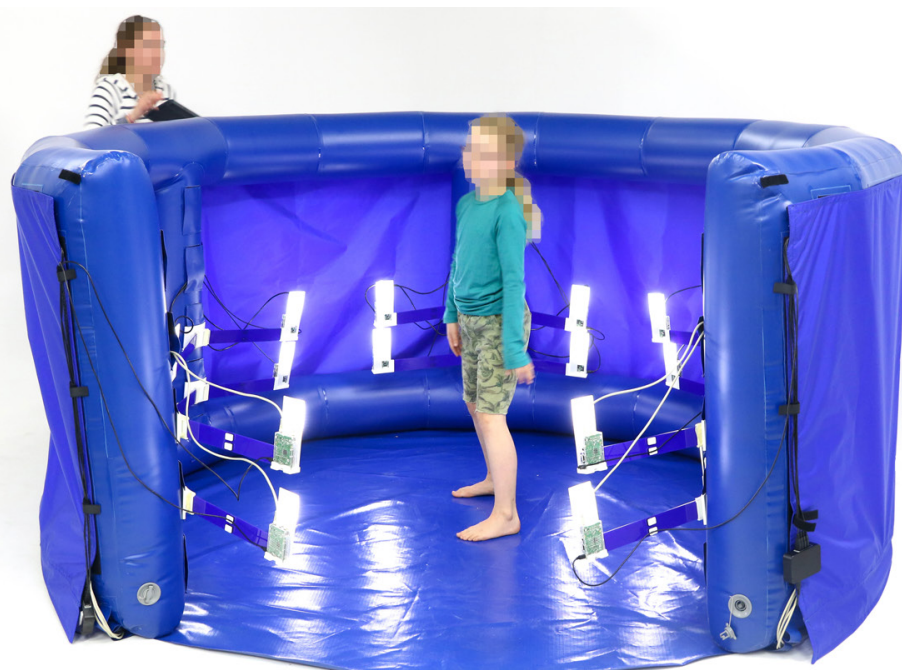

Figure 105. Interaction between participant and operator. Copyright 2019 by Senai Leniston-Kahsai. 


\section{Patient experience}

Data generated from the observations and SSIs indicated that the scanner was for the most part, successful in addressing criteria related to patient experience. The common attitude amongst the participants was that the scanner structure, and scanning procedure: were easy to use and understand; were not what was expected; looked like a bouncy castle; and did not function as first thought.

First, the majority of participants reported a positive experience when entering, standing, and exiting the scanner, describing it as safe, fun, or indifferent . However, Participant Three also commented feeling "weird" inside, explaining that it was due to the Raspberry PI circuitry. Participant Two felt "nervous", as they entered the scanner, and "strange" while inside, due to the new nature of the scanner, and their uncertainty of the procedure. Highlighted by all participants was how the prototype's design was not what they had anticipated. When asked, they disclosed that they expected the prototype to be smaller in size and not inflatable. However, when prompted further, this was not perceived as a negative feature, evident in similar comments amongst three of the participants that the prototype looked like a bouncy castle:

"Um, when the blue thing, I thought it was one of those bouncy castle things." (participant one)

"And I thought that it looked a bit like a bouncy castle also." (participant two)

"That it was like uh, kind of a bit like a bouncy castle, but not really bouncy." (participant four)

This finding is of particular relevance for this study. It was found through follow-up prompts that the colour, enclosure material, and inflation of the scanner influenced their opinion. Since the design allows for easy set up, storage and provides a familiar and fun connotation for children, helping them have a more positive experience in the scanning procedure. The majority of participants identified that to improve the experience an inclusion of interactive features within the scanner design was needed. This was deduced from evaluating suggestions given by participants:

"It would also look cool like, you had, like, little smiley faces on the cameras, so it would look really cool, and funny...” (participant one)

"That it would be a bouncy castle and you could just do whatever you like and it would just go around doing and it would actually do the whole thing and then maybe like it would take ages and you just see lots of your legs just going everywhere. That would be cool" (participant two)
"That the floor would be a bit bouncy...but not that you'd bounce in it...like a tiny bit more like the walls" (participant three)

Despite only needing to interact the prototype for a short period of time, to improve the user experience, more interactive features need to be included.

\section{Assessment and evaluation against criteria}

Photogrammetry scanne

LOW MED HIGH

The design should facilitate quick patient scanning

Novel scanner development

The scanner interaction should consider use by patients age between $1-16$ years old

$\bigcirc \bigcirc 0 \bigcirc 0 \bigcirc 0$

The design should allow the patient to be positioned into a loadbearing stance

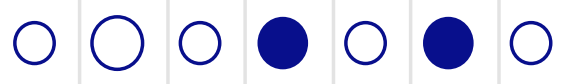

USABILITY

The design should create a clear and easy entry and exit point for patients to move through

The design should provide patients with balancing issues support before, during, and after use

\section{Patient experience}

The design should create a positive user experience potentially through familiarity and fun connotations, and not evoke negative responses

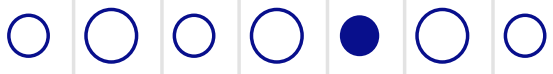

Figure 106 . Assessment against user experience related criteria. 


\section{Generated surface models}

The models produced show uneven and broken surfaces, unusable for its intention of analysis in the generation of custom AFOs. The generation of imperfect models can be due to inadequate lighting, but when evaluated against models previously generated from the pre-existing prototype's lighting, the scanner still partially facilitated the generation of models in comparison. However, compared to those generated by the previous work done in the project, and even against the LED strip tests, it can be seen that those solutions, though not perfect, were better at illuminating the subject, instead of the final chosen one.

As well, software issues could have been a contributing factor. For example, not enough images were produced, due to a malfunction during capture, even when a fix was attempted by the operating technicians. It was found that only 15 out of the required 20 were produced, meaning that full coverage of the participant was not achieved, resulting in inadequate camera coverage, and resulting holes. Also present were incorrect camera settings, where different values were present in settings such as brightness and white-balance, causing issues during image to model compiling.

In an attempt to make the most of the images generated, 5 images were duplicated in order to make up the 20 images needed for AutoDesk PhotoRecap to compile the images into a 3D model (Figure 107). The images duplicated were kept the same in each set, to try and maintain consistent results. As well, three sets of each participant image were produced; unedited, with the background removed, and with the brightness of the images altered. However, this still resulted in imperfect models, with some, such as participant four's unedited model failing to compile (Figure 111).

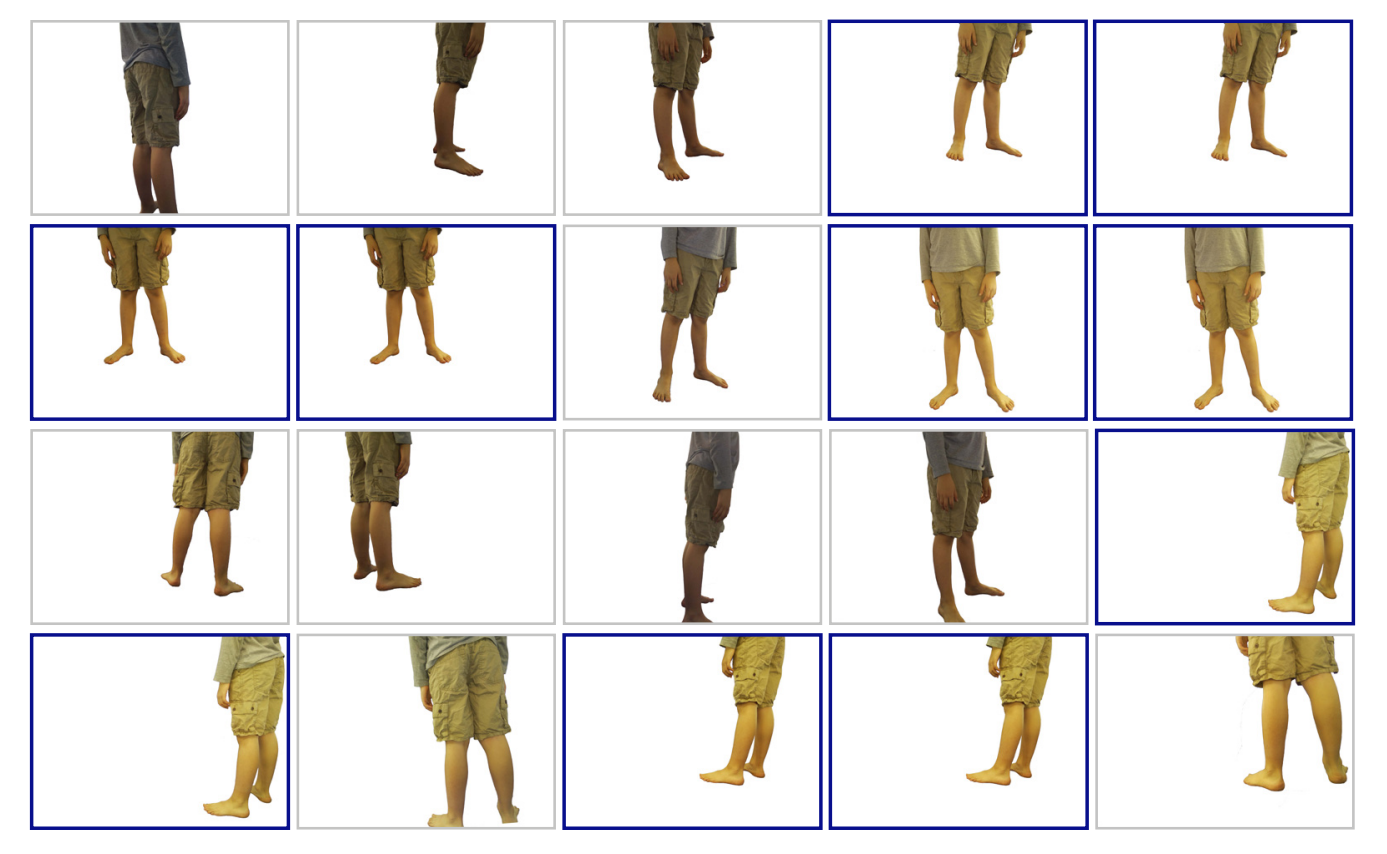

Figure 107. Participant one image set with duplicated images used to compile the images into a 3D model.
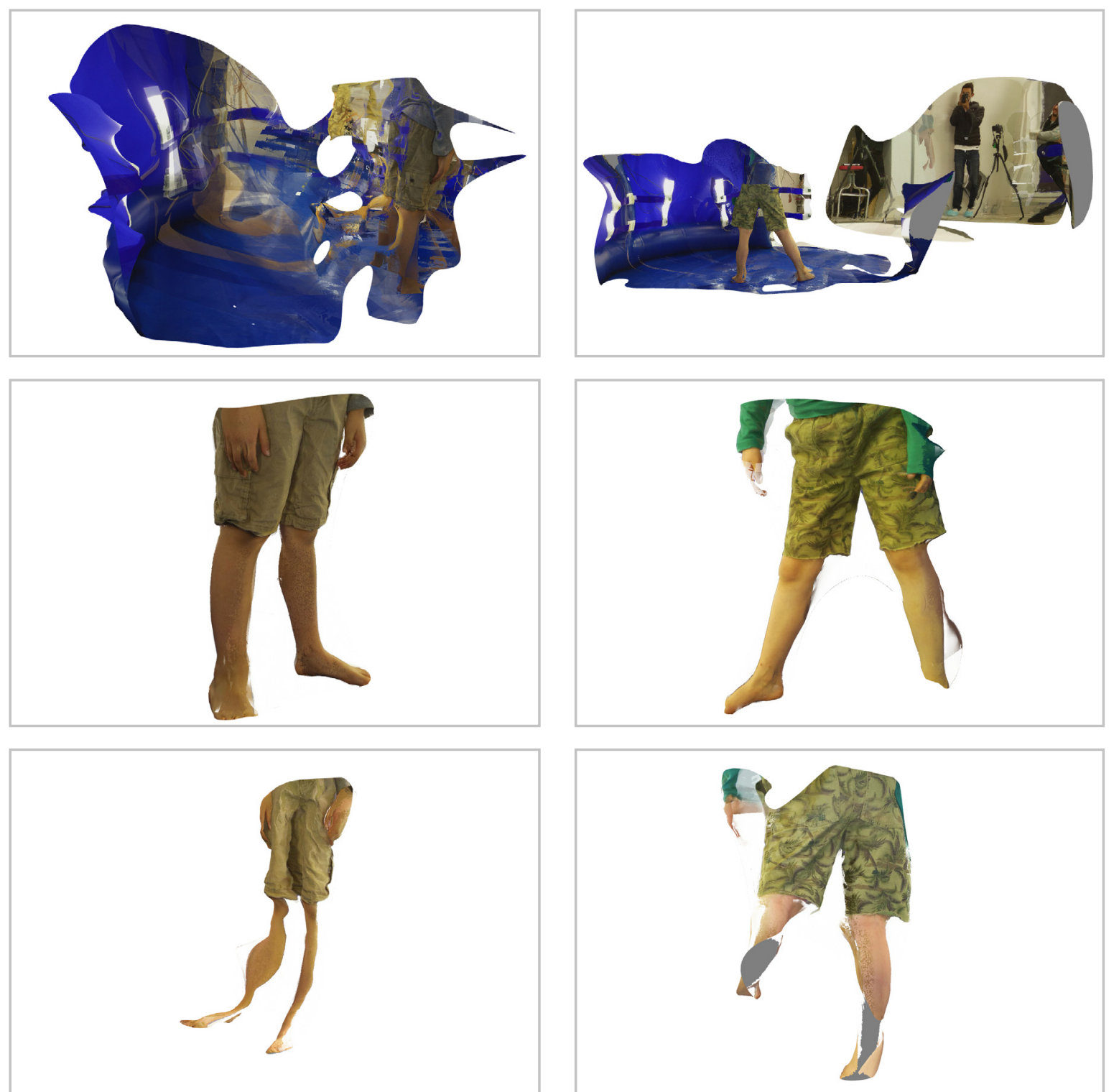

Figure 108. Participant one generated models: with background, without, and with images brightened by $90 \%$

Figure 109. Participant two generated models: with background, without, and with images brightened by $90 \%$. 

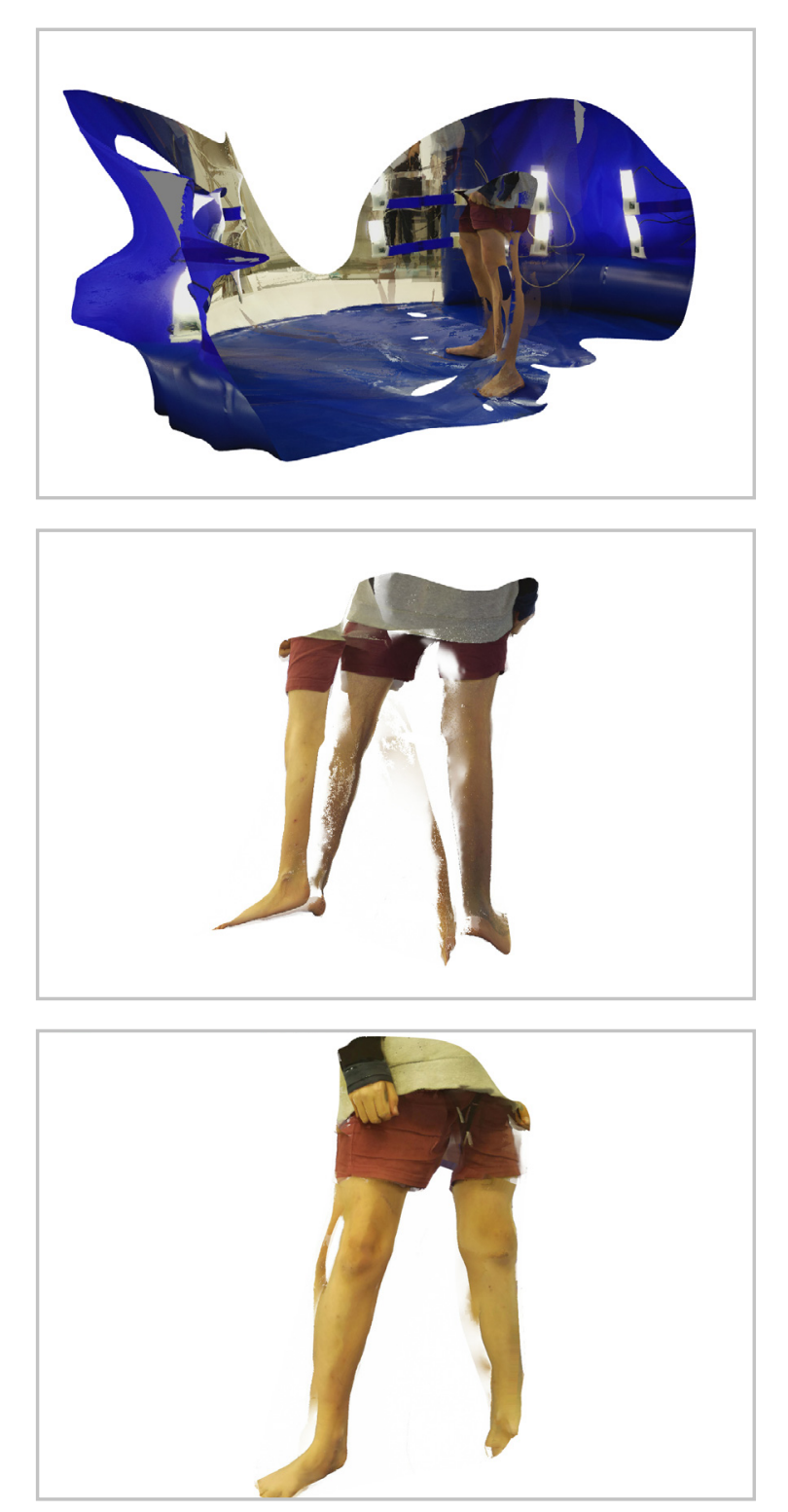

Figure 110. Participant three generated models: with background, without, and with images brightened by $90 \%$
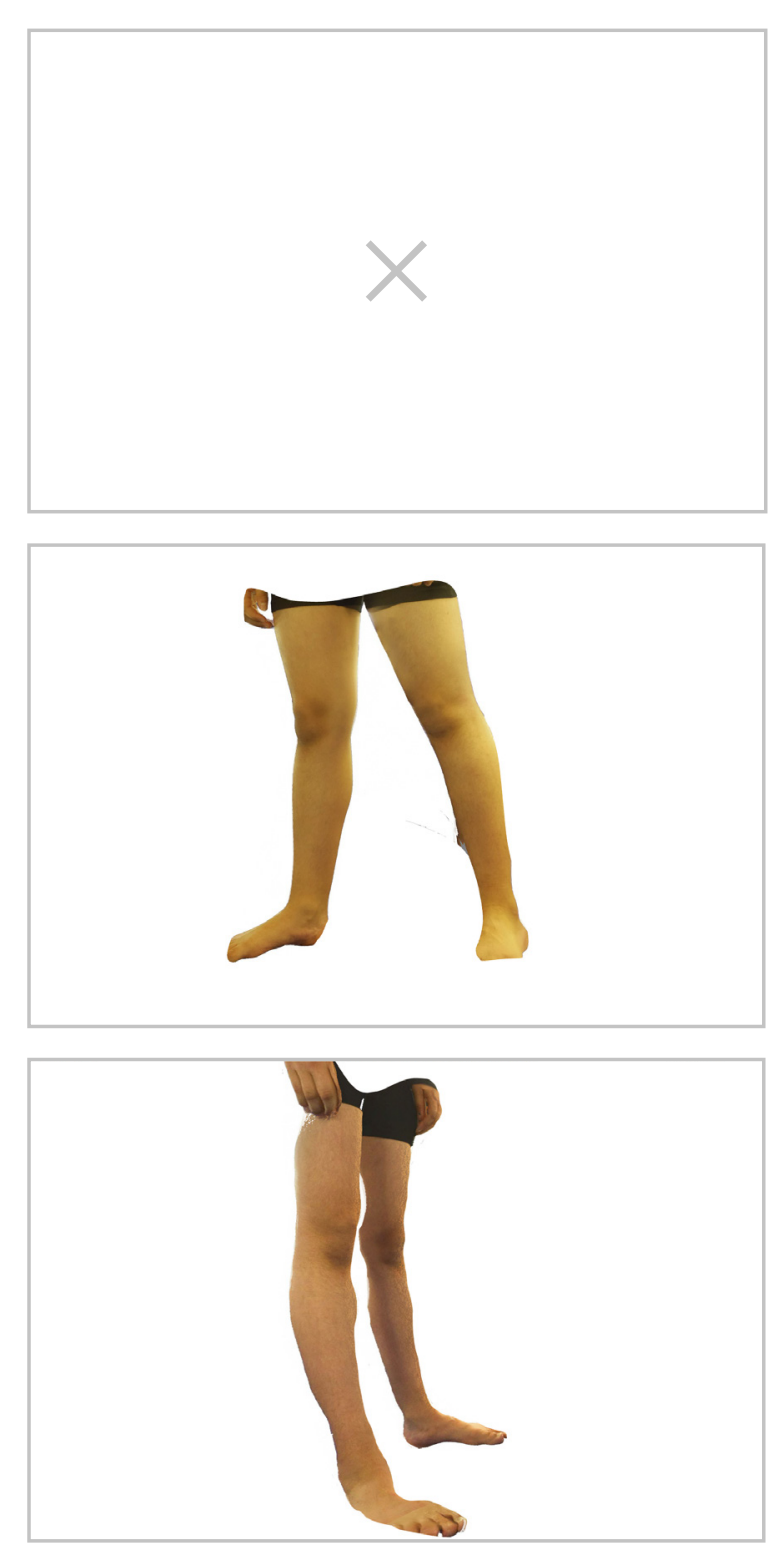

Figure 111. Participant three generated models: without a background, and with images brightened by $90 \%$.

\section{Assessment and evaluation against criteria}

\begin{tabular}{|c|c|c|c|c|c|c|}
\hline CRITERIA & \multicolumn{6}{|c|}{ SUCCESS SCALE } \\
\hline Photogrammetry scanner & \multicolumn{2}{|c|}{ LOW } & MED & \multicolumn{3}{|c|}{ HIGH } \\
\hline The design should facilitate optimal uniform lighting & $\bigcirc$ & & & 0 & & 0 \\
\hline \multicolumn{7}{|l|}{ Novel scanner development } \\
\hline The design should allow for camera overlap & $\bigcirc$ & & 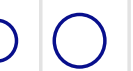 & ○ & O & O \\
\hline \multicolumn{7}{|l|}{ Aesthetics } \\
\hline $\begin{array}{l}\text { The design should create a clear and easy entry and exit point for } \\
\text { patients to move through }\end{array}$ & O & & U & O & O & O \\
\hline
\end{tabular}




\section{Implications}

Design for an easy user experience

A major finding during the development period of this research was a consistent need to explore and develop solutions through design decisions that focused on making them simple and easy to understand. This finding reflects the absence of user-experience exploration in past photogrammetry scanner, but the importance of designing for users, highlighted in the literature and precedent review (Hunfeld \& Passchier, 2012; Mitchell \& Newton, 2002), and the positive effects from assessment and discussion of previous work within the larger project.

Give equal attention to different user needs

Based on conclusions drawn from analysis of solutions, focus should be balanced equally between different user base needs. This is in relation to how the experience of patient users was sometimes second to operating technicians' during design development. For example, when exploration into patient support solutions was stopped, going against the identified importance of considering the patient and their needs, especially in photogrammetry systems (Mitchell \& Newton, 2002).

\section{Form often followed function}

The focus on user experience, especially in regards to those identified in the constraints and initial criteria of chapter four for operating technicians, resulted in the form of the scanner often following its function. This was present in the development and exploration period from its onset, such as how exploration of rigid but expandable solutions in design phase one, transitioned into flexible inflation solutions to address assembly and hardware related criteria in design phase two.

\section{Inflation is unique but not perfect}

From the prototype's formative evaluation, findings highlighted the 'bouncy castle' like aesthetic, and associated connotations, engages with the user's in a positive manner, making them more comfortable with the system, and the idea of future scans. However, inflatables is not a suitable solution as a permanent structure, as the idea of keeping it inflated for convenience was suggested. But it was found that the structure deflates overtime.

\section{Applications}

The findings generated can be used for the continual future exploration and improvement of photogrammetry scanners for use in the field of medicine and orthotics. While past studies focused on the low-cost design of photogrammetry scanners, the outputs generated, or both. This research primarily focused on the experience of users, with some focus on the generation of models. Therefore, the value of this research is it presents findings of the design and the development of an inflatable photogrammetry prototype with emphasis placed on the user experience throughout the process, and how novel solutions such as inflation can address and heighten user experiences. Rather than as a cost saving measure.

\section{Limitations}

Limited exploration

The large scale nature of solutions present throughout the design development often limited exploration and assessment. This is because of the required resources, skills, and lead time needed to generate each concept. This was ineffective in phases that called for quick generation of low fidelity ideas. Such as in design phase two, where high fidelity inflatable prototypes, requiring professional manufacturing and long lead times, even for early idea exploration, were required to facilitate proper assessment. As a consequence, design decisions were sometimes based simply on the subjective assumption that a particular idea would work better then others. Whereas othe times decisions relied on the assessment of sketches, and insight from professionals.

Insufficient exploration of large scale experiments generated a limited amount of testable prototypes available for assessment, which were often hindered by componen materiality and construction methods used to offset as much of the concept lead time as possible. This in turn impeded concept performances in cognitive walk-through or user testing session, potentially skewing the findings. This was a consistent issue through the design development.

Limited user testing

This was further exacerbated by limited access to the research project participant with Spastic $\mathrm{CP}$, which was a result of factors such as conflicting schedules and concern for their health. Therefore despite testing with alternative, but appropriately aged participants, their assessment may not have the same focus as users with Spastic $\mathrm{CP}$, and so, it can be concluded that the prototype cannot be fully assessed until tested with a user with Spastic CP.

This Masters portfolio did not conduct human factors validation testing, in which there is an expectation to test with participants that represent the intended users of the photogrammetry scanner (CDRH, 2016). This is a vital step in validating the use of the design in a medical setting, and it is necessary to obtain certification from, for instance, the Food and Drug Administration (FDA, USA). However, the test requires a substantial number of participants from each group of representative users (clinicians, technicians, patients) and a large amount of resources in time and 
analysis. This is outside the scope of a Master's portfolio. However, the findings from this portfolio do inform the FDA process, because a safe and usable prototype, that can be taken into the next stage of research and further developed and tested for human factors validation, was created. A human factors validation test's scope is closer to the scope of a $\mathrm{PhD}$ project, and this project represents a necessary basis for the future development of the larger project.

\section{Improvements}

As noted by Chen et al, in order to benefit from the digital methods of photogrammetry generated models for 3D printing AFOs, "a software platform tailored for AM of O\&P is required" (p. 86). A developed digital work-flow therefore can allow for easier implementation of digital methods later on. But a work-flow that correctly optimises camera settings to a lighting solution, while systematically, quickly, and accurately processes generated images into digital models, would allow solutions that could address issues in the generated models as they appear. As well as eliminating software as a contributing factor to the models' quality, allowing focus to be placed solely on physical design development.

\section{Extensions}

This research portfolio could not support explorations into some avenues due to the scope of the project, or time. However, the following suggestions can develop and refine the scanner, and as a result, better address the experience of users:

- The technician operating station was noted as being in a similar state to that of the pre-existing prototype. Future consideration is needed to address this.

- Further exploration should be conducted into engaging the young patients through fun and positive means, to further elevate their experience, and avoid negative ones, as noted by participant responses.

- The proposed assembly process requires refinement to aspects such as component placement and materiality to fully address criteria such as usability.

- Generated digital models were still distorted. Therefore, despite the chosen light solution addressing criteria related to ease of use, extensive lighting exploration is still needed before adequate model generation can occur.

- Patient support integration should be explored. It is an important aspect that could heighten patients' experience.

- A systematic method positioning the cameras to a desired position can optimis the use of the scanner, and be used for the range of heights $\mathrm{CP}$ patients between $1-16$ years old.

\section{Reflection}

The final output was a inflatable photogrammetry scanner that is partially prepackaged and designed to be 'plug and play', allowing it to be assembled quicker then previously explored solutions completed before this research. Its design wa developed based on criteria from findings generated throughout the research. Focus was on how the development and exploration of a photogrammetry scanner's design could address and explore user experience. It was found that focus tended to be on the user experience of operating technicians, and not on patients, or generating 3D models. However, it was found that addressing operating technician experience, simultaneously addressed patient experience. 


\subsubsection{Conclusion}

The research portfolio was a part of a larger project that aimed to create a novel work-flow to improve the generation of patient surface measurements and AFOs, through the digital methods of photogrammetry scanning and 3D printing. The focus of this portfolio was on the design of a photogrammetry scanner, developed through exploration and assessment in a multi-method RtD approach and pragmatic design framework. In order to answer the driving question of this research:

How might a photogrammetry scanner be designed to address the user experience of Spastic Cerebral Palsy patients in a load bearing stance, and operating technicians, during $3 D$ lower limb data generation?

This question and resulting design development decisions were based on current body of knowledge findings that highlighted an opportunity to develop a photogrammetry scanner. This is in response to a lack of evidence that any photogrammetry scanner focused on the user experience of $\mathrm{CP}$ patients and operator, in the generation of digital surface measurement models for custom $\mathrm{AFO}$ creation. This is despite the importance of considering the needs of vulnerable users such as children and adolescents with Spastic CP, for creating successful, and unbiased designs and procedures. Therefore, the final prototype, an inflatable photogrammetry scanner, offers a new and unique solution to fulfil and address this gap in knowledge.

The tangible solution of an inflatable, 1:1, fully-functional 3D scanner prototype offers a system that addresses different user needs. For clinicians and technicians, it offers an easy portable system that can be quickly assembled and disassembled thanks to the integrated cable management system and its inflatable qualities. This facilitates storage, as feedback from the bioengineer collaborator expressed that the space and laborious assembly that photogrammetry scanners require is currently a barrier to adoption, particularly for clinical settings that may carry out only a few scans every week, and may need to have them idle for long periods of time. The production costs for this scanner would be much lower and potentially around $1 / 5$ of current photogrammetry scanners, mainly thanks to the camera type used and its inflatable structure, while still offering good resolution for the digital manufacture of orthoses. This would make a system for digitally manufacturing orthoses much more feasible. However, some refinement and further design of the scanner, particularly around the hub for the technician to control the session, is needed. For patients, the inflation qualities of the scanner reminds children of a bouncy castle. The semantics of this familiar connotation can help children feel at ease and more comfortable with the procedure.
The resulting design of this Masters portfolio was assessed with children in a simulated-use testing as part of a formative usability assessment, as per the recommendation guidelines of the FDA. The findings indicate that its usability is high; technicians find it easy and quick to use and set up, and children view it with a sense of familiarity due to its inflatable and bouncy-castle-like characteristics. Future research stages can use this portfolio's findings to develop a new iteration that can be tested with children with $\mathrm{CP}$, as the safety and usability of the device need to be tested before exposing more vulnerable populations to it. Therefore, a $\mathrm{PhD}$ project could develop new iterations and test them with children with $\mathrm{CP}$ for clinical validation. This would require refinement of the camera and software arrangement, to ensure all the cameras are reliable, as some of our testing found that the cameras can disconnect without real-time feedback to the technician.

While the goal of the project was to develop a 3D scanner for manufacture of orthoses for children with $\mathrm{CP}$, the resulting design could be used for many other applications. Its cost and portability means that it could be taken to fairs where 3D scanning of visitors or other subjects could be relevant. It could also be used for sports equipment, where fit is important. Finally, its medical applications can span any medical condition where custom orthoses are required, including injuries, stroke rehabilitation and others.

This research portfolio can be used as a stepping stone in the continual research to improve photogrammetry scanning systems for use in custom AFO generation. By analysing the generated findings and conclusions, future research can build and improve upon areas of potential, and avoid areas of failures. As well, the inflatable photogrammetry scanner prototype and assessment findings can act as a startin platform into how the experience of users can be addressed in a scanner's design, and how well informed design decisions that consider user needs, can improve the usability and success of a medical device. 


\section{Reference list}

3DcopySystems. (n.d.). Big Alice. Retrieved July 12, 2019, from https://3dcopysystems.com/bigalice/

3DFY.ME. (n.d.). Our services. Retrieved July 12, 2019, from https://3dfy.me/?v=8e3eb2c69a18

3dMD. (n.d.). Static-3dMD Systems. Retrieved July 12, 2019, from http://www.3dmd.com/static3dmd_systems/

4Dmax. (n.d.). Bubble. Retrieved July 12, 2019, from http://www.4dmax.co.uk/services/bodyscanning-character-scanning/

Abas, E. E. E. (2013). Design and fabrication of ankle-foot orthoses through 3D scanning and rapid prototyping (Unpublished doctoral dissertation). UMP, [].

Adams, W. C. (2015). Conducting Semi-Structured Interviews. In K. E. Newcomer, H. P.

Hatry, \& J. S. Wholey (Eds.), Handbook of Practical Program Evaluation (pp. 492-505). doi: 10.1002/9781119171386.ch19

Arbutina, M., Dragan, D., Mihic, S., \& Anisic, Z. (n.d.). Review of 3D body scanning systems. 9

Apeagyei, P. R. (2010). Application of 3D body scanning technology to human measurement for clothing fit. International Journal of Digital Content Technology and Its Applications, 4(7), 58-68. doi: 10.4156/jdcta.vol4.issue7.6

Banga, H. K., Belokar, R. M., Kalra, P., \& Kumar, R. (2018). Fabrication and stress analysis of ankle foot orthosis with additive manufacturing. Rapid Prototyping Journal, 24(2), 301-312. doi: 10.1108/RPJ-08-2016-0125

Barnum, C. M. (2010). Usability Testing Essentials: Ready, Set...Test! :Elsevier.

Botspot. (n.d.). botscan PRO S. Retrieved July 12, 2019, from https://botspot.de/en/3d-scanners/ botscan-pros/

Brunstrom, J. E. (2001). Clinical Considerations in Cerebral Palsy and Spasticity. Journal of Child Neurology, 16(1), 10-15. doi: 10.1177/088307380101600103

Buchenau, M., \& Suri, J. F. (2000). Experience prototyping. In Proceedings of the Conference on Designing Interactive Systems Processes, Practices, Methods, and Techniques - DIS '00 (pp. 424433). doi: $10.1145 / 347642.347802$
Cagan, J., \& Vogel, C. M. (2002). Creating breakthrough products: Innovation from product planning to program approval. Ft Press.

Canfield. (n.d.). Vectra XT. Retrieved July 12, 2019, from https://www.canfieldsci.com/imagingsystems/vectra-xt-3d-imaging-system/

Center for Devices and Radiological Health. (2016). Applying Human Factors and Usability Engineering to Medical Devices: Guidance for Industry and Food and Drug Administration Staff. Center for Devices and Radiological Health.

Cagan, J., \& Vogel, C. M. (n.d.). Creating Breakthrough Products: Innovation from Product Planning to Program. Retrieved from https://books.google.co.nz/books?hl=en\&lr=\&id=hlSRf61

Chen, R. K., Jin, Y., Wensman, J., \& Shih, A. (2016). Additive manufacturing of custom orthoses an prostheses-A review. Additive Manufacturing, 12, 77-89. doi: 10.1016/j.addma.2016.04.002

Chiarello, L. A., Palisano, R. J., Bartlett, D. J., \& McCoy, S. W. (2011). A Multivariate Model of Determinants of Change in Gross-Motor Abilities and Engagement in Self-Care and Play of Young Children With Cerebral Palsy. Physical \& Occupational Therapy In Pediatrics, 31(2),

150-168 doi: 10.3109/01942638.2010.525601

Ciobanu, O., Ciobanu, G., \& Rotariu, M. (2013). Photogrammetric Scanning Technique and Rapid Prototyping Used for Prostheses and Orthoses Fabrication. Applied Mechanics and Materials, 371, 230-234. doi: 10.4028/www.scientific.net/AMM.371.230

Dalsgaard, P. (2014). Pragmatism and Design Thinking. 8(1),

Datta, L. E. (1997). A pragmatic basis for mixed-method designs. New directions for evaluation 1997(74),

Davids, J. R., \& Tabaie, S. A. (2016). Foot and Ankle Motion in Cerebral Palsy. In B. Müller, S. I. Wolf, G. P. Brueggemann, Z. Deng, A. McIntosh, F. Miller, \& W. S. Selbie (Eds.), Handbook of Human Motion (pp. 1-29).doi: 10.1007/978-3-319-30808-1_58-1

De Temmerman, N., Mira, L. A., Vergauwen, A., Hendrickx, H., \& De Wilde, W. P. (2012, June 18) Transformable structures in architectural engineering. 457-468. doi: 10.2495/HPSM120411

Dombroski, C. E., Balsdon, M. E., \& Froats, A. (2014). The use of a low cost 3D scanning an printing tool in the manufacture of custom-made foot orthoses: A preliminary study. $B M C$ Research Notes, 7(1), 443. doi: 10.1186/1756-0500-7-443 
Druin, A. (2002). The role of children in the design of new technology. Behaviour and Information Technology, 38.

ESPER. (n.d.). Lightcage. Retrieved July 12, 2019, from https://www.esperhq.com/product/lightcagescanning-rig/

Feng, Y., \& Song, Y. (2017). The Categories of AFO and Its Effect on Patients With Foot Impair: A Systemic Review. Physical Activity and Health, 1(1), 8-16. doi: 10.5334/paah.3

Fenci, G. E., \& Currie, N. G. (2017). Deployable structures classification: A review. Internationa Journal of Space Structures, 32(2), 112-130. doi: 10.1177/0266351117711290

Foster, J. (2010). The Green Screen Handbook: Real World Production Techniques. Indianapolis, Indiana: Wiley Publishing, Inc

Friedman, N. (2012). Investigation of highly flexible, deployable structures: review, modelling, control, experiments and application. 200

Gage, J. R., Schwartz, M. H., \& Koop, S. E. (2009). Identification and Treatment of Gait Problems in Cerebral Palsy. Retrieved from http://ebookcentral.proquest.com/lib/vuw/detail. action?docID=3329153

Garsthagen, R. (2014). An Open Source, Low-Cost, Multi Camera Full-Body 3D Scanner. Proceedings of the 5th International Conference on 3D Body Scanning Technologies, Lugano, Switzerland, 21-22 October 2014, 174-183. doi: 10.15221/14.174

Gesslein, T., Scherer, D., \& Grubert, J. (2017). BodyDigitizer: An Open Source Photogrammetrybased 3D Body Scanner. ArXiv:1710.01370 [Cs]. Retrieved from http://arxiv.org/abs/1710.01370

Grazioso, S., Selvaggio, M., Di Gironimo, G., \& Ruggiero, R. (2016). INBODY: Instant

Photogrammetric 3D Body Scanner. Proceedings of the 7th International Conference on 3D Body Scanning Technologies, Lugano, Switzerland, 30 Nov-1 Dec. 2016, 296-301. doi: 10.15221/16.296

Grazioso, S., Selvaggio, M., \& Di Gironimo, G. (2018). Design and development of a novel body scanning system for healthcare applications. International Journal on Interactive Design and Manufacturing (IIIDeM), 12(2), 611-620. doi: 10.1007/s12008-017-0425-9

Guest, G., MacQueen, K., \& Namey, E. (2012). Applied Thematic Analysis. doi: $10.4135 / 9781483384436$
Hunfeld, J. A. M., \& Passchier, I. (2012). Participation in medical research; a systematic review of the understanding and experience of children and adolescents. Patient Education and Counselling, 87(3), 268-276. doi: 10.1016/j.pec.2011.09.006

Ibrahim, M. (2012). Thematic analysis: a critical review of its process and evaluation. 1(1), 9.

International Committee of the Red Cross. (2006). Manufacturing Guidelines: Ankle Foot Orthosis (Physical Rehabilitation Programme). Geneva, Switzerland: International Committee of the Red Cross.

IvarFace. (n.d.). 3D Scanning: Android Based Photogrammetry System. Retrieved July 12, 2019, from http://ivarface.org/scanning_android.html

Khalili, K., \& Zeraatkar, M. (2017). Design and Development of a Rotary 3D Scanner for Human Body Scanning. Proceedings of 3DBODY.TECH 2017 - 8th International Conference and Exhibition on 3D Body Scanning and Processing Technologies, Montreal QC, Canada, 11-12 Oct. 2017, 312318. doi: $10.15221 / 17.312$

Krogh, P. G., Markussen, T., \& Bang, A. L. (2015). Ways of drifting-Five methods of experimentation in research through design. In ICoRD'15-Research into Design Across Boundaries Volume 1 (pp. 39-50). Springer, N01ew Delhi.

Lang, A. R., Martin, J. L., Sharples, S., Crowe, J. A., \& Murphy, E. (2014). Not a minor problem: involving adolescents in medical device design research. Theoretical Issues in Ergonomics Science, 15(2), 181-192. doi: 10.1080/1463922X.2012.678910

Leipner, A., Baumeister, R., Thali, M. I., Braun, M., Dobler, E., \& Ebert, L. C. (2016). Multi-camera system for 3D forensic documentation. Forensic Science International, 261, 123-128. doi: 10.1016/j.forsciint.2016.02.003

Luhmann, T., Robson, S., \& Kyle, S. (2006). Close Range Photogrammetry: Principles, Techniques and Applications. Retrieved from http://ebookcentral.proquest.com/lib/vuw/detail. action?docID=3417309W

Majnemer, A., \& Mazer, B. (2004). New directions in the outcome evaluation of children with cerebral palsy. Seminars in Pediatric Neurology, 11(1), 11-17. doi: 10.1016/j.spen.2004.01.003 10.1016/j.spen.2004.01.003 
Martin, J. L., Murphy, E., Crowe, J. A., \& Norris, B. J. (2006). Capturing user requirements in medical device development: the role of ergonomics. Physiological Measurement, 27(8), R49-R62. doi: 10.1088/0967-3334/27/8/R01

Martin, B., \& Hanington, B. (2012). Universal methods of design: 100 ways to research complex problems, develop innovative ideas, and design effective solutions. United States of America: Rockport Publishers.

Mavroidis, C., Ranky, R. G., Sivak, M. L., Patritti, B. L., DiPisa, J., Caddle, A., ... Bonato, P. (2011) Patient specific ankle-foot orthoses using rapid prototyping. Journal of NeuroEngineering and Rehabilitation, 8(1). doi:10.1186/1743-0003-8-1

Mastro, B. A., \& Curry, B. D. (1980). Developmental Factors in the Care of Adolescent Amputee

Miller, F. (Ed.). (2005). Gait. In Cerebral Palsy (pp. 251-386). doi: 10.1007/0-387-27124-4_7

Mitchell, H. L., \& Newton, I. (2002). Medical photogrammetric measurement: overview and prospects. ISPRS Journal of Photogrammetry and Remote Sensing, 56(5-6), 286-294. doi: 10.1016/ S0924-2716(02)00065-5

MyEggo (n.d.). My Eggo. Retrieved July 12, 2019, from https://myeggo.com/

Pallari, J. H. P., Dalgarno, K. W., Munguia, J., Muraru, L., Peeraer, L., Telfer, S., \& Woodburn, J. (2010, August). Design and additive fabrication of foot and ankle-foot orthoses. Proceedings of the 21st Annual International Solid Freeform Fabrication Symposium-An Additive Manufacturing Conference (pp. 9-11).

Payne, C. (2007). Cost benefit comparison of plaster casts and optical scans of the foot for the manufacture of foot orthoses. 41(2), 3 .

Percoco, G. (2011). Digital close range photogrammetry for 3D body scanning for custom-made garments. The Photogrammetric Record, 26(133), 73-90. doi: 10.1111/j.1477-9730.2010.00605.x

Pesce, M., Galantucci, L. M., Percoco, G., \& Lavecchia, F. (2015). A low-cost multi camera 3D scanning system for quality measurement of non-static subjects. Procedia CIRP, 28, 88-93. doi: 10.1016/j.procir.2015.04.015

Pesce, M., Galantucci, L. M., \& Lavecchia, F. (2016). A 12-camera body scanning system based on close-range photogrammetry for precise applications. Virtual and Physical Prototyping, 11(1), 49-56. doi: 10.1080/17452759.2015.1101872
Peyer, K. E., Morris, M., \& Sellers, W. I. (2015). Subject-specific body segment parameter estimation using 3D photogrammetry with multiple cameras. PeerJ, 3, 831. doi: 10.7717/peerj.831

Pics3D. (n.d.). Cobra. Retrieved July 12, 2019, from https://pics-3d.com/photogrammetry-instantcapture-system/pics-3d-scanners/cobra-3d-body-scanner/

Pixel (n.d.). Facial 3D Scanning System. Retrieved July 12, 2019, from https://pixellighteffects.com/ photogrammetry-facial-rig/

People’s Architecture Office. (2016). 3D CopyPod. Retrieved July 12, 2019, from http://www. peoples-architecture.com/pao/en/project-detail/15

Radhakrishna, R. B. (2007). Tips for developing and testing questionnaires/instruments. Journal of extension, 45(1), 1-4.

Scally, A. (2014). Ethical issues in research involving children and young people. Radiography 20(3), 202-205. doi: 10.1016/j.radi.2014.01.006

Scanologics. (n.d.). Scanlounge 2.5. Retrieved July 12, 2019, from

https://www.scanologics.com/\#scanlounge

Scan Engine (n.d.). Scan Engine. Retrieved July 12, 2019, from http://www.scan-engine.fr/\#!studio

Scherer, K. R. (2005). What are emotions? And how can they be measured? Social Science Information, 44(4), 695-729. doi: 10.1177/0539018405058216

Schrank, E. S., \& Stanhope, S. J. (2011). Dimensional accuracy of ankle-foot orthoses constructed by rapid customization and manufacturing framework. Journal of Rehabilitation Research and Development, 48(1), 31-42. doi: 10.1682/JRRD.2009.12.0195

Shapify. (n.d.). Artec Shapify Booth. Retrieved July 12, 2019, from https://www.shapify.me/partner/ booth

SizeStream. (n.d.). ss20 Classic. Retrieved July 12, 2019, from http://sizestream.com/ss20-classic/

Staramba. (n.d.). Scanning with 3D Instagraph. Retrieved July 12, 2019, from https://www.staramba. com/scanning-with-3d-instagraph/ 
Stevens, P. (2017). People's industrial design office develops 3D scanning booth that digitizes its subjects. Retrieved July 12, 2019, from https://www.designboom.com/design/peoplesarchitecture-office-3d-copypod-pavilion-05-23-2017/

Straub, J., \& Kerlin, S. (2014). Development of a large, low-cost, instant 3D scanner. Technologies, 2(2), 76-95. doi: 10.3390/technologies2020076

Straub, J., Kading, B., Mohammad, A., \& Kerlin, S. (2015). Characterization of a large, low-cost 3D scanner. Technologies, 3(1), 19-36. doi: 10.3390/technologies3010019

Totah, D., Kovalenko, I., Saez, M., \& Barton, K. (2017). Manufacturing choices for anklefoot orthoses: a multi-objective optimization. Procedia CIRP, 65, 145-150. doi: 10.1016/j. procir.2017.04.014

Treleaven, P., \& Wells, J. (2007). 3D body scanning and healthcare applications. Computer, 40(7), 28-34. doi: 10.1109/MC.2007.225

Tugui, R. D., \& Anotnescu, D. (2013). Cerebral palsy gait, clinical importance. Maedica, 8(4), 388-

Totah, D., Kovalenko, I., Saez, M., \& Barton, K. (2017). Manufacturing choices for anklefoot orthoses: a multi-objective optimization. Procedia CIRP, 65, 145-150. doi: 10.1016/j. procir.2017.04.014

Twindom. (n.d.). Twinstand mobile. Retrieved July 12, 2019, from https://web.twindom.com/ twinstant-mobile-full-body-3d-scanner/\#twinstantmobile

Tschuppik, W. M., \& Martins, B. (2006). Exploring the design and fabrication of inflatables.

Walbran, M., Turner, K., \& McDaid, A. J. (2016). Customized 3D printed ankle-foot orthosis with adaptable carbon fibre composite spring joint. Cogent Engineering, 3(1). doi $10.1080 / 23311916.2016 .1227022$

Wang, F., \& Hannafin, M. J. (2005). Design-based research and technology-enhanced learning environments. Educational Technology Research and Development, 53(4), 5-23. doi: 10.1007/ BF02504682

Wahyuni, D. (2012). The research design maze: understanding paradigms, cases, methods and methodologies. 10(1), 14.
Welsh, A. (2012). National Collaborating Centre for Women's and Children's Health. 302.

Wilson, C. (2014). Cognitive Walkthrough. User Interface Inspection Methods, 65-79.

Yamaguchi, R., Nicholson Perry, K., \& Hines, M. (2014). Pain, pain anxiety and emotional and behavioural problems in children with cerebral palsy. Disability and Rehabilitation, 36(2), 125-130. doi: 10.3109/09638288.2013.782356

Xangle 3D (n.d.). Photogrammetry studios and softwares. Retrieved July 12, 2019, from https:// xangle3d.com/ 


\section{Appendix 1}

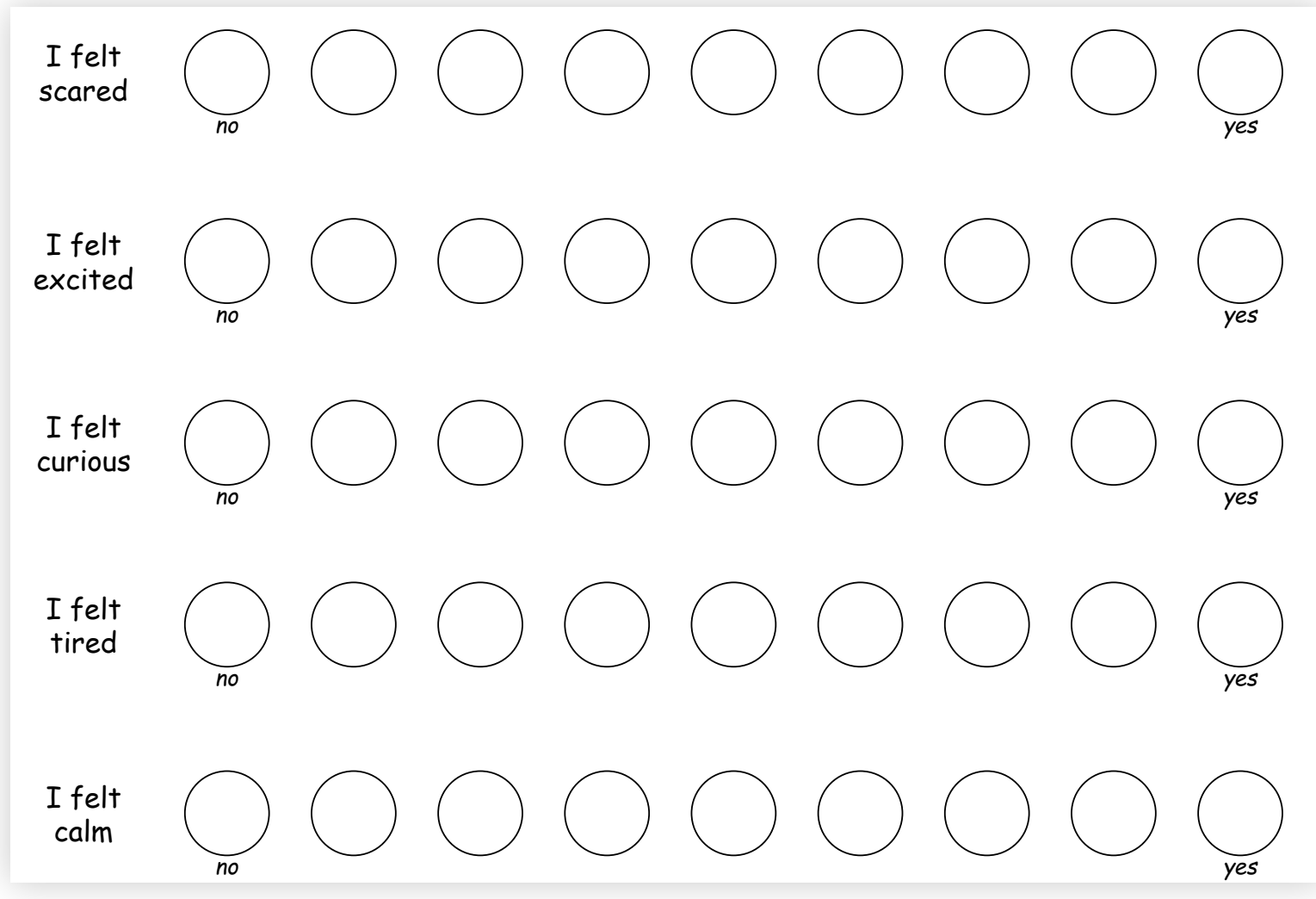


Research Office

Research Office
Post-Award Support Services

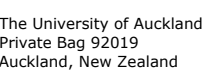

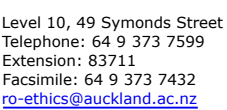

UNIVERSITY OF AUCKLAND HUMAN PARTICIPANTS ETHICS COMMITTEE (UAHPEC)

27-Aug-2018

MEMORANDUM TO:

Dr Julie Choisne

Bioengineering Institute

Re: Request for change of Ethics Approval (Our Ref. 017026): Amendments Approved

The Committee considered your request for change for your study entitled 3D scanning of the surface of the

foot and approval was grant

The Committee approved the following amendments:

1. Adding William Zheng, a Masters student at Victoria University of Wellington, to the research team. He will be co-supervised by the PI and A/Prof Edgar Rodriguez, a co-investigator from VUW already part of the team. The
data will be used as part of the student researcher's thesis, and updated PIS and CF documents were provided.

The expiry date for this approval is 18-Apr-2019.

If the project changes significantly you are required to resubmit a new application to the Committee for further consideration.

In order that an up-to-date record can be maintained, it would be appreciated if you could notify the Committee once your study is completed.

The Chair and the members of the Committee would be happy to discuss general matters relating to ethics approvals. If you wish to do so, please contact the UAHPEC Ethics Administrators at ro-ethics@auckland.ac.nz the first instance.

Please quote reference number $\mathbf{0 1 7 0 2 6}$ on all communications with the UAHPEC regarding this application.

(This is a computer generated letter. No signature required.)

Copyright 2019 by UoA Human Participants Ethic Committee. 


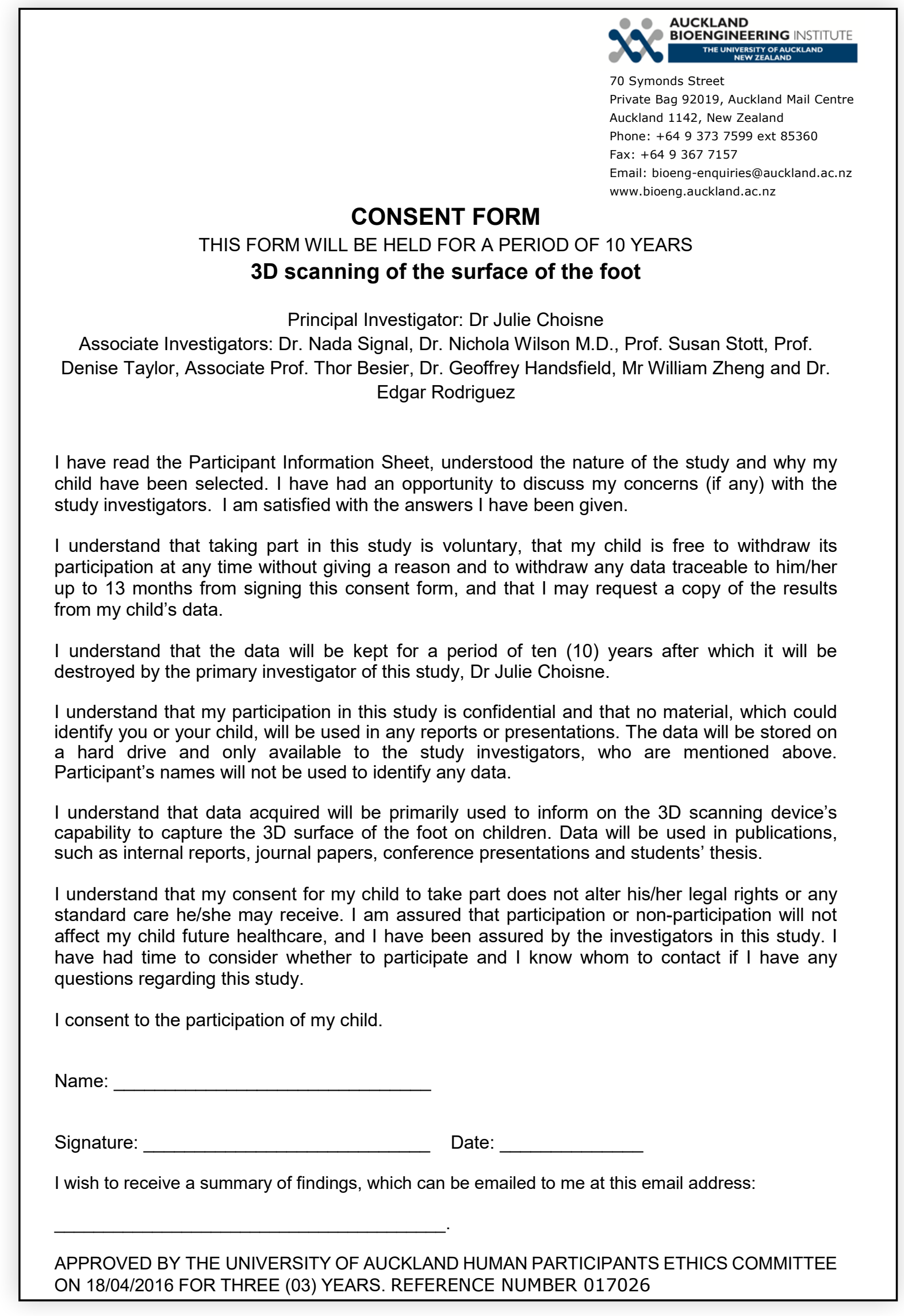

Copyright 2019 by Julie Choisne.

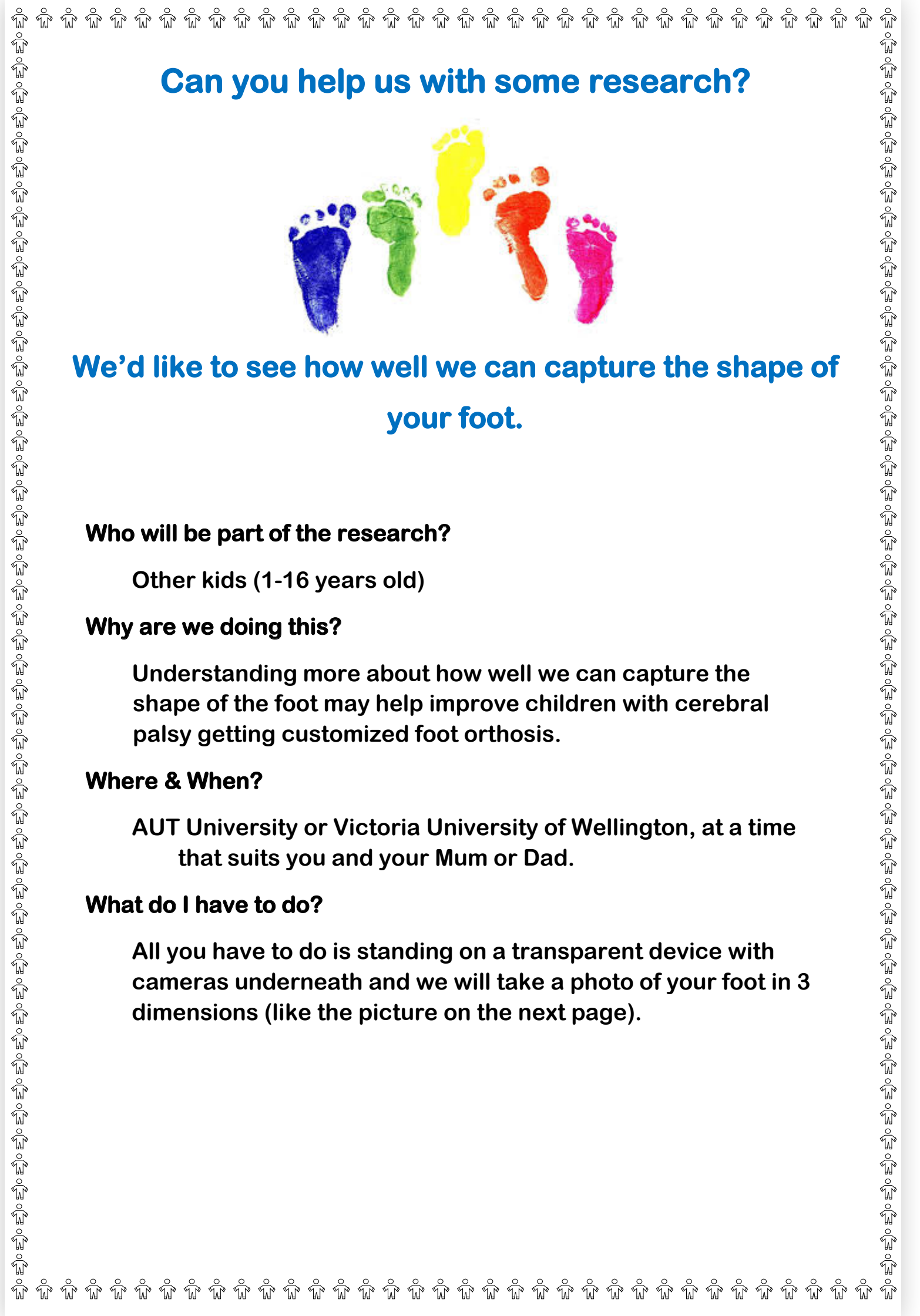

Copyright 2019 by Julie Choisne. 


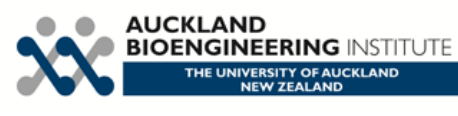

70 Symonds Street Private Bag 92019, Auckland Mail Centre Phone: +64937375999 ext 85360

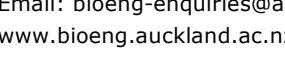

\section{PARTICIPANT INFORMATION SHEET}

For parents/guardians of children with cerebral palsy

\section{D scanning of the surface of the foot}

Principal Investigator: Dr Julie Choisne

Associate Investigators: Dr. Nada Signal, Dr. Nichola Wilson M.D., Prof. Susan Stott, Prof. Denise Taylor, Associate Prof. Thor Besier, Dr. Geoffrey Handsfield, Mr William Zheng and Dr.

$$
\text { Edgar Rodriguez }
$$

Invitation

You and your child are invited to take part in a study to help improve the design of a 3D scanning device for 3 dimensional capture of an individual foot surface. This research project is jointly undertaken by the researchers at the Auckland Bioengineering Institute (ABI), Auckland University of Technology (AUT), Victoria University of Wellington (VUW) and Starship Children's Hospital for a period of 18 months and funded by the MedTech Core. The study will be overseen by $\mathrm{Dr}$ Julie Choisne, a research fellow and primary investigator in the $A B I$ musculoskeletal modelling group; Dr Nada Signal, a research fellow at AUT specializing in neuroscience, motor control and rehabilitation for people with neurological conditions, Ass. Prof. Thor Besier, a specialist in musculoskeletal systems and orthopaedics; Prof. Susan Stott, a consultant Paediatric Orthopaedic Surgeon at Starship Children's hospital and Professor of Paediatric Orthopaedic Surgery at the University of Auckland; Prof. Denise Taylor, a specialist in neurological rehabilitation, Dr Edgar Rodriguez, a specialist in design at VUW, Mr William Zheng, a master student in design at VUW, Dr. Geoff Handsfield, postdoctoral fellow at the ABI and Dr Nichola Wilson, an orthopaedic surgeon at the Starship Children's Hospital.

This Parent/Guardian Information Sheet will help you decide if you and your child would like to take part. It sets out why we are doing the study, what is involved, what the benefits and risks to you might be, and what would happen after the study ends. There is also a separate information sheet for your child. We will go through this information with you and answer any questions you both may have. You may also want to talk about the study with other people,

\section{- AUCKLAND}

70 Symonds Street Phone: +6493737599 ext 85360 Fax: +6493677157 Email: bioeng enquiries@auck nd.ac.nz

\section{Questionnaire}

\section{D scanning of the surface of the foot}

Principal Investigator: Dr Julie Choisne

Associate Investigators: Dr. Nada Signal, Dr. Nichola Wilson M.D., Prof. Susan Stott, Prof. Denise Taylor, Associate Prof. Thor Besier, Dr. Geoffrey Handsfield, Mr William Zheng and Dr. Edgar Rodriguez

Age:

Weight:

Height:

GMFCS level:

History of musculoskeletal injury?

If yes please list:

History of orthopaedic surgery or Botox injections in the past 6 months?

If yes please list:

Do you have a prescription for an Ankle-Foot Orthosis?

If yes for how long?

Copyright 2019 by Julie Choisne. 


\section{VOLUNTEERS NEEDED}

3D scanning of the surface of the foot

\section{Can you help us with some research?}

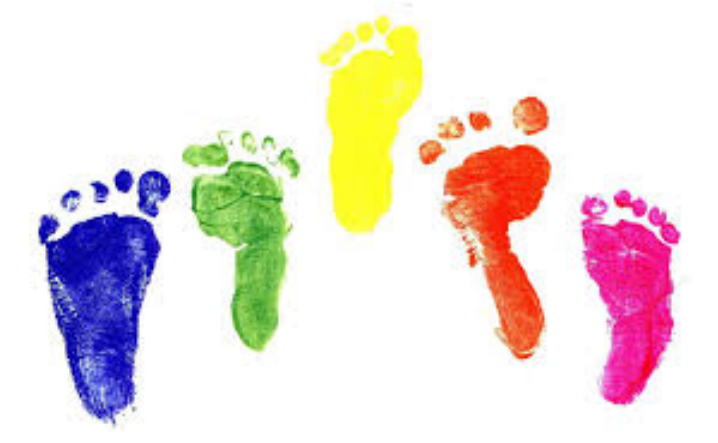

We'd like to see how well we can capture the shape of your foot.

We need children to help inform on our new 3D scanning device capability to capture the 3 dimensional surface of the foot in a weight bearing position

Your participation will greatly assist researchers in understanding the capability of our new system to capture the 3 dimensional shape of the foot. This device aims to facilitate the customization of Ankle-Foot Orthosis design for children with Cerebral Palsy.

If you are interested, please contact the study investigators below for more information and how to join!

Prof. Denise Taylor

Associate Investigator

Dr Julie Choisne

Auckland University of Technology

Principal Investigator

Faculty of Health and Environmental Science

The University of Auckland

denise.taylor@aut.ac.nz

Auckland Bioengineering Institute

jcho911@aucklanduni.ac.nz

(09) 9211999 ext. 9680

(09) 3737599 ext. 83506

Approved by the University of Auckland Human Participants Ethics Committee on 18/04/2016 for three years, Reference Number 017026

Copyright 2019 by Julie Choisne.

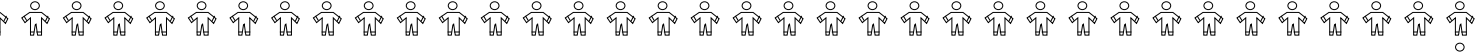 \\ Can you help us with some research?

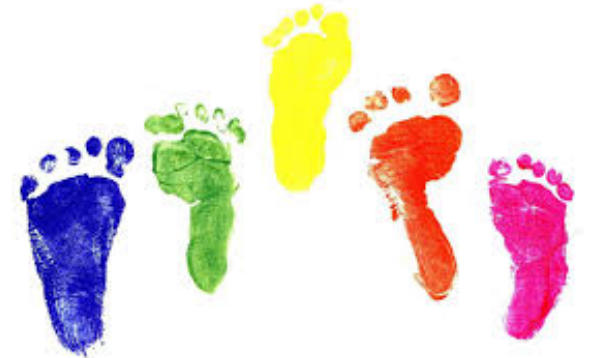 \\ We'd like to see how well we can capture the shape of your foot. \\ Who will be part of the research? \\ Other kids (1-16 years old) \\ Why are we doing this? \\ Understanding more about how well we can capture the shape of the foot may help improve children with cerebral palsy getting customized foot orthosis. \\ Where \& When? \\ Auckland Bioengineering Institute (at the University of Auckland) or at Victoria University of Wellington, at a time that suits you and your Mum or Dad. \\ What do I have to do? \\ All you have to do is standing on a transparent device with cameras underneath and we will take a photo of your foot in 3 dimensions (like the picture on the next page).}




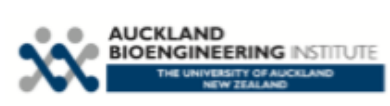

70 symonds Street

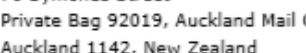

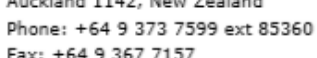
Emaili: bioeng-ennuirieseseauckland.ac.ne www. bioeng. auckland.ac.nz

Questionnaire

3D scanning of the surface of the foot

Principal Investigator: Dr Julie Choisne

Associate Investigators: Dr. Nada Signal, Dr. Nichola Wilson M.D., Prof. Susan Stott, Prof. Denise Taylor, Associate Prof. Thor Besier, Dr. Geoffrey Handsfield, Mr William Zheng and D Edgar Rodriguez

Can you tell which part you liked about the scanner?

Was there any part the you didn't like?

Any parts you really want to talk about?

\section{Appendix 3}




\section{Before scanning}

1. What do you think made you feel this more?

- Can you tell me when you felt it?

It looks like you felt next, can you tell me about that?

What made you feel that you think?

\section{Right after scanning}

2. Can you explain to me what you were feeling while you were inside?

- When did you feel this/these feelings?

What is the reason for you to also feel ile inside?

What were you feeling when you had to stand properly while being scanned?

What part of the standing made you feel this? Position? Time?

If we had something to make you feel better while inside, what would you think of

What would you think of the idea of the cameras being hidden? So that there was less distractions?

\section{After rest}

3. What part of the scanning made you feel this?

Can you tell me more about what you think about that?

- If you had to use the scanner again, what do you think you would feel?

What would you think of the idea of the cables being hidden away? So the area is nice and

4. The last question. Why did you feel that the most about the test?

What parts of the test really made you feel that?

Thank you very much for your help today, anything else you would like to add about anything? 
Appendix 4
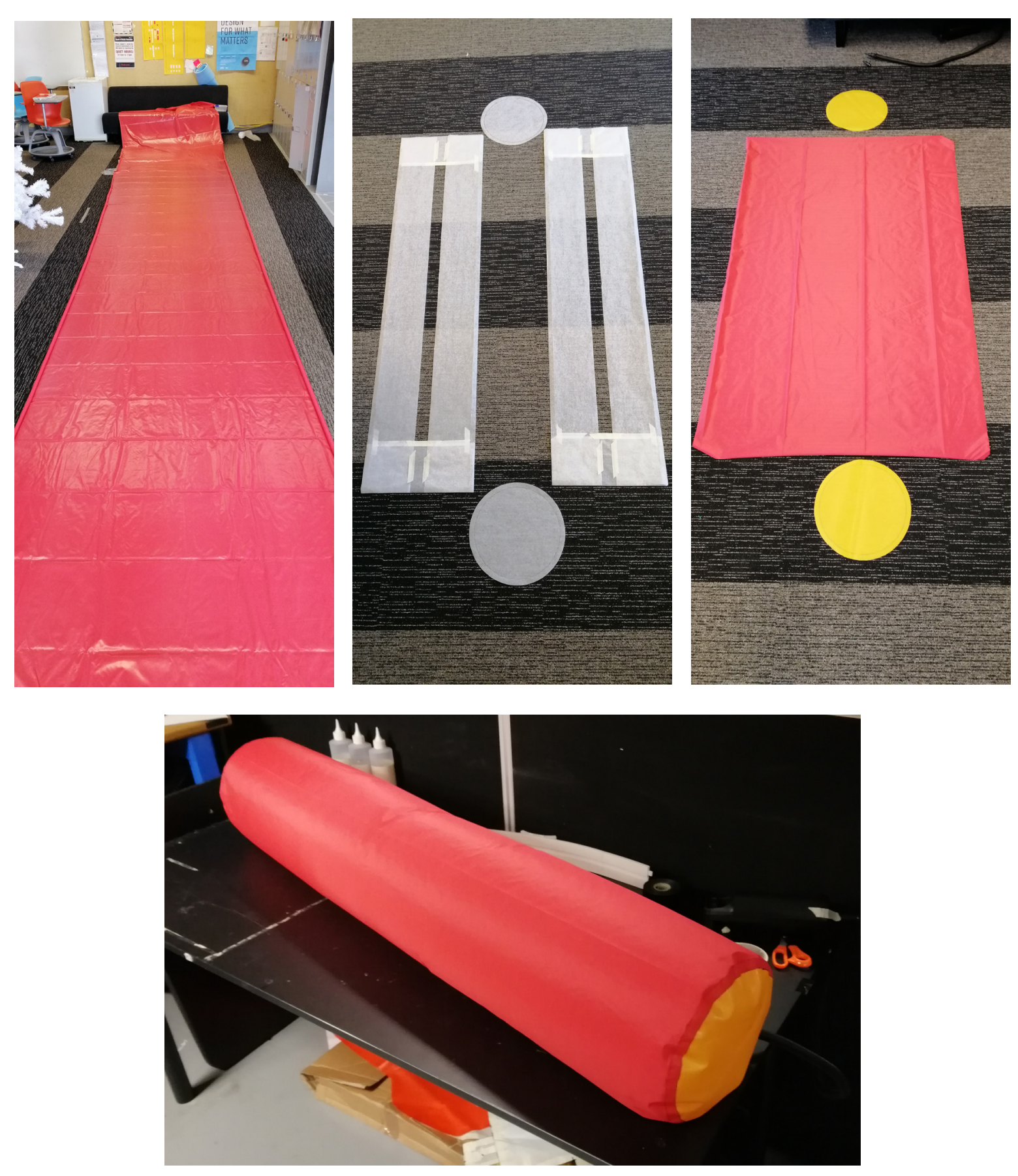


\section{Appendix 5}

Having just finished the assembly and disassembly procedure for the scanner, I would like to ask you questions about your experience while you were assembling and disassembling the scanner. As well as your thoughts about the process itself. There are no right or wrong answers:

\section{Overall user experience questions}

1. What did you think of the process?

a. Were there any positives or negatives?

i. What would be an example of each?

b. Can you tell me more about why you picked _?

2. How would you describe your experience of the scanner?

a. Can you think of a time when you felt

$$
\text { i. Can you explain that? }
$$

3. How do you think the design of the components affect the assembly process?

a. What would be an example of?

4. Can you think of a time when you were having issues with assembling the scanner?

a. Can you take me through what happened?

$$
\text { i. Can you explain that? }
$$

b. Can you walk me through the process of how you/ would want solved the problem?

5. __ at this point I noticed you were can you take me through what happened?

a. Can you explain that? 
or

I noticed that you were having some issues during the assembly and disassembly process. Would you be able to give me an example of when you believed the process was confusing, or something similar?

a. Can you explain that?

6. How easy do you think the intended assembly and disassembly process would be in different clinical environments?

a. Can you explain that?

b. Would there be any examples where you think it would be _ ?

7. What do you think your experience would be like if you had to go through the process again?

a. Can you explain that?

\section{Specific/Review questions:}

1. What are your thoughts on the look of the scanner?

a. Are there any positives or negatives?

b. What would an example be?

2. Can you tell me your thoughts on the use of inflatables as the primary assembly method?

a. Can you explain that?

3. On that same subject, how do you think this effects the aesthetic of the scanner?

a. Can you explain that?
4. And what do you think of how it has housed the hardware and cabling?

a. Can you tell me more about that?

5. What are your thoughts on the ability to customise the positioning of the cameras?

a. Are there any positives or negatives?

b. Can you explain that?

6. Can you think of any improvements or add-ons that could help improve the process?

b. Can you explain that? 


\section{Children Participant SSI questions}

Having just finished being scanned, I would like to ask you some questions about your experience? Mainly when you were in the scanner, and what you thought about the scanner itself. There are no right or wrong

1. Can you tell me what was your first thought of when you saw the scanner?

a. Can you explain that?

i. Can you tell me more about...

b. Would you be able to give me an example of..

2. What did you think it would be before you saw the scanner?

3. How did you feel being inside the scanner?

a. Would you be able to give me an example of what made you think/feel that?

i. Can you tell me more about that?

4. How did you feel getting in and out of the scanner?

a. Can you tell me more about it that?

i. Did you find easy or hard?

$$
\text { 1. Can you explain that? }
$$

5. How do you think you would feel if you had to be scanned again?

a. Can you tell me more about that?

6. How would you describe the scanner to someone, like a friend, who was going to be scanned? i. Can you tell me how you came to that description?

7. Can you tell what you thought of the look of the scanner? (liked or dislike)

a. Can you explain tha

$$
\text { i. Could you give me some examples? }
$$

8. If you could change anything about the scanner, what would you change?
a. Can you give me an example?
b. Can you tell me more about that? 
Appendix 7
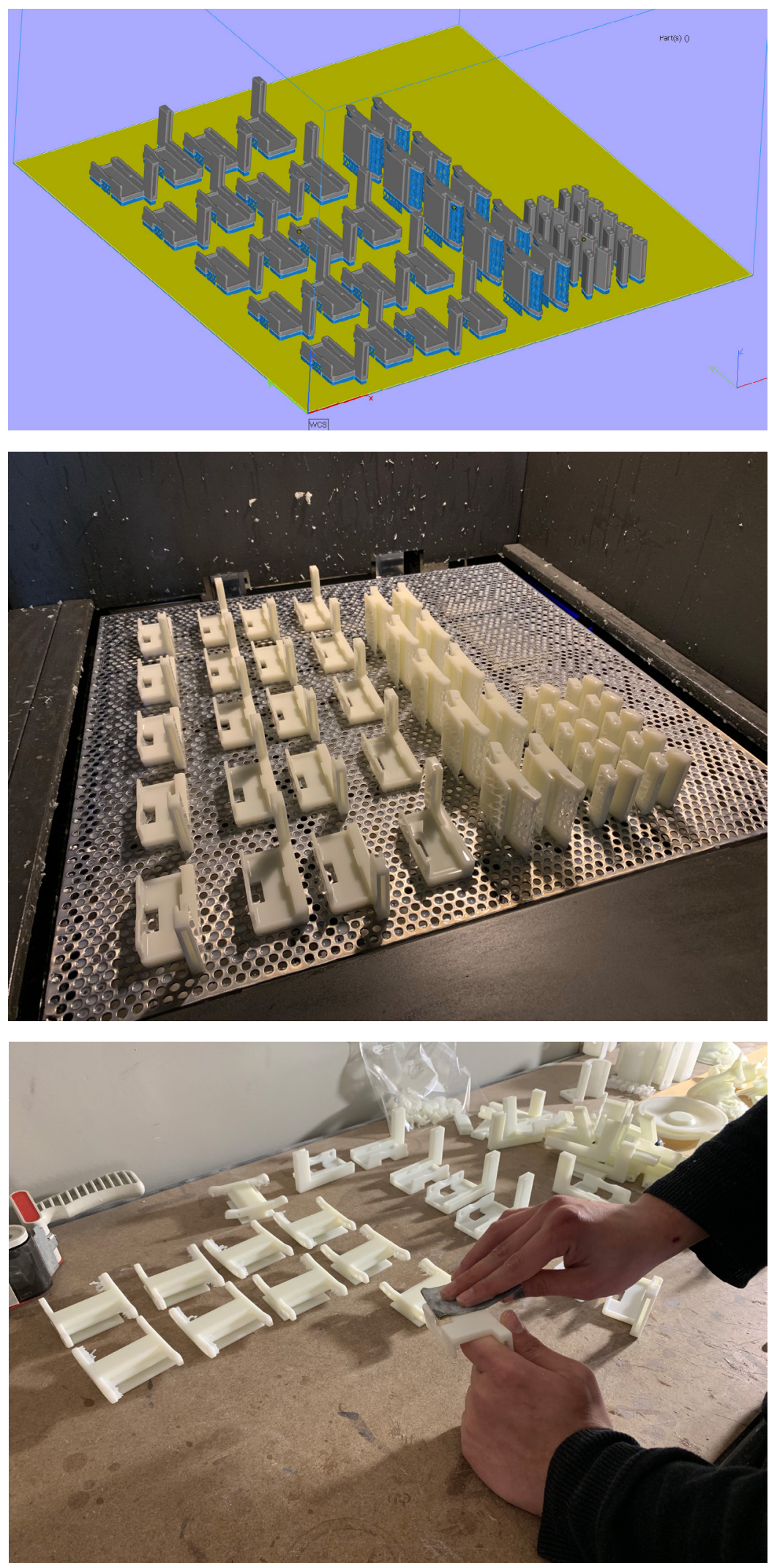

Copyright 2019 by Clone 3D Print and Production. 
Appendix 8
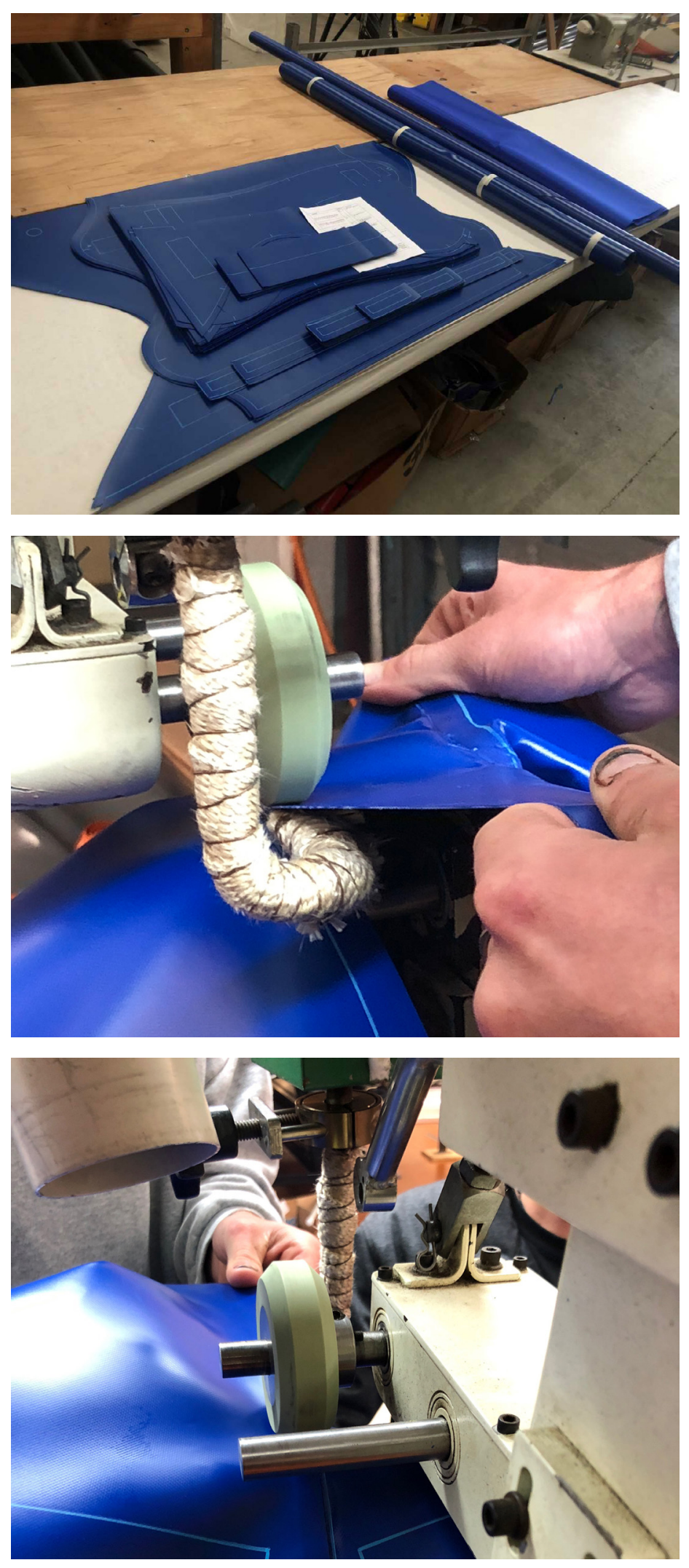

Copyright 2019 by Canvasland 